Tatiana de Cássia Coutinho Silva da Fonseca

\title{
REFORÇO E INCREMENTO DA RIGIDEZ À FLEXÃO DE LIGACCÕES VIGA-PILAR DE ESTRUTURAS DE CONCRETO PRÉ-MOLDADO COM POLÍMERO REFORÇADO COM FIBRA DE CARBONO (PRFC)
}

Dissertação apresentada à Escola de Engenharia de São Carlos da Universidade de São Paulo como parte dos requisitos para obtenção do Título de Mestre em Engenharia Civil (Engenharia de Estruturas).

Orientador: Prof. Titular João Bento de Hanai 
AUTORIZO A REPRODUÇÃO E DIVULGAÇÃO TOTAL OU PARCIAL DESTE TRABALHO, POR QUALQUER MEIO CONVENCIONAL OU ELETRÔNICO, PARA FINS DE ESTUDO E PESQUISA. DESDE QUE CITADA A FONTE.

Ficha catalográfica preparada pela Seção de Tratamento da Informação do Serviço de Biblioteca - EESC/USP

Fonseca, Tatiana de Cássia Coutinho Silva da

F676r Reforço e incremento da rigidez à flexão de ligações viga-pilar de estruturas de concreto pré-moldado com polímero reforçado com fibra de carbono (PRFC) / Tatiana de Cássia Coutinho Silva da Fonseca ; orientador João Bento de Hanai. -- São Carlos, 2007.

Dissertação (Mestrado-Programa de Pós-Graduação em Engenharia de Estruturas) -- Escola de Engenharia de São Carlos da Universidade de São Paulo, 2007.

1. Ligações viga-pilar. 2. Concreto pré-moldado. 3. Polímero reforçado com fibras de carbono. 4: PRFC. 5. Reforço. I. Título. 
FOLHA DE JULGAMENTO

Candidata: Engenheira TATIANA DE CÁSSIA COUTINHO SILVA DA FONSECA

Dissertação defendida e julgada em 18/12/2007 perante a Comissão Julgadora:
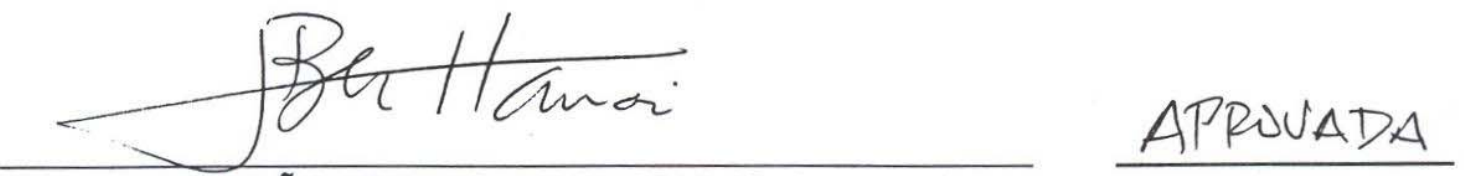

Prof. Titular JOÃO BENTO DE HANAI (Orientador)

(Escola de Engenharia de São Carlos/USP)

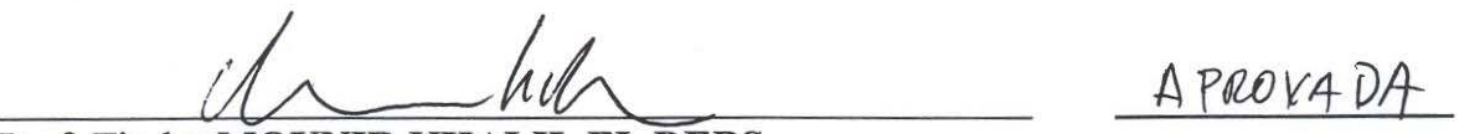

Prof. Titular MOUNIR KHALIL EL DEBS

(Escola de Engenharia de São Carlos/USP)

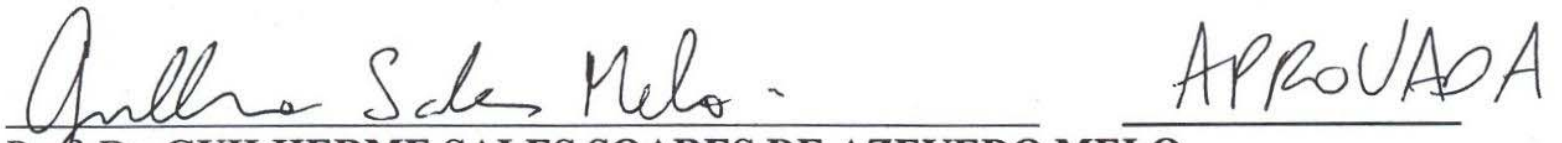

Prof. Dr. GUILHERME SALES SOARES DE AZEVEDO MELO

(Universidade de Brasília/UnB)

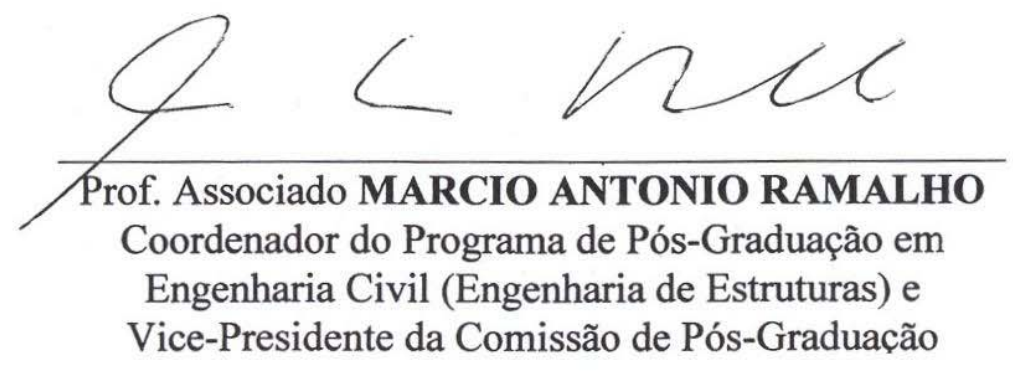



À minha família, meu alicerce. 



\section{AGRADECIMENTO}

Ao longo da realização deste trabalho, recebi diversas contribuições que me fazem agora render sinceros agradecimentos.

A Deus, acima de tudo, por sempre me fazer ciente da Sua dimensão e da minha capacidade, nunca me deixando sucumbir perante as adversidades.

Aos meus pais, Ronaldo e Olívia e à meu tio Dariel exemplos de retidão e responsabilidade, fontes de carinho e eterna compreensão. Às minhas irmãs, Priscila e Tamara, incentivadoras incansáveis. Aos meus pequeninos sobrinhos: Eduardo, Francisco e Thiago, que me impelem à busca de um futuro melhor. Aos meus tios, tias e primos. Aos amigos de muitos anos, Ana Fábia, André, Antônio, Camila, Edilene e Karina, sempre prontos a compartilhar risos e lágrimas.

Ao meu Orientador, João Bento de Hanai, que compartilhou comigo sua grande experiência e ampla visão.

Aos notáveis professores do Departamento de Engenharia de Estruturas, em especial ao professor Mounir Khalil El Debs.

Às conterrâneas, colegas de faculdade, colegas de mestrado, mas, sobretudo amigas, Fernanda Calmon e Marta Paes, que enfrentaram comigo tantas dificuldades, crescendo comigo e me fazendo crescer.

Aos amigos, incentivadores, professores da Universidade Federal da Bahia; Mário Mendonça de Oliveira, Inês Silva Rezende, Mônica Cristina Cardoso da Guarda e Tatiana Bitencourt Dumêt cujos exemplos fortaleceram meu desejo de seguir carreira acadêmica.

Aos colegas de departamento que me emprestaram seus conhecimentos e amizade, em especial a Ana Paula Ferreira, Karenina Carolina da Silva, Lezzir Rodrigues, Sandra Freire de Almeida, e Vladimir Ferrari.

Ao Eng $^{\circ}$ Dr. Luiz Vareda e demais colaboradores do Laboratório de Estruturas: Amaury, Caio, Claudinei, Fabiano, Mário, Mauri, Romeu, Valdir, cuja competência e disposição foram fundamentais para o sucesso do programa experimental.

Aos funcionários do SET, sempre prestativos e eficientes.

À CAPES que por meio da bolsa de mestrado proporcionou condições financeiras para a realização deste trabalho.

À FAPESP que disponibilizou recursos importantes para a execução do programa experimental. 

FONSECA, T. C. C. S. Reforço e incremento da rigidez à flexão de ligações viga-pilar de estruturas de concreto pré-moldado com polímero reforçado com fibra de carbono (PRFC). 2007. Dissertação (Mestrado) - Escola de Engenharia de São Carlos, Universidade de São Paulo, São Carlos, 2007.

Este trabalho apresenta o desenvolvimento de uma técnica de incremento da resistência e da rigidez à flexão de ligações de elementos de concreto pré-moldado, com aplicação de laminados de polímero reforçado com fibra de carbono (PRFC). O procedimento adotado consiste na colagem dos laminados de PRFC em entalhes no concreto de cobrimento, de acordo com a técnica conhecida como "near-surface mounted" (NSM), de modo a incorporar à ligação novos elementos resistentes à tração. Para solidarizar a ligação e possibilitar a transferência de esforços de compressão entre os elementos de concreto existentes, preenchem-se os espaços vazios (grauteamento) com argamassa fluida à base de cimento Portland. Foram desenvolvidos modelos em escala reduzida, com o intuito de representar os mecanismos resistentes de uma ligação viga-pilar composta por encaixe de dente Gerber e consolo, com uso de chumbador, almofada de apoio e graute. Esse tipo de ligação é muito utilizado na construção de galpões e tem, na sua concepção original, comportamento essencialmente de articulação. Em uma etapa preliminar, realizaram-se ensaios para a caracterização da aderência segundo a configuração de reforço proposta. Os resultados dessa análise subsidiaram a fixação do comprimento de laminado a ancorar e a escolha do tipo de resina a empregar para colagem do reforço. Os modelos representativos da técnica de reforço proposta foram preparados, cada um deles, pela montagem de um elemento de pilar-consolo com elementos de viga nos respectivos chumbadores e almofadas. Foram também preparados modelos de referência para o estudo da influência da almofada de apoio e do grauteamento no comportamento resistente e da deformabilidade da ligação. Nesses modelos, as juntas eram perfeitamente conjugadas, isto é, os trechos de viga foram concretados com um elemento prémoldado de pilar-consolo posicionado dentro da fôrma, sem disposição de almofadas. Todos os modelos de ligação foram reforçados e submetidos a ensaios estáticos. Esses ensaios consistiram na aplicação de carregamento cíclico alternado de curta duração, solicitando-se os modelos a momento fletor positivo ou negativo. Este trabalho também apresenta procedimento executivo de ensaios dinâmicos para avaliação da rigidez dos modelos de ligação em três condições: modelo íntegro reforçado, modelo reforçado fissurado (após aplicação de carregamento de aproximadamente $30 \%$ do carregamento de ruptura da ligação, em ensaio estático) e modelo reforçado rompido. Com o reforço, a ligação apresentou comportamento semi-rígido e adquiriu resistência à flexão compatível à de estrutura monolítica armada com barras de PRF.

Palavras-chave: Ligações viga-pilar. Concreto pré-moldado. Polímero reforçado com fibra de carbono. PRFC. Reforço. 



\section{ABSTRACT}

FONSECA, T. C. C. S. Flexural strengthening and stiffness increasing of precast beamto-column connections by NSM CFRP strips. 2007. MSc. Thesis - Escola de Engenharia de São Carlos, Universidade de São Paulo, São Carlos, 2007.

This work presents the development of a technique for flexural strengthening and stiffness increasing of precast beam-to-column connections by the embedding of FRP strips into grooves made on the concrete cover. According to this technique, the tension in the connection is transferred by the Near-Surface Mounted (NSM) FRP strips. To allow the transference of compression efforts among the concrete elements, the empty spaces are filled out with grout. Small-scale specimens were developed to represent the resistant mechanisms of pined beam-to-column connection composed by elastomeric cushion and dowels. Preliminary experimental tests on bond behavior of NSM strips were carried out. The results analysis conducted the decision about the adhesive type and bond length to be employed in the beam-to-column connection specimens. Each specimen was made of the assembly of a column section connected to beam sections through their respective dowels and cushions. The connection specimens were reinforced by embedding CFRP strips in the lateral concrete cover and filling out the spaces between beams and column. In addition, control specimens were prepared to study the influence of the cushion and grout in the connection performance. In those models, the joints were conjugated perfectly, which means that the beam sections were laid inside the wooden forms and cast together with a precast column section with no cushions between them. Experimental static and dynamic tests were done. The tests results show that strengthened connection exhibits semi-rigid behavior and acquires flexural strength compatible to monolithic structure reinforced with FRP bars.

Key-words: Beam-to-column connection. Precast structures. NSM. CFRP. Connection strengthening. 



\section{LISTA DE FIGURAS}

Figura 2.1 - Evolução no tempo da utilização da fibra de carbono em função do preço, da produção e do campo de aplicação (Fonte: Juvandes (2002)). 36

Figura 2.2 - Curvas "tensão de tração x deformação" das fibras mais utilizadas em compósitos, baseadas em dados do ACI 440.2R-02 (2002). 38

Figura 2.3 - Diagrama esquemático do processo de pultrusão (Fonte: Beber (2003)). 39

Figura 3.1 - Perda de aderência na interface barra-epóxi (Fonte: adaptado de De Lorenzis e Teng (2006)...... 42

Figura 3.2 - Destacamento do concreto de cobrimento iniciado na extremidade do reforço (Fonte: adaptado de

De Lorenzis e Teng (2006). .43

Figura 3.3 - Destacamento do concreto de cobrimento entre duas fissuras na região de momento máximo

(Fonte: adaptado de De Lorenzis e Teng (2006). 43

Figura 3.4 - Destacamento do concreto de cobrimento ao longo de uma grande parte do comprimento da viga (Fonte: adaptado de De Lorenzis e Teng (2006)... 44

Figura 3.5 - Destacamento de concreto ao longo do canto da viga (Fonte: adaptado de De Lorenzis e Teng 44

Figura 3.6 - Mecanismos secundários de descolamento: (a) perda de aderência entre o epóxi e o concreto; (b) desprendimento do cobrimento de epóxi (Fonte: adaptado de De Lorenzis e Teng (2006). 45

Figura 3.7 - Armaduras das vigas - vista lateral. 45

Figura 3.8 - Armaduras das vigas - cortes e detalhes do posicionamento dos laminados (Fonte: Fortes (2004)).

Figura 3.9 - Disposição dos transdutores de deslocamento (LVDTs) e extensômetros elétricos (Ext.1, Ext.2,

Ext.3) (Fonte: Fortes (2004)).

Figura 3.10 - Detalhamento das vigas da série S3 (Fonte: Fortes (2004)).

Figura 3.11 - Detalhamento das vigas utilizadas na série S2 (Fonte: Fortes (2004)). 48

Figura 3.12 - (a) Esquema estático de carregamento; (b) seção transversal da viga (Fonte: Castro (2005))..... 50 
Figura 3.13 - Características dos modelos físicos e configuração do ensaio (Fonte: Kang et al. (2005)).

Figura 3.14 - Influência da disposição dos laminados na eficiência do reforço para duas profundidades de entalhe: 15 mm e 25 mm (Fonte: adaptado de Kang et al. (2005))......

Figura 3.15 - Características geométricas do consolo curto investigado e modelo de escora e tirantes (Fonte:

Souza et al. (2006)). 56

Figura 3.16 - Detalhamento do consolo A (Fonte: Souza et al. (2006)). 56

Figura 3.17 - Detalhamento do consolo B (Fonte: Souza et al. (2006)). 57

Figura 3.18 - Consolo B após ruptura (Fonte: Souza et al. (2006)). 57

Figura 3.19 - Detalhes das vigas da série NS (Fonte: adaptado de Liu, Oehlers e Seracino (2006)). 58

Figura 3.20 - Detalhes da seção das vigas da série NB: (a) sagging region; (b) hogging region para vigas com laminados inseridos na face tracionada; e (c) hogging region para vigas com laminados inseridos nas faces laterais (Fonte: adaptado de Liu, Oehlers e Seracino (2006)). 58

Figura 3.21 - Modelo de viga contínua com dois vãos (Fonte: adaptado de Liu, Oehlers e Seracino (2006)).....58

Figura 3.22 - Modos de ruptura adesiva de sistemas NSM observados em ensaios de aderência (Fonte:

adaptado de De Lorenzis e Teng (2006)). 61

Figura 3.23 - Geometria do modelo e configuração de ensaio (Fonte: adaptado de De Lorenzis e Nanni (2001)).

Figura 3.24 - Geometria dos modelos e configuração dos ensaios da série S1 (Fonte: Sena-Cruz e Barros (2002)). Obs.: medidas em mm. 64

Figura 3.25 - Geometria dos modelos e configuração dos ensaios da série S2 (Fonte: adaptado de Cruz (2004)). Obs.: medidas em mm 64

Figura 3.26 - Força de arrancamento anterior ao deslizamento da extremidade não carregada do laminado $\left(N\left(\check{S}_{I}\right)\right)$ e deslizamento da zona carregada $\left(\check{S}_{I}\right)$ como função do comprimento de ancoragem (Fonte: adaptado de Cruz (2004)).

Figura 3.27 - “Força de arrancamento x comprimento de ancoragem” (Fonte: adaptado de Cruz (2004)).......67

Figura 3.28 - Configuração de ensaio (Fonte: adaptado de Shield, French e Milde (2005)).

Figura 4.1 - Curvas “momento x rotação” ideais para ligações articuladas semi-rígidas e rígidas (Fonte:

Miotto (2002)) 71

Figura 4.2 - Ligação de resistência total (Fonte: adaptado do Eurocode 3 (2002)). 72

Figura 4.3 - Proposta de classificação para ligações semi-rígidas (Fonte: Ferreira, El Debs e Elliot (2002))...74 
Figura 5.1 - Procedimento de injeção a vácuo (Fonte: adaptado de French, Thorp e Tsai (1990)).

Figura 5.2 - Tipos de reforço empregados nos modelos de ligação (Fonte: adaptado de Engindeniz, Kahn e

Zureick (2005)). 80

Figura 5.3 - Modelo H2 rompido (Fonte: Prota et al. (2001)). 81

Figura 5.4 - Esquema de carregamento: (a) cargas gravitacionais; (b) carregamento sísmico antes da inversão de momento nas vigas e (c) carregamento sísmico após a inversão de momento nas vigas (Fonte: adaptado de Prota et al. (2004)) 81

Figura 5.5 - Configuração esquemática do ensaio (Fonte: adaptado de Pantelides et al. (2003)). 82

Figura 6.1 - Características geométricas do modelo. 87

Figura 6.2 - Detalhamento da armadura empregada nos modelos de ensaio de aderência. 88

Figura 6.3 - Diagramas "tensão x deformação": (a) barras de 6,3 mm de diâmetro; (b)barras de 8 mm de diâmetro. 89

Figura 6.4 - Ensaio para a determinação da resistência à compressão e do módulo de elasticidade. 91

Figura 6.5 - Ensaio para determinação das propriedades no laminado à tração. 93

Figura 6.6 - Corpo-de-prova para ensaio de tração. 94

Figura 6.7 - Corpos-de-prova após ensaio de tração. 94

Figura 6.8 - Gráfico “tensão x deformação” para os corpos-de-prova utilizados na caracterização do laminado.

Figura 6.9 - Configuração esquemática do ensaio. 95

Figura 6.10 - (a) Mistura do concreto em betoneira; (b) adensamento do concreto em mesa vibratória; (c) modelos após a moldagem na área externa do Laboratório de Estruturas; (d) realização do entalhe. 96

Figura 6.11 - Laminados utilizados nos modelos da série R2.

Figura 6.12 - Etapas principais da colagem dos laminados nos modelos de ensaio de aderência: (a) limpeza do entalhe com jato de ar; (b) limpeza do entalhe com estopa embebida em alcool; (c) aplicação do adesivo no entalhe com uso de espátula; (d) aplicação do adesivo no laminado; (e) introdução do laminado no entalhe; ( $f$ ) retirada do excesso de adesivo e acabamento.

Figura 6.13 - Quadros para suporte da instrumentação...............................................................................98

Figura 6.14 - Ensaio de aderência. 98

Figura 6.15 - Padrões de deslizamento observados: (a) ensaios da série R1; (b) ensaios da série R2 com comprimento de 70 e 140 mm; (c) ensaio da série R2 com comprimento de $210 \mathrm{~mm}$. 
Figura 6.16 - Configuração esquemática usada na determinação da força média no laminado por meio do equilíbrio estático.

Figura 6.17 - Gráfico “força x tempo" definido por meio do equilíbrio de forças e dos dados obtidos nos extensômetros: (a) modelo M1L70R2; (b) modelo M1L210R2.

Figura 6.18 - Gráficos “força nos laminado x deslocamento do pistão" obtidos nos ensaios de aderência da série R1: (a) M1L90R1; (b) M2L90R1; (c) M1L120R1; (d) M2L120R1; (e) M1L150R1; (f) M2L150R1 101

Figura 6.19 - Gráficos “força no laminados x deslocamento do pistão” obtidos nos ensaios de aderência da série R2: (a) M1L70R2; (b) M2L70R2; (c) M1L140R2; (d) M2L140R2; (e) M1L210R2; (f) M2L210R2. .........102 Figura 6.20 - Curva "tensão x deslizamento”, no início da zona de ancoragem - M2L150R1. ........................104

Figura 6.21 - Curva "tensão x deslizamento", no final da zona de ancoragem- M2L150R1. 104

Figura 6.22 - Desprendimento do dispositivo de referência para obtenção do deslizamento: (a) desprendimento entre a cantoneira e a chapa; (b) desprendimento entre a chapa e o laminado. 105

Figura 6.23 - Variação da força máxima no laminado com comprimento de ancoragem: (a) série R1; (b) série $R 2$

Figura 6.24 - Variação da tensão máxima de aderência com o comprimento de ancoragem: (a) série R1; (b) série R2.

Figura 6.25 - Variação da força máxima no laminado (valores médios) com o comprimento de ancoragem....109

Figura 6.26 - Variação tensão máxima no laminado (valores médios) com o comprimento de ancoragem. 109

Figura 6.27 - Variação tensão de aderência máxima (valores médios) com o comprimento de ancoragem......109

Figura 6.28 - Variação deformação máxima no laminado (valores médios) com o comprimento de ancoragem.

Figura 6.29 - Variação do deslizamento no inicio da zona de ancoragem correspondente à força máxima no laminado (valores médios) com o comprimento de ancoragem.

Figura 6.30 - Acabamento superficial do reforço: (a) série $R 1$; (b) série $R 2$.

Figura 6.31 - Gráfico “deformação máxima x comprimento de ancoragem” com linha de tendência: (a) para estimativa do comprimento de ancoragem correspondente a deformação na ruptura; (b) para estimativa da deformação correspondente ao comprimento de ancoragem de $375 \mathrm{~mm}$.

Figura 7.1 - Porção de uma estrutura com trecho equivalente ao modelo de ensaio em destaque.

Figura 7.2 - Características do modelo-piloto. 
Figura 7.5 - Características do modelo N1 SJ.

Figura 7.6 - Características do modelo P1 SJ.

Figura 7.7 - Detalhamento da armadura do consolo.

Figura 7.8 - Detalhamento da armadura da viga. 118

Figura 7.9 - Características geométricas da almofada de apoio: (a) desenho; (b) fotografia. 120

Figura 7.10 - Fôrmas para concretagem dos elementos do modelo de ligação: (a) fôrma do trecho de pilar; (b) fôrma do trecho de viga.

Figura 7.11 - Adensamento do concreto em mesa vibratória: (a) trecho de viga; (b) trecho de pilar. 123

Figura 7.12 - Fôrmas para segunda etapa de concretagem dos modelos P1 SJ e N1 SJ com o trecho de pilar e com as armaduras dos trechos de viga posicionados em seu interior. 123

Figura 7.13 - Confecção dos modelos de ligação reforçados: (a) conferência do prumo; (b) conferência do alinhamento; (c) execução do reforço; (d) umedecimento dos vazios entre os elementos da ligação; (e) vazios preenchidos com graute; ( $f$ ) modelo P1 SJ.

Figura 7.14 - Posicionamento da instrumentação na armadura e laminados do modelo-piloto. 125

Figura 7.15 - Posicionamento da instrumentação na armadura e laminado do ensaio dos modelos N1 CJ, N1 CJ e N1 SJ. 125

Figura 7.16 - Posicionamento da instrumentação na armadura e laminado do ensaio dos modelos P1 CJ e P1 SJ. 126

Figura 7.17 - Configuração esquemática do ensaio e instrumentação externa para o modelo-piloto. 127

Figura 7.18 - Configuração esquemática do ensaio e instrumentação externa dos modelos N1 CJ, N2 CJ e N1 SJ.

Figura 7.19 - Configuração esquemática do ensaio e instrumentação externa para os modelos P1 CJ e P1 SJ.

Figura 7.20 - Configuração do ensaio e instrumentação externa para o modelo P1 SJ.......

Figura 7.21 - Ciclos de carregamento: (a) aplicados ao modelo-piloto; (b) aplicados ao modelo P1-SJ.

Figura 7.22 - Evolução da fissuração em uma das faces do modelo-piloto.

Figura 7.23 - Configuração das fissuras após a ruptura do modelo-piloto de ligação.

Figura 7.24 - Evolução da fissuração em uma das faces do modelo N1 CJ. 133 
Figura 7.25 - (a) Configuração das fissuras após a ruptura; (b) detalhe da armadura exposta - modelo N1 CJ.

Figura 7.26 - Evolução da fissuração em uma das faces do modelo N2 CJ..................................................135

Figura 7.27 - (a) Configuração das fissuras após a ruptura; (b) detalhe da ruptura - modelo N2 CJ...............136

Figura 7.28 - Evolução da fissuração em uma das faces do modelo N1 SJ.

Figura 7.29 - Configuração das fissuras após a ruptura; (b) desprendimento de porção de concreto; (c)

delaminação do reforço - modelo N1 SJ. 138

Figura 7.30 - Evolução da fissuração em uma das faces do modelo P1 CJ.

Figura 7.31 - (a) Configuração das fissuras após a ruptura; (b) detalhe da ruptura; (c) delaminação do reforço;

(d) fragmentos de concreto com lâminas de reforço ainda aderidas - modelo P1 CJ. 140

Figura 7.32 - Evolução da fissuração em uma das faces do modelo P1 SJ. 141

Figura 7.33 - (a) Configuração das fissuras após a ruptura; (b) ruptura; (c) do desprendimento de concreto e laminas do reforço; (d) deslizamento do reforço - modelo P1 SJ. 142

Figura 7.34 - Gráfico “força x deformação” nos laminados - modelo-piloto. 142

Figura 7.35 - Gráfico “força x deformação” nos laminados - modelo N1 CJ....... 143

Figura 7.36 - Gráfico “força x deformação” nos laminados - modelo N2 CJ. 143

Figura 7.37 - Gráfico “força x deformação” nos laminados - modelo N1 SJ. 143

Figura 7.38 - Gráfico “força x deformação” nos laminados - modelo P1 CJ. 144

Figura 7.39 - Gráfico “força x deformação” nos laminados - modelo P1 SJ. 144

Figura 7.40 - Gráfico “força x deformação” na armadura do tirante do consolo - modelo-piloto. 145

Figura 7.41 - Gráfico “força x deformação” na armadura do tirante do consolo - modelo N1 CJ. 145

Figura 7.42 - Gráfico “força x deformação” na armadura do tirante do consolo - modelo N2 CJ. 146

Figura 7.43 - Gráfico “força x deformação” na armadura do tirante do consolo - modelo N1 SJ. 146

Figura 7.44 - Gráfico “força x deformação” na armadura do tirante do consolo - modelo P1 CJ. 146

Figura 7.45 - Gráfico “força x deformação” na armadura do tirante do consolo - modelo P1 SJ. 147

Figura 7.46 - Gráfico “força x deformação” na armadura de suspensão - modelo-piloto. 148

Figura 7.47 - Gráfico “força x deformação” na armadura de suspensão - modelo N1 CJ. 148

Figura 7.48 - Gráfico “força x deformação” na armadura de suspensão - modelo N2 CJ. 148

Figura 7.49 - Gráfico “força x deformação” na armadura de suspensão - modelo N1 SJ. 149

Figura 7.50 - Gráfico “força x deformação” na armadura de suspensão - modelo P1 CJ. 149 
Figura 7.51 - Gráfico “força x deformação” na armadura de suspensão - modelo P1 SJ.

Figura 7.52 - Configuração esquemática do ensaio do modelo-piloto.

Figura 7.53 - Configuração valida para os modelos N1CJ, N2 CJ, N1 SJ, P1 CJ e P1 SJ. ...... 151

Figura 7.54 - Curvas “momento x rotação” original e corrigida do modelo-piloto. 152

Figura 7.55 - Curva “momento x rotação" do modelo-piloto e a aproximação bi-linear. 153

Figura 7.56 - Curva “momento x rotação” do modelo N1 CJ e a aproximação bi-linear. 153

Figura 7.57 - Curva “momento x rotação” do modelo N2 CJ e a aproximação bi-linear. 153

Figura 7.58 - Curva “momento x rotação” do modelo N1 SJ e a aproximação bi-linear. 154

Figura 7.59 - Curva “momento x rotação” do modelo P1 CJ e a aproximação bi-linear. 154

Figura 7.60 - Curva “momento x rotação” do modelo P1 SJ e a aproximação bi-linear. 154

Figura 7.61 - Aspectos geométricos em que se baseou a formulação para estimativa da rigidez inicial. 156

Figura 7.62 - Gráfico “força x deslocamento” no meio do vão - modelo-piloto. 160

Figura 7.63 - Gráfico “força x deslocamento” no meio do vão - modelo N1 CJ. 160

Figura 7.64 - Gráfico “força x deslocamento” no meio do vão - modelo N2 CJ. 160

Figura 7.65 - Gráfico “força x deslocamento” no meio do vão - modelo N1 SJ. 161

Figura 7.66 - Gráfico “força x deslocamento” no meio do vão - modelo P1 CJ. 161

Figura 7.67 - Gráfico “força x deslocamento” no meio do vão - modelo P1 SJ. 161

Figura 7.68 - Esquema estático para determinação da flecha teórica. 162

Figura 7.69 - Gráficos “força x flecha” com a consideração de carga distribuída e concentrada. 163

Figura 7.70 - Envoltória da curva experimental “força x deslocamento”, aproximação bi-linear e curva teóricas do modelo P1 CJ. 163

Figura 7.71 - (a) Curvas “momento rotação"; (b) curvas “força x deslocamento”. 164

Figura 7.72 - Arranjo para medição da resposta rotacional (Fonte: Nóbrega (2004)). 165

Figura 7.73 - Arranjo esquemático para determinação da resposta rotacional e momento dinâmico. 166

Figura 7.74 - Desenho esquemático do ensaio de vibração livre - condição de contorno livre-livre (Fonte:

Almeida (2007)). 167

Figura 7.75 - Vinculação do ensaio de vibração livre. 168

Figura 7.76 - Desenho esquemático da instrumentação e da aplicação do carregamento do ensaio dinâmico de vibração forçada (Fonte: Almeida (2007)). 169

Figura 7.77 - Ensaio de vibração forçada realizado na maquina universal de ensaios INSTRON. 170 
Figura 7.78 - Ensaio de vibração forçada em um modelo íntegro realizado no pórtico de reação. 170

Figura 1-B - Variação da força média nos laminados com o tempo, nos ensaios de aderência da série R1: (a) M1L70R1; (b) M1L90R1; (c) M2L90R1; (d) M1L120R1; (e) M2L120R1; (f) M1L150R1; (g) M2L150R1........189

Figura 2-B - Variação da força média nos laminados com o tempo, nos ensaios de aderência da série R2: (a) M1L70R2; (b) M2L70R2; (c) M1L140R2; (d) M2L140R2; (e) M1L210R2; (f) M2L210R2. 190

Figura 1-C - Curvas “tensão x deslizamento”, no início da zona de ancoragem, obtidas nos ensaios de aderência da série R1: (a) M1L90R1; (b) M2L90R1; (c) M1L120R1; (d) M2L120R1; (e) M1L150R1; (f) M2L150R1. 191

Figura 2-C - Curvas “tensão x deslizamento”, no início da zona de ancoragem, obtidas nos ensaios de aderência da série R2: (a) M1L70R2; (b) M2L70R2; (c) M1L140R2; (d) M2L140R2; (e) M1L210R2; (f) M2L210R2. 192

Figura 3-C - Curvas “tensão x deslizamento”, no final da zona de ancoragem, obtidas nos ensaios de aderência da série R1: (a) M1L90R1; (b) M2L90R1; (c) M1L120R1; (d) M2L120R1; (e) M1L150R1; (f) M2L150R1......193 Figura 4-C - Curvas “tensão x deslizamento”, no final da zona de ancoragem, obtidas nos ensaios de aderência da série R2: (a) M1L70R2; (b) M2L70R2; (c) M1L140R2; (d) M2L140R2; (e) M1L210R2; (f) M2L210R2......194 Figura 1-D - Distribuições de tensão e deformação no estado limite último para ruptura governada por esmagamento do concreto (Fonte: adaptado do ACI 440.1R-03 (2003))...... 196 Figura 2-D - Modelo simplificado de distribuição de tensões proposto para estruturas de concreto armadas com PRF (Fonte: FIB 9.3 TG (2003)). 198

Figura 1-E - Distribuição de deformações e tensões na seção. 201 


\section{LISTA DE QUADROS}

Quadro 1.1 - Premissas, ações e limitações de abrangência da pesquisa. .............................................................33

Quadro 3.1 - Informações das vigas ensaiadas na série S2 (Fonte: Fortes (2004))............................................ 49

Quadro 3.2 - Características das vigas (Fonte: Castro (2005)). ......................................................................... 51

Quadro 3.3 - Resultados experimentais (Fonte: Castro (2005))......................................................................... 52

Quadro 4.1 - Limites de classificação da ligação quanto à rigidez (Fonte: adaptado de EUROCODE 3 (2002)).

72

Quadro 5.1 - Características dos modelos (Fonte: adaptado de Prota et al. (2004)). ........................................... 79

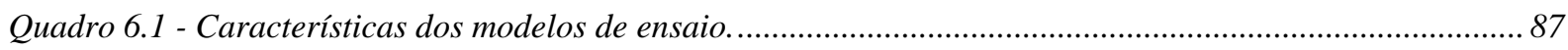

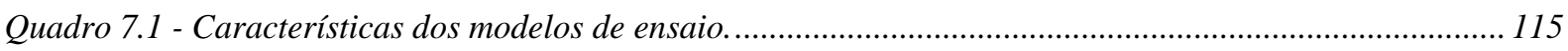



Tabela 2.1 - Propriedades das resinas dos tipos poliéster e epóxi (Fonte: adaptado de Carolin (2003)). 37

Tabela 2.2 - Propriedades típicas na tração de fibras utilizadas em sistema de PRF (Fonte: adaptado de ACI

440.2R-02 (2002)). 38

Tabela 3.1 - Cargas de fissuração, escoamento e ruína dos consolos (Fonte: Souza et al. (2006)). 57

Tabela 3.2 - Resultados dos ensaios de aderência (Fonte: adaptado de De Lorenzis e Nanni (2001)). 63

Tabela 3.3 - Valores médios dos dados principais das séries S1 (Fonte: adaptado de Cruz (2004)). 65

Tabela 3.4 - Valores médios dos dados principais das séries S2 (Fonte: adaptado de Cruz (2004)). 66

Tabela 5.1 - Sumário dos resultados experimentais (Fonte: adaptado de Prota et al. (2004)). 82

Tabela 5.2 - Resultados dos ensaios com conectores de PRFC (Fonte: adaptado de Pantelides et al. (2003))... 83

Tabela 6.1 - Propriedades das armaduras de aço utilizadas nos modelos de ensaio de aderência. .89

Tabela 6.2 - Consumo de materiais por metro cúbico para o concreto utilizado na série de ensaio R1. 90

Tabela 6.3 - Consumo de materiais por metro cúbico para o concreto utilizado na série de ensaio R2. 90

Tabela 6.4 - Propriedades do concreto utilizado na série R1. 92

Tabela 6.5 - Propriedades do concreto utilizado na série R2. 92

Tabela 6.6 - Propriedades físicas do adesivo utilizado nos modelos da série R1 (dados do fornecedor) 92

Tabela 6.7 - Propriedades físicas do adesivo utilizado nos modelos da série R2 (dados do fornecedor).. 92

Tabela 6.8 - Propriedades físicas do laminado (dados do fornecedor). 94

Tabela 6.9 - Propriedades físicas do laminado (dados obtidos experimentalmente)...... 94

Tabela 6.10 - Resultados obtidos na série de ensaios R1. 107

Tabela 6.11 - Resultados obtidos na série de ensaios R2.. 108

Tabela 7.1 - Consumo de materiais por metro cúbico para o concreto utilizado no modelo de ligação. 118

Tabela 7.2 - Propriedades do concreto utilizado no modelo-piloto de ligação. 119

Tabela 7.3 - Propriedades do concreto utilizado nos trechos de pilar e viga dos modelos N1 CJ, N2 CJ, P1 CJ e trecho de pilar dos modelos N1 SJ e P1 SJ. 119 
Tabela 7.4 - Propriedades do concreto utilizado nos trechos de viga dos modelos N1 SJ e P1 SJ.

Tabela 7.5 - Propriedades do graute para preenchimento do furo do chumbador do modelo-piloto de ligação.

Tabela 7.6 - Propriedades do graute para preenchimento dos vazios do modelo-piloto de ligação.

Tabela 7.7 - Propriedades do graute para preenchimento do furo do chumbador - modelos N1 CJ, N2 CJ e P1

CJ.

Tabela 7.8 - Propriedades do graute para preenchimento dos vazios da ligação - modelos N1 CJ, N2 CJ e P1

CJ.

Tabela 7.9 - Intervalos entre etapas de confecção dos modelos.

Tabela 7.10 - Deformações máximas nos laminados.

Tabela 7.11 - Deformações máximas nas armaduras do tirante do consolo.

Tabela 7.12 - Deformações máximas nas armaduras de suspensão.

Tabela 7.13 - Resultados relacionados à curva "momento x rotação".

Tabela 7.14 - Classificação das ligações quanto à rigidez.

Tabela 7.15 - Estimativas teóricas pelo ACI 440.1R-03 (2003).

Tabela 7.16 - Estimativas teóricas pelo FIB 9.3 TG (2003). 158

Tabela 7.17 - Comparação entre os valores teóricos e experimentais da rigidez inicial. 158

Tabela 7.18 - Resultados relacionados à curva "força x deslocamento". 162

Tabela 1-D - Dados de entrada e resultados dos cálculos dos momentos resistentes pelo ACI 440.1R-03 (2003).

Tabela 2-D - Dados de entrada e resultados dos cálculos dos momentos resistentes pelo FIB 9.3 TG (2003). .199 


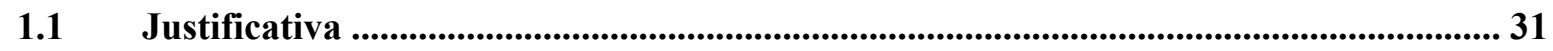

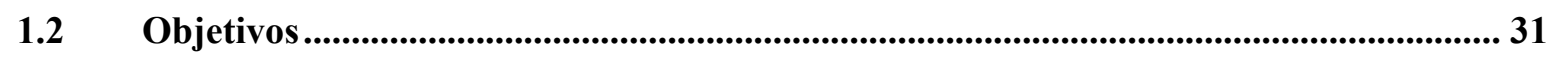

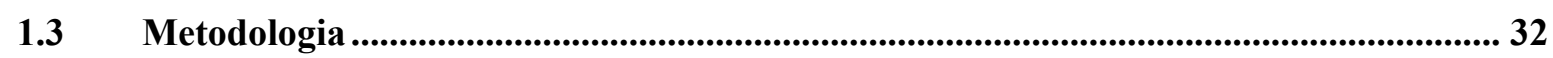

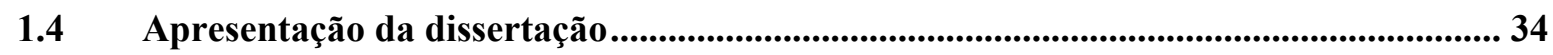

CAPÍTULO 2 - Polímero reforçado com fibra de carbono ..................................................... 35

$2.1 \quad$ Matriz polimérica ................................................................................................................ 36

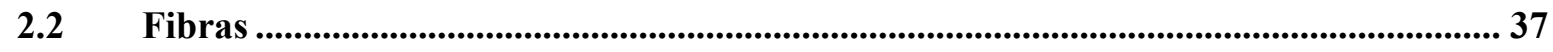

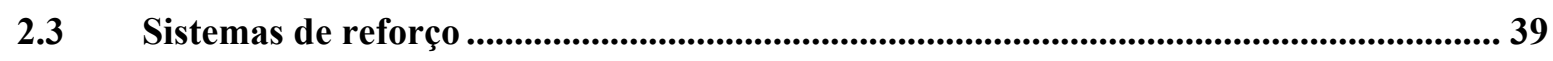

CAPÍTULO 3 - Reforço por colagem de barras e laminados de PRF em entalhes............... 41

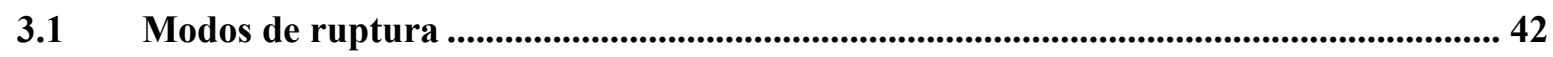

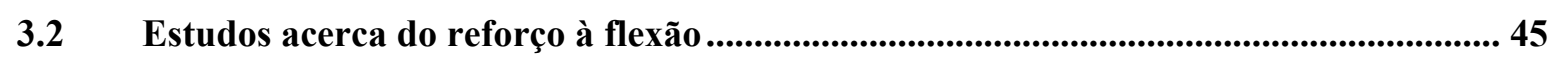

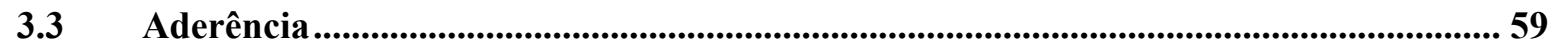

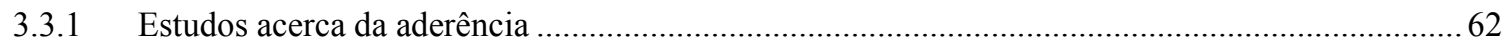

CAPÍTULO 4 - Ligações de estruturas de concreto pré-moldado...........................................69

CAPÍTULO 5 - Reforço de ligações........................................................................... 75

CAPÍTULO 6 - Ensaios de aderência................................................................................. 85

6.1 Características do modelo de ensaio ........................................................................................ 86

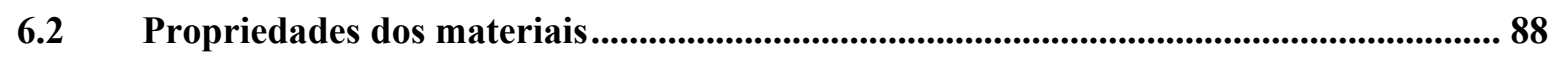

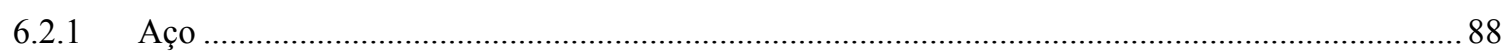




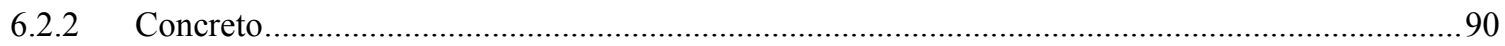

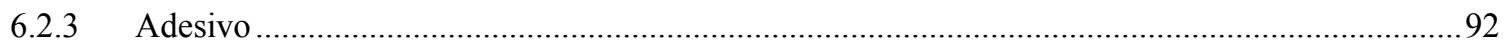

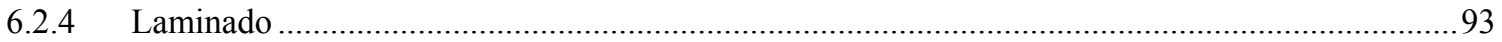

6.3 Configuração do ensaio e instrumentação ..................................................................94

6.4 Confecção dos modelos ................................................................................................. 95

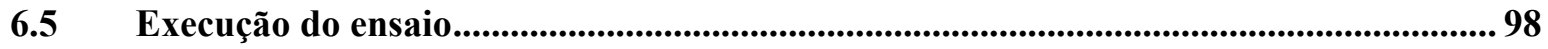

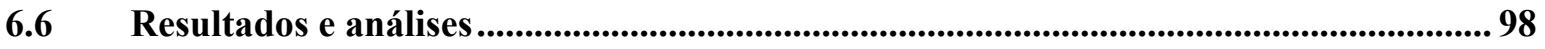

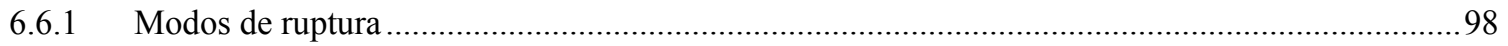

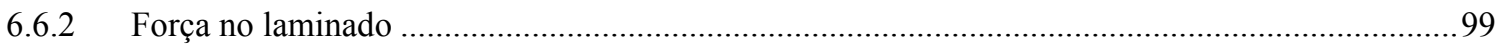

6.6.3 Tensão de aderência e deslizamento ............................................................................. 103

6.6.4 Variação da força máxima no laminado com o comprimento de ancoragem ............................ 105

6.6.5 Variação da tensão máxima de aderência com o comprimento de ancoragem ........................... 105

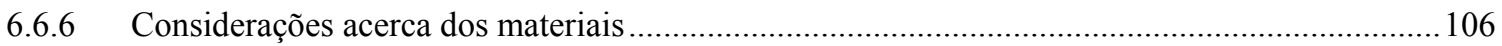

6.6.7 Comparações entre as duas séries de ensaio ..................................................................... 106

CAPÍTULO 7 - Ensaios em modelos reduzidos de ligação ....................................................... 113

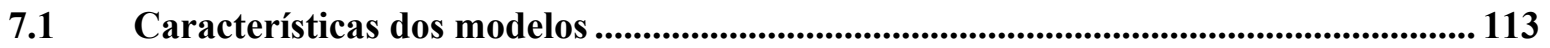

7.2 Propriedades dos materiais .............................................................................................. 118

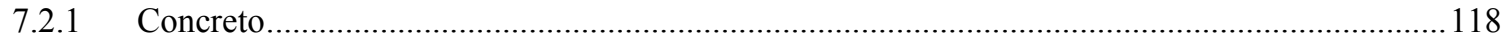

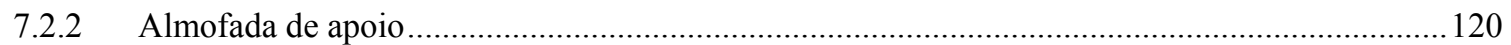

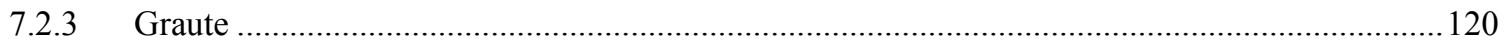

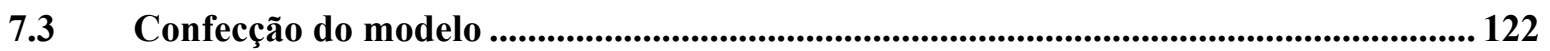

7.4 Instrumentação e configuração dos ensaios estáticos ........................................................ 125

7.5 Execução dos ensaios estáticos ............................................................................................ 128

7.6 Resultados e análises dos ensaios estáticos................................................................... 129

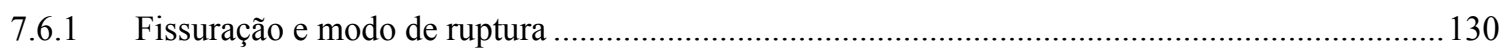

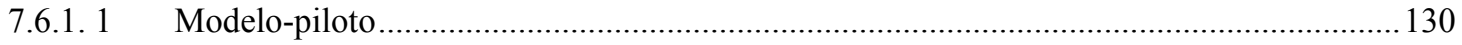

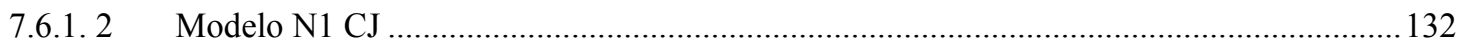

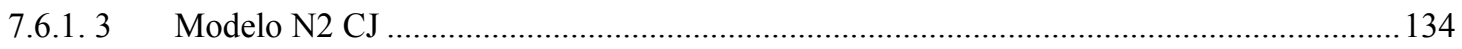

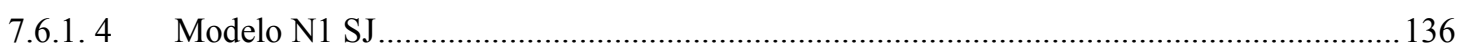


7.6.1. 5 Modelo P1 CJ.

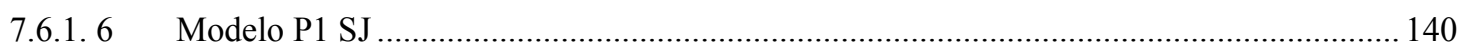

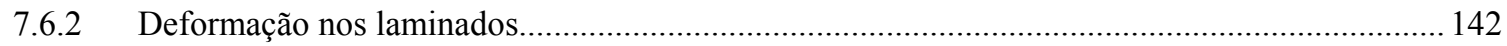

7.6.3 Deformação na armadura do tirante do consolo ................................................................ 145

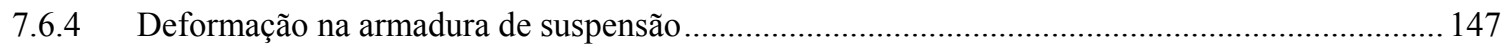

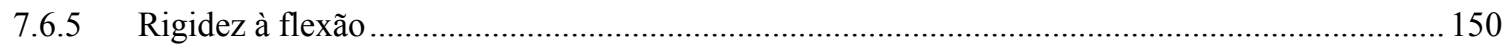

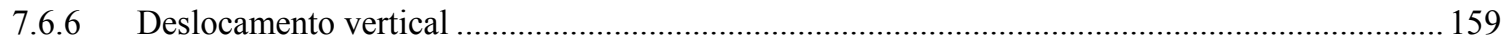

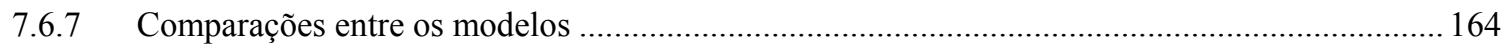

Ensaios dinâmicos em modelos reduzidos de ligação ................................................. 164

7.7.1 Instrumentação, configuração e execução dos ensaios dinâmicos ............................................ 167

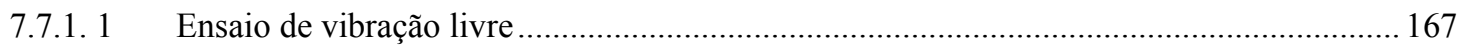

7.7.1. 2 Ensaio de vibração forçada .................................................................................. 168

CAPÍTULO 8 - Conclusões e sugestões para trabalhos futuros .........................................173

8.1 Conclusões acerca dos ensaios de aderência............................................................... 173

8.2 Conclusões acerca dos ensaios de ligações .................................................... 174

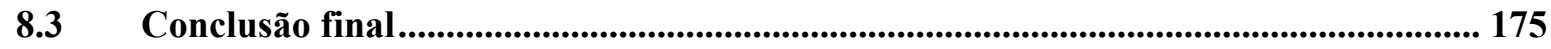

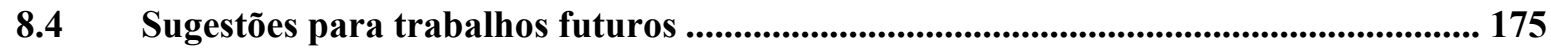

REFERÊNCIAS BIBLIOGRÁFICAS ....................................................................... 177

APÊEDICE A - Equipamentos e instrumentação ...........................................................185

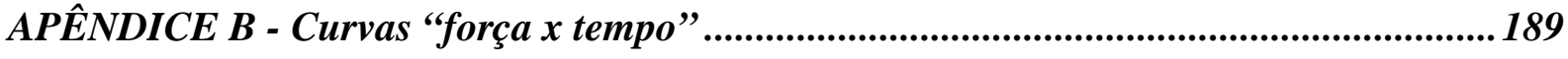

APÊEDICE C - Curvas “tensão x deslizamento" .............................................................191

APÊEDICE D - Estimativa da resistência da ligação ................................................195

APÊNDICE E - Correção da rotação................................................................201 



\section{CAPÍTULO 1}

\section{INTRODUÇÃO}

A História da Construção mostra o homem em constante busca pelo desenvolvimento de materiais e métodos construtivos. Assim, observa-se a sua evolução desde o simples empilhamento de pedras, passando pela utilização de materiais cimentícios na união destes elementos, até a composição entre agregados, material cimentício e aço, que é o fundamento do concreto armado. Atualmente, os polímeros reforçados com fibras (PRF) ocupam o topo da cadeia evolutiva dos materiais de construção. Seu uso, em substituição ao aço, como reforço ou armadura de estruturas de concreto, se justifica pelas suas excelentes propriedades: baixo peso, elevada resistência e alto módulo de elasticidade, durabilidade, resistência à corrosão, resistência a ataques químicos, permeabilidade eletromagnética e resistência a impacto.

O emprego do PRF como armadura foi impulsionado inicialmente pela necessidade de uma alternativa ao aço em estruturas sujeitas a ambientes altamente corrosivos, como zonas costeiras. Contudo, o maior mercado para armaduras não metálicas é o de estruturas hospitalares nas quais o uso de armadura convencional se contrapõe ao funcionamento adequado de equipamentos como o de ressonância magnética (ACI 440.1R-03, 2003).

No reforço de estruturas de concreto, destacam-se a colagem externa de mantas e laminados pré-fabricados de PRF. As duas técnicas já consolidadas contam com recomendações internacionais como FIB (2001) e ACI 440.2R-02 (2002), entretanto apresentam desvantagens associadas à sua aplicação externa, apontadas por Fortes (2004):

- Necessidade de proteção contra raios ultravioletas, em estruturas aparentes;

- Necessidade de proteção contra ataques de vândalos;

- Sensibilidade a temperaturas elevadas, acima da ambiente (acima de $70^{\circ} \mathrm{C}$ );

- Pouco acréscimo de rigidez do elemento reforçado; 
- Aumento, apesar da pequena espessura, da dimensão do elemento reforçado em alguns milímetros;

- Susceptibilidade à ruptura por descolamento do reforço (peeling-off);

- Pequena mobilização da capacidade resistente do material compósito - PRFC.

Uma técnica recente, relatada por Blaschko e Zilch ${ }^{1}$ (1999 apud FORTES, 2004), soluciona ou pelo menos ameniza essas questões. Consiste na colagem de laminados em entalhes realizados no concreto de cobrimento. Dessa forma, o reforço conta com maior proteção a atos de vandalismo, fogo e radiação ultravioleta. Os laminados inseridos são menos suscetíveis ao descolamento prematuro, permitindo uma maior mobilização da capacidade resistente do PRF. Não há alteração nas dimensões originais dos elementos e o preparo do substrato é mais simples e rápido em relação à colagem externa.

A inserção de laminados ou barras de PRF em entalhes no concreto de cobrimento é referenciada internacionalmente por Near-Surface Mounted (NSM). Existem estudos sobre seu emprego no reforço à flexão de vigas (BARROS; FORTES, 2005; CASTRO, 2005; FORTES, 2004; LIU, 2006; LIU; OEHLERS; SERACINO, 2006; TENG et al., 2006; QUATTLEBAUM; HARRIES; PETRON, 2005), pilares (BARROS; FERREIRA; LOURENÇO, 2000) e consolos (SOUZA et al., 2006), reforço ao cisalhamento de vigas (BARROS; DIAS, 2006; DE LORENZIS; NANNI, 2001a; 2001b; DIAS; BARROS, 2006) e reforço de ligações monolíticas viga-pilar (PROTA et al., 2004).

Diante do aspecto promissor da técnica, decidiu-se avaliar, nesta pesquisa, a sua eficiência no incremento de rigidez e resistência à flexão de ligações viga-pilar de estruturas de concreto pré-moldado. Duas aplicações podem ser exploradas: como reforço ou como recurso de projeto de novas estruturas.

Uma vez constatada a sua eficiência, o reforço de ligações viga-pilar de estruturas prémoldadas poderia se prestar à reabilitação de estruturas que apresentassem comportamento global insatisfatório, tanto do ponto de vista de capacidade resistente e instabilidade decorrente de deslocamentos laterais excessivos, como de uso por vibração excessiva. Poderia também aumentar a versatilidade das estruturas, viabilizando reformas e ampliações. $\mathrm{Na}$ pesquisa bibliográfica realizada não se encontrou relatos sobre esse tipo de intervenção. No capítulo 5 descreve-se uma pesquisa em que a técnica NSM foi empregada no reforço de

1 BLASCHKO M.; ZILCH, K. Rehabilitation of Concrete Structures with PRFC Strips Glued into Slits. Proceedings of the Twelfth International Conference on Composite Materials, Paris, 1999. 
ligação viga-pilar monolítica. Apresenta-se também um estudo em que mantas de polímero reforçado com fibra de carbono (PRFC), coladas externamente, foram utilizadas no reforço de ligações entre painéis pré-moldados.

A idéia de utilização de laminados inseridos como elemento de projeto de estruturas pré-moldadas é, à primeira vista, muito atrativa. Sua execução rápida e simples permitiria o estabelecimento de continuidade à flexão nas ligações sem prejuízo da rapidez executiva, característica das construções de estruturas pré-moldadas, e sem a necessidade de grande quantidade de funcionários ou equipamentos especiais. Ressalta-se o caráter exploratório da pesquisa, uma vez que não se fundamenta em aplicações correntes na prática.

\subsection{Justificativa}

A pré-moldagem é um caminho para a racionalização e industrialização da Construção Civil, entretanto seu potencial tem sido pouco explorado. Dentre as razões disso está a complexidade que envolve a execução e o comportamento de suas ligações, especialmente daquelas resistentes à flexão.

Em função da importância das ligações, o Departamento de Engenharia de Estruturas da Escola de Engenharia de São Carlos (SET) conta com um histórico de desenvolvimento de pesquisas no tema, iniciado por Ballarin (1993) e Ferreira (1993). Seguiram-se a estes trabalhos Soares (1998), Ferreira (1999), Barboza (2001), Miotto (2002), Canha (2004), Ebeling (2006) e Baldissera (2006). O estudo das ligações de estruturas de concreto prémoldado é atualmente um dos enfoques do projeto temático "Nucleação e incremento da

pesquisa, inovação e difusão em concreto pré-moldado e estruturas mistas para a modernização da Construção Civil", no qual se insere o presente trabalho, bem como os dois últimos listados.

Nesta dissertação, avalia-se a utilização da técnica NSM no estabelecimento de continuidade à flexão em ligações viga-pilar de estruturas de concreto pré-moldado. Imaginase que a eficácia do método contribuiria para a versatilidade dessas estruturas tendo como grandes vantagens praticidade e rapidez executiva.

\subsection{Objetivos}

O objetivo geral é avaliar a aplicabilidade da técnica NSM no incremento da rigidez e da resistência de ligações de estruturas de concreto pré-moldado. Pretende-se alcançar os seguintes objetivos específicos: 
- Analisar a aderência dos laminados colados em entalhes sob configuração semelhante à que se pretende empregar no modelo experimental de ligação;

- Avaliar as dificuldades de execução inerentes à técnica de reforço;

- Avaliar a influência da presença do graute e da almofada no comportamento da ligação reforçada;

- Elaborar uma formulação teórica para estimativa da rigidez à flexão da ligação reforçada;

- Confirmar a validade da Análise Dinâmica Modal na obtenção experimental da rigidez de ligações de estruturas de concreto pré-moldado.

\subsection{Metodologia}

Nesta pesquisa utilizou-se a seguinte metodologia:

- Elaboração de síntese bibliográfica sobre os assuntos relacionados ao tema;

- Realização de ensaios experimentais para avaliação da aderência do reforço;

- Definição e confecção de modelos reduzidos de ligação;

- Reforço dos modelos reduzidos de ligação de comportamento articulado pela colagem de laminados em entalhes;

- Realização de ensaios experimentais estáticos para avaliação da rigidez e da resistência a momentos fletores positivos e negativos dos modelos reforçados;

- Realização de ensaios experimentais de vibração para avaliação da rigidez dos modelos reduzidos de ligação em três condições: modelo íntegro reforçado, modelo reforçado fissurado e modelo reforçado rompido;

- Analise dos resultados e elaboração de conclusões.

O Quadro 1.1 descreve em linhas gerais as premissas, ações e limitações de abrangência que serviram como diretrizes no desenvolvimento deste trabalho. 


\begin{tabular}{|c|c|c|c|}
\hline 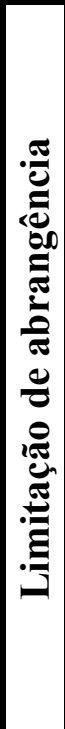 & 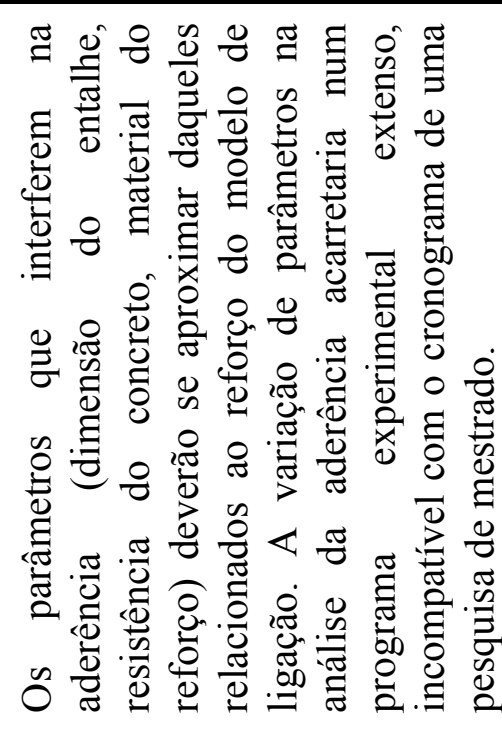 & 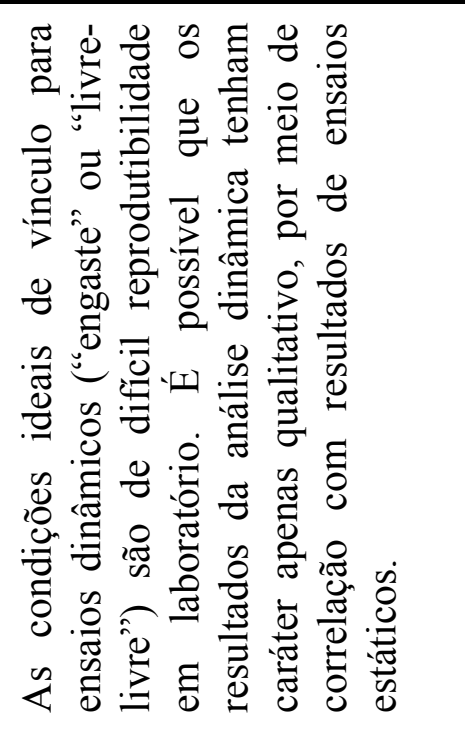 & 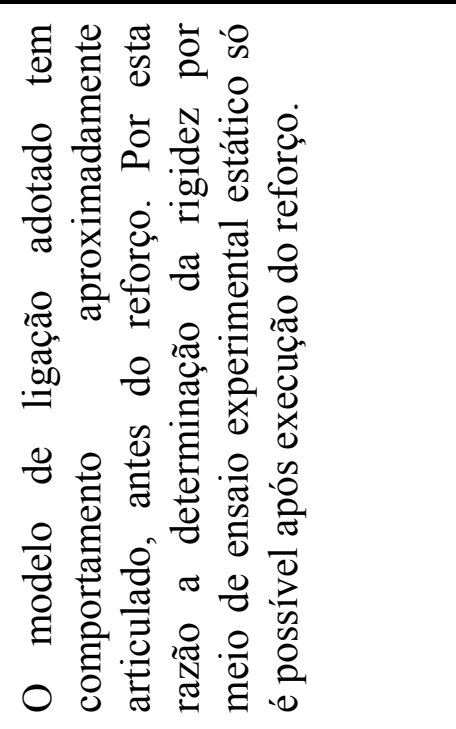 \\
\hline 惫 & 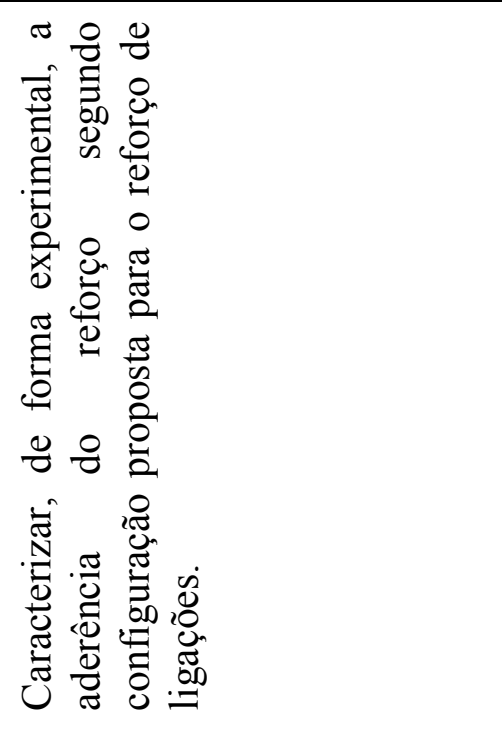 & 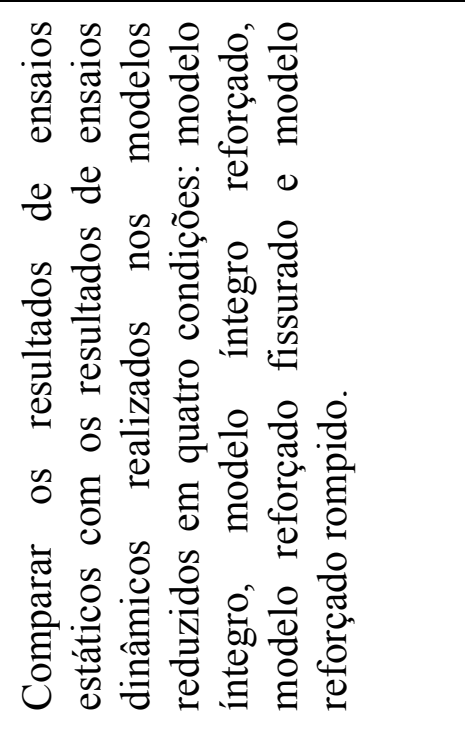 & 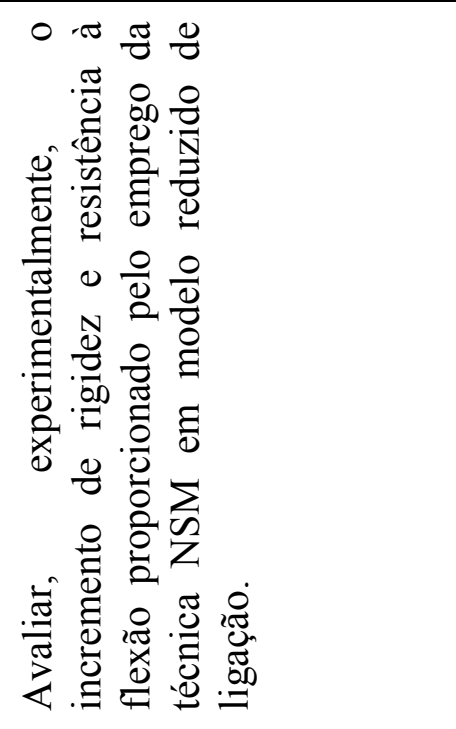 \\
\hline 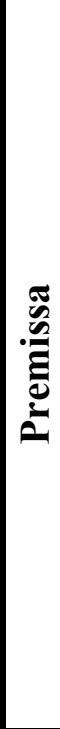 & 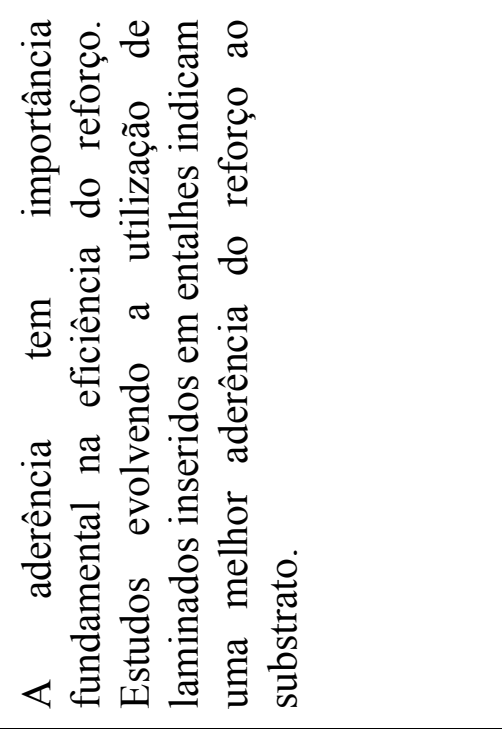 & 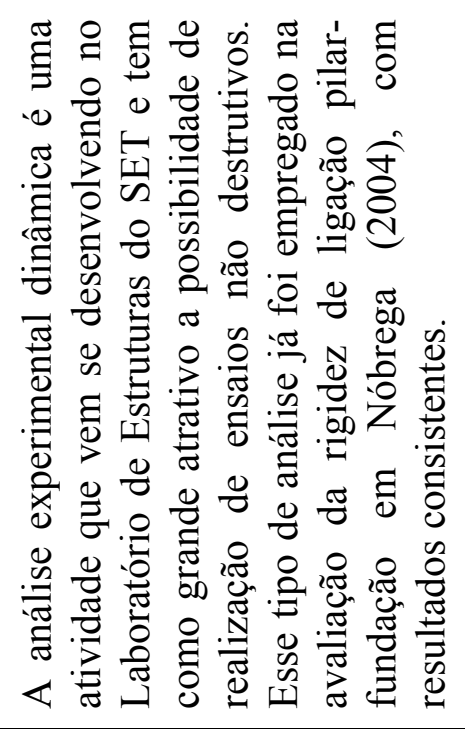 & 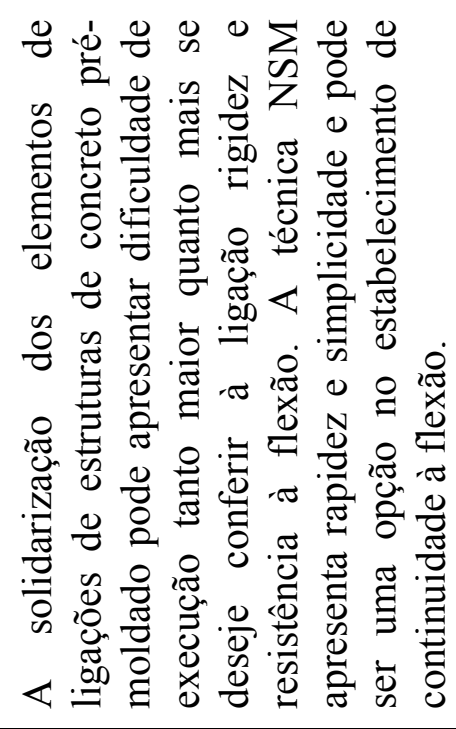 \\
\hline
\end{tabular}

Quadro 1.1 - Premissas, ações e limitações de abrangência da pesquisa. 


\subsection{Apresentação da dissertação}

O estudo foi desenvolvido na confluência de dois campos temáticos: reforço de estruturas e ligações de estruturas de concreto pré-moldado. Por esta razão foi necessária revisão bibliográfica diversificada, convenientemente dividida em capítulos, conforme descrição a seguir.

Capítulo 1 - Introdução: apresenta os aspectos gerais do trabalho, justificativa da pesquisa, delimitação dos objetivos e metodologia resumida.

Capítulo 2 - Polímeros reforçados com fibra de carbono: trata de aspectos gerais acerca dos polímeros reforçados com fibras, com ênfase aos polímeros reforçados com fibras de carbono.

Capítulo 3 - Reforço por inserção de barras e laminados de PRF em entalhes: apresenta revisão bibliográfica sobre a técnica de reforço por colagem de barras e laminados de PRF em entalhes, com destaque para estudos experimentais sobre a aderência.

Capítulo 4 - Ligações de estruturas de concreto pré-moldado: apresenta aspectos gerais a respeito das ligações de estruturas de concreto pré-moldado. Enfoca os limites classificatórios quanto à rigidez e à resistência.

Capítulo 5 - Reforço de ligações: apresenta revisão sobre reforço de ligações. A maior parte deste capítulo trata do reforço de ligações viga-pilar monolíticas, uma vez que não foram encontrados relatos de reforço de ligações viga-pilar de estruturas pré-moldadas.

Capítulo 6 - Ensaios de aderência: descrição dos ensaios de aderência. Apresentação dos resultados e análises.

Capítulo 7 - Ensaios em modelos reduzidos de ligação: descrição dos ensaios em modelos de ligação estáticos e dinâmicos. Apresentação dos resultados e análises dos ensaios estáticos.

Capítulo 8 - Conclusões e sugestões para trabalhos futuros: síntese das conclusões e sugestões para trabalhos futuros. 


\section{CAPÍTULO 2}

\section{POLÍMERO REFORÇADO COM FIBRA DE CARBONO}

Os polímeros reforçados com fibras de carbono têm diversas aplicações na indústria, desde a fabricação de materiais esportivos à confecção de equipamentos aeroespaciais. A extensa gama de aplicações se deve à suas propriedades mecânicas, leveza e resistência a ataques químicos. $\mathrm{O}$ alto custo representou um entrave inicial à expansão do seu uso na Construção Civil, que apenas ganhou força no final da década de 90, concentrando-se no reforço de estruturas de concreto armado (FORTES, 2004). A Figura 2.1 ilustra a relação entre a produção industrial e o custo dos PRFC, bem como traça um panorama das suas formas de utilização ao longo do tempo.

Os PRF são comumente designados por compósitos. O termo compósito define a união de materiais diferentes em forma e composição química, insolúveis entre si, com interface identificável (ACI 440.1R-03, 2003). De acordo com esta definição, o concreto armado é um exemplo de compósito cujos componentes são a pasta, os agregados e o aço. Há também compósitos naturais, como a madeira, que é a união de fibras de celulose e lignina. Ao longo deste trabalho o termo compósito se refere aos PRF, em que os materiais unidos são fibras e matriz polimérica. Os PRF podem ter ainda fillers e aditivos em sua composição. Os fillers são adicionados principalmente para redução de custos e controle da fissuração. Atuam também na melhoria de propriedades mecânicas e como retardadores de combustão. $\mathrm{O}$ uso de aditivos visa a melhoria de propriedades mecânicas ou da trabalhabilidade.

O comportamento físico dos compósitos é afetado principalmente pelas propriedades mecânicas, orientação, comprimento, forma e composição das fibras, pelas propriedades mecânicas da matriz e pela adesão entre fibra e matriz (ACI 440R-96, 1996). 


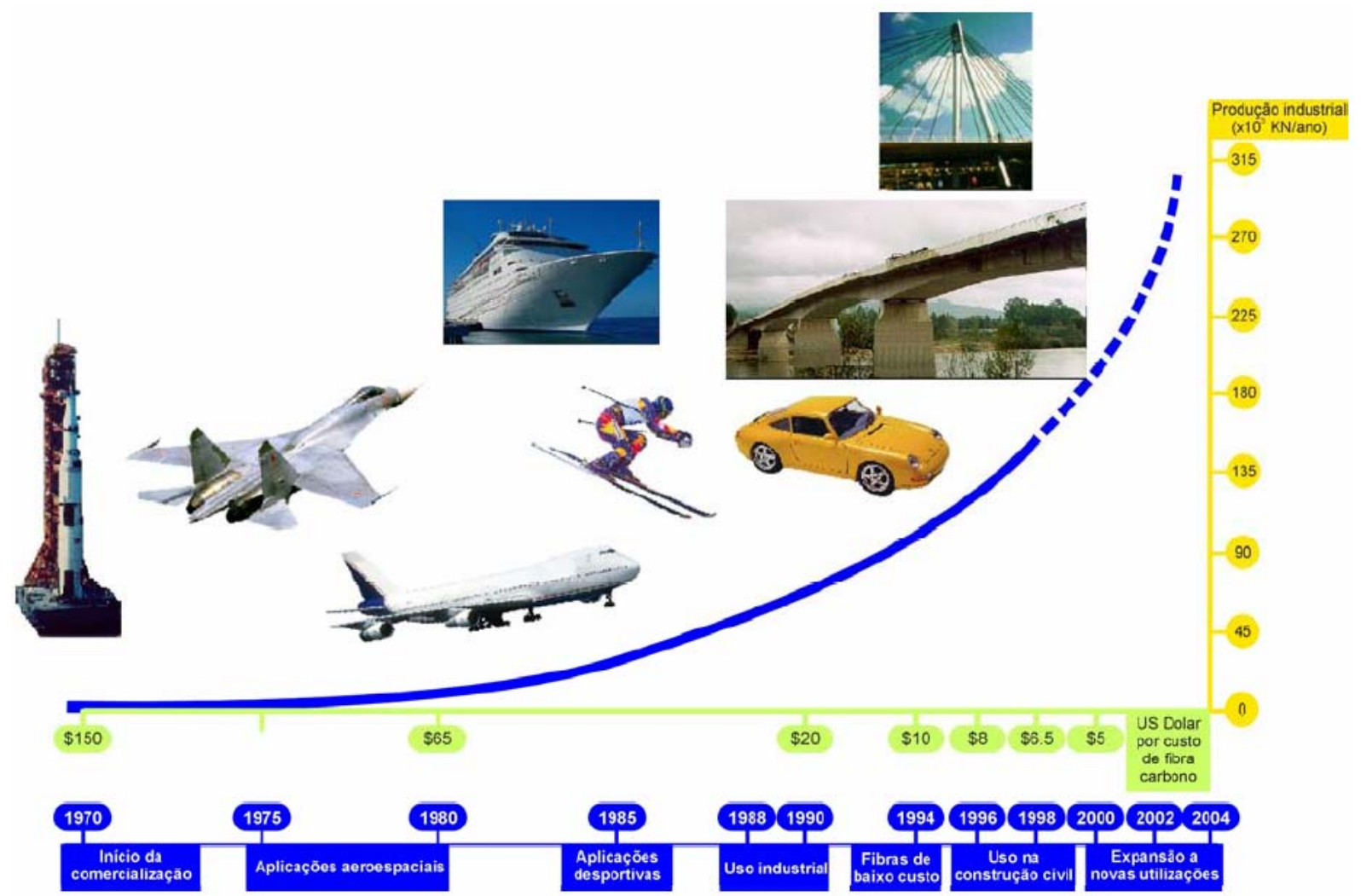

Figura 2.1 - Evolução no tempo da utilização da fibra de carbono em função do preço, da produção e do campo de aplicação (Fonte: Juvandes (2002)).

\subsection{Matriz polimérica}

A matriz é responsável pela transferência de tensões entre as fibras, por mantê-las agrupadas, protegê-las de danos mecânicos e de agentes agressivos. É capaz ainda de prover suporte à flambagem das fibras quando comprimidas. As propriedades da matriz podem limitar a utilização do compósito, a exemplo da temperatura máxima a que ele pode ser submetido (HYER, 1998). Isso se justifica pela influência da temperatura em suas propriedades mecânicas. Ao atingir uma determinada temperatura, denominada temperatura de transição vítrea ( $\mathrm{Tg}$ ), a matriz tem o módulo de elasticidade reduzido e perde o aspecto original de sólido frágil.

As resinas dividem-se basicamente em duas classes, as termoplásticas e as termoendurecíveis, que diferem no comportamento quando aquecidas (HYER, 1998). As resinas termoplásticas são moldáveis enquanto em estado aquecido semi-fluido, endurecendo quando resfriadas. Oferecem vantagens em relação às termoendurecíveis, como maior resistência a impacto e possibilidade de remodelagem com aquecimento (ACI 440R-96, 1996). A maior viscosidade e a dificuldade na incorporação de fibras contínuas representam obstáculo ao seu uso comercial em estruturas (ACI 440R-96, 1996). As resinas 
termoendurecíveis sofrem processo químico irreversível quando aquecidas, denominado cura (HYER, 1998). Possuem boa estabilidade térmica e resistência química. As matrizes poliméricas termoendurecíveis da classe dos poliésteres, vinilésteres e epóxidos são as mais comuns na fabricação dos compósitos utilizados em estruturas (ACI 440R-96, 1996). A Tabela 2.1 apresenta algumas propriedades das resinas dos tipos poliéster e epóxi.

Tabela 2.1 - Propriedades das resinas dos tipos poliéster e epóxi (Fonte: adaptado de Carolin (2003)).

\begin{tabular}{|c|c|c|c|c|}
\hline Resina & $\begin{array}{c}\text { Módulo de } \\
\text { elasticidade (GPa) }\end{array}$ & $\begin{array}{l}\text { Resistência à } \\
\text { tração (MPa) }\end{array}$ & $\begin{array}{l}\text { Deformação na } \\
\text { ruptura }(\%)\end{array}$ & Densidade $\left(\mathrm{Kg} / \mathrm{m}^{3}\right)$ \\
\hline Poliéster & $2,1-4,1$ & $20-100$ & $1,0-6,5$ & $1000-1450$ \\
\hline Epóxi & $2,5-4,1$ & $55-130$ & $1,5-9,0$ & $1100-1300$ \\
\hline
\end{tabular}

\subsection{Fibras}

As fibras têm a função de conferir rigidez e resistência ao PRF e por isso são apontadas como principal constituinte do compósito. Podem ser curtas ou longas. As curtas apresentam menor custo e maior facilidade de processamento, porém é mais difícil controlar sua orientação no compósito e consequentemente otimizar suas propriedades mecânicas em uma direção. As fibras longas, embora mais difíceis de processar, são mais fáceis de orientar e resultam em compósito com menor retração e maior resistência ao impacto.

O arranjo das fibras pode ser unidirecional, bidirecional ou tridimensional. No primeiro caso obtêm-se os máximos valores de resistência e módulo de elasticidade na direção axial à fibra. Para arranjos bidirecionais as propriedades mecânicas variam conforme o ângulo de orientação das fibras. O compósito com arranjo tridimensional tem comportamento pseudo-isotrópico.

Compósitos de fibras de vidro, aramida e carbono são os mais utilizados na Construção Civil. A Tabela 2.2 traz algumas propriedades destas fibras, que têm suas curvas de “tensão x deformação" na tração apresentadas graficamente na Figura 2.2. 
Tabela 2.2 - Propriedades típicas na tração de fibras utilizadas em sistema de PRF (Fonte: adaptado de ACI 440.2R-02 (2002)).

\begin{tabular}{lccc}
\hline \multicolumn{1}{c}{ Tipo de fibra } & $\begin{array}{c}\text { Módulo de elasticidade } \\
(\mathbf{G P a})\end{array}$ & $\begin{array}{c}\text { Resistência última } \\
\text { (MPa) }\end{array}$ & $\begin{array}{c}\text { Mínima deformação na } \\
\text { ruptura (\%) }\end{array}$ \\
\hline Carbono & $220-240$ & $2050-3790$ & 1,2 \\
Normal & $220-240$ & $3790-4820$ & 1,4 \\
Alta resistência & $220-240$ & $4820-6200$ & 1,5 \\
Ultra alta resistência & $340-520$ & $1720-3100$ & 0,5 \\
Alto módulo & $520-690$ & $1380-2400$ & 0,2 \\
Ultra alto módulo & & & 4,5 \\
Vidro & $69-72$ & $1860-2680$ & 5,4 \\
Vidro-E & $86-90$ & $3440-4140$ & \\
Vidro - S & & & 2,5 \\
Aramida & $69-83$ & $3440-4140$ & 1,6 \\
Normal & $110-124$ & $3440-4140$ & \\
Alto desempenho & & & \\
\hline
\end{tabular}

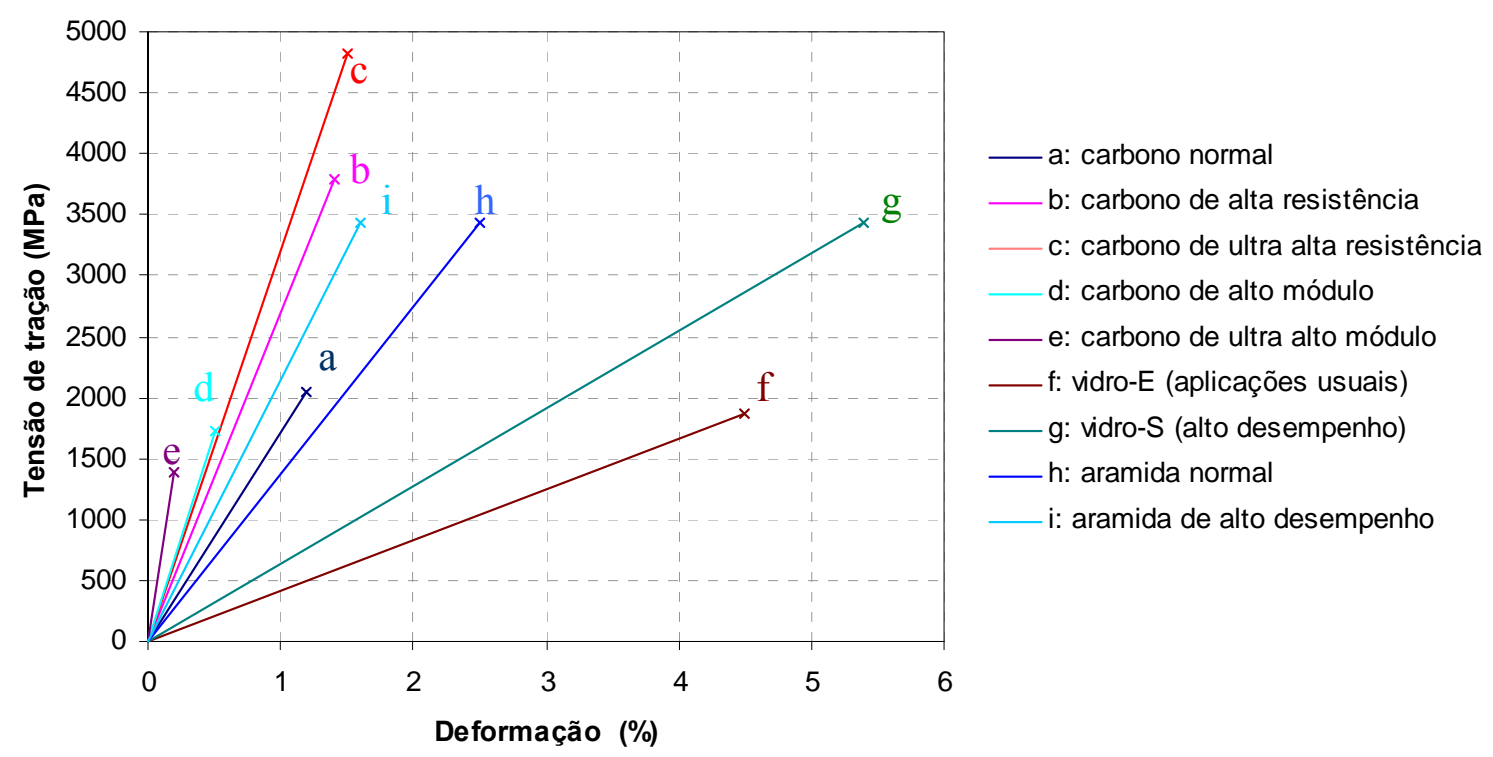

Figura 2.2 - Curvas "tensão de tração x deformação" das fibras mais utilizadas em compósitos, baseadas em dados do ACI 440.2R-02 (2002).

As fibras de carbono originam-se do aquecimento de matéria-prima, que contém quantidade substancial de carbono como rayon, poliacronitrila (PAN) ou piche (ACI 440.1R03, 2003). A matéria-prima não influencia significativamente nas propriedades mecânicas das fibras, mas interfere em seu processamento (HYER, 1998). Existem dois tipos de fibra de 
carbono: fibra de carbono de alto módulo (HM) e fibra de carbono de alta resistência (HS). A diferença entre as propriedades dos dois tipos é função das diferenças na microestrutura (ACI 440R-96, 1996).

Embora o custo das fibras de carbono seja mais alto em relação às fibras de vidro e aramida, seu uso é cada vez mais freqüente na Construção Civil. As fibras de carbono são as menos suscetíveis à ruptura por fadiga (ACI 440.1R-03, 2003). Possuem alta resistência a fatores agressivos do meio ambiente e seu módulo de elasticidade e resistência à tração mantêm-se estáveis com o aumento de temperatura (FIB, 2001). Beber (2003) destaca a grande diversidade de características físicas e mecânicas das fibras de carbono o que permite que os compósitos apresentem grande versatilidade para aplicações na Engenharia.

\subsection{Sistemas de reforço}

Os sistemas de PRF para reforço de estruturas podem ser pré-fabricados ou curados in situ (JUVANDES, 2002). Os pré-fabricados são compostos por material de PRF, geralmente sob a forma de laminados com fibras orientadas na direção longitudinal, e pelo adesivo. Os laminados são resultado de processo de pultrusão, com controle de largura e espessura (JUVANDES,1999). Beber (2003) define pultrusão como o processo contínuo que combina ações de tração e extrusão para a produção de um compósito de PRF com seção final constante. A Figura 2.3 ilustra esquematicamente esse processo.

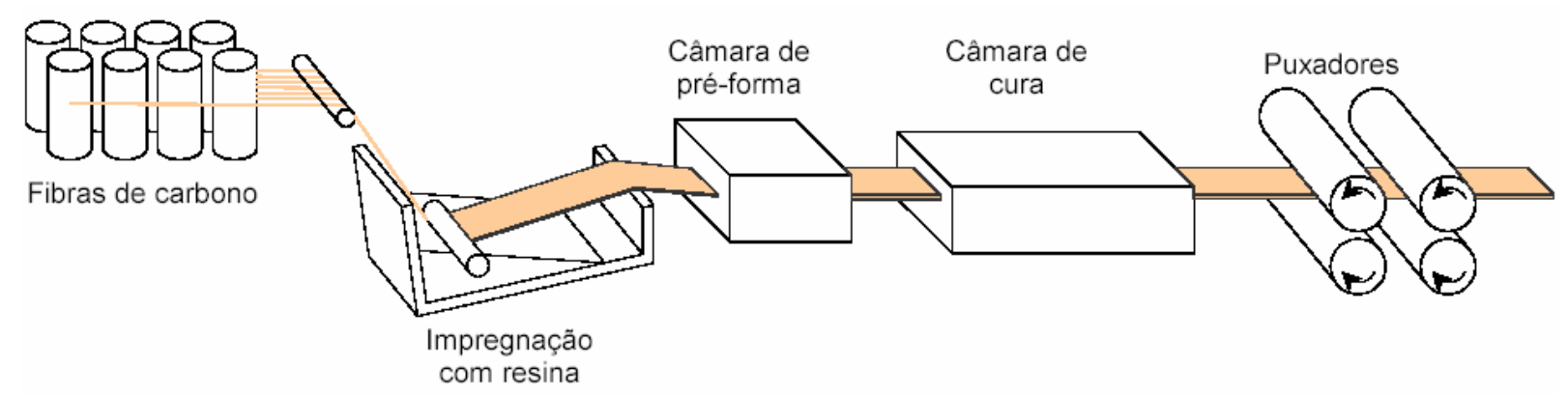

Figura 2.3 - Diagrama esquemático do processo de pultrusão (Fonte: Beber (2003)).

A técnica tradicionalmente empregada para reforço com laminados pré-fabricados consiste na sua colagem externa ao substrato. $\mathrm{O}$ adesivo utilizado para isso é, em geral, do tipo epóxi bi-componente. Pode-se também recorrer ao uso de agentes primários ("primers") para melhorar a aderência do reforço ao substrato. A técnica de reforço que envolve a colagem de laminados em entalhes no concreto de cobrimento vem se desenvolvendo e ganhando aceitação na última década. Quando utilizados para esse fim, os laminados apresentam uma maior relação entre comprimento e largura, sendo freqüentemente 
denominados por fitas ou tiras de PRF. A referida técnica é abordada com maior profundidade no Capítulo 3, por se tratar de tema em avaliação neste trabalho.

Os sistemas curados in situ são compostos basicamente por uma resina de impregnação, agentes primários e pelas fibras, sob a forma de tecidos ou mantas. A execução do reforço consiste na impregnação das fibras com a resina na superfície da peça a ser reforçada. Nos sistemas curados in situ, a resina é ao mesmo tempo matriz do compósito e elemento de transferência de esforços das fibras para a superfície onde estão coladas (BEBER 2003). De acordo com Meier $^{2}$ (1997 apud BEBER, 2003, p. 33), segundo este conceito, o compósito só se forma com a cura do reforço.

${ }^{2}$ MEIER, U. Repair using advanced composites. In: International conference on composite construction conventional and innovative, p.113-124, 1997, Innsbruck. Conference report... Zurich: IABSE: ETH_Hönggerberg, 1997. 


\section{CAPÍTULO 3}

\section{REFORÇO POR COLAGEM DE BARRAS E LAMINADOS DE PRF EM ENTALHES}

A primeira investigação científica sobre a colagem de laminados de PRF em entalhes é atribuída a Blaschko e Zilch ${ }^{3}$ (1999 apud FORTES, 2004). O aspecto inovador desse trabalho consiste na utilização dos PRF, uma vez que 50 anos antes já se relatava o reforço por inserção de barras de aço no concreto de cobrimento, fixadas com uso de argamassa, em Asplund $^{4}$ (1949 apud CRUZ, 2004). O trabalho de Blaschko e Zilch ${ }^{5}$ (1999 apud FORTES, 2004), contudo, impõe-se como um marco para o reforço mediante utilização de PRF, por apresentar solução para algumas deficiências inerentes à colagem externa, principalmente em relação ao descolamento prematuro do reforço. A técnica tem ainda por vantagens: execução menos trabalhosa, maior facilidade de ancoragem em membros adjacentes ao elemento reforçado, maior facilidade de pré-tensionamento, proteção pelo concreto de cobrimento e consequentemente menor exposição a danos mecânicos, impactos acidentais, fogo e vandalismo e a não interferência em aspectos estéticos das estruturas (DE LORENZIS; TENG, 2006).

A execução desta técnica de reforço pode ser resumida nas seguintes etapas:

- Realização de entalhe na face a ser reforçada com uso de serra de corte;

- Limpeza do entalhe com jato de ar;

- Limpeza do laminado com solvente apropriado;

\footnotetext{
${ }^{3}$ BLASCHKO M.; ZILCH, K. Rehabilitation of Concrete Structures with PRFC Strips Glued into Slits. Proceedings of the Twelfth International Conference on Composite Materials, Paris, 1999.

${ }^{4}$ ASPLUND, S.O. Strengthening bridge slabs with grouted reinforcement. Journal of the American Concrete Institute, v. 20, n. 6, p. 397-406, Jan., 1949.

${ }^{5}$ BLASCHKO M.; ZILCH, K. Rehabilitation of Concrete Structures with PRFC Strips Glued into Slits. Proceedings of the Twelfth International Conference on Composite Materials, Paris, 1999.
} 
- Aplicação de adesivo no laminado;

- Aplicação de adesivo no entalhe;

- Introdução do laminado no entalhe.

Variações no procedimento executivo são observadas, como a pré-moldagem do entalhe e a utilização de argamassa fluida na fixação no reforço.

Diversas pesquisas vêm ampliando o conhecimento sobre essa técnica de reforço, porém isto ainda não foi traduzido em recomendações formais. De Lorenzis e Teng (2006) afirmam que FIB e ACI estão no momento considerando revisões em suas diretrizes (FIB, 2001 e ACI 440.2R-02, 2002, respectivamente) para incluir prescrições para o reforço por colagem de barras e laminados de PRF em entalhes.

\subsection{Modos de ruptura}

Os possíveis modos de ruptura de vigas reforçadas por colagem de laminados em entalhes podem ser divididos em dois grupos: modos de ruptura clássicos, nos quais a ação conjunta entre reforço e viga é mantida praticamente até a ruptura e modos de ruptura prematura, nos quais ocorre a perda da ação conjunta entre reforço e viga. Os modos de ruptura clássicos englobam:

1. Esmagamento do concreto;

2. Deformação excessiva da armadura de tração;

3. Ruptura do reforço;

4. Ruptura por cisalhamento.

De Lorenzis e Teng (2006) afirmam que ainda se tem limitada compreensão dos mecanismos de descolamento em vigas reforçadas por inserção de laminados no concreto de cobrimento. Classificam os modos de ruptura prematura em:

1. Ruptura na interface barra-epóxi: envolve o descolamento do reforço na interface barra-epóxi (Figura 3.1);

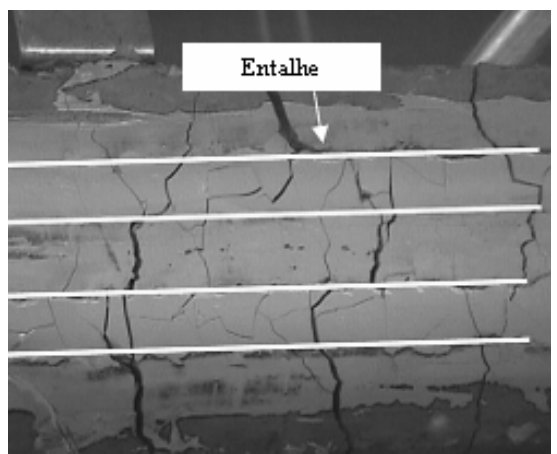

Figura 3.1 - Perda de aderência na interface barra-epóxi (Fonte: adaptado de De Lorenzis e Teng (2006). 
2. Destacamento do concreto de cobrimento: nesse modo de ruptura, fissuras de aderência a $45^{\circ}$ na base da viga se propagam até alcançar o canto da viga. A fissura continua se propagando a $45^{\circ}$ na face da viga até atingir o nível da armadura longitudinal e passa a se propagar horizontalmente. A ruptura pode apresentar as seguintes configurações:

- Destacamento do cobrimento na seção da extremidade da barra: quando a extremidade final do reforço se encontra distante do apoio, o destacamento se inicia na seção que contém a extremidade do reforço (Figura 3.2);

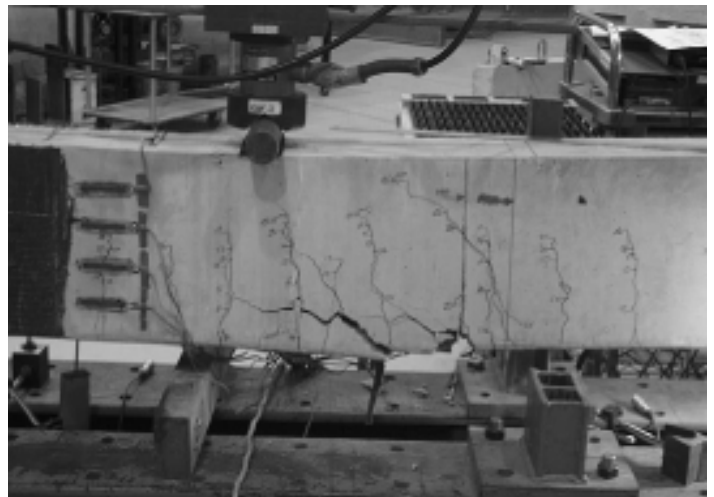

Figura 3.2 - Destacamento do concreto de cobrimento iniciado na extremidade do reforço (Fonte: adaptado de De Lorenzis e Teng (2006).

- Destacamento local do cobrimento: fissuras de aderência juntamente com fissuras de flexão e de flexão e cisalhamento combinados podem isolar cunhas de concreto triangulares ou trapezoidais, que são eventualmente destacadas da viga (Figura 3.3);

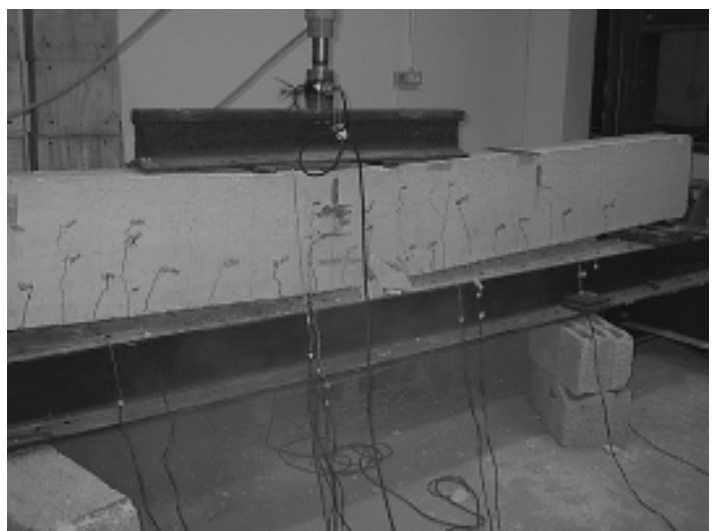

Figura 3.3 - Destacamento do concreto de cobrimento entre duas fissuras na região de momento máximo (Fonte: adaptado de De Lorenzis e Teng (2006).

- Destacamento do cobrimento induzido por fissuras de flexão: fissuras de flexão induzem o destacamento da camada de concreto de cobrimento. Esse destacamento se dá ao longo de grande porção da região reforçada da viga (Figura 3.4); 


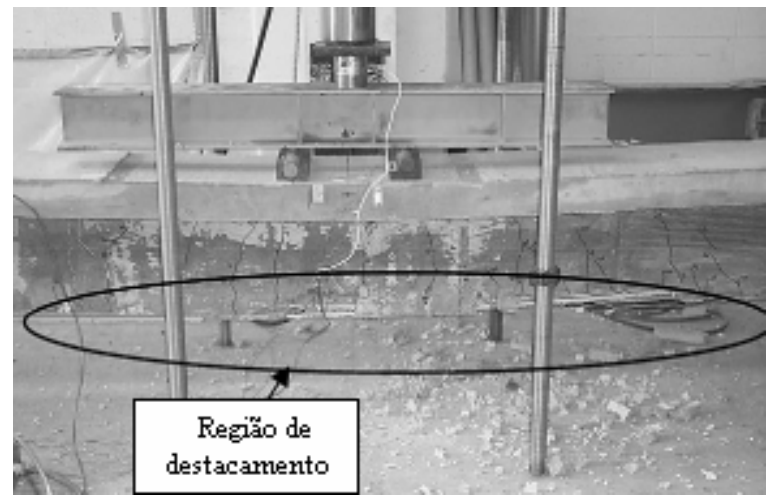

Figura 3.4 - Destacamento do concreto de cobrimento ao longo de uma grande parte do comprimento da viga (Fonte: adaptado de De Lorenzis e Teng (2006).

- Destacamento do cobrimento ao longo do canto da viga: pode ser gerado pelo posicionamento do reforço nas proximidades do canto da viga (Figura $3.5)$.

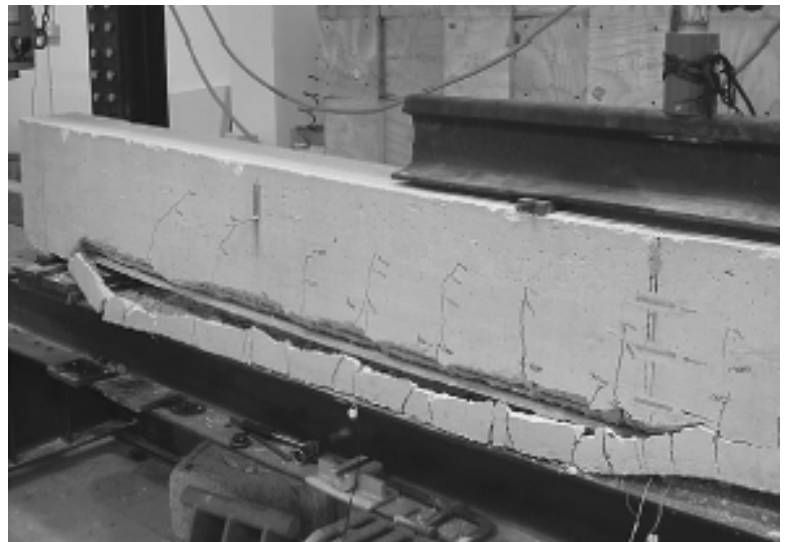

Figura 3.5 - Destacamento de concreto ao longo do canto da viga (Fonte: adaptado de De Lorenzis e Teng (2006).

3. Ruptura na interface concreto-epóxi: para vigas reforçadas com limitado comprimento de reforço, observa-se a ocorrência de ruptura coesiva por cisalhamento na interface concreto-epóxi, iniciada na extremidade do reforço;

4. Mecanismos secundários de descolamento: engloba outros mecanismos cujo papel no contexto da ruptura por descolamento ainda não é claro. Foi observado por Teng et al. (2006) que a abertura das fissuras de aderência é restringida pelo efeito pino do reforço o que tende a provocar o destacamento do reforço na base da viga. Após a ruptura, o prisma formado pelo laminado e epóxi adjacente retém uma fina camada de concreto com espessura variável, indicando forte aderência entre o concreto e o epóxi. Além disso, ocorre desprendimento local do epóxi de cobrimento expondo o laminado em alguns pontos (Figura 3.6-a e Figura 3.6-b). 


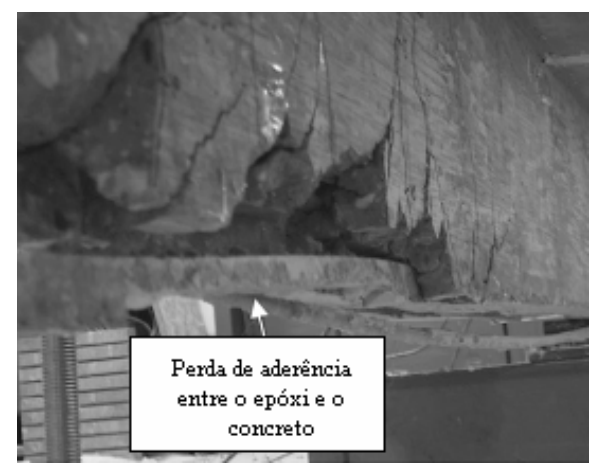

(a)

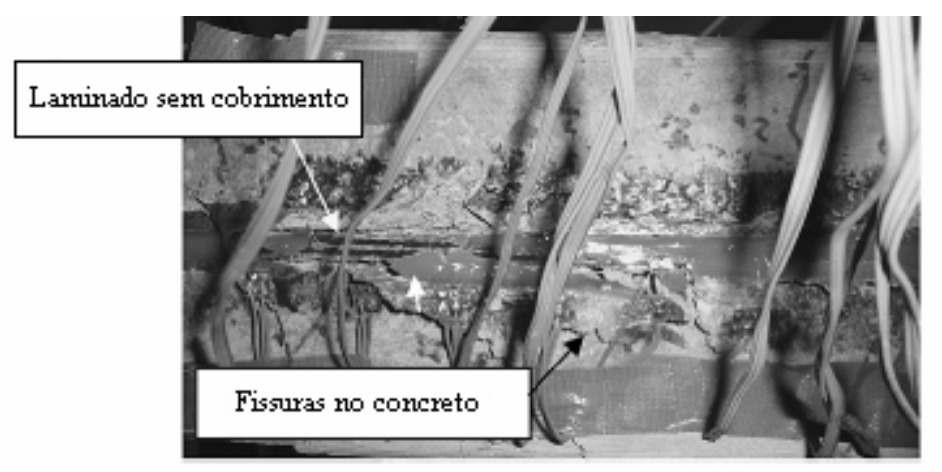

(b)

Figura 3.6 - Mecanismos secundários de descolamento: (a) perda de aderência entre o epóxi e o concreto; (b) desprendimento do cobrimento de epóxi (Fonte: adaptado de De Lorenzis e Teng (2006).

\subsection{Estudos acerca do reforço à flexão}

Fortes (2004) apresenta um estudo experimental dividido em duas etapas. A primeira visou a avaliação do comportamento de vigas reforçadas pela colagem de laminados no concreto de cobrimento, as quais foram dimensionadas para terem sua capacidade de carga duplicada. Duas séries de ensaios compuseram essa etapa: S1 e S3. Para as duas séries os modelos apresentaram o mesmo comprimento de $1600 \mathrm{~mm}$. As vigas da série $\mathrm{S} 1$ foram divididas em quatro grupos com diferentes taxas de armadura convencional e taxas de armadura equivalente $\left(\rho_{e q}\right)$ para as vigas reforçadas. As vigas reforçadas dos quatro grupos: S1-1, S1-2, S1-3, S1-4 apresentaram, respectivamente, $\rho_{\text {eq }}$ de 0,$47 ; 0,70 ; 0,85$; e 1,19. A taxa de armadura equivalente foi calculada por meio da Equação 3.1. Na Figura 3.7 e na Figura 3.8 , ilustram-se os detalhes dos modelos e o esquema de ensaio.

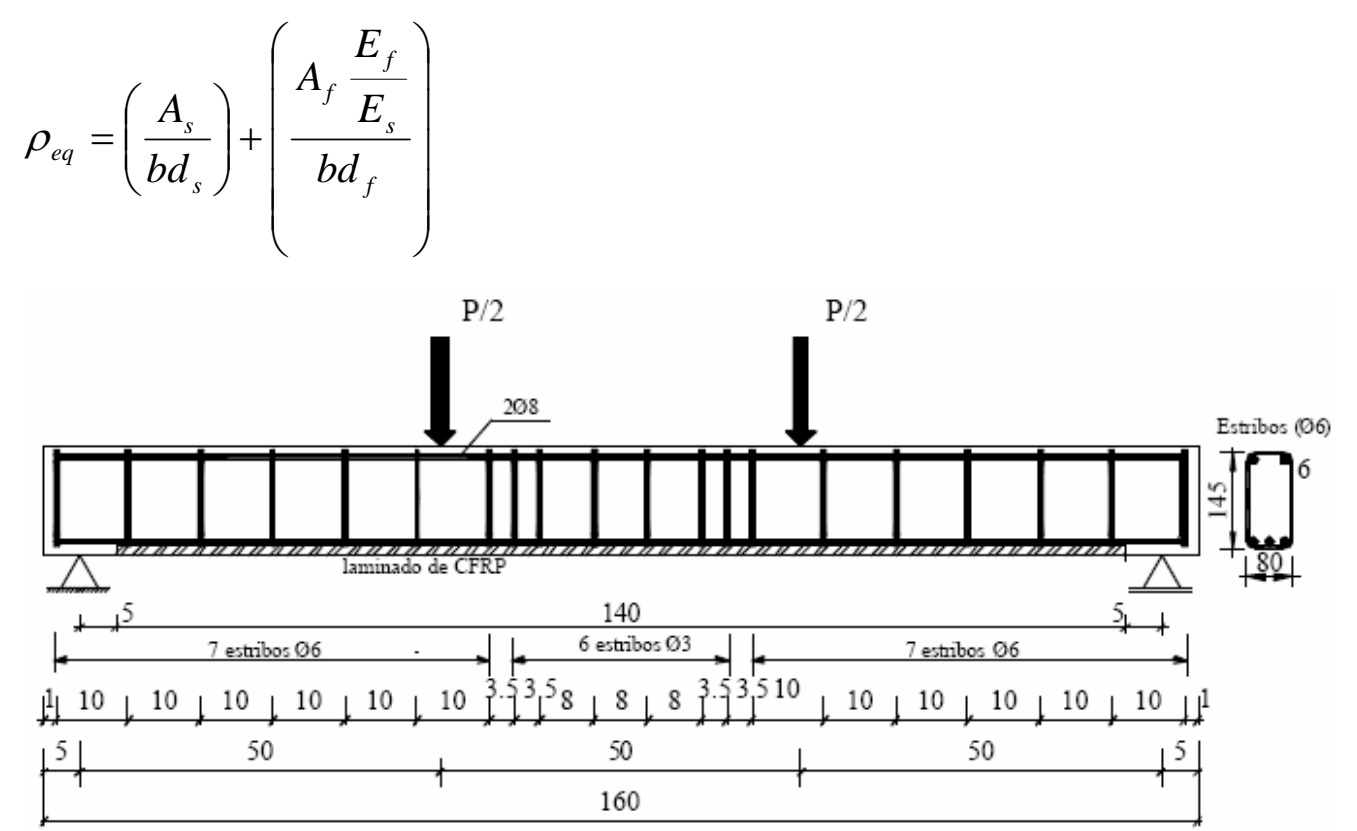

Figura 3.7 - Armaduras das vigas - vista lateral. 


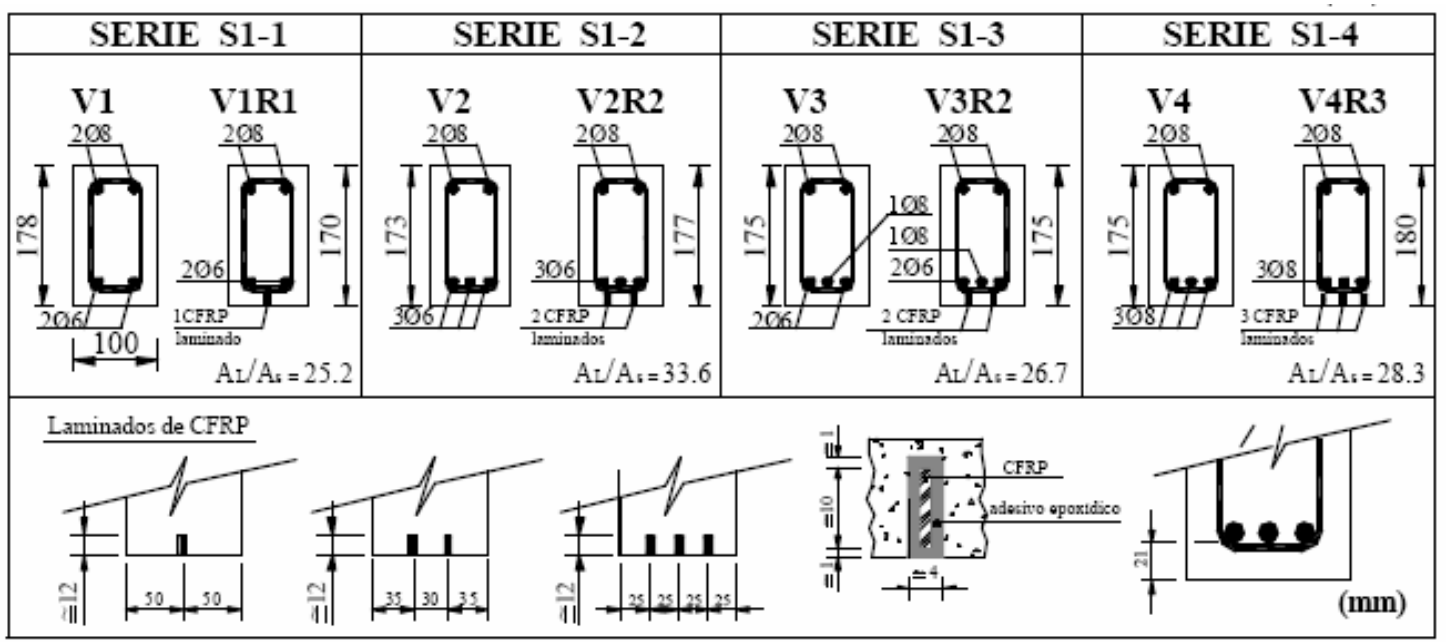

Figura 3.8 - Armaduras das vigas - cortes e detalhes do posicionamento dos laminados (Fonte: Fortes (2004)).

O ensaio foi realizado sob controle de deslocamento a uma taxa de $20 \mu \mathrm{m} / \mathrm{s}$. Os deslocamentos verticais foram obtidos por meio de transdutores e a deformação longitudinal dos laminados por meio de extensômetros posicionados conforme a Figura 3.9.

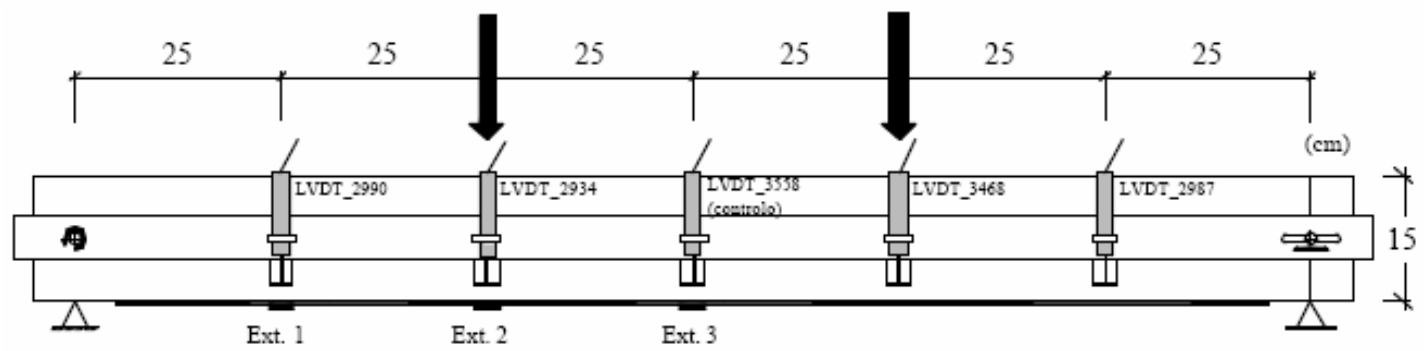

Figura 3.9 - Disposição dos transdutores de deslocamento (LVDTs) e extensômetros elétricos (Ext.1, Ext.2, Ext.3) (Fonte: Fortes (2004)).

As vigas de referência apresentaram ruptura dúctil por escoamento da armadura longitudinal. As vigas reforçadas romperam por destacamento de uma camada de concreto no banzo tracionado. Segundo Fortes (2004), a carga de ruptura das vigas reforçadas não está relacionada com o descolamento do reforço (tipo peeling-off), mas com a ruptura por traçãocisalhamento do concreto na zona próxima à armadura de aço pré-existente. $\mathrm{O}$ acréscimo na carga última das vigas reforçadas apresentou proporcionalidade direta com a taxa de armadura equivalente e variou de 78 a 96\%. A deformação última no laminado aumentou com a diminuição da taxa de armadura equivalente. Houve acréscimo de rigidez de aproximadamente $39 \%$ para a carga de serviço e de $47 \%$ para uma carga de $90 \%$ da carga última da viga de referência. Fortes (2004) conclui que o reforço por inserção de laminados no concreto de cobrimento apresenta eficiência não somente para o aumento da capacidade de carga última, mas também no incremento de rigidez para ações correspondentes aos estados limites de serviço. 
As vigas da série S3 tiveram a seção transversal aumentada em relação às da série $\mathrm{S} 1$ para minimizar o efeito do esforço cortante. A série S-3, composta de doze vigas, foi subdividida em três séries de quatro vigas (S3-1, S3-2 e S3-3), cada uma delas contendo determinada taxa de armadura convencional de barras de aço. Uma das vigas da série S3-1 possuía apenas armadura convencional e serviu como modelo de referência. As outras três vigas da série foram reforçadas com um laminado, sendo uma para ser submetida a carregamento monotônico e as outras duas para carregamento cíclico. As vigas das séries S32 e S3-3 seguiram o mesmo critério, sendo reforçadas com dois e três laminados, respectivamente. O detalhamento das vigas da série é apresentado na Figura 3.10. As taxas de armadura equivalente para as vigas reforçadas foram de 0,38 em S3-1, 0,59 em S3-2 e 0,89 em S3-3.

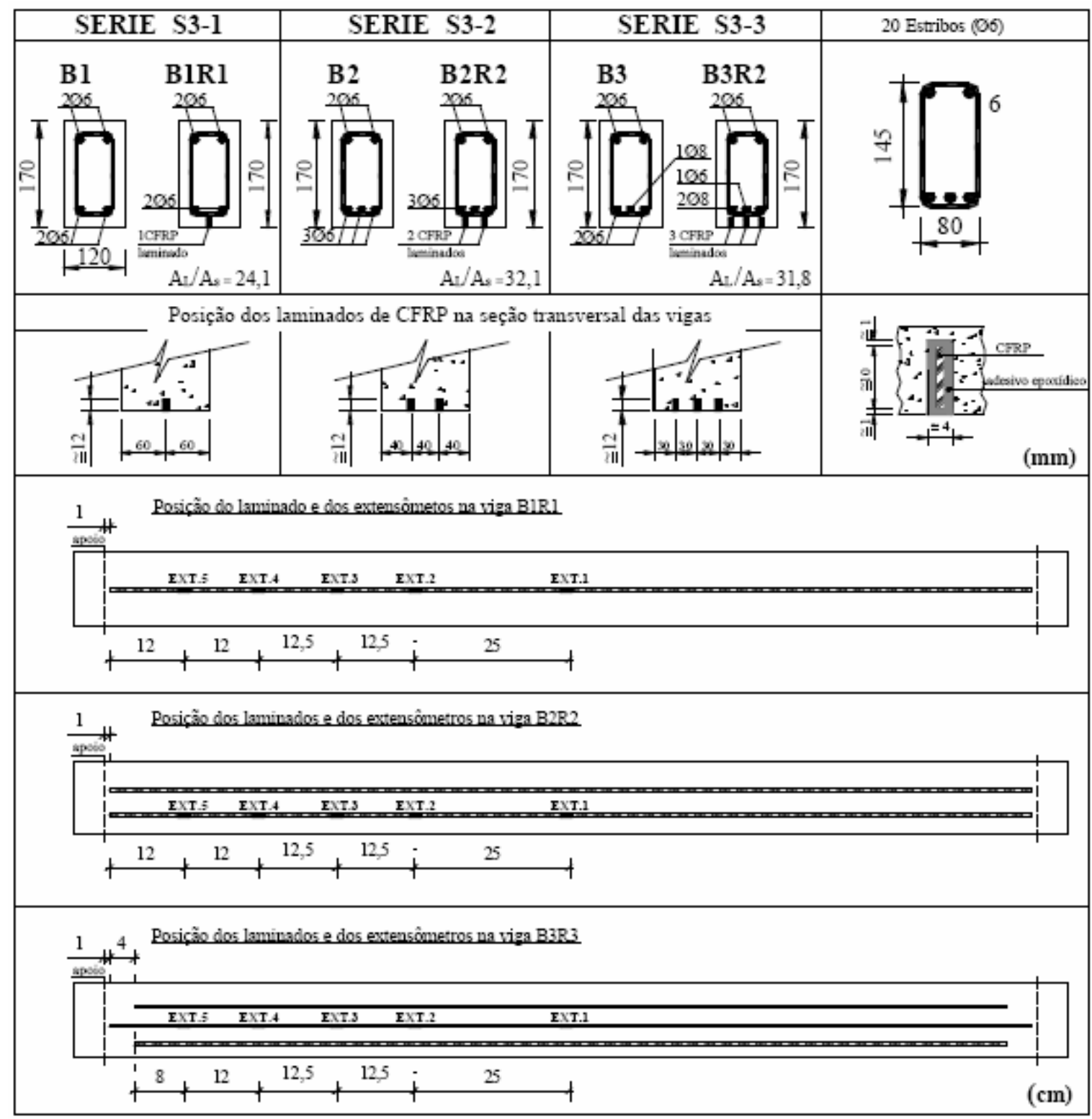

Figura 3.10 - Detalhamento das vigas da série S3 (Fonte: Fortes (2004)). 
Adotou-se o mesmo procedimento de ensaio empregado na série S1. As vigas de referência apresentaram ruptura dúctil por escoamento da armadura longitudinal. As vigas reforçadas BR1 e BR2 romperam por esmagamento do concreto na região de aplicação da carga. Na viga BR3, houve destacamento de uma camada de concreto no banzo tracionado limitada pelos laminados externos. O laminado central permaneceu aderido. As vigas reforçadas apresentaram fissuração mais intensa com fissuras mais distribuídas ao longo do comprimento e com maior espaçamento entre elas. O reforço proporcionou um acréscimo na carga última variando de 87 a 95\%. A deformação nos laminados variou de 10 a 16\%. Fortes (2004) afirma que a deformação de 16\% jamais foi alcançada em se tratando de reforço por colagem externa de laminados e portanto classifica a técnica de colagem de laminados em entalhes do concreto de cobrimento mais eficiente.

Fortes (2004) efetua um estudo comparativo entre as técnicas de colagem de laminados em entalhes no concreto de cobrimento, colagem externa de laminados e colagem externa de mantas de PRFC, na série S2 de ensaios. A Figura 3.11 ilustra as características dos modelos e a disposição das armaduras.

$\underline{\text { Disposiçào das armaduras }}$

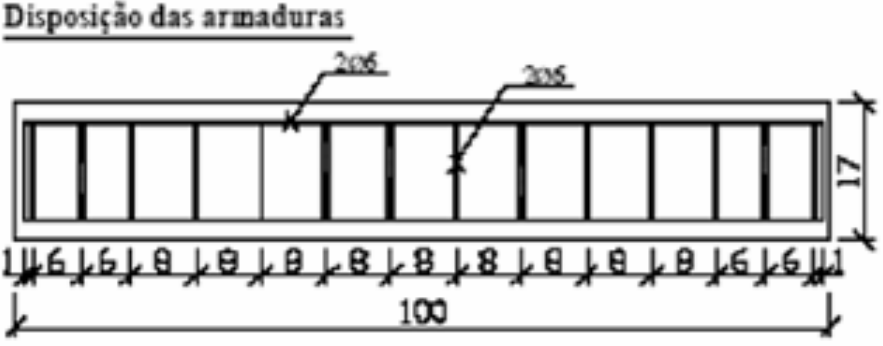

Secçôes transversais

\section{Condiçòes de apoio e carregamento}
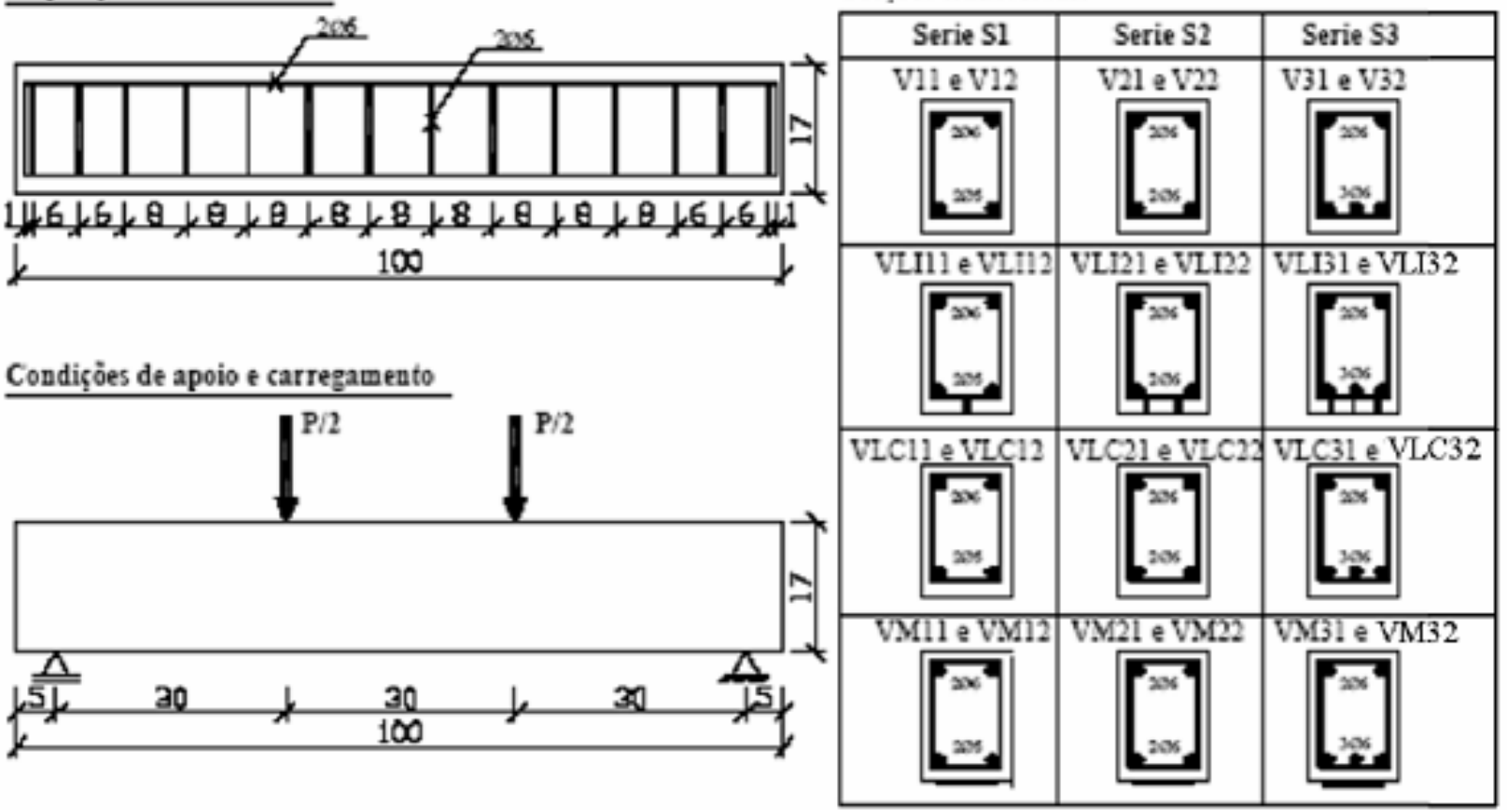

Figura 3.11 - Detalhamento das vigas utilizadas na série S2 (Fonte: Fortes (2004)).

No Quadro 3.1, estão contidas as informações das vigas ensaiadas. As vigas foram identificadas conforme a seguinte nomenclatura:

- Vigas de referência - V; 
- Vigas reforçadas com laminados inseridos em entalhes - VLI;

- Vigas reforçadas com laminados colados na superfície do concreto - VLC.

- Vigas reforçadas com mantas coladas na superfície do concreto - VM.

\begin{tabular}{|c|c|c|c|c|c|c|c|}
\hline Série & Viga & $\begin{array}{c}\text { Peso } \\
(\mathrm{N})\end{array}$ & $\begin{array}{c}\text { Peso } \\
\text { Especifico } \\
\left(\mathrm{kN} / \mathrm{m}^{3}\right)\end{array}$ & $\begin{array}{l}\text { Idade } \\
\text { (dias) }\end{array}$ & Tipo de reforço & $\begin{array}{l}\rho_{\star q} \\
(\%)\end{array}$ & $\begin{array}{l}\frac{A_{f}}{A_{S}} \\
(\%)^{(1)}\end{array}$ \\
\hline \multirow{3}{*}{ S2-1 } & V11 & 498,6 & 24,44 & 66 & Referência & - & - \\
\hline & V12 & 498,6 & 24,44 & 66 & Referência & - & - \\
\hline & VLI11 & 496,4 & 24,33 & 65 & 1 laminado inserido & \multirow{6}{*}{0,28} & 35.4 \\
\hline \multirow{8}{*}{$\mathrm{S} 2-2$} & VLI12 & 505,0 & 24,75 & 65 & 1 laminado inserido & & 35.4 \\
\hline & VLC11 & 492,4 & 24,14 & 68 & 1 laminado colado & & 35.4 \\
\hline & VLC12 & 498,0 & 24,41 & 68 & 1 laminado colado & & 35.4 \\
\hline & VM11 & 496,2 & 24,32 & 64 & 1 manta colada & & 22.6 \\
\hline & VM12 & 501,0 & 24,56 & 64 & 1 manta colada & & 22.6 \\
\hline & V21 & 498,4 & 24,43 & 66 & Referência & - & - \\
\hline & V22 & 497,0 & 24,36 & 66 & Referência & - & - \\
\hline & VLI21 & 497,2 & 24,37 & 65 & 2 laminados inserido & \multirow{6}{*}{0,43} & 49.2 \\
\hline & VLI22 & 495,8 & 24,30 & 65 & 2 laminados inserido & & 49.2 \\
\hline & VLC21 & 500,6 & 24,54 & 68 & 2 laminados colado & & 49.2 \\
\hline & VLC22 & 503,6 & 24,69 & 68 & 2 laminados colado & & 49.2 \\
\hline & VM21 & 499,0 & 24,46 & 64 & 2 mantas colada & & 31.4 \\
\hline & VM22 & 499,8 & 24,50 & 64 & 2 mantas colada & & 31.4 \\
\hline \multirow{3}{*}{ S2-3 } & V31 & 508,4 & 24,92 & 66 & Referência & - & - \\
\hline & V32 & 500,2 & 24,52 & 66 & Referência & - & - \\
\hline & VLI31 & 503,8 & 24,70 & 65 & 3 laminados inserido & \multirow{6}{*}{0,65} & 49.2 \\
\hline \multirow{5}{*}{ שעس } & VLI32 & 501,8 & 24,60 & 65 & 3 laminados inserido & & 49.2 \\
\hline & VLC31 & 500,8 & 24,55 & 68 & 3 laminados colado & & 49.2 \\
\hline & VLC32 & 505,8 & 24,79 & 68 & 3 laminados colado & & 49.2 \\
\hline & VM31 & 508,2 & 24,91 & 64 & 3 mantas colada & & 31.4 \\
\hline & VM32 & 500,4 & 24,53 & 64 & 3 mantas colada & & 31.4 \\
\hline
\end{tabular}

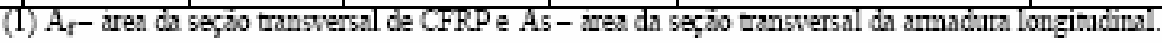

Quadro 3.1 - Informações das vigas ensaiadas na série S2 (Fonte: Fortes (2004)).

A ruptura das vigas de referência foi dúctil por escoamento da armadura longitudinal. As vigas reforçadas por laminados colados em entalhes no concreto de cobrimento apresentaram ruptura no concreto do banzo tracionado. Nas vigas reforçadas por colagem externa de laminados, houve descolamento do reforço a partir de suas extremidades sem 
destacamento do concreto. Observaram-se dois tipos de ruptura para as vigas reforçadas por colagem externa de mantas de PRFC. Houve rompimento do reforço na região central para vigas reforçadas com uma e duas camadas de manta. Para as vigas reforçadas com três camadas de manta, observou-se destacamento do concreto com início nas extremidades do reforço. Em todas as séries (S2-1, S2-2 e S2-3), o reforço por inserção de laminados em entalhes apresentou maior eficiência, tanto em relação ao aumento de carga quanto em relação aos deslocamentos verticais. As vantagens da técnica em relação às outras são mais significativas para menores taxas de armadura equivalente. Na série S2-1, o laminado colado no entalhe aumentou carga de ruptura das vigas de referência em $118 \%$, enquanto que para o laminado e a manta colados externamente, o aumento foi de $5 \%$ e $17 \%$, respectivamente. $\mathrm{Na}$ série S2-2, os laminados colados nos entalhes proporcionaram incremento de $92 \%$ na carga de ruptura. Os laminados e as duas camadas de mantas coladas sobre a superfície do concreto incrementaram $69 \%$ e $62 \%$, respectivamente. Na série S2-3, as três técnicas de reforço permitiram um aumento de carga de ruptura de $35 \%, 19 \%$ e $21 \%$.

Castro (2005) apresenta a avaliação do comportamento estrutural de vigas "T" reforçadas pela colagem externa de PRFC e pela colagem de diversos compósitos em entalhes no concreto de cobrimento. Foram realizados ensaios experimentais em vigas cujas características geométricas estão expostas na Figura 3.12

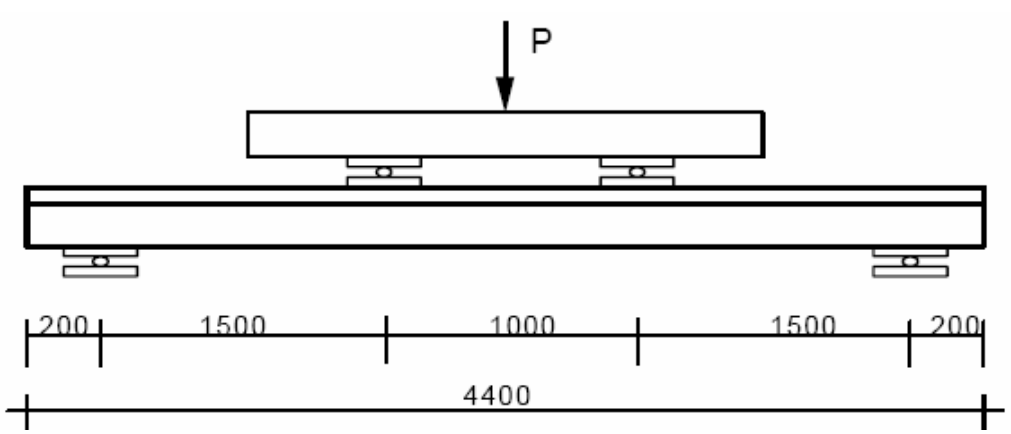

(a)

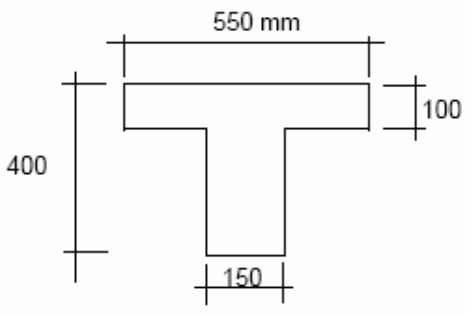

(b)

Figura 3.12 - (a) Esquema estático de carregamento; (b) seção transversal da viga (Fonte: Castro (2005)).

Procurou-se manter a rigidez do reforço, produto do módulo de elasticidade pela área (E.A), constante para todos os tipos de reforço a fim de possibilitar comparações entre eles. Os aspectos observados foram: capacidade de carga, modo de ruptura, rigidez, deformação (da armadura longitudinal, do concreto e dos compósitos) e deslocamentos verticais. Os ensaios foram divididos em duas séries com diferentes taxas de armadura longitudinal antes do reforço $\left(\rho=A_{s} / A_{c}\right)$. Para a série I, foi utilizada a taxa de $0,63 \%$ e para a série II, de 
1,57\%. Cada série foi dividida em seis grupos em função tipo de material e da técnica de reforço, conforme a descrição no Quadro 3.2.

\begin{tabular}{|c|c|c|c|c|}
\hline \multirow{2}{*}{ Grupos } & \multicolumn{2}{|c|}{ Vigas } & \multirow{2}{*}{ Tipo de reforço } & \multirow{2}{*}{ Técnica utilizada } \\
\hline & $\begin{array}{c}\text { Série I } \\
\rho=0,63 \%\end{array}$ & $\begin{array}{c}\text { Série I } \\
\rho=1,57 \%\end{array}$ & & \\
\hline \multirow{2}{*}{ A } & VA 2.1 & VA 5.1 & \multirow{2}{*}{ Vigas de referência } & \multirow{2}{*}{-} \\
\hline & VA 2.2 & VA 5.2 & & \\
\hline \multirow{2}{*}{ B } & VB 2.1 & \multirow{2}{*}{ VB 5.1} & \multirow{2}{*}{$\begin{array}{c}3 \text { fitas de PRFC (2 mm x } 16 \mathrm{~mm}) \text { Hughes } \\
\text { Brothers - Aslan } 500\end{array}$} & \multirow{2}{*}{$\begin{array}{l}\text { Coladas em entalhes } \\
\text { no concreto }\end{array}$} \\
\hline & VB 2.2 & & & \\
\hline \multirow{2}{*}{$\mathrm{C}$} & VC 2.1 & \multirow{2}{*}{ VC 5.1} & \multirow{2}{*}{$\begin{array}{c}1 \text { barra de PRFC }-(\Phi 10 \mathrm{~mm}) \text { Mitsubishi Kasei } \\
\text { Corporation - Leadline }\end{array}$} & \multirow{2}{*}{$\begin{array}{l}\text { Coladas em entalhes } \\
\text { no concreto }\end{array}$} \\
\hline & VC 2.2 & & & \\
\hline \multirow{2}{*}{$\mathrm{D}$} & VD 2.1 & \multirow{2}{*}{ VD 5.1} & \multirow{2}{*}{$\begin{array}{c}2 \text { barras de polímero reforçado com fibra de } \\
\text { vidro (PRFV) - ( } \Phi \text { 12,7 mm) Hughes Brothers - } \\
\text { Aslan } 100\end{array}$} & \multirow{2}{*}{$\begin{array}{l}\text { Coladas em entalhes } \\
\text { no concreto }\end{array}$} \\
\hline & VD 2.2 & & & \\
\hline \multirow{2}{*}{$\mathrm{E}$} & VE 2.1 & \multirow{2}{*}{ VE 5.1} & \multirow{2}{*}{$\begin{array}{l}2 \text { camadas de tecido de PRFC - }(0,165 \mathrm{~mm} \times 150 \\
\mathrm{mm}) \text { Master Builders Technologies - CF-130 W }\end{array}$} & \multirow{2}{*}{$\begin{array}{l}\text { Coladas na superfície } \\
\text { do concreto }\end{array}$} \\
\hline & VE 2.2 & & & \\
\hline \multirow{2}{*}{$\mathrm{F}$} & VF 2.1 & \multirow{2}{*}{ VF 5.1} & \multirow{2}{*}{1 barra de aço - (Ф $8 \mathrm{~mm})$} & \multirow{2}{*}{$\begin{array}{l}\text { Coladas em entalhes } \\
\text { no concreto }\end{array}$} \\
\hline & VF 2.2 & & & \\
\hline
\end{tabular}

Quadro 3.2 - Características das vigas (Fonte: Castro (2005)).

As vigas foram instrumentadas com extensômetros elétricos no concreto, armadura longitudinal e reforço. O deslocamento vertical foi obtido por meio de relógios comparadores. $\mathrm{O}$ esquema de carregamento está ilustrado na Figura 3.12-a. As vigas foram carregadas com incrementos de carga de $10 \mathrm{kN}$ até a primeira fissura e posteriormente com incremento de 20 $\mathrm{kN}$ até a ruptura. Os resultados obtidos em relação à carga e ao modo de ruptura para todas as vigas ensaiadas são apresentados no Quadro 3.3.

Com base em seus resultados experimentais, Castro (2005) propõe a utilização de um coeficiente $\lambda$ para a correção da flecha teórica no estádio II. O coeficiente $\lambda$ é determinado por meio da Equação 3.2, em que $b_{w}$ e $b_{f}$ representam, respectivamente, a largura da alma e da mesa de vigas “ $T$ ”. Para vigas retangulares obtém-se $\lambda=1,2$.

$$
\lambda=1,47-0,27 \frac{b_{w}}{b_{f}}
$$




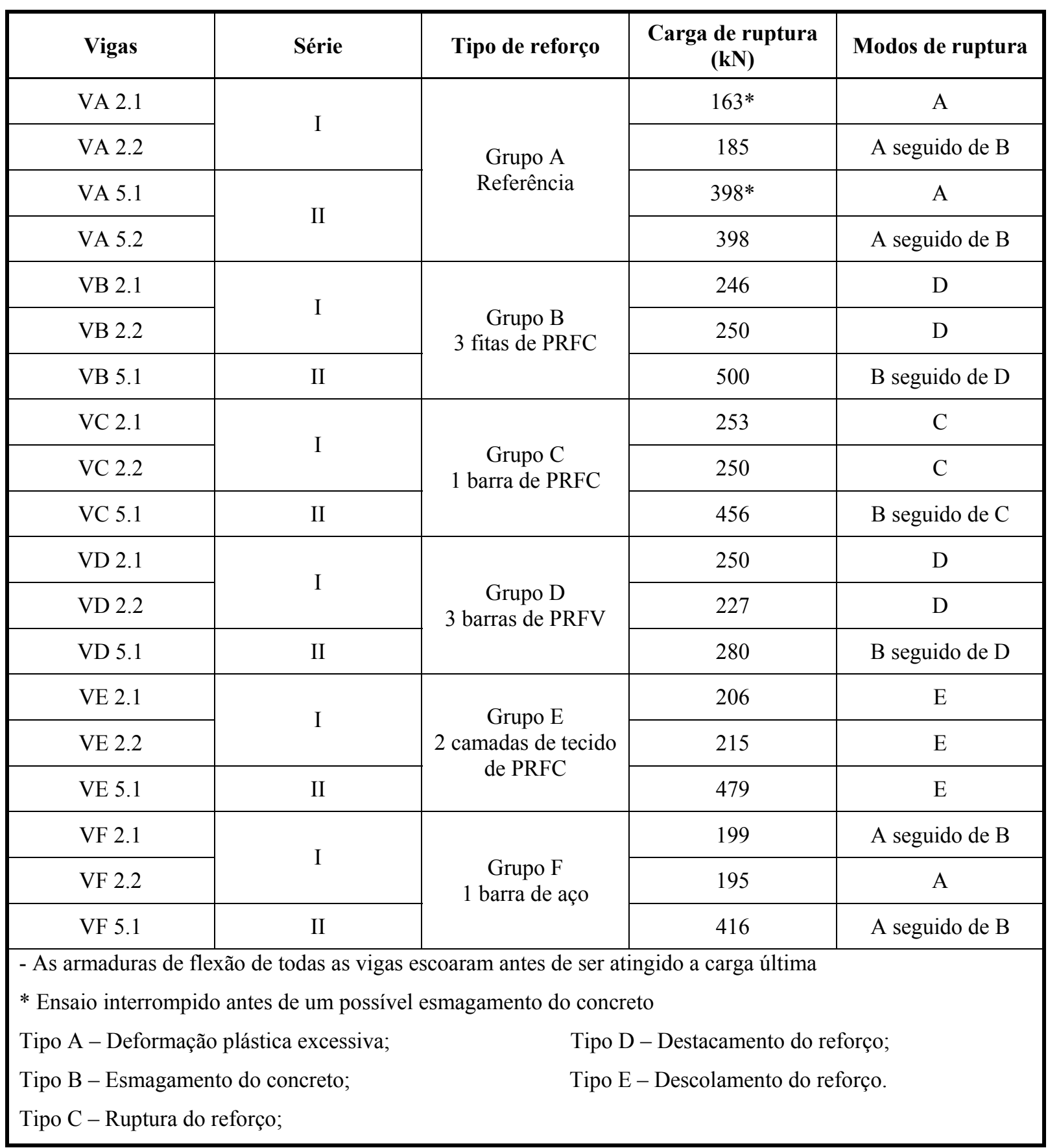

Quadro 3.3 - Resultados experimentais (Fonte: Castro (2005)).

Algumas das principais conclusões de Castro (2005) são em relação aos aspectos: eficiência da técnica de reforço; influência do tipo de compósito e da taxa de armadura.

- Eficiência da técnica de reforço: a colagem de PRF em entalhes de cobrimento mostrou-se mais eficiente do que a colagem externa no caso das vigas com taxa de armadura de $0,63 \%$ e teve igual desempenho para as vigas com taxa de armadura de $1,57 \%$. O reforço com barra de aço inserida no concreto de cobrimento teve desempenho inferior aos demais tipos de reforço. As vigas reforçadas com PRF apresentaram ruptura frágil, envolvendo destacamento, descolamento ou ruptura 
do reforço para vigas com taxa de armadura de $0,63 \%$, e esmagamento do concreto acompanhado de destacamento, descolamento ou ruptura do reforço para as vigas com taxa de armadura de $1,57 \%$. A técnica de reforço não influenciou no aumento de rigidez no estágio pós fissuração. O aumento da rigidez foi mais significativo nas vigas com menor taxa de armadura. A ação completa entre o reforço de fitas de PRFC e de barras de PRFV coladas em entalhes no concreto de cobrimento e o concreto foi alcançada. Não se observou deslizamento do reforço que atingiu deformações superiores a $11 \%$ antes do destacamento.

- Influência do tipo de compósito: as fitas de PRFC inseridas no concreto de cobrimento apresentaram bom desempenho, alcançando deformação máxima de $11 \%$ e promovendo acréscimo de resistência em relação às vigas de referência de $34 \%$ (média) e 25\% para as vigas com taxa de armadura de $0,63 \%$ e $1,57 \%$, respectivamente. As vigas reforçadas por colagem de PRFC apresentaram ruptura por perda gradativa de aderência entre a barra e o epóxi com a ocorrência de deslizamentos parciais da barra nas proximidades dos apoios e, em seguida, ruptura da barra nas proximidades de um dos apoios. As barras de PRFC apresentaram deformação máxima superior a 14\% na série I, e na série II, superior a 13\%. O acréscimo de resistência, para esse tipo de reforço, foi de $36 \%$ para a série I (média) e de 14,5\% para a série II. Para as vigas com reforço de barras inseridas de PRFV, alcançou-se aumento de resistência, em relação às vigas de referência, de $35 \%$ para uma das vigas da série I, e de $21 \%$ para a viga da série II. O modo de ruptura das vigas envolveu o destacamento do reforço quando apresentava deformação entre $11 \%$ e $14 \%$ ( $82 \%$ da deformação última do material). A eficiência do reforço com tecidos de PRFC colados externamente foi limitada pelo descolamento prematuro do reforço com deformação em torno de $8 \%$. O acréscimo de resistência foi de $13,5 \%$ para a série I (média) e $20 \%$ para a série II. As vigas reforçadas com barras de aço coladas em entalhes no concreto de cobrimento apresentaram ruptura por escoamento da armadura seguido do esmagamento do concreto, mas resultaram em baixo o acréscimo de resistência.

- Influência da taxa de armadura: o reforço com PRF pode ser mais eficiente para vigas com menor taxa de armadura. Para vigas com maior taxa de armadura, pode ocorrer esmagamento do concreto antes que o compósito tenha atingido sua capacidade resistente. Entretanto, a ruptura prematura por descolamento ou 
destacamento do reforço limita sua eficiência. Não foram consideradas prematuras as rupturas observadas nas vigas reforçadas pela colagem de PRF em entalhes, já que as deformações dos compósitos excederam 11\%. As vigas da série I reforçadas pela colagem de PRF em entalhes apresentaram maior acréscimo de resistência em relação às vigas igualmente reforçadas da série II (média de 20 \%). As vigas reforçadas por colagem externa de PRFC da série I apresentaram ruptura prematura, com menor acréscimo de resistência (média de 13,5\%) do que a viga com maior taxa de armadura (20\%).

Kang et al. (2005) avaliam a eficiência da técnica NSM no reforço à flexão de vigas por meio de um estudo paramétrico, tendo como variáveis a profundidade do entalhe e a disposição dos laminados de PRFC. O estudo foi realizado com utilização de modelo numérico baseado no Método dos Elementos Finitos. Para calibração do modelo, foram realizados ensaios experimentais de flexão a quatro pontos em vigas com quatro diferentes configurações de reforço (Type 1-1, Type 1-2, Type 2-1 e Type 2-2) e em uma viga não reforçada (Control) (Figura 3.13).

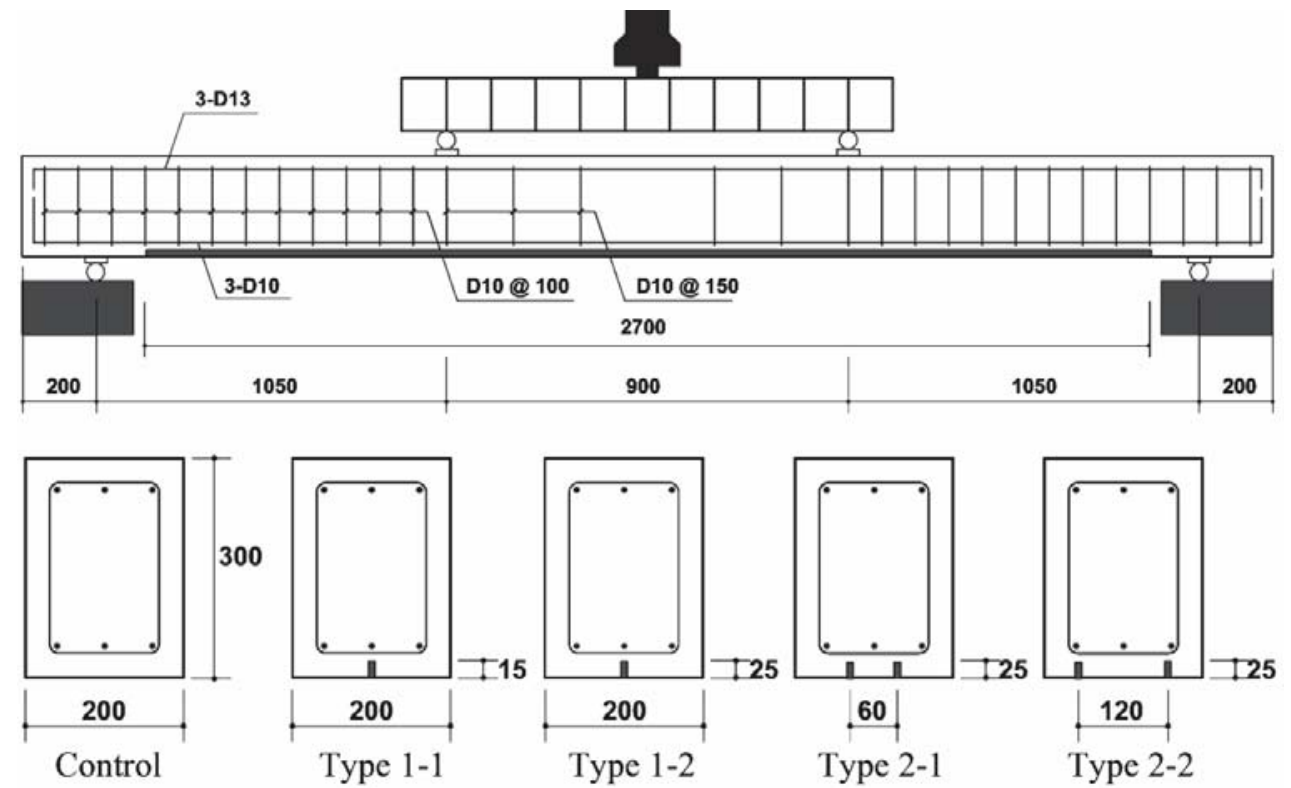

Figura 3.13 - Características dos modelos físicos e configuração do ensaio (Fonte: Kang et al. (2005)).

Observou-se acréscimo de $40 \%$ a $95 \%$ na carga de ruptura para as vigas reforçadas. $\mathrm{O}$ percentual de acréscimo foi diferente para os modelos Type 2-1 e Type 2-2 com mesma área de reforço. Fundamentados nisso, Kang et al. (2005) concluem que a eficiência do reforço varia com a disposição dos laminados.

Atestada a precisão do modelo numérico, Kang et al. (2005) procederam análise paramétrica dividida em dois casos: reforço com um laminado e reforço com dois laminados. 
Para o primeiro caso, variou-se a profundidade do entalhe de $5 \mathrm{~mm}$ a $35 \mathrm{~mm}$ com incremento de $5 \mathrm{~mm}$. Para o segundo caso, variações na profundidade do entalhe e na disposição dos laminados foram consideradas simultaneamente. Para entalhes de profundidade de $15 \mathrm{~mm}$ e $25 \mathrm{~mm}$, variou-se o espaçamento entre os laminados de $20 \mathrm{~mm}$ a $180 \mathrm{~mm}$.

Os resultados do primeiro caso em estudo revelam que a eficiência do reforço não é diretamente proporcional à profundidade do entalhe ou à área de PRFC. Existe uma profundidade ótima de entalhe que maximiza a eficiência do reforço.

Com base nos resultados do segundo caso da análise, Kang et al. (2005) afirmam que, na definição de uma disposição ótima, deve-se garantir uma distância mínima entre os laminados de forma que eles trabalhem independentemente (Figura 3.14). Deve-se, ao mesmo tempo, garantir um espaçamento mínimo do reforço em relação às faces laterais da viga, uma vez que, nas proximidades dos cantos de concreto, o laminado não desenvolve capacidade aderente, além de essa situação favorecer ao arrancamento do canto de concreto. Kang et al. (2005) recomendam que o espaçamento entre laminados e a distância do reforço ao canto da viga sejam sempre superiores a $40 \mathrm{~mm}$. A prescrição de Kang et al. (2005) para distância do reforço ao canto é conservadora em relação á sugestão de Blaschko ${ }^{6}$ (2003 apud DE LORENZIS E TENG, 2006) que é de uma distância mínima de $30 \mathrm{~mm}$ ou igual à maior dimensão do agregado, o que for maior.
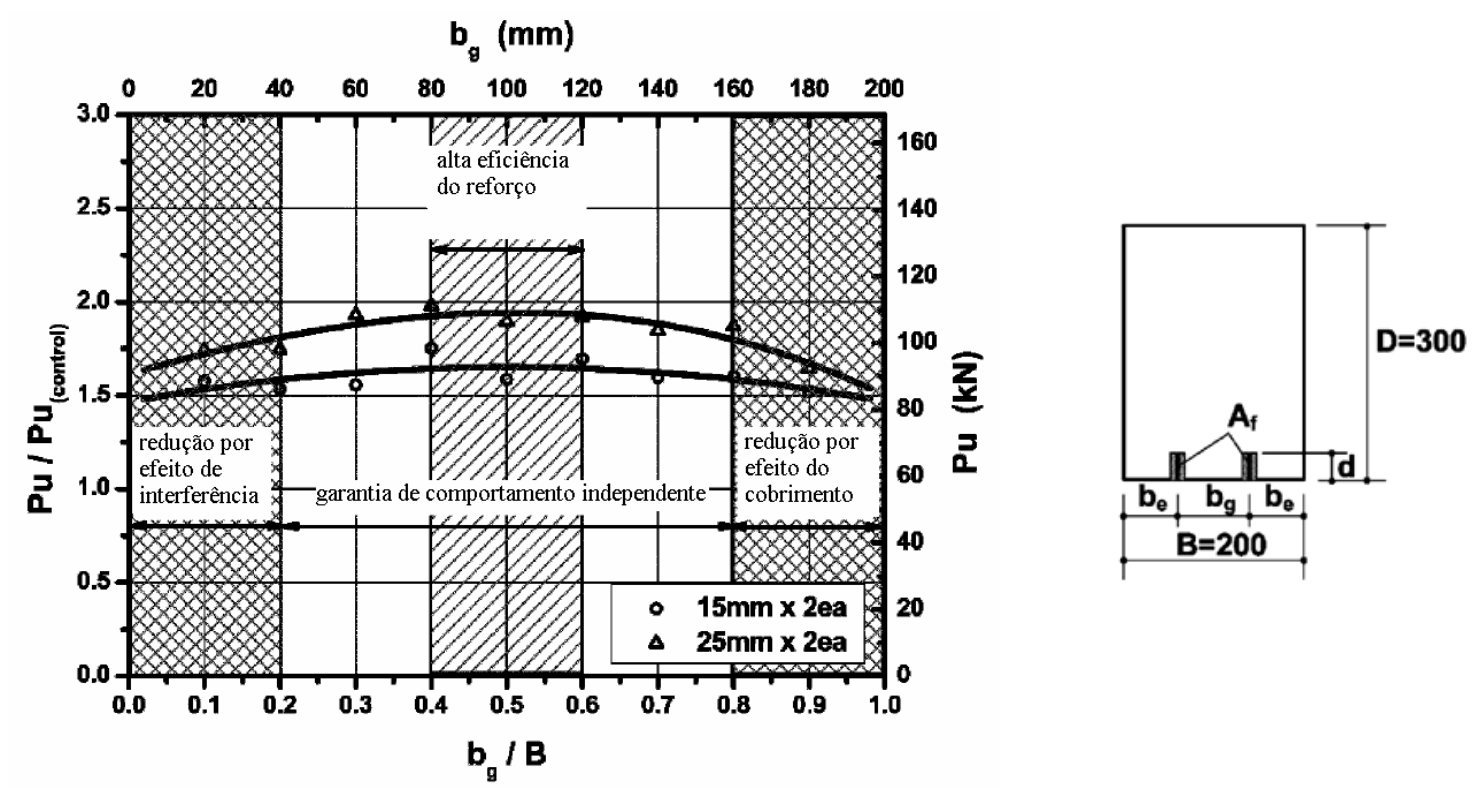

Figura 3.14 - Influência da disposição dos laminados na eficiência do reforço para duas profundidades de entalhe: $15 \mathrm{~mm}$ e $25 \mathrm{~mm}$ (Fonte: adaptado de Kang et al. (2005)).

\footnotetext{
6 Blaschko M. Bond behaviour of CFRP strips glued into slits. In: Proceedings FRPRCS-6. Singapore: World Scientific; 2003. p.205-14.
} 
Souza et al. (2006) apresentam avaliação experimental da utilização da técnica de reforço por colagem de laminados no concreto de cobrimento no reforço em consolo curto duplo de concreto armado. Dois modelos de consolo foram ensaiados. Um com armadura de tirante adequada (consolo A) e outro com armadura do tirante abaixo da necessária, posteriormente completada pelo reforço. Os consolos foram dimensionados pelo modelo de escoras e tirantes para suportar uma carga de $100 \mathrm{kN}$. As características geométricas dos modelos estão ilustradas na Figura 3.15. Os detalhamentos dos consolos são apresentados nas Figura 3.16 e Figura 3.17.

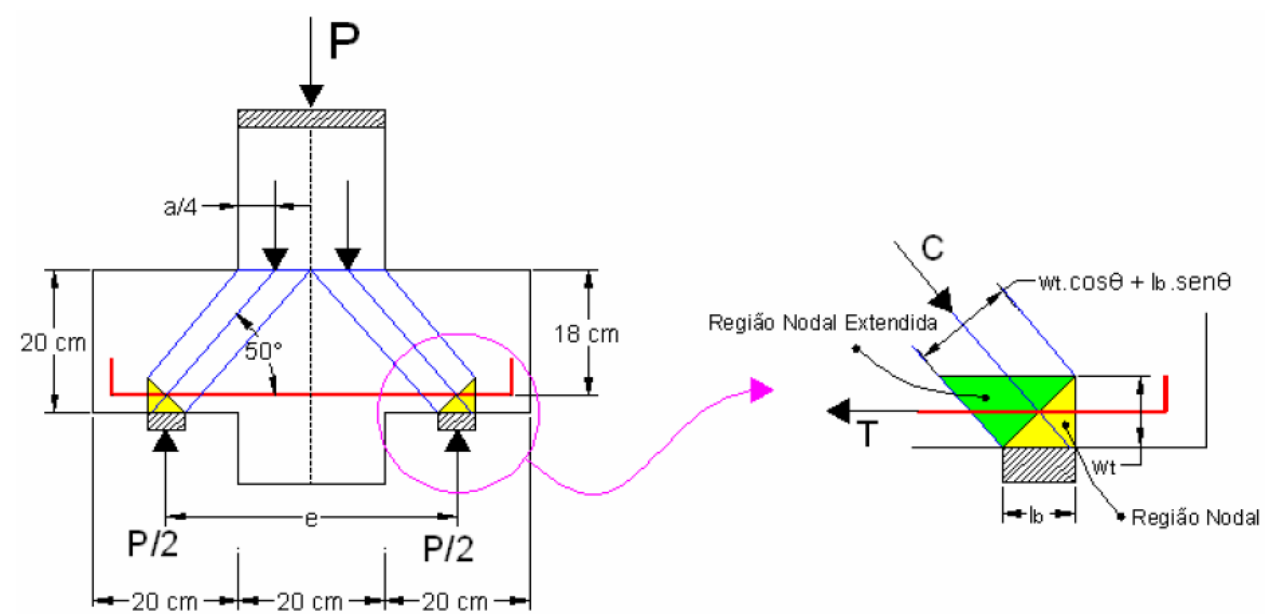

Figura 3.15 - Características geométricas do consolo curto investigado e modelo de escora e tirantes (Fonte: Souza et al. (2006)).

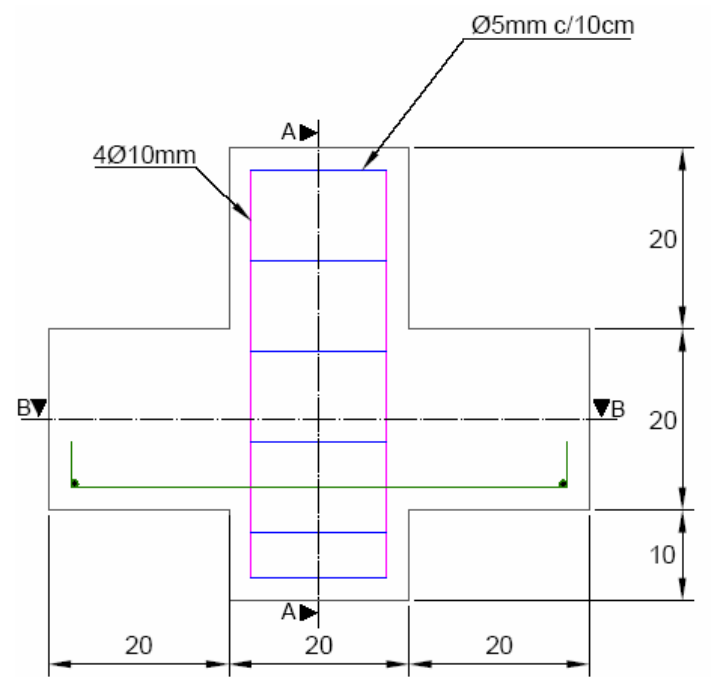

\section{Corte AA}
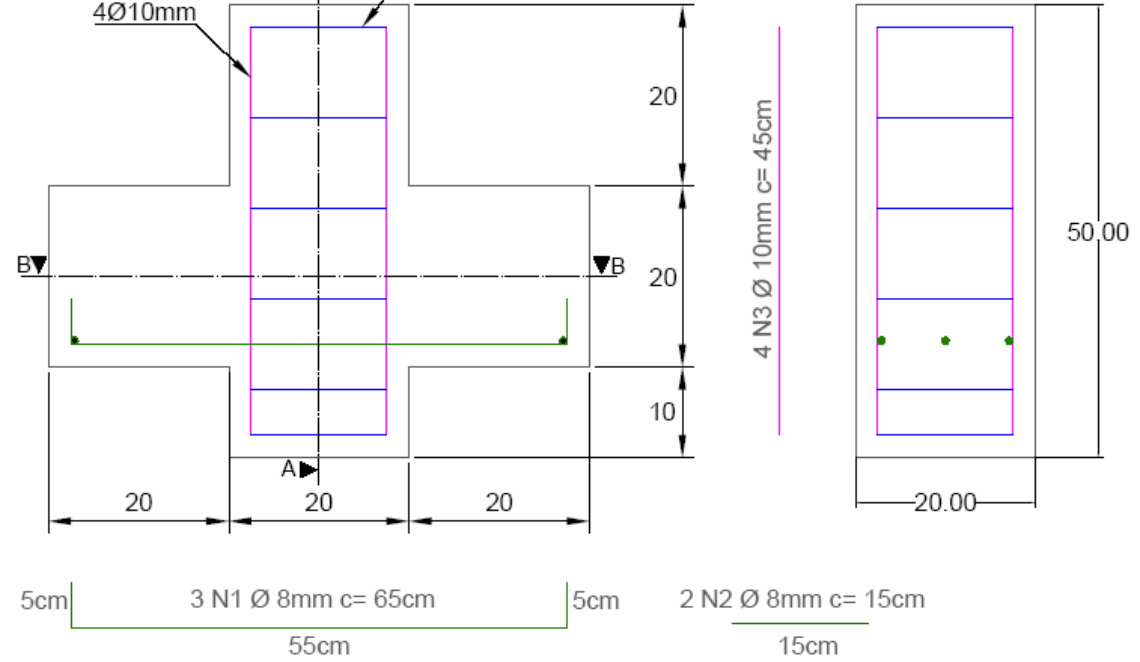

Figura 3.16 - Detalhamento do consolo A (Fonte: Souza et al. (2006)). 


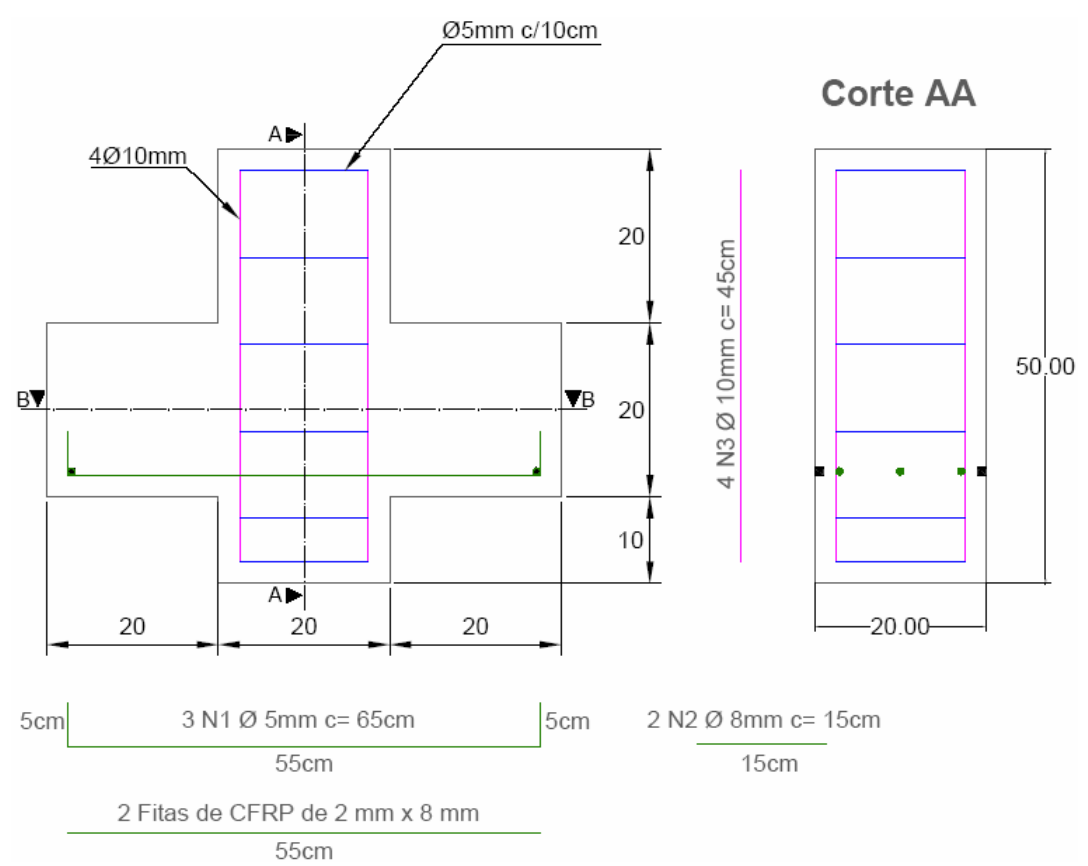

Figura 3.17 - Detalhamento do consolo B (Fonte: Souza et al. (2006)).

Para o reforço, uma fita de fibra de carbono MFC com dimensões de $2 \mathrm{~mm}$ x $16 \mathrm{~mm}$, fornecida pela empresa "Rogertec", foi separada ao meio e as duas fitas resultantes foram inseridas em entalhes de aproximadamente $1 \mathrm{~cm}$ de profundidade. Os ensaios foram realizados com carregamento monotônico. A ruptura do consolo A se deu de forma brusca por ruína da escora diagonal com danificação da região do apoio. O consolo B também apresentou ruptura brusca (Figura 3.18). Os principais resultados obtidos estão sintetizados na Tabela 3.1.

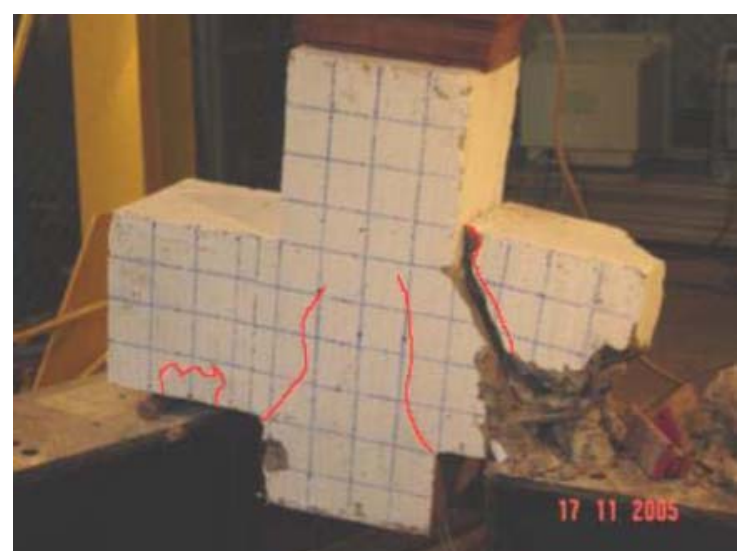

Figura 3.18 - Consolo B após ruptura (Fonte: Souza et al. (2006)).

Tabela 3.1 - Cargas de fissuração, escoamento e ruína dos consolos (Fonte: Souza et al. (2006)).

\begin{tabular}{cccccc}
\hline Consolo & $\begin{array}{c}\text { Fissuração } \\
\text { teórica }(\mathbf{k N})\end{array}$ & $\begin{array}{c}\text { Fissuração } \\
\text { experimental } \\
\mathbf{( k N )}\end{array}$ & $\begin{array}{c}\text { Escoamento } \\
\text { teórico (kN) }\end{array}$ & $\begin{array}{c}\text { Escoamento } \\
\text { experimental } \\
(\mathbf{k N})\end{array}$ & $\begin{array}{c}\text { Ruína } \\
\text { experimental } \\
\mathbf{( k N )}\end{array}$ \\
\hline Consolo A & $75,12 \pm 6,61$ & 69,85 & 178,76 & 133,82 & 217,08 \\
Consolo B & $70,42 \pm 6,19$ & 95,58 & 135,13 & 127,03 & 257,97 \\
\hline
\end{tabular}


Liu, Oehlers e Seracino (2006) avaliam a ductilidade de vigas reforçadas por laminados inseridos no concreto de cobrimento pela medição da redistribuição de momento da região da viga localizada sobre o apoio (hogging region) para a região do vão da viga (sagging region), observada em ensaios experimentais. O programa experimental foi dividido em duas séries de ensaios em vigas com seções distintas: NS (Figura 3.19) e NB (Figura 3.21). Manteve-se armadura constante ao longo de todo o comprimento das vigas. O reforço por colagem de fitas de aço ou PRFC foi executado apenas na região sob o apoio central. A configuração do ensaio está apresentada na Figura 3.21.
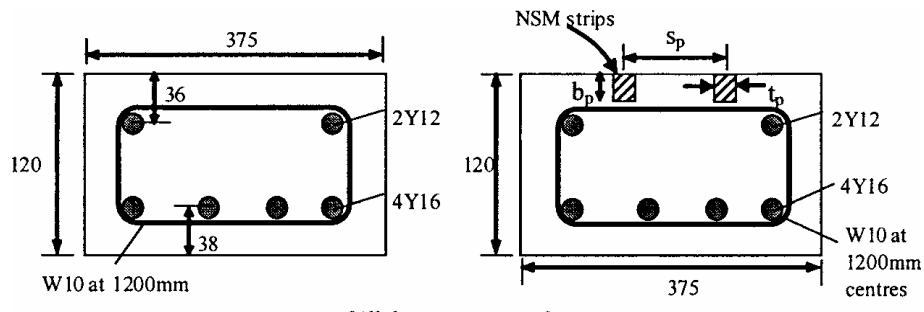

(a) Sagging region

(b) Hogging region

Figura 3.19 - Detalhes das vigas da série NS (Fonte: adaptado de Liu, Oehlers e Seracino (2006)).

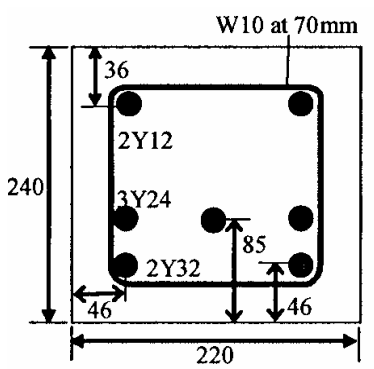

(a)

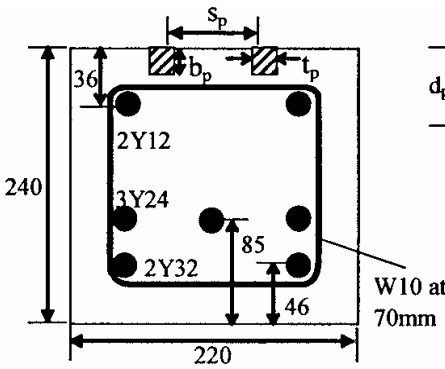

(b)

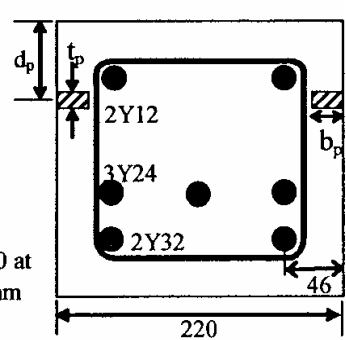

(c)

Figura 3.20 - Detalhes da seção das vigas da série NB: (a) sagging region; (b) hogging region para vigas com laminados inseridos na face tracionada; e (c) hogging region para vigas com laminados inseridos nas faces laterais (Fonte: adaptado de Liu, Oehlers e Seracino (2006)).

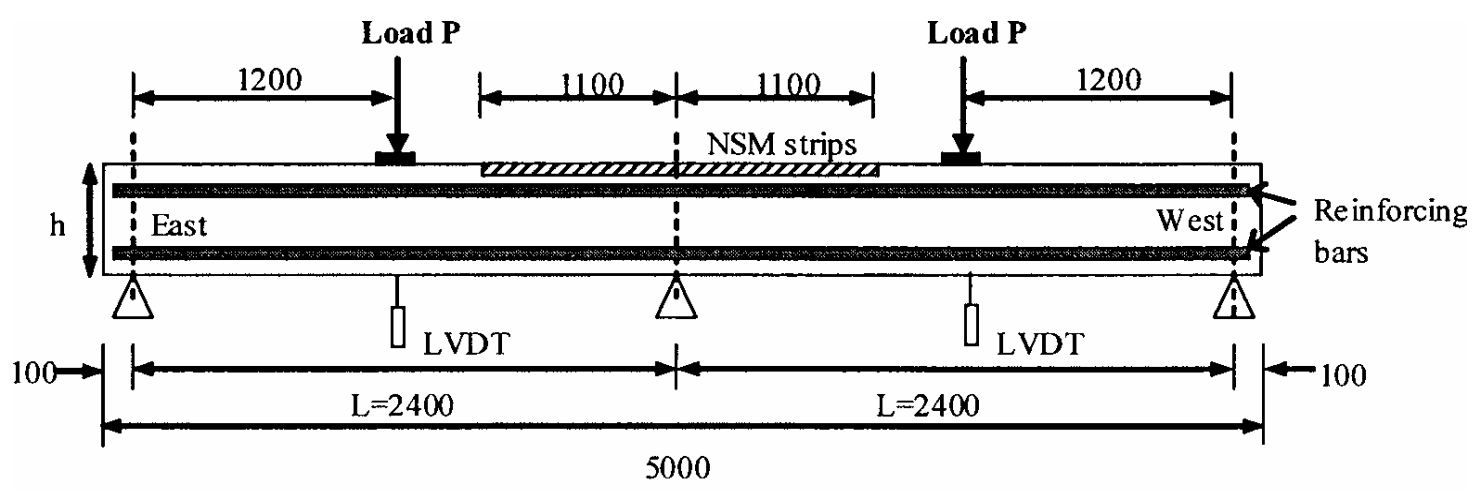

[All dimensions in $\mathrm{mm}$ ]

Figura 3.21 - Modelo de viga contínua com dois vãos (Fonte: adaptado de Liu, Oehlers e Seracino (2006)). 
As propriedades das fitas inseridas foram as principais variáveis em nove modelos testados. Os ensaios foram realizados sob controle de carregamento e a ruptura foi definida pela queda capacidade de carga. A porcentagem de redistribuição de momento da região sobre o apoio foi calculada por meio da Equação 3.3, na qual: $\left(M_{\text {hog }}\right)_{\text {EIcnst }}$ é o momento teórico na região do apoio para uma análise elástico-linear em que se assume a rigidez à flexão E.I constante, para um dado momento estático; $\left(M_{\text {hog }}\right)_{\text {test }}$ é momento obtido experimentalmente na região do apoio para o mesmo momento estático.

$$
\% M R=\frac{\left(M_{\text {hog }}\right)_{\text {EIcnst }}-\left(M_{\text {hog }}\right)_{\text {test }}}{\left(M_{\text {hog }}\right)_{\text {EIcnst }}} \times 100
$$

Liu, Oehlers e Seracino (2006) afirmam que devido ao reforço na região sobre o apoio, a redistribuição de momento obtida para todos os modelos testados foi inferior à máxima redistribuição possível em uma viga não reforçada. Contudo, significativas quantidades de redistribuição de momento foram alcançadas. A percentagem de redistribuição de momento foi inferior a 30\% em apenas um dos modelos. A redistribuição de momento variou de 13,9 a 45,5\% para os modelos reforçados com PRFC e de 31,8 a 39,4\% para os modelos reforçados com fitas de aço. Liu, Oehlers e Seracino (2006) concluem que vigas reforçadas com fitas de PRFC inseridas em entalhes podem exibir redistribuição de momento tanto quanto aquelas reforçadas por barras de aço inseridas em entalhes.

\subsection{Aderência}

A aderência presente nas interfaces compósito-resina-concreto é o fator responsável pela solidarização entre o reforço e concreto, ditando a transferência de esforços entre estes e possibilitando que eles trabalhem em conjunto quando da solicitação da peça reforçada. A aderência é influenciada por diversos parâmetros: dimensão das barras e entalhes, resistência à tração e ao cisalhamento do concreto e adesivo, seção e configuração superficial da barra e grau de rugosidade do entalhe (DE LORENZIS; TENG, 2006). De Lorenzis e Teng (2006) fazem um resumo dos possíveis modos de ruptura em ensaios de aderência ilustrados na Figura 3.22.

- Ruptura na interface PRF - epóxi: pode ocorrer puramente na interface ou por falha coesiva do adesivo (BE-I e BE-C). A ruptura puramente na interface é o modo de ruptura crítico para barras de superfície lisa ou levemente impregnada por areia quando o grau de rugosidade é insuficiente para promover a interação entre a barra e o material de preenchimento do entalhe. Para barras circulares, este modo é 
crítico se as dimensões do entalhe são grandes o suficiente para prevenir a ruptura pelo destacamento do material de preenchimento do entalhe. A ruptura por falha coesiva do adesivo é critica para fitas de PRF de superfície rugosa quando a resistência do epóxi é excedida.

- Ruptura na interface epóxi - concreto: pode ocorrer puramente na interface ou por falha coesiva do concreto (EC-I e EC-C). A ruptura puramente na interface é crítica nos casos em que o entalhe é pré-moldado. A falha coesiva do concreto não foi observada em ensaios de aderência, mas sim em ensaios de flexão em vigas na região reforçada ou na extremidade do reforço.

- Desprendimento do epóxi de cobrimento: pode ocorrer com fissuração visível ou não do adesivo e com ou sem arrancamento do concreto adjacente (SP-E, SPC1, SP-C2 e SP-ED). Compreende os modos de ruptura em que há a fissuração longitudinal e/ou a fratura do concreto adjacente. Quando a razão entre a profundidade do entalhe e o diâmetro da barra é muito baixa $(1,12-1,18)$, a ruptura se limita ao epóxi de cobrimento sem dano significativo ao concreto (SP-E). Para valores maiores da razão entre a profundidade do entalhe e o diâmetro da barra, verifica-se a combinação da fissuração longitudinal do epóxi de cobrimento com a fratura do concreto ao redor ao longo de planos inclinados (SP-C1). Para grande profundidade do entalhe e/ou quando a razão entre as resistências à tração do concreto e do epóxi é pequena, a fratura do concreto pode ocorrer antes da fissura do epóxi atingir a superfície externa (SP-C2). Quando as barras são dispostas à pequena distância dos cantos (distância menor que $20 \mathrm{~mm}\left(\mathrm{BLASCHKO}^{7}, 2001\right.$ apud DE LORENZIS; TENG, 2006)) pode ocorrer ruptura por destacamento do canto de concreto (SP-ED). Espera-se que a resistência de aderência associada ao modo de ruptura SP-E tenha forte dependência da resistência à tração do concreto. Para os modos SP-C1 e SP-C2 essa resistência deve ser influenciada pela resistência à tração do concreto

${ }^{7}$ Blaschko M. Zum tragverhalten von betonbauteilen mit in schlitze eingeklebten CFK-lamellen. Bericht 8/2001 aus dem Konstruktiven Ingenieurbau, TU München, 2001. 147 pp [in German]. 

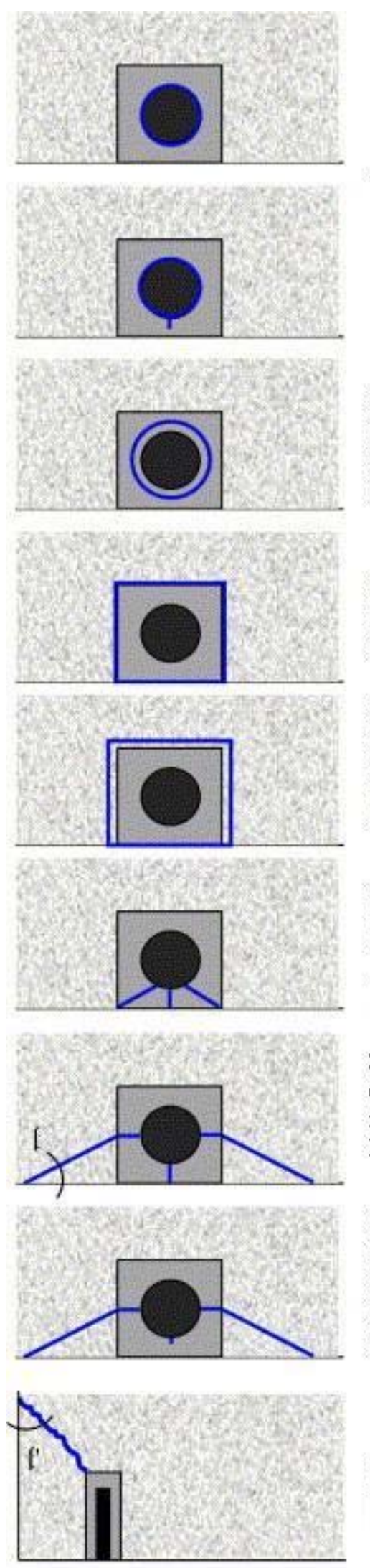

SP-ED: fratura do canto de concreto

BE-I: interface na interface

BE-C: interface cisalhamento

EC-I: interface concreto-epóxi -

EC-C: interface concreto-epóxi ruptura coesiva no concreto por cisalhamento sem fissuração do concreto planos inclinados

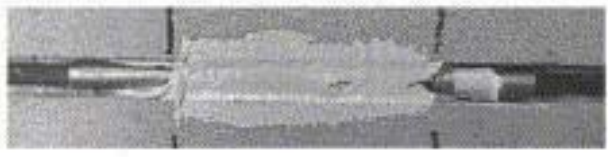
barra-epóxi - ruptura barra-epóxi - ruptura coesiva no epóxi por ruptura na interface

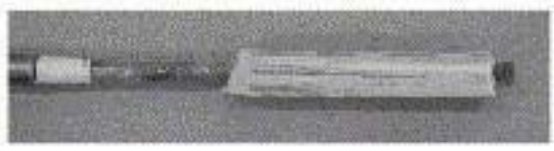

SP-E: desprendimento do epóxi de cobrimento

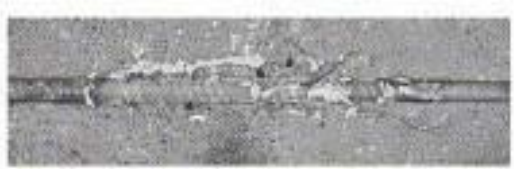

SP-CI: fissuração do epóxi de cobrimento e fratura do concreto ao longo de planos inclinados

SP-C2: fissuração do epóxi de cobrimento rão identificável fratura do concreto ao longo de
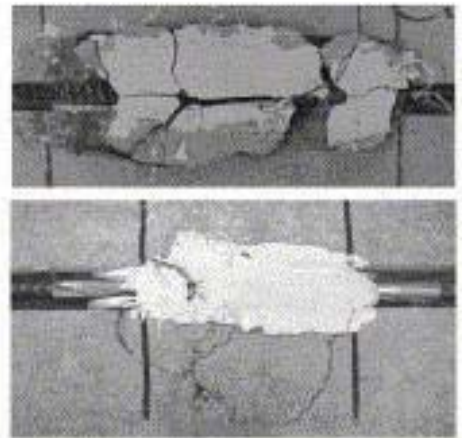

Nota: A maioria das figuras se refere a barras circulares porém BE-C e EC-C tem sido observadas também para fitas Figura 3.22 - Modos de ruptura adesiva de sistemas NSM observados em ensaios de aderência (Fonte: adaptado de De Lorenzis e Teng (2006)). 
A caracterização da aderência pode ser feita por meio de ensaios experimentais em modelos de aderência. Juvandes (1999) apresenta relação dos modelos utilizados nos principais trabalhos científicos, agrupados segundo a ação preponderante no ensaio, e observa não existirem referências na literatura que apontem para uma padronização destes modelos. Nos principais trabalhos referentes à caracterização da aderência de elementos reforçados por inserção de compósitos em entalhes, tem-se recorrido a ensaios do tipo arrancamento em viga e arrancamento direto. É geralmente aceito que os ensaios de arrancamento em viga são mais representativos do comportamento da aderência em elementos reais (DE LORENZIS E NANNI, 2001). Contudo, De Lorenzis e Teng (2006) apontam como desvantagens deste último: utilização de modelos grandes, dificuldade na condução do ensaio sob controle de deslizamento e dificuldade de inspeção visual do comportamento da ligação durante o carregamento. De Lorenzis e Teng (2006) ponderam que os ensaios de arrancamento direto são uma boa escolha devido à sua simplicidade e confiabilidade.

\subsubsection{Estudos acerca da aderência}

De Lorenzis e Nanni (2001) apresentam investigação acerca do comportamento da aderência de barras inseridas no concreto em que adotaram modelo de viga não reforçada, com seção em T invertido (Figura 3.23). A meio vão da viga posicionaram-se, no topo, uma rótula metálica e, na base, um entalhe transversal para controle da distribuição das forças internas. A barra foi inserida em entalhe longitudinal realizado na base da viga. A região de teste se restringiu a um dos lados da viga e, no outro, a barra de PRF foi totalmente ancorada para garantir a ruptura na região de teste. Foram investigados três comprimentos de ancoragem (6, 12 e 18 vezes o diâmetro da barra) e três dimensões de entalhes, mantido o comprimento de ancoragem de 12 vezes o diâmetro da barra.

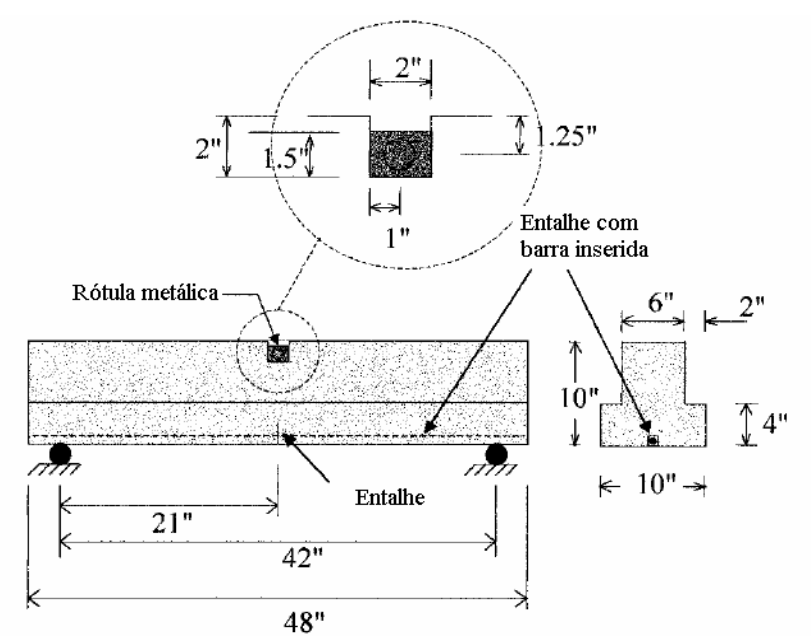

Figura 3.23 - Geometria do modelo e configuração de ensaio (Fonte: adaptado de De Lorenzis e Nanni (2001)). 
Quatro dos cinco modelos ensaiados romperam por fissuração do epóxi. Apenas para o modelo com maior dimensão de entalhe observou-se ruptura no concreto adjacente à ligação. De Lorenzis e Nanni (2001) afirmam que quando a ruptura se dá no epóxi, espera-se que a carga de ruptura seja independente da resistência à tração do concreto. Entretanto, se a profundidade do entalhe for suficiente para causar ruptura no concreto, a resistência do concreto à tração se torna um parâmetro importante. Os resultados do estudo mostram que a carga de ruptura da ligação é diretamente proporcional ao comprimento de ancoragem e que a resistência de aderência, calculada como a razão da carga de ruptura pela área superficial aderida da barra, se mantém praticamente constante. Na Tabela 3.2, estão resumidos os resultados obtidos.

Tabela 3.2 - Resultados dos ensaios de aderência (Fonte: adaptado de De Lorenzis e Nanni (2001)).

\begin{tabular}{lccccc}
\hline $\begin{array}{c}\text { Código } \\
\text { do } \\
\text { modelo }\end{array}$ & $\begin{array}{c}\text { Razão entre } \\
\text { comprimento de } \\
\text { ancoragem e diâmetro }\end{array}$ & $\begin{array}{c}\text { Dimensão } \\
\text { do entalhe } \\
(\mathbf{m m})\end{array}$ & $\begin{array}{c}\text { Carga de } \\
\text { ruptura } \\
\mathbf{( k N )}\end{array}$ & $\begin{array}{c}\text { Resistência média } \\
\text { de aderência } \\
(\mathbf{M P a})\end{array}$ & Modo de ruptura \\
\hline 6-a & 6 & 12,70 & 15,67 & 9,16 & Fissuração do epóxi \\
$12-\mathrm{a}$ & 12 & 12,70 & 26,71 & 7,81 & $\begin{array}{c}\text { Fissuração do epóxi } \\
12-\mathrm{b}\end{array}$ \\
12 & 19,05 & 30,60 & 8,92 & $\begin{array}{c}\text { Fissuração do epóxi + } \\
\text { ruptura do concreto }\end{array}$ \\
$12-\mathrm{c}$ & 12 & 25,40 & 28,79 & 8,42 & Ruptura do concreto \\
$18-\mathrm{a}$ & 18 & 12,70 & 42,04 & 8,20 & Fissuração do epóxi \\
\hline
\end{tabular}

Cruz (2004) estudou a aderência de laminados inseridos em um programa experimental dividido em duas partes. Na primeira parte, referenciada por S1, investigou-se a influência do comprimento de ancoragem $(40,60$ e $80 \mathrm{~mm})$ e da resistência do concreto a compressão $(35,45$ e $70 \mathrm{MPa})$. Na segunda, S2, as variáveis foram o histórico de carregamento e o comprimento de ancoragem (60, 90 e $120 \mathrm{~mm})$.

Cruz (2004) baseou seu ensaio na proposta da RILEM ${ }^{8}$ (1982 apud CRUZ, 2004) para caracterização da aderência de armaduras convencionais de aço ao concreto. A geometria dos modelos empregados nas séries S1 e S2 apresentaram algumas diferenças em função de terem sido confeccionados em laboratórios distintos (Figura 3.24 e Figura 3.25). A configuração do ensaio consistiu de dois blocos de concreto, bloco A e bloco B, unidos na parte superior por uma rótula e na parte inferior pelo laminado. Manteve-se o comprimento de ancoragem no bloco B com valor suficiente para impedir o deslizamento do laminado em relação ao

\footnotetext{
${ }^{8}$ RILEM (1982). Bond test for reinforcement steel 1. Beam test. TC9-RC.
} 
concreto. No bloco A, estudaram-se comprimentos variáveis de ancoragem, sempre inferiores àqueles que ocasionariam a ruptura do laminado. O transdutor de deslocamento, LVDT2, posicionado na zona carregada, foi utilizado no controle do ensaio, a uma taxa de $5 \mu \mathrm{m} / \mathrm{s}$ e o LVDT1 usado para aquisição do deslizamento na zona livre. As células de carga posicionadas nos apoios e o extensômetro, a meio vão, permitiram o cálculo da força atuante no laminado por dois métodos. Para a série S1 o carregamento foi monotônico enquanto para os ensaios da série S2 também foram aplicados carregamentos cíclicos.

Adotou-se para os modelos a denominação genérica fcmXX_LbYY_Z em que XX é a classe de resistência do concreto em MPa, YY é o comprimento de ancoragem em $\mathrm{mm}$ e Z define o tipo de carregamento $(\mathrm{M}, \mathrm{C} 1$ ou $\mathrm{C} 10)$. $\mathrm{M}$ indica carregamento monotônico, $\mathrm{C} 1$ indica carregamento com um ciclo de carga/descarga a determinados deslizamentos e C10 indica carregamento em dez ciclos de carga/descarga.

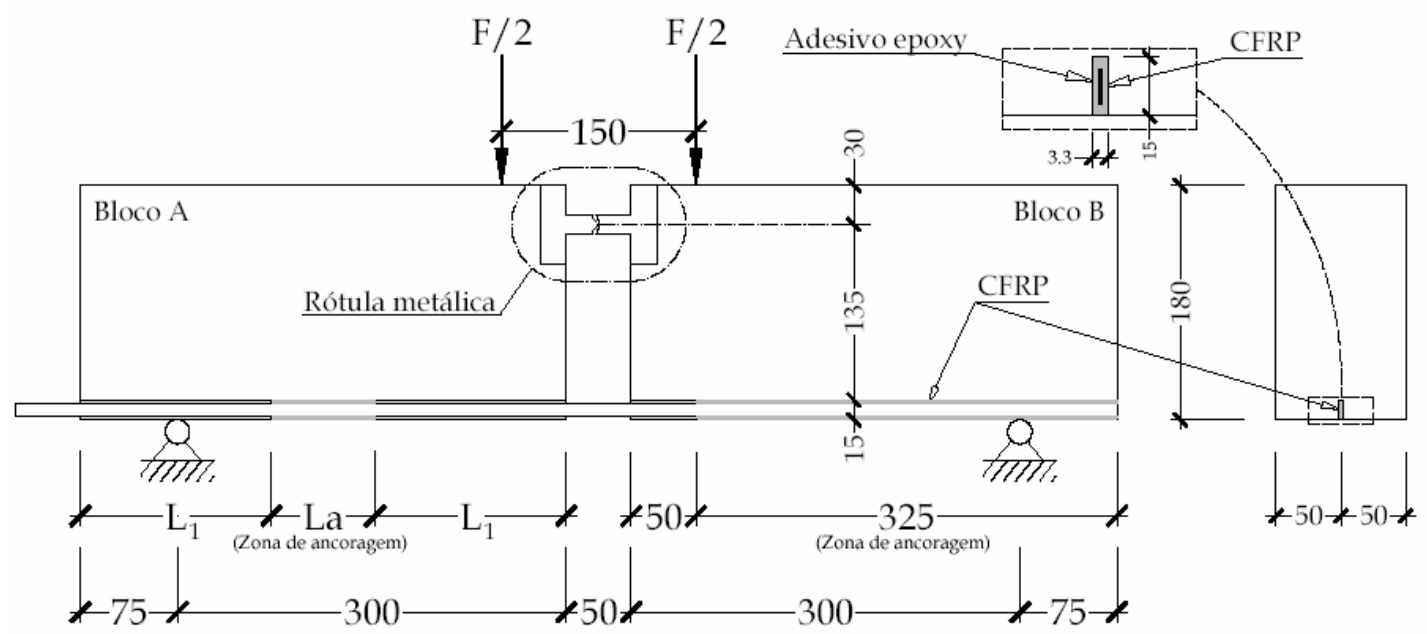

Figura 3.24 - Geometria dos modelos e configuração dos ensaios da série S1 (Fonte: Sena-Cruz e Barros (2002)). Obs.: medidas em mm.

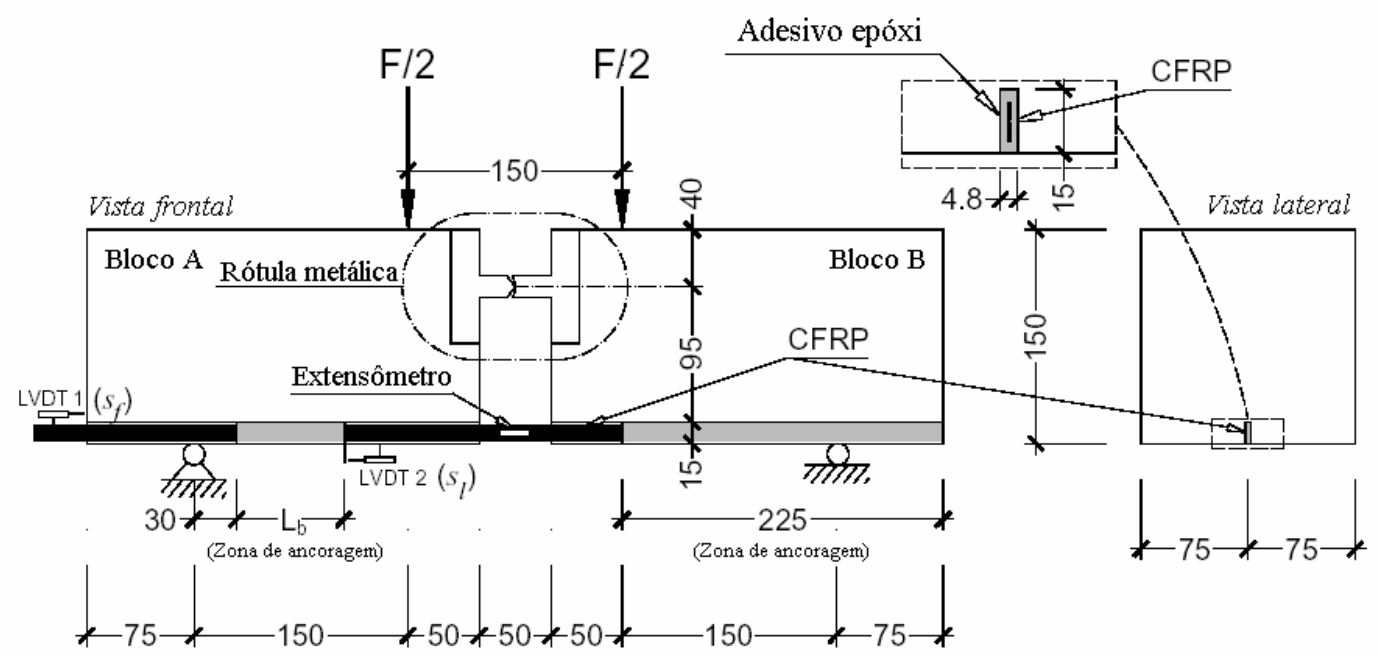

Figura 3.25 - Geometria dos modelos e configuração dos ensaios da série S2 (Fonte: adaptado de Cruz (2004)). Obs.: medidas em $\mathrm{mm}$. 
$\mathrm{Na}$ Tabela 3.3 e na Tabela 3.4 estão resumidos os resultados dos ensaios monotônicos das duas séries de ensaios. As rupturas ocorreram ou na interface adesivo-laminado ou na interface adesivo-concreto. Em nenhum dos modelos houve fissuração do concreto. Verificou-se relação de proporcionalidade direta entre força máxima de arrancamento e o comprimento de ancoragem bem como entre o deslizamento máximo e o comprimento de ancoragem, aproximando-se está última da linearidade. A resistência do concreto aparentemente não teve influência no deslizamento máximo e na tensão cisalhante máxima e teve influência marginal na força máxima de arrancamento. A tensão cisalhante máxima decresceu com o aumento do comprimento de ancoragem. Na comparação entre a Tabela 3.3 e a Tabela 3.4 percebe-se que o aumento da força de arrancamento com o aumento do comprimento de ancoragem é mais pronunciado na série S1 que na S2. Cruz (2004) atribui isso ao maior volume de adesivo nos modelos S2 em função da maior largura do entalhe. Contudo, há que se observar que os adesivos utilizados nas duas séries apresentaram propriedades diferentes, o que não foi considerado nessa justificativa. Observou-se semelhança formal entre a envoltória da relação força versus deslizamento, obtida nos ensaios cíclicos $\mathrm{C} 10$, e a curva alcançada no ensaio monotônico homólogo. Foi observado decréscimo contínuo da força de arrancamento, no final do ramo de carregamento, nos ciclos de carregamento/descarregamento efetuados antes da força máxima de arrancamento. Isto, entretanto, não interferiu no valor da força máxima de arrancamento. Nos ensaios com 1 ciclo de carga/descarga, a rigidez (inclinação média de um ciclo completo) decresceu significativamente antes da força máxima de arrancamento.

Tabela 3.3 - Valores médios dos dados principais das séries S1 (Fonte: adaptado de Cruz (2004)).

\begin{tabular}{lccccc}
\hline Séries & $\begin{array}{c}\text { Máximo } \\
\text { deslizamento } \\
(\mathbf{m m})\end{array}$ & $\begin{array}{c}\text { Máxima } \\
\text { força no } \\
\text { laminado } \\
\mathbf{( k N )}\end{array}$ & $\begin{array}{c}\text { Máxima } \\
\text { tensão no } \\
\text { laminado } \\
\mathbf{( M P a )}\end{array}$ & $\begin{array}{c}\text { Razão entre as } \\
\text { tensões máxima } \\
\text { e última no } \\
\text { laminado (\%) }\end{array}$ & $\begin{array}{c}\text { Razão entre tensão } \\
\text { cisalhante residual e a } \\
\text { tensão cisalhante } \\
\text { máxima (-) }\end{array}$ \\
\hline fcm35_Lb40_M & 0,29 & 15,0 & 17,5 & 42,1 & 0,41 \\
fcm35_Lb60_M & 0,49 & 22,8 & 17,7 & 64,0 & 0,47 \\
fcm35_Lb80_M & 0,65 & 22,4 & 13,0 & 62,1 & 0,37 \\
fcm45_Lb40_M & 0,27 & 15,5 & 18,1 & 43,5 & 0,39 \\
fcm45_Lb60_M & 0,46 & 19,9 & 15,5 & 55,8 & 0,33 \\
fcm45_Lb80_M & 0,84 & 26,4 & 15,4 & 73,9 & 0,41 \\
fcm70_Lb40_M & 0,32 & 15,7 & 18,3 & 44,0 & 0,50 \\
fcm70_Lb60_M & 0,40 & 18,9 & 14,7 & 52,9 & 0,39 \\
fcm70_Lb80_M & 0,74 & 25,6 & 14,9 & 71,6 & 0,48 \\
\hline
\end{tabular}


Tabela 3.4 - Valores médios dos dados principais das séries S2 (Fonte: adaptado de Cruz (2004)).

\begin{tabular}{cccccc}
\hline Séries & $\begin{array}{c}\mathbf{s}_{\text {I máx }} \\
(\mathbf{m m})\end{array}$ & $\begin{array}{c}\mathbf{f}_{\text {Imáx }} \\
(\mathbf{k N})\end{array}$ & $\begin{array}{c}\boldsymbol{\tau}_{\text {máx }} \\
(\mathbf{M P a})\end{array}$ & $\begin{array}{c}\boldsymbol{\sigma}_{1 \text { mán }} / \mathbf{f}_{\text {fu }} \\
\mathbf{( \% )}\end{array}$ & $\begin{array}{c}\boldsymbol{\tau}_{\mathbf{r}} / \boldsymbol{\tau}_{\text {máx }} \\
(-)\end{array}$ \\
\hline fcm40_Lb60_M & 0,43 & 18,7 & 13,6 & 47,5 & 0,45 \\
fcm40_Lb90_M & 0,79 & 23,9 & 11,6 & 60,7 & 0,52 \\
fcm40_Lb120_M & 1,13 & 27,7 & 10,1 & 70,5 & 0,54 \\
\hline
\end{tabular}

Cruz (2004) propõe a utilização dos gráficos apresentados na Figura 3.26 e na Figura 3.27, como critério de projeto, para determinação dos comprimentos de ancoragem que atendam ao estado limite de serviço e estado limite último. O gráfico da Figura 3.26 foi obtido por meio de um procedimento numérico, com base nos resultados experimentais, e relaciona a força normal no laminado que não promove deslizamento na extremidade não carregada do laminado e o comprimento de ancoragem. O gráfico da Figura 3.27 relaciona a força máxima de arrancamento e o comprimento de ancoragem. Cruz (2004) apresenta o exemplo em que o laminado de PRFC deve ser submetido a $10 \mathrm{kN}$ e $30 \mathrm{kN}$ nos estados limite de serviço e último respectivamente. Utilizando-se os gráficos nas Figura 3.26 e Figura 3.27, determinam-se os comprimentos de ancoragem de $50 \mathrm{~mm}$ e $89 \mathrm{~mm}$. Nesse caso, deve-se adotar o comprimento de ancoragem de $89 \mathrm{~mm}$ que atende aos dois critérios.

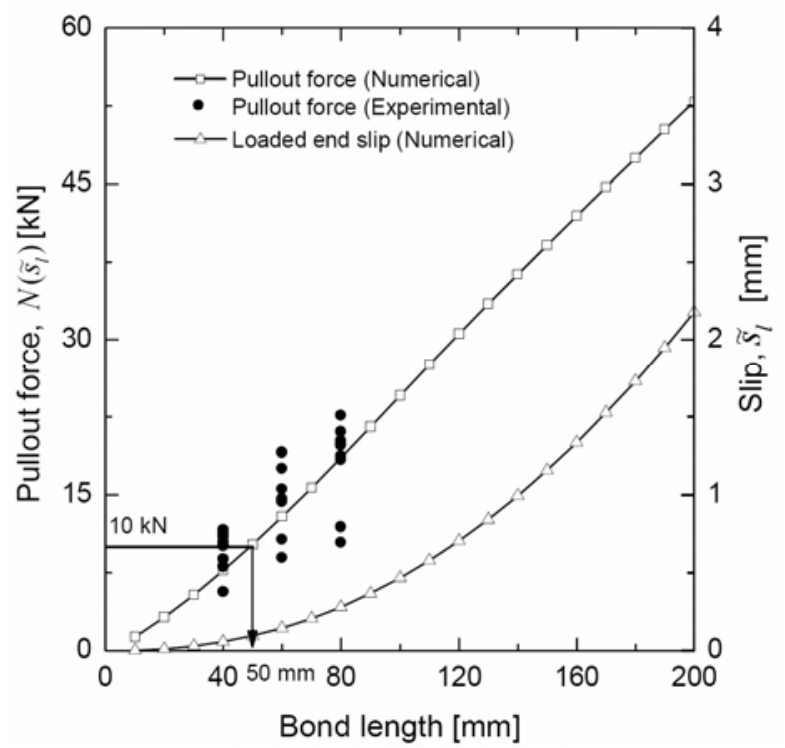

Figura 3.26 - Força de arrancamento anterior ao deslizamento da extremidade não carregada do laminado $\left(\mathrm{N}\left(\check{\mathrm{s}}_{1}\right)\right)$ e deslizamento da zona carregada ( $\left.\breve{\mathrm{s}}_{1}\right)$ como função do comprimento de ancoragem (Fonte: adaptado de Cruz (2004)). 


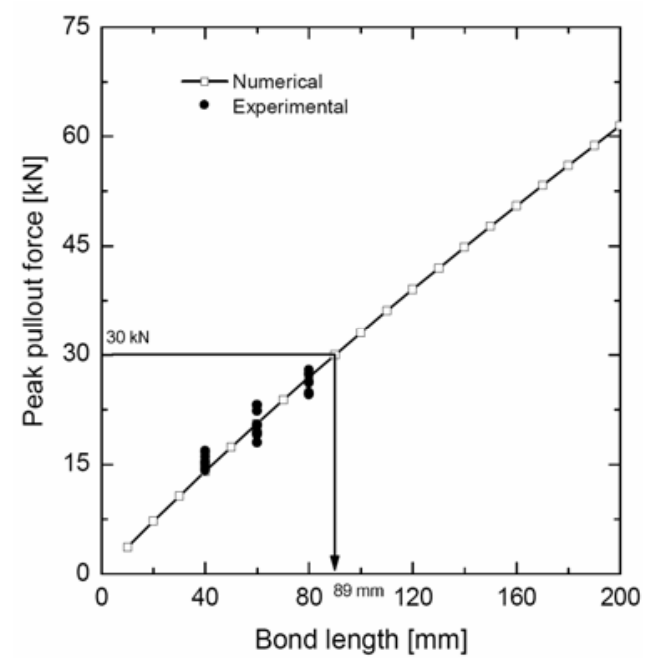

Figura 3.27 - "Força de arrancamento x comprimento de ancoragem" (Fonte: adaptado de Cruz (2004)).

Shield, French e Milde (2005) estudaram a influência do tipo de adesivo na aderência do reforço segundo a técnica NSM. Para tanto, efetuaram ensaios de arrancamento em modelos com escala reduzida, segundo a configuração ilustrada na Figura 3.28. Foram testados seis tipos de adesivo cujas propriedades relativas a tempo de cura, viscosidade, resistência à tração, módulo de elasticidade na tração, deformação última e resistência ao cisalhamento foram, em sua maior parte, informadas pelos fabricantes. Utilizou-se laminado com espessura de $2 \mathrm{~mm}$ e largura de $16 \mathrm{~mm}$, com resistência à tração de 2,5 GPa (valor experimental), módulo de elasticidade de $130 \mathrm{GPa}$ e deformação última de 1,7\%. As dimensões do entalhe foram 6,4 x 19 mm. Shield, French e Milde (2005) afirmam não haver correlação clara entre nenhuma das propriedades dos adesivos e os resultados destes ensaios. Os autores sugerem que o comprimento de ancoragem para laminados inseridos em concreto altamente confinado seja dependente da habilidade do adesivo em se deformar e escoar no cisalhamento.
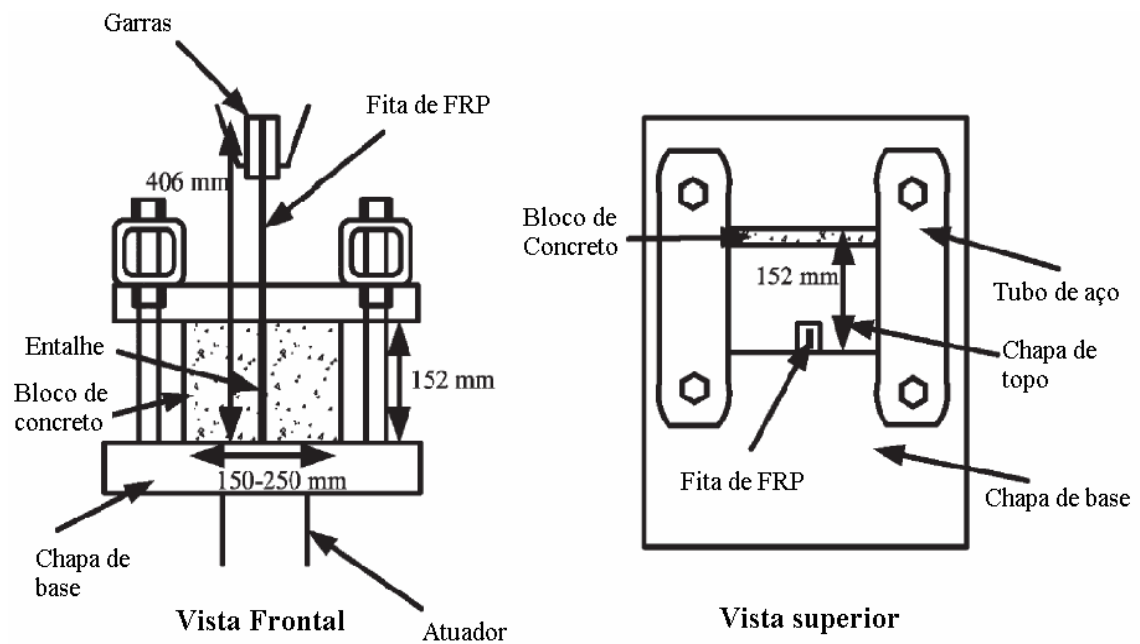

Figura 3.28 - Configuração de ensaio (Fonte: adaptado de Shield, French e Milde (2005)). 


\section{CAPÍTULO 4}

\section{LIGAÇÕES DE ESTRUTURAS DE CONCRETO PRÉ- MOLDADO}

A concepção das ligações tem importância fundamental no comportamento das estruturas de concreto pré-moldado. As ligações são responsáveis pela transferência de esforços e pela estabilidade na fase de montagem e de utilização da estrutura. Além de desempenhar eficientemente essas funções, uma boa ligação deve ainda apresentar praticidade e economia.

O CEB-FIP (1990) destaca que a ligação deve ser idealizada de forma a ser capaz de acomodar deslocamentos relativos necessários à mobilização de resistência da ligação, resistir a todas as ações resultantes da análise da estrutura como um todo, bem como da análise dos membros individualmente, ter resistência e deformabilidade que assegurem a estabilidade da estrutura como um todo. Esse código destaca também a necessidade de serem consideradas, em projeto, as tolerâncias de fabricação e montagem.

O projeto das ligações deve ser norteado por critérios como resistência, ductilidade, resistência a fogo e a sismos. A escolha do modelo de ligação é função também dos esforços que se pretende transmitir e sua execução tende a ser mais trabalhosa quanto mais se tente reproduzir o monolitismo de estruturas de concreto moldado in loco. Como a velocidade de execução é uma das vantagens atribuídas à utilização da pré-moldagem, o emprego de ligações simples é mais conveniente, entretanto se restringe aos edifícios com pequena altura. El Debs (2000) sugere o limite referencial de 12 metros. Em edifícios mais altos, as ações laterais devidas ao vento passam a ser significativas, os momentos nas bases dos pilares se tornam elevados e suas seções injustificáveis em termos econômicos. Nesses casos, se faz 
necessária a adoção de ligações resistentes à flexão cuja execução, conforme Ballarin (1993), pode envolver operações de solda, traspasse ou entrelaçamento de armaduras ou soldagem de insertos metálicos ancorados nos elementos a serem unidos. Há ainda processos executivos que demandam protensão ou grande volume de concretagem. O desenvolvimento de ligações resistentes à flexão e de execução simples é ainda um desafio. Em todo o mundo, as estruturas tipo galpão, exeqüíveis com ligações articuladas, são o principal campo de aplicação da prémoldagem.

As ligações podem ser classificadas segundo diversos critérios. El Debs (2000) exibe a classificação quanto ao tipo de vinculação, emprego de argamassa e concreto no local, esforço principal transmitido. Ballarin (1993) apresenta as seguintes formas de classificação:

- Quanto à vinculação: rígida ou articulada;

- Quanto à exigência de concretagem in loco ou quanto à presença de material de preenchimento: seca ou úmida;

- Quanto à classificação estrutural dos elementos envolvidos: pilar-fundação, pilarpilar, viga-pilar, viga-viga, concreto pré-moldado-concreto moldado in loco, lajeviga, laje-parede, parede-fundação, parede-parede, laje-laje, dispositivos de içamento e insertos;

- Quanto à solicitação predominante: compressão, tração, flexão, cisalhamento;

- Quanto à dureza: soft e hard.

Ballarin (1993) pondera que os critérios de classificação aqui expostos terminam por enquadrar em um mesmo grupo ligações que às vezes apresentam frágil ponto de similaridade. Ferreira (1993) afirma que a classificação quanto à rigidez e quanto aos elementos estruturais envolvidos são as mais usuais. Na classificação quanto à vinculação apresentada por Ballarin (1993) apenas as condições ideais de vinculo são consideradas.

É prática comum em escritórios de projeto estrutural a especificação de ligações rígidas ou articuladas idealizando que estas sejam capazes, respectivamente, de permitir ou restringir por total as rotações entre as peças. Embora essa concepção simplificada do funcionamento das ligações seja prática e até eficiente estruturalmente, ela se distancia de uma acepção realista e eficiente do ponto de vista econômico. Em função da deformabilidade dos elementos que a compõem, o comportamento real de uma ligação em estruturas prémoldadas se situa no intermédio das articulações e ligações rígidas, podendo tender a algum dos extremos, reproduzindo suas características. As ligações com características intermediárias são definidas como semi-rígidas. 
O termo "semi-rigidez" tem origem no vocabulário empregado no estudo de estruturas metálicas, refletindo a capacidade parcial de transferência de momento fletor. As ligações semi-rígidas podem também ser classificadas como deformáveis, sendo a deformabilidade “[...] definida como a relação dos deslocamentos relativos entre os elementos que compõem a ligação com o esforço solicitante na direção desse deslocamento.” (El DEBS, 2000, p. 222). Além da deformabilidade à flexão, as ligações de estruturas de concreto pré-moldado podem apresentar deformabilidade ao esforço normal, ao cisalhamento e à torção (SOARES, 1998). Na Figura 4.1, observam-se as curvas "momento x rotação" para três tipos de ligação: perfeitamente rígida, semi-rígida e perfeitamente articulada. A Figura 4.1 ilustra também a relação inversa existente entre os conceitos de rigidez $\left(K_{m}\right)$ e deformabilidade $\left(D_{m}\right)$.

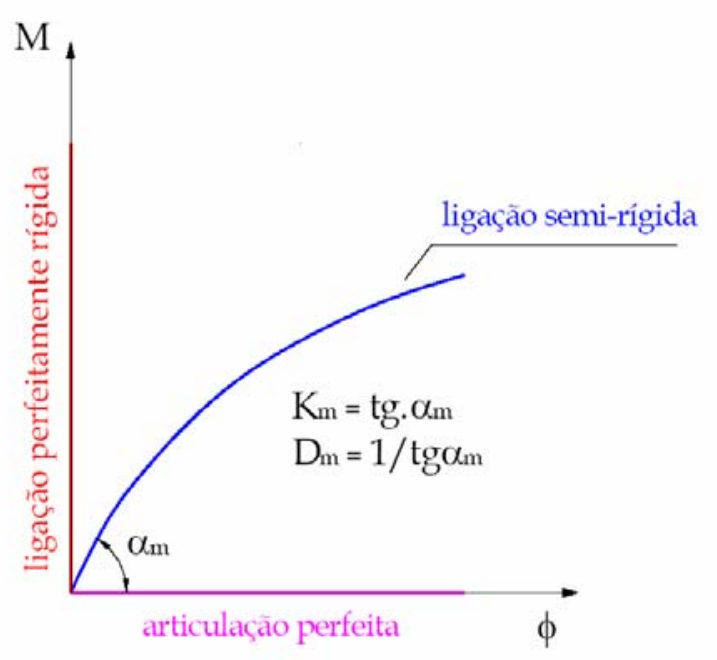

Figura 4.1 - Curvas “momento x rotação” ideais para ligações articuladas semi-rígidas e rígidas (Fonte: Miotto (2002)).

A rigidez de uma ligação pode ser obtida por meio de experimentação, com custo elevado, ou de métodos analíticos, escassos. A dificuldade na estimativa da rigidez contribui para que a semi-rigidez não seja considerada na análise estrutural, embora haja disponibilidade de programas computacionais que contemplem esse efeito. Contudo, as ligações semi-rígidas apresentam vantagens. Sua execução pode ser menos onerosa e demorada que a de ligações rígidas, sem alterações significativas no comportamento global da estrutura. Por outro lado, a consideração da semi-rigidez de ligações pretensamente articuladas pode levar à redução das seções de pilares e vigas, resultando em dimensionamento estrutural otimizado.

O Eurocode 3 (2002) delimita, para as ligações, três zonas de classificação quanto à rigidez, conforme Quadro 4.1. 


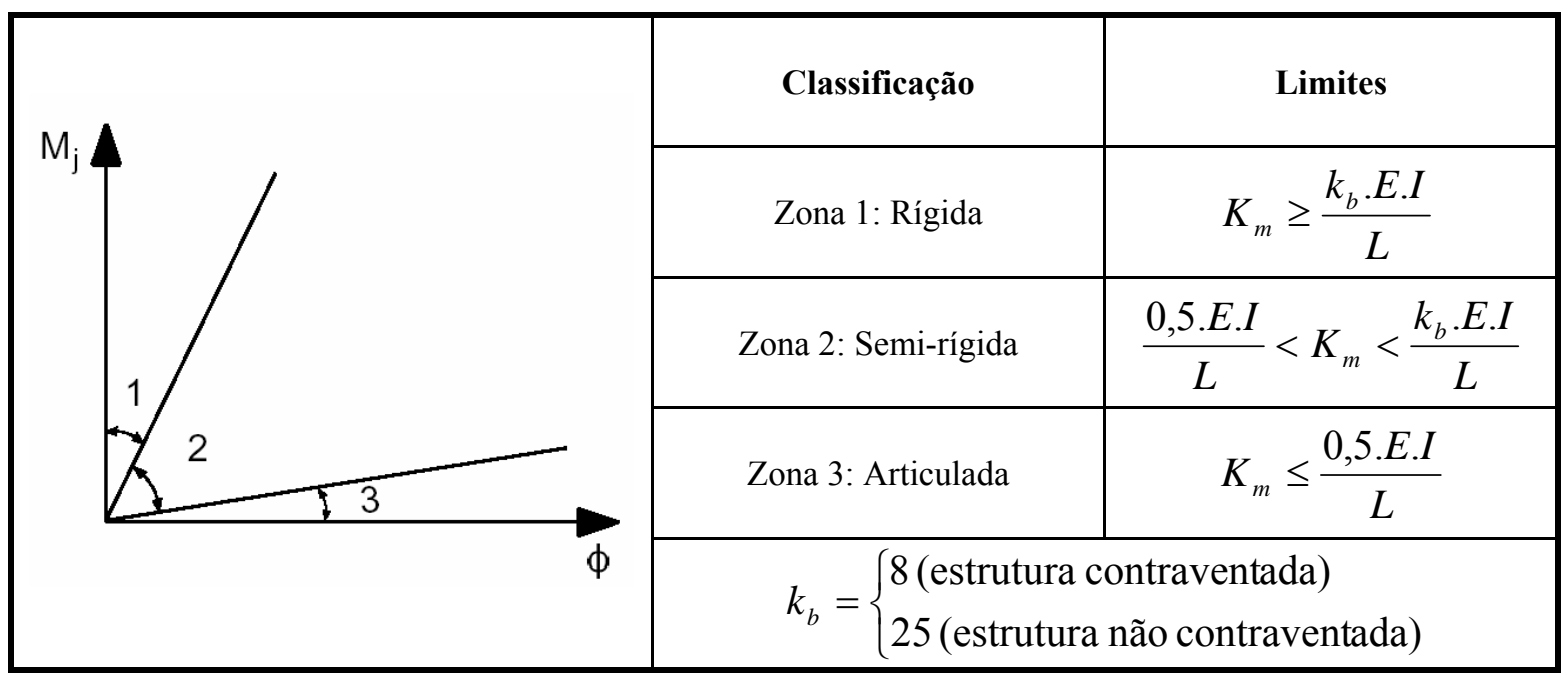

Quadro 4.1 - Limites de classificação da ligação quanto à rigidez (Fonte: adaptado de EUROCODE 3 (2002)).

Quanto à resistência a momento fletor, as ligações são classificadas como articuladas de resistência total e de resistência parcial (EUROCODE 3, 2002). As ligações articuladas devem apresentar resistência de cálculo a momento fletor $\left(\mathrm{M}_{\mathrm{j}, \mathrm{Rd}}\right)$ inferior a $25 \%$ da resistência requerida para a ligação de resistência total. Os critérios para a classificação da ligação como de resistência total estão definidos na Figura 4.2. As ligações de resistência parcial são aquelas que não se encaixam nos critérios dos dois outros tipos de ligação. Ressalta-se que Eurocode 3 (2002) está direcionado à análise de estruturas metálicas.

a) Topo do pilar

$$
\prod \mathrm{M}_{\mathrm{j}, \mathrm{Sd}} \quad \mathrm{e} / \mathrm{ou} \quad \begin{aligned}
& M_{\mathrm{j}, \mathrm{Rd}} \geq M_{\mathrm{b}, \mathrm{pl}, \mathrm{Rd}} \\
& M_{\mathrm{j}, \mathrm{Rd}} \geq M_{\mathrm{c}, \mathrm{pl}, \mathrm{Rd}}
\end{aligned}
$$

b) Intermediária ao pilar

$$
\prod \mathrm{M}_{\mathrm{j}, \mathrm{Sd}} \text { elou } \begin{aligned}
M_{\mathrm{j}, \mathrm{Rd}} & \geq M_{\mathrm{b}, \mathrm{p} \ell, \mathrm{Rd}} \\
M_{\mathrm{j}, \mathrm{Rd}} & \geq 2 M_{\mathrm{c}, \mathrm{pl}, \mathrm{Rd}}
\end{aligned}
$$

$M_{\mathrm{j}, \mathrm{Rd}} \quad$ - momento resistente de projeto da ligação

$M_{\mathrm{b}, \mathrm{pl}, \mathrm{Rd}}$ - momento de plastificação de projeto da viga

$M_{c, p \ell, R d}$ - momento de plastificação de projeto do pilar

Figura 4.2 - Ligação de resistência total (Fonte: adaptado do Eurocode 3 (2002)).

Ferreira, El Debs e Elliot (2002) ponderam que “... apenas a informação de que uma ligação é semi-rígida é algo genérico e não fornece critérios objetivos de desempenho para serem utilizados quer na análise ou no projeto de ligações semi-rígidas." Ferreira, El Debs e Elliot (2002) propõem uma classificação para ligações semi-rígidas em estruturas prémoldadas em função do fator de rigidez $\gamma$, que relaciona a rigidez da ligação $K_{\phi} \operatorname{com}$ a rigidez da viga. Esse fator é determinado pela Equação 4.1 e varia de 0 a 1 correspondendo às condições ideais de articulação e engastamento, respectivamente. 


$$
\gamma=\left[1+\frac{3 E I}{K_{\phi} L}\right]^{-1}
$$

Algumas relações entre momentos, rotações e deslocamentos (Equações 4.2, 4.3, 4.4 e 4.5) são expressas em função do fator de rigidez e se constituem em parâmetros para a classificação das ligações. A forma de classificação proposta por Ferreira, El Debs e Elliot (2002) está sintetizada na Figura 4.3.

$$
\begin{aligned}
& \frac{M_{E}}{M_{R}}=\left[\frac{3 \gamma}{2+\gamma}\right] \\
& \frac{M_{M S}}{M_{R}}=\left[\frac{3-1.5 \gamma}{2+\gamma}\right] \\
& \frac{\phi_{E}}{\theta_{R}}=1-\left[\frac{3 \gamma}{2+\gamma}\right] \\
& \frac{\delta_{M S}}{\delta_{R}}=\left[\frac{2-1.4 \gamma}{2+\gamma}\right]
\end{aligned}
$$

$M_{E}$ : momento modificado na extremidade da viga devido à ligação semi-rígida

$M_{R}:$ momento de engastamento no apoio

$M_{M S}$ : momento modificado no meio do vão

$\phi_{E}$ : rotação efetiva na extremidade da viga

$\theta_{R}$ : rotação livre na extremidade de uma viga bi-apoiada

$\delta_{M S}:$ flecha efetiva no meio do vão

$\delta_{R}$ : flecha para a condição de uma viga simplesmente apoiada

$\mathrm{Na}$ Figura 4.3, as zonas de classificação especificam:

Zona I: ligação articulada

Zona II: ligação semi-rígida com baixa resistência à flexão

Zona III: ligação semi-rígida com resistência média à flexão

Zona IV: ligação semi-rígida com alta resistência à flexão

Zona V: ligação rígida. 


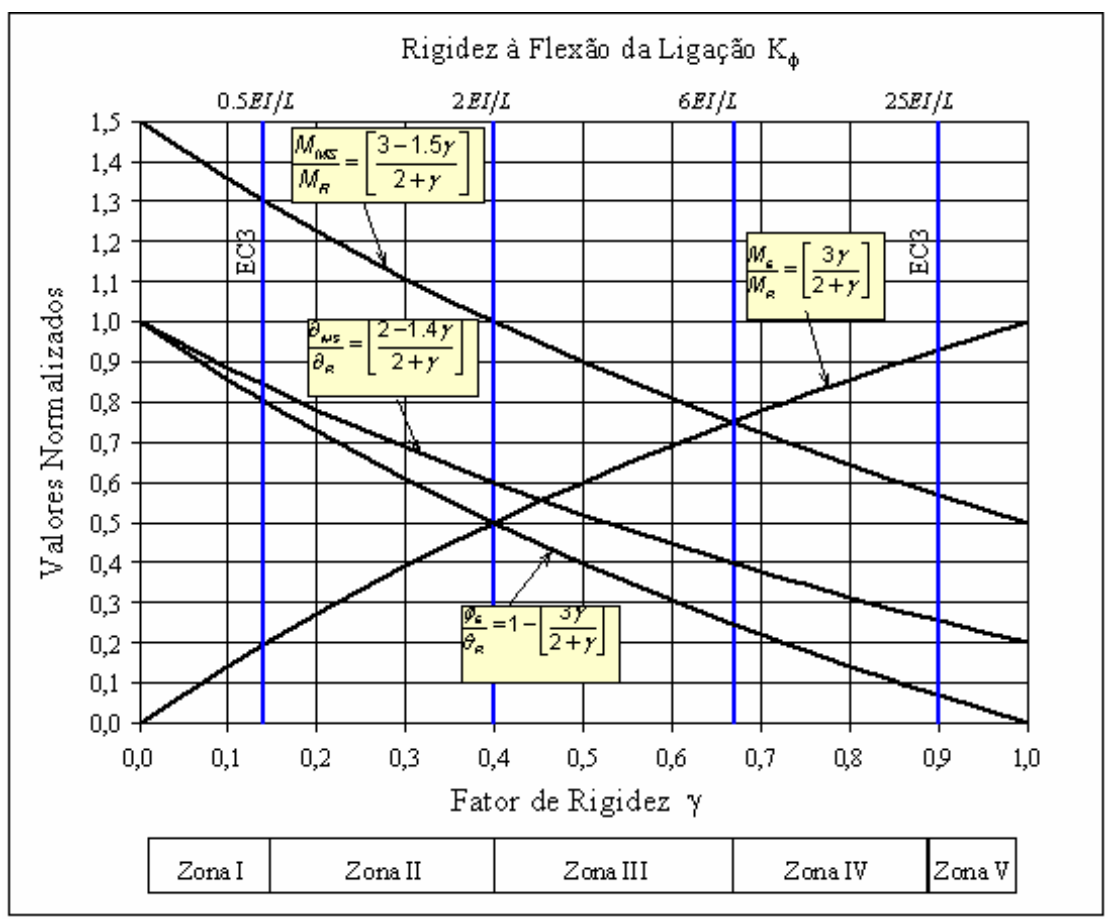

Figura 4.3 - Proposta de classificação para ligações semi-rígidas (Fonte: Ferreira, El Debs e Elliot (2002)). 


\section{CAPÍTULO 5}

\section{REFORÇO DE LIGAÇÕES}

As manifestações patológicas que afetam as estruturas podem ter origens diversas, dentre as quais: erros de projeto e execução, alteração na funcionalidade da edificação, alteração das solicitações, ações excepcionais (ex.: terremotos, furacões). "Para cada origem há uma terapia mais adequada, embora o fenômeno e os sintomas possam ser os mesmos." (HELENE, 1992, p. 21).

Em estruturas de concreto armado, monolíticas ou pré-moldadas, a reabilitação é geralmente empregada nos elementos de viga e pilar que a compõem. Certamente, para a maioria dos casos é o procedimento mais prático a adotar. Entretanto, se a questão a ser corrigida está relacionada ao comportamento global da estrutura, o reforço das ligações entre vigas e pilares deve ser considerado. Sobretudo, para estrutura de concreto pré-moldado, em que o desempenho das ligações é algo cercado de incertezas. Um obstáculo inerente a essa opção é a acessibilidade limitada à ligação e a dificuldade de execução do reforço.

$\mathrm{Na}$ pesquisa bibliográfica realizada, foram encontrados poucos estudos voltados ao reforço de ligações, em sua maioria, aplicados à adequação de estruturas monolíticas a condições sísmicas (seismic retrofit) e à reabilitação de estruturas danificadas por terremotos. A justificativa para isto está no fato de que estruturas antigas de paises sujeitos a sismos foram projetadas segundo normas que não previam detalhamento para as ligações que contemplasse esse tipo de solicitações. Engindeniz, Kahn e Zureick (2005) destacam que as primeiras recomendações para o projeto de ligações viga-pilar de concreto armado foram publicadas em 1976 nos EUA e em 1982 na Nova Zelândia. Sendo assim, muitas das construções anteriores a 1976 apresentam comportamento deficiente das ligações. Prota et al. (2004) afirmam que, em zonas sujeitas a ações sísmicas, o reforço de estruturas é um 
problema que envolve questões sociais e técnicas. Uma vez que essas estruturas foram projetadas originalmente para suportar somente cargas gravitacionais, falta- lhes ductilidade e hierarquia de resistência que induzam mecanismos de ruptura apropriados para condições sísmicas. O ACI ASCE Committee $352^{9}$ (2002, apud ENGINDENIZ, KAHN E ZUREICK, 2005) ressalta que métodos para incremento do desempenho de ligações antigas precisam ser estudados e que escassas informações sobre reparo e reforço de ligações estão disponíveis.

Engindeniz, Kahn e Zureick (2005) apresentam um levantamento das principais técnicas utilizadas no reforço de ligações viga-pilar explicitando suas vantagens e desvantagens:

- Reparo por injeção de epóxi: consiste no fechamento das trincas do concreto por meio da injeção de epóxi por pressão ou impregnação a vácuo (Figura 5.1). A confiabilidade da técnica é questionável. Não é aplicável quando há presença de vigas transversais e não é capaz de restabelecer por completo a aderência entre armadura e concreto;

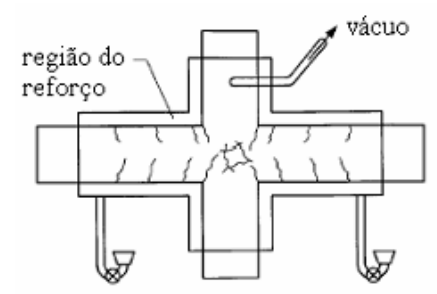

(a) as válvulas de entrada são fechadas e é feito vácuo

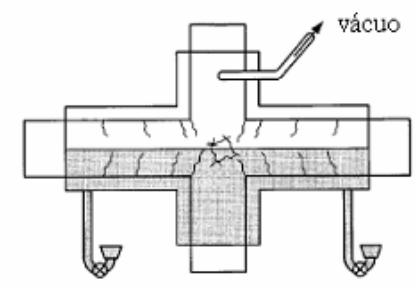

(b) as válvulas de entrada são abertas e o epóxi é injetado até completa submersão

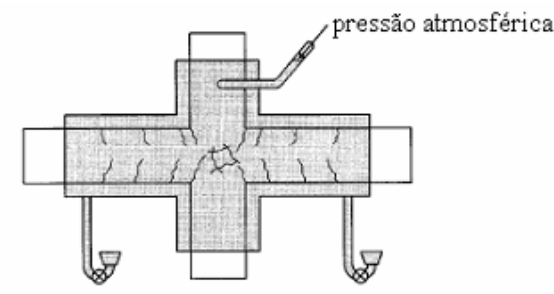

(c) as válvulas de entrada são fechadas e o vácuo é aliviado

Figura 5.1 - Procedimento de injeção a vácuo (Fonte: adaptado de French, Thorp e Tsai (1990)).

- Remoção e recolocação: opção única para ligações excessivamente danificadas apresentando alto grau de fissuração do concreto, armadura longitudinal encurvada ou armadura transversal rompida. Implica na retirada da parte danificada da estrutura e substituição por novos materiais. Deve-se garantir a aderência entre os concretos novo e antigo. Técnica altamente laboriosa, mas por vezes inevitável;

- Encamisamento com concreto: enquadra-se entre as técnicas mais recentes e mais utilizadas. Consiste no encamisamento do pilar com concreto ao longo da ligação, com acréscimo de novas armaduras longitudinais e transversais. Promove

\footnotetext{
9 Joint ACI-ASCE Committee 352, Recommendations for Design of Beam-Column Connections in Monolithic Reinforced Concrete Structures (ACI 352R-02), American Concrete Institute, Farmington Hills, Mich., 2002, 37 pp.
} 
aumento de resistência, afasta o ponto de ruptura para a viga, aumenta a resistência lateral global e a dissipação de energia. É, entretanto, de execução trabalhosa. Exige perfuração de vigas e corte de lajes. Acrescenta massa, o que resulta na diminuição da freqüência natural da estrutura e no aumento da carga nas fundações;

- Encamisamento por alvenaria estrutural: estudos analíticos mostram que ligações viga-pilar monolíticas reforçadas por encamisamento por alvenaria estrutural podem apresentar desejável modo de ruptura dúctil na viga. Não há dados experimentais que validem essa constatação. A execução desse tipo de reforço tem as mesmas desvantagens do encamisamento por concreto.

- Encamisamento por elementos metálicos: consiste basicamente no encamisamento por chapas de aço, soldadas ao redor da ligação, com espaço entre a chapa e o concreto preenchido por graute não retrátil ou argamassa expansiva. As partes metálicas são frequentemente ancoradas mecanicamente ao concreto para aumentar o confinamento. Pode ser executado também pela fixação das placas ao concreto com adesivo ou parafusos e conexão destas por cantoneiras. Quando comparado ao encamisamento por concreto ou alvenaria, apresenta tempo de execução reduzido devido à pré-fabricação. Entretanto, possui alto potencial de corrosão, dificuldade de manuseio de placas pesadas, prejuízo à estética, perda de espaço em alguns casos. Pode resultar em excessivo aumento na capacidade de carga, mesmo quando apenas o confinamento é pretendido, e conduzir a modo de falha inesperado.

- Compósitos poliméricos reforçados com fibras: tem o custo inicial elevado superado pelas vantagens: alta relação entre resistência e peso, resistência a corrosão, facilidade de aplicação (incluindo limitada interrupção na ocupação da construção), baixa alocação de trabalho, insignificante acréscimo nas dimensões originais. São mais atrativos por sua versatilidade; a orientação das fibras em cada camada pode se ajustar a objetivos específicos de reforço como aumentar somente a resistência, aumentar somente o confinamento ou ambos. O reforço por colagem externa pode eliminar algumas limitações importantes das outras técnicas (dificuldades construtivas e acréscimo nas dimensões) e ainda aumentar a resistência ao cisalhamento e deslocar o modo de falha para mecanismo dúctil de formação de rótula plástica na viga. A maioria dos estudos mostra comportamento 
dominado pelo descolamento do reforço do substrato e indicam necessidade de desenvolvimento da preparação da superfície bem como de métodos confiáveis de ancoragem mecânica que levem ao confinamento efetivo da ligação e completo desenvolvimento da resistência das fibras.

Sobre o uso de da técnica NSM no reforço de ligações, apenas uma pesquisa foi encontrada na revisão bibliográfica realizada. Prota et al. (2001) enfocam o reforço de ligações viga-pilar de estruturas subdimensionadas em relação a solicitações sísmicas. A metodologia proposta para o reforço tem como critério diretor o estabelecimento de uma hierarquia de resistência. Pelo aumento da resistência dos elementos da estrutura cuja ruptura é indesejável em maior grau, é possível obter um desempenho global caracterizado pela ruptura mais dúctil e com maior dissipação de energia. A ruptura de pilares é a menos desejável. Reforçando-se um pilar pode-se deslocar a ruptura para a ligação. Contudo, se a ligação apresenta ruptura frágil por cisalhamento, sua influência no desempenho global deve ser avaliada para compreender o acréscimo ou redução que ela provê em termos de dissipação de energia na estrutura. Reforçando-se a ligação alcança-se a ruptura na viga que é o melhor resultado esperado para um reforço sísmico.

A técnica proposta por Prota et al. (2004), denominada por reforço seletivo, baseia-se em diferentes combinações do reforço por colagem externa de PRF e na colagem de barras de PRF em entalhes no concreto de cobrimento, para obtenção de diferentes comportamentos estruturais. A colagem externa deve ser utilizada para confinamento dos pilares e acréscimo da ductilidade, aumentando o desempenho do concreto comprimido. Pode também ser empregado na região da junta (o termo junta em Prota et al. (2004) designa o trecho comum a vigas e pilares) para aumentar sua resistência ao cisalhamento. A colagem de barras de PRF em entalhes no concreto de cobrimento pode ser empregada ao longo do pilar para aumentar sua resistência à flexão. A presença simultânea de confinamento pelo laminado colado externamente previne que o reforço colado em entalhes torne-se ineficiente pela inversão no carregamento. Para validar a metodologia proposta, Prota et al. (2004) desenvolveram um programa experimental composto por ensaios em 11 modelos de ligação viga-pilar de interior da edificação. Os parâmetros investigados foram: a carga axial nos pilares (P), o tipo e a quantidade de reforço. O Quadro 5.1 resume as características dos modelos. 


\begin{tabular}{|c|c|c|c|c|c|c|c|}
\hline \multirow[b]{2}{*}{ Modelo } & \multirow[b]{2}{*}{$\begin{array}{c}\text { Carga } \\
\text { axial } \\
(\mathbf{k N})\end{array}$} & \multirow[b]{2}{*}{$\begin{array}{c}\text { Tipo da } \\
\text { barra } \\
\text { inserida }\end{array}$} & \multicolumn{2}{|c|}{ Pilar } & \multicolumn{3}{|c|}{ Junta / Viga } \\
\hline & & & $\begin{array}{l}\text { Colagem } \\
\text { externa }\end{array}$ & $\begin{array}{c}\text { Colagem } \\
\text { em } \\
\text { entalhes }\end{array}$ & $\begin{array}{c}\text { || ao eixo } \\
\text { da viga }\end{array}$ & $\begin{array}{c}\perp \text { ao } \\
\text { eixo da } \\
\text { viga }\end{array}$ & $\begin{array}{c}\text { Barra inserida } \\
\text { || ao eixo da } \\
\text { viga }\end{array}$ \\
\hline L1 & 124,5 & - & - & - & - & - & - \\
\hline $\mathrm{L} 2$ & 124,5 & - & $X$ & - & - & - & - \\
\hline L3 & 124,5 & 1 & $X$ & $\mathrm{X}$ & - & - & - \\
\hline L4 & 124,5 & 2 & $X$ & $\mathrm{X}$ & - & $X$ & $\mathrm{X}$ \\
\hline H1 & 249 & - & - & - & - & - & - \\
\hline $\mathrm{H} 2$ & 249 & - & $X$ & - & - & - & - \\
\hline $\mathrm{H} 2 \mathrm{U}$ & 249 & - & $\mathrm{X}$ & - & - & - & - \\
\hline H3 & 249 & 1 & $\mathrm{X}$ & $\mathrm{X}$ & - & - & - \\
\hline $\mathrm{H} 4$ & 249 & 2 & $\mathrm{X}$ & $\mathrm{X}$ & - & $\mathrm{X}$ & $\mathrm{X}$ \\
\hline H5 & 249 & 1 & $\mathrm{X}$ & $\mathrm{X}$ & $\mathrm{X}$ & $\mathrm{X}$ & - \\
\hline M3 & 373,5 & 2 & $\mathrm{X}$ & $\mathrm{X}$ & - & - & - \\
\hline
\end{tabular}

Quadro 5.1 - Características dos modelos (Fonte: adaptado de Prota et al. (2004)).

Os modelos L1 e H1 são modelos de referência, sem reforço. L2, H2 e H2U (Tipo 2) representam o primeiro nível de reforço pretendido em que se prioriza o deslocamento da ruptura do pilar para a junta. H2U tem a configuração de reforço igual a H2, porém este modelo foi executado com dois estribos a menos para simular uma deficiência de confinamento. Posicionaram-se barras em entalhes ao longo do pilar em L3, H3 e M3 (Tipo 3). Em L4 e H4 (Tipo 4) reforçaram-se também as juntas e posicionaram-se barras de PRF em entalhes no concreto de cobrimento paralelamente ao eixo da viga. Nos modelos com reforço dos Tipos 3 e 4, executou-se a colagem de reforço em "U" para ancorar as barras coladas em entalhe, na direção paralela ao eixo da viga. O modelo H5 (Tipo 5) teve a configuração de reforço igual a H4 exceto pelo reforço externo na direção paralela ao eixo da viga ao invés das barras inseridas. Os tipos de reforço empregados estão ilustrados na Figura 5.2. 


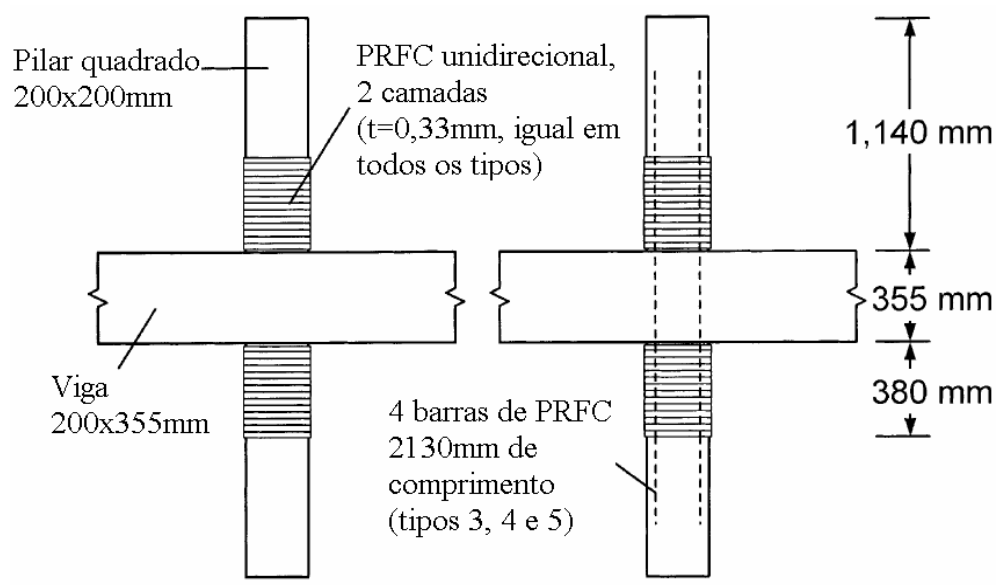

Tipo 2

Tipo 3

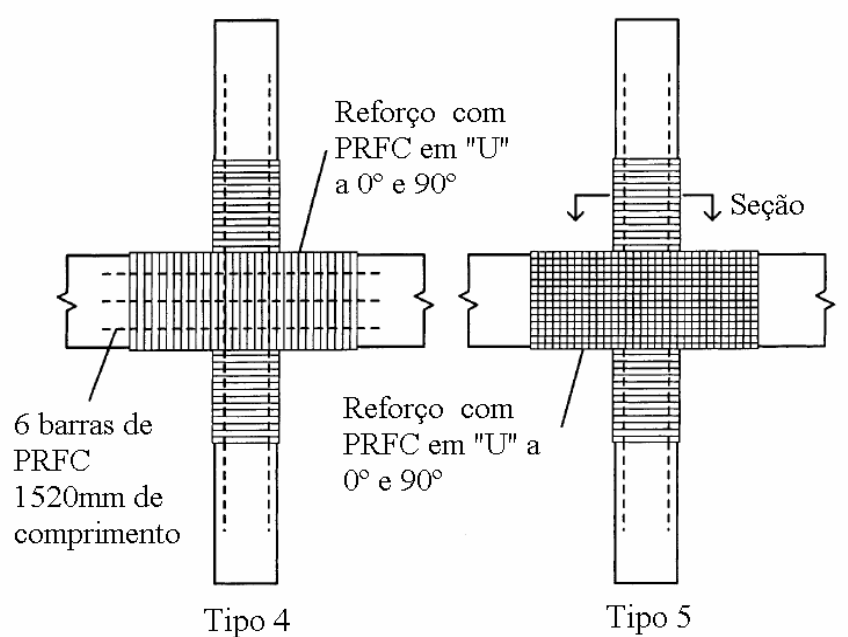

Barras de PRFC coladas em entalhes $(\Phi=8$ ou $9,5 \mathrm{~mm})$

\begin{tabular}{|l||l|l||}
\hline Entalhes & 0 \\
preenchidos com & $\vdots$ & 0 \\
epóxi & $\vdots$ & $\vdots$ \\
\hline
\end{tabular}

Seção (Tipos 3, 4 e 5)

Figura 5.2 - Tipos de reforço empregados nos modelos de ligação (Fonte: adaptado de Engindeniz, Kahn e Zureick (2005)).

Os ensaios foram realizados nos modelos "deitados" no piso do laboratório. Dois cilindros de aço nas extremidades de ambos os pilares simularam uma condição de articulação. $\mathrm{Na}$ extremidade correspondente ao pilar superior foi aplicada uma carga axial constante $(\mathrm{P})$ e na extremidade correspondente ao pilar inferior posicionou-se uma célula de carga para obtenção das reações ao longo da execução do ensaio. Duas cargas adicionais eram aplicadas independentemente nas extremidades das vigas. Inicialmente, aplicavam-se cargas representativas de carregamento gravitacional nas extremidades das vigas e no pilar (Figura 5.4-a). Posteriormente, duas cargas nas vigas alternaram-se ciclicamente, representando uma condição sísmica (Figura 5.4-b e Figura 5.4-c). 


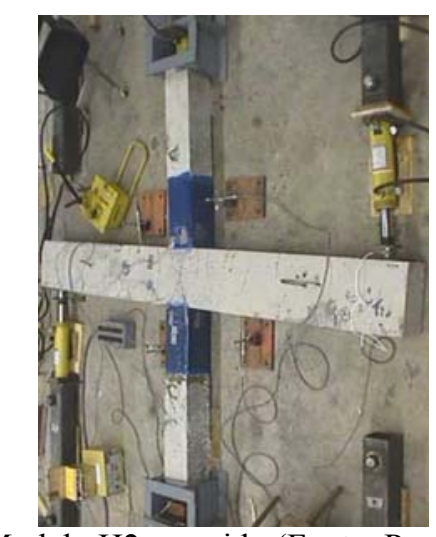

Figura 5.3 - Modelo H2 rompido (Fonte: Prota et al. (2001)).

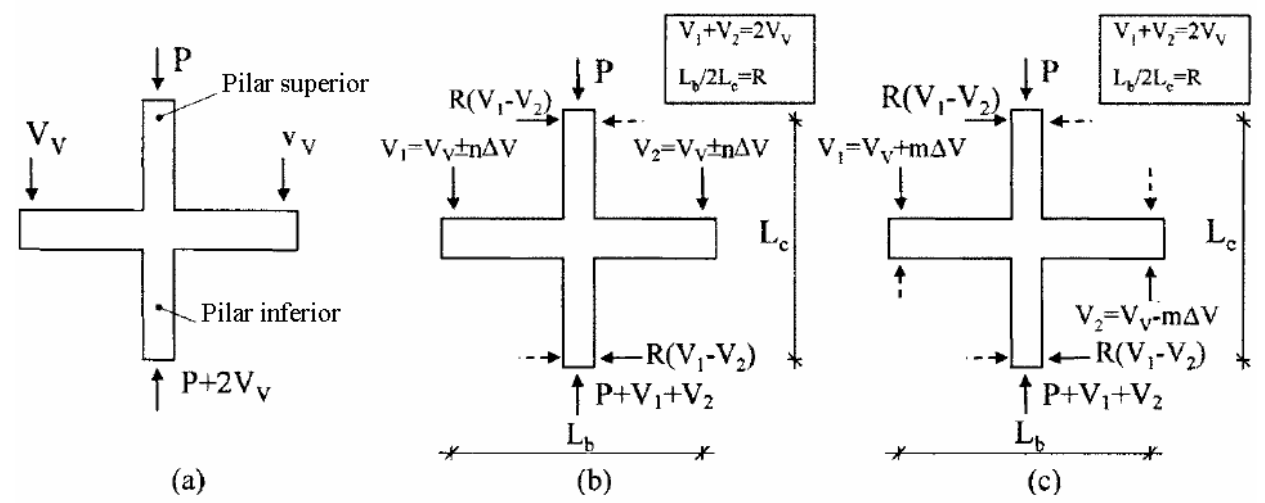

Figura 5.4 - Esquema de carregamento: (a) cargas gravitacionais; (b) carregamento sísmico antes da inversão de momento nas vigas e (c) carregamento sísmico após a inversão de momento nas vigas (Fonte: adaptado de Prota et al. (2004)).

Na Tabela 5.1, estão resumidos os resultados dos ensaios experimentais. Os modelos de referência romperam por esmagamento do concreto no pilar. O reforço do tipo 2 moveu a ruptura da face comprimida para a face tracionada do pilar, para a carga axial mais baixa. Para os modelos ensaiados com a carga axial mais alta, observou-se ruptura na junta e no pilar. $\mathrm{O}$ tipo 3 de reforço moveu a ruptura do pilar para a junta. Nas ligações reforçadas com as configurações dos tipo 4 e 5, a ruptura se deu na interface entre o pilar e a junta. O reforço do tipo 2 aumentou a resistência da ligação entre $7 \%$ e 33\%. H2 e H2U apresentaram desempenho semelhante que indica a validade do reforço na correção da defíciência de confinamento do modelo H2U. Para o reforço do tipo 3, o aumento foi de $39 \%$ a $62 \%$. O reforço do tipo 4 proporcionou um incremento de resistência de 37\% a 83\%. Transdutores de deslocamentos posicionados nas vigas foram utilizados para a determinação do desvio angular. As alterações no desvio angular na ruptura para a carga axial mais baixa e mais alta foram: $-11 \%$ e $25 \%$ para modelos com reforço do tipo $2 ; 6 \%$ e $-14 \%$ para modelos com reforço do tipo 3 e 73 e $51 \%$ para modelos com reforço do tipo 4 . Os valores negativos indicam a perda de ductilidade. 
Tabela 5.1 - Sumário dos resultados experimentais (Fonte: adaptado de Prota et al. (2004)).

\begin{tabular}{cccccc}
\hline Junta & $\begin{array}{c}\text { fc' } \\
\text { (MPa) }\end{array}$ & Modo de ruptura & $\begin{array}{c}\text { Força } \\
\text { cisalhante } \\
\text { última (kN) }\end{array}$ & $\begin{array}{c}\text { Desvio angular } \\
\text { No início da } \\
\text { fissuração (\%) }\end{array}$ & $\begin{array}{c}\text { Na ruptura } \\
\text { (\%) }\end{array}$ \\
\hline L1 & 38,9 & Ruptura dos pilares por compressão & 41,18 & 0,30 & 3,11 \\
L2 & 39,8 & Ruptura dos pilares por tração & 44,21 & 0,27 & 2,76 \\
L3 & 38,9 & Ruptura por cisalhamento da junta & 57,24 & 0,56 & 3,30 \\
L4 & 36,5 & Interface pilar-junta & 56,60 & N/A & 5,38 \\
H1 & 31,7 & Ruptura dos pilares por compressão & 38,45 & 0,30 & 2,82 \\
H2 & 36,5 & Combinada pilar-junta & 49,70 & 0,35 & 3,50 \\
H2U & 36,5 & Combinada pilar-junta & 51,19 & 0,35 & 3,53 \\
H3 & 31,7 & Ruptura por cisalhamento da junta & 62,35 & 0,36 & 2,42 \\
H4 & 39,8 & Interface pilar-junta & 70,42 & N/A & 4,27 \\
M3 & 39,8 & Ruptura por cisalhamento da junta & 56,17 & 0,62 & 3,27 \\
\hline
\end{tabular}

Pantelides et al. (2003) apresentam a análise experimental de uma técnica para reabilitação sísmica (seismic retrofit) de estruturas de painéis portantes em concreto prémoldado. A proposta de reforço consistiu na colagem de mantas de fibra de carbono conectando os painéis e possibilitando a transferência de esforços cortantes. O modelo de ensaio foi composto de três painéis de concreto pré-moldado de 1,22 x 3,66 m com espessura de $203 \mathrm{~mm}$, mantidos em conjunto por uma cinta de aço posicionada no topo dos painéis. A cinta conectada a um atuador hidráulico submetia o modelo a carregamento lateral cíclico, simulando o efeito sísmico (Figura 5.5). As ligações (duas por modelo, uma vez que se tratava de três painéis) eram aplicadas em uma das faces do modelo.

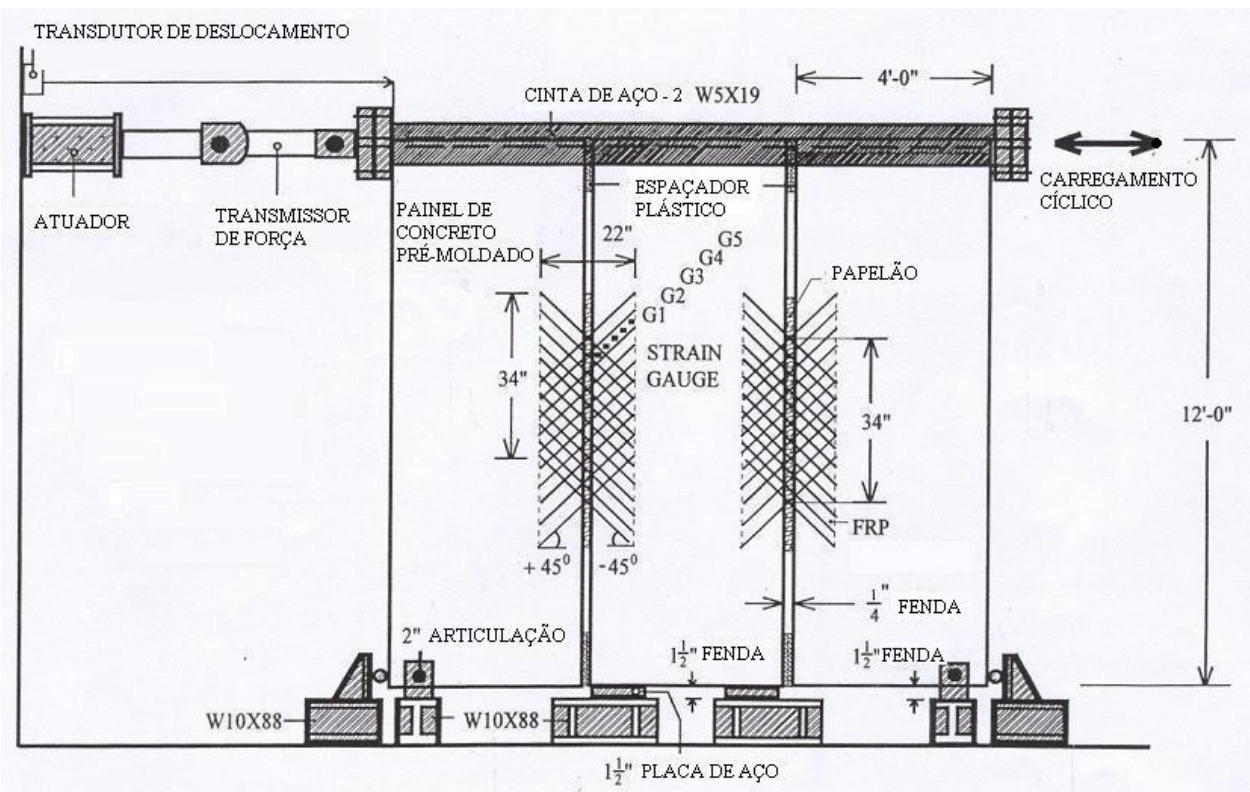

Figura 5.5 - Configuração esquemática do ensaio (Fonte: adaptado de Pantelides et al. (2003)). 
Antes de se executar o reforço com PRF, os modelos foram ensaiados com ligações em chapa de aço para que se obtivesse um comportamento referencial. Foram testadas dez configurações de ligação em PRF diferentes. Para nove delas, a preparação do substrato para recebimento do compósito consistiu no uso de jato de água, limpeza e aplicação de agente de colagem. Em apenas uma das ligações, a etapa de jateamento com água foi substituída por uma simples escovação da superfície. Além da preparação do substrato os modelos diferiram quanto ao tipo de fibra de carbono $(12 \mathrm{~K}$ e $48 \mathrm{~K})$, quanto à orientação das fibras $\left( \pm 60^{\circ} \mathrm{e} \pm 45^{\circ}\right)$, quanto ao número de camadas por ligação $(2,4$ e 6$)$ e quanto ao desenho final da ligação.

A resistência das ligações variou basicamente em função do tipo de PRF, da área da ligação, da resistência superficial do concreto, do comprimento de ancoragem efetivo das fibras e das condições da superfície de concreto. A capacidade de transmissão de esforço cortante original, correspondente à ligação com chapa de aço, foi acrescida de 17 a $40 \%$. Os resultados da pesquisa estão resumidos na Tabela 5.2

Tabela 5.2 - Resultados dos ensaios com conectores de PRFC (Fonte: adaptado de Pantelides et al. (2003))

\begin{tabular}{|c|c|c|c|c|c|c|c|c|c|}
\hline $\begin{array}{c}\mathrm{N}^{0} \text { do } \\
\text { modelo }\end{array}$ & $\begin{array}{c}\text { Tipo } \\
\text { da } \\
\text { fibra }\end{array}$ & $\begin{array}{l}\text { Tipo do } \\
\text { conector }\end{array}$ & $\begin{array}{c}\mathbf{N}^{\circ} \text { de } \\
\text { camadas } \\
\text { por } \\
\text { conector }\end{array}$ & $\begin{array}{c}\text { Espessura } \\
\text { do } \\
\text { conector } \\
(\mathrm{mm})\end{array}$ & $\begin{array}{c}\text { Área do } \\
\text { conector } \\
(\mathrm{mm} 2)\end{array}$ & $\begin{array}{l}\text { Preparo da } \\
\text { superfície }\end{array}$ & $\begin{array}{c}\text { Modo } \\
\text { de } \\
\text { ruptura }\end{array}$ & $\begin{array}{c}\text { Carga } \\
\text { de } \\
\text { ruptura } \\
(\mathbf{k N})\end{array}$ & $\begin{array}{c}\text { Desloc. } \\
\text { lateral } \\
(\mathbf{m m})\end{array}$ \\
\hline 1 & $12 \mathrm{~K}^{*}$ & Retangular & $6 @ \pm 60^{\circ}$ & 2,3 & 0,49 & Jato de água & Suporte & 182 & 13,2 \\
\hline 2 & $48 \mathrm{~K}$ & Borboleta & $2 @ \pm 45^{\circ}$ & 2,5 & 0,33 & Jato de água & Adesiva & 161 & 14,0 \\
\hline 3 & $12 \mathrm{~K}$ & Retangular & $4 @ \pm 45^{\circ}$ & 1,5 & 0,21 & Jato de água & Coesiva & 102 & 11,7 \\
\hline 4 & $48 \mathrm{~K}$ & Borboleta & $2 @ \pm 45^{\circ}$ & 2,5 & 0,58 & Jato de água & Suporte & 156 & 15,0 \\
\hline 6 & $48 \mathrm{~K}$ & Borboleta & $2 @ \pm 45^{\circ}$ & 2,5 & 0,68 & Escovamento & Adesiva & 69 & 16,8 \\
\hline 7 & $48 \mathrm{~K}$ & Borboleta & $2 @ \pm 45^{\circ}$ & 2,5 & 0,64 & Jato de água & Coesiva & 197 & 18,0 \\
\hline 8 & $48 \mathrm{~K}$ & Borboleta & $2 @ \pm 45^{\circ}$ & 2,5 & 0,64 & Jato de água & Coesiva & 155 & 15,0 \\
\hline 9 & $48 \mathrm{~K}$ & Borboleta & $2 @ \pm 45^{\circ}$ & 2,5 & 0,64 & Jato de água & Coesiva & 157 & 16,0 \\
\hline 10 & $48 \mathrm{~K}$ & Borboleta & $2 @ \pm 45^{\circ}$ & 2,5 & 0,83 & Jato de água & Coesiva & 147 & 16,5 \\
\hline
\end{tabular}

$* 1 \mathrm{~K}=1000$ fibras por filamento 


\section{CAPÍTULO 6}

\section{ENSAIOS DE ADERÊNCIA}

Diante do conhecimento relativamente escasso e da necessidade de inserção direta desta pesquisadora no estudo e na experimentação sobre o comportamento da aderência no reforço de estruturas por inserção de laminados, considerou-se importante a realização de um estudo de caracterização da aderência, com objetivo principal de avaliar a mobilização da capacidade resistente do compósito e definir um comprimento de ancoragem satisfatório para o modelo físico de ligação.

Uma discussão a respeito dos modelos de ensaio utilizados na caracterização da aderência foi apresentada no Capítulo 3. Neste trabalho, optou-se pela utilização de modelo de arrancamento em viga, baseado nas recomendações da RILEM-CEB-FIB (1973). A justificativa para essa escolha reside na possibilidade de se reproduzir nesse tipo de ensaio condições bastante semelhantes àquelas dos ensaios estáticos em modelos físicos de ligação, descritos no Capítulo 7. De fato, no próprio ensaio de aderência, o laminado trabalha como elemento de ligação de peças pré-moldadas. Contribuíram para essa decisão, a disponibilidade de equipamentos, dispositivos (rótula e apoios) e instrumentação no Laboratório de Estruturas da EESC, onde já se havia realizado esse tipo de ensaio, e a facilidade de manuseio dos elementos do modelo. Ao contrário do que afirmam De Lorenzis e Teng (2006) em relação aos modelos de arrancamento em viga tratam-se de modelos pequenos. Os blocos que compõem o modelo têm massa de aproximadamente $18 \mathrm{~kg}$, o que permite que sejam transportados sem grande esforço. Mesmo a massa do modelo completo, aproximadamente 36 $\mathrm{kg}$, não implica necessidade de utilização de máquinas para transporte, sendo facilmente manipulado por duas pessoas. Além disso, como a colagem dos laminados foi executada nas laterais do modelo, é possível a inspeção visual do reforço ao longo do ensaio. 
A princípio, não se pretendia que a resina utilizada na colagem dos laminados fosse uma variável no estudo da aderência. Contudo, a primeira opção de resina "Epóxi Estruturante FC", comercializada pela mesma empresa do laminado, apresentou resultados insatisfatórios nesta e em outras investigações realizadas paralelamente no Departamento de Estruturas da Escola de Engenharia de São Carlos. Por essa razão, são apresentados os resultados dos ensaios com dois tipos de resina: "Epóxi Estruturante FC", adquirido junto à empresa "Rogertec" e "Sikadur 330", fornecido pela empresa "Sika". Para a série de ensaios com uso da resina do primeiro tipo, é adotada a referência R1. A série de ensaios com a resina "Sikadur 330" é referenciada por R2.

A inadequação do epóxi estruturante, especificamente para o emprego proposto no presente trabalho, é antecipada nesta introdução do Capítulo 6 apenas para justificar o uso de dois tipos de resina no ensaio de aderência. A questão é discutida detalhadamente nos itens $6.4,6.6 .2,6.6 .6$ e 6.6.7.

\subsection{Características do modelo de ensaio}

A configuração do ensaio foi baseada nas recomendações da RILEM-CEB-FIB (1973) que originalmente se aplicam à caracterização da aderência de barras de aço, utilizadas como armadura em concreto. Foram feitas adaptações para que o ensaio melhor se adequasse ao material estudado, bem como à configuração de utilização proposta. Algumas dessas adaptações foram fundamentadas nos ensaios de Cruz (2004).

Conforme se pode observar na Figura 6.1, o modelo de ensaio consiste em dois blocos de concreto, A e B, unidos na parte superior por uma rótula e na parte inferior por laminados inseridos em entalhes no concreto de cobrimento lateral. Os entalhes foram executados com dimensões aproximadas de $18 \mathrm{~mm}$ de profundidade e $5 \mathrm{~mm}$ de largura, a uma altura de 50 $\mathrm{mm}$ a partir do fundo do modelo. A região de teste se restringiu ao bloco A no qual se variou o comprimento de ancoragem $\left(\ell_{\mathrm{a}}\right)$. No bloco $\mathrm{B}$, foi mantido comprimento de ancoragem fixo igual a $325 \mathrm{~mm}$, suficiente para impedir o deslizamento do laminado em relação ao concreto neste bloco. Foram estudados nos ensaios da série R1, os comprimentos de 90, 120 e $150 \mathrm{~mm}$. Na série R2, os comprimentos foram de 70, 140 e 210 mm. Para ambas as séries, utilizaramse dois modelos para cada comprimento de ancoragem estudado. O Quadro 6.1 sintetiza as características dos modelos de ensaio. A armadura adotada nos blocos está detalhada na Figura 6.2. 


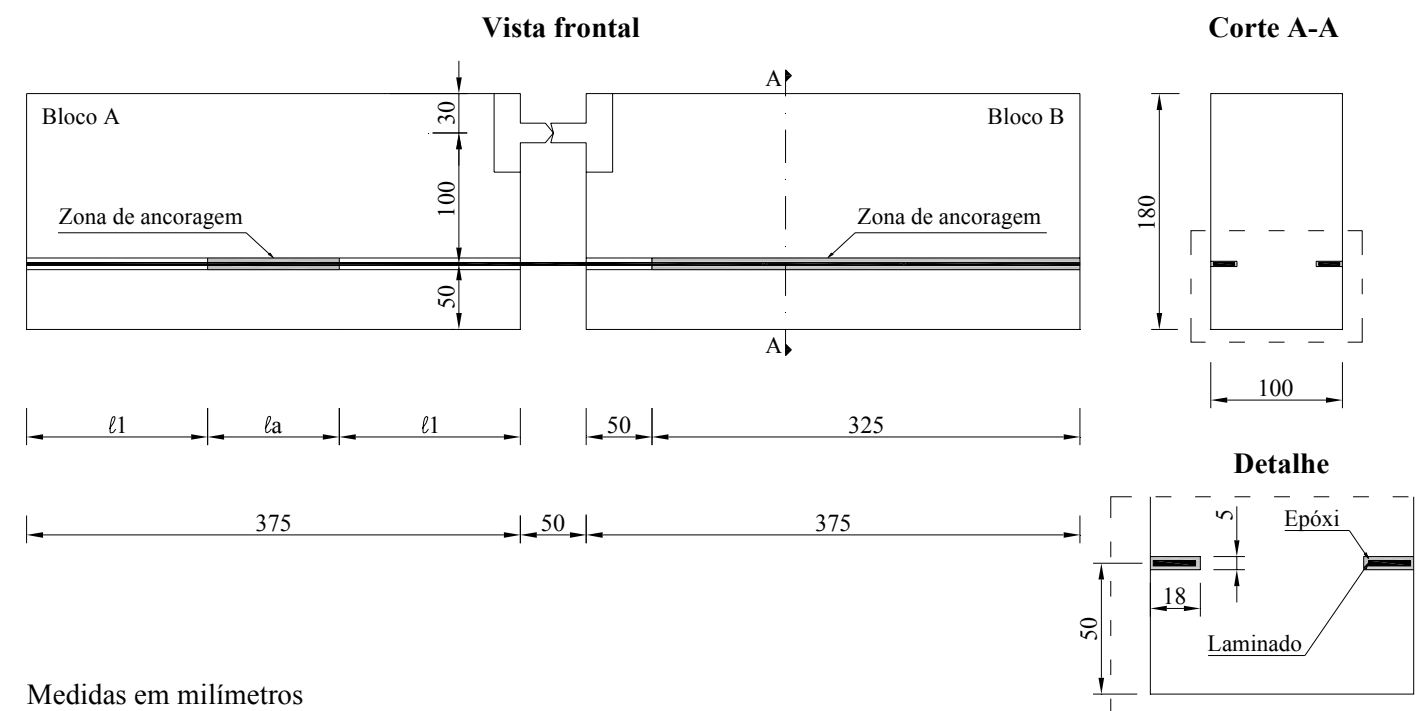

Figura 6.1 - Características geométricas do modelo.

\begin{tabular}{|c|c|c|c|}
\hline Série & Resina & Comprimento de ancoragem (mm) & Modelo \\
\hline \multirow{6}{*}{$\mathrm{R} 1$} & \multirow{6}{*}{ Epóxi Estruturante FC } & \multirow{2}{*}{90} & M1L90R1 \\
\hline & & & M2L90R1 \\
\hline & & \multirow{2}{*}{120} & M1L120R1 \\
\hline & & & M2L120R1 \\
\hline & & \multirow{2}{*}{150} & M1L150R1 \\
\hline & & & M2L150R1 \\
\hline \multirow{6}{*}{$\mathrm{R} 2$} & \multirow{6}{*}{ Sikadur ${ }^{\circledR} 330$} & \multirow{2}{*}{70} & M1L70R2 \\
\hline & & & M2L70R2 \\
\hline & & \multirow{2}{*}{140} & M1L140R2 \\
\hline & & & M2L140R2 \\
\hline & & \multirow{2}{*}{210} & M1L210R2 \\
\hline & & & M2L210R2 \\
\hline
\end{tabular}

Quadro 6.1 - Características dos modelos de ensaio.

No Quadro 6.1, os modelos de ensaio são referenciados por nomenclatura do tipo $\mathrm{M} \underline{\boldsymbol{a}} \mathrm{L} \underline{\boldsymbol{b}} \mathrm{R} \underline{\boldsymbol{c}}$ onde o campo $\underline{\boldsymbol{a}}$ define o número do modelo (o valor de $\underline{\boldsymbol{a}}$ pode ser 1 ou 2 uma vez que sempre foram ensaiados dois modelos por comprimento estudado), o campo $\underline{\boldsymbol{b}}$ define o comprimento de ancoragem estudado e o campo $\underline{\underline{c}}$ define a que série pertence o ensaio. 


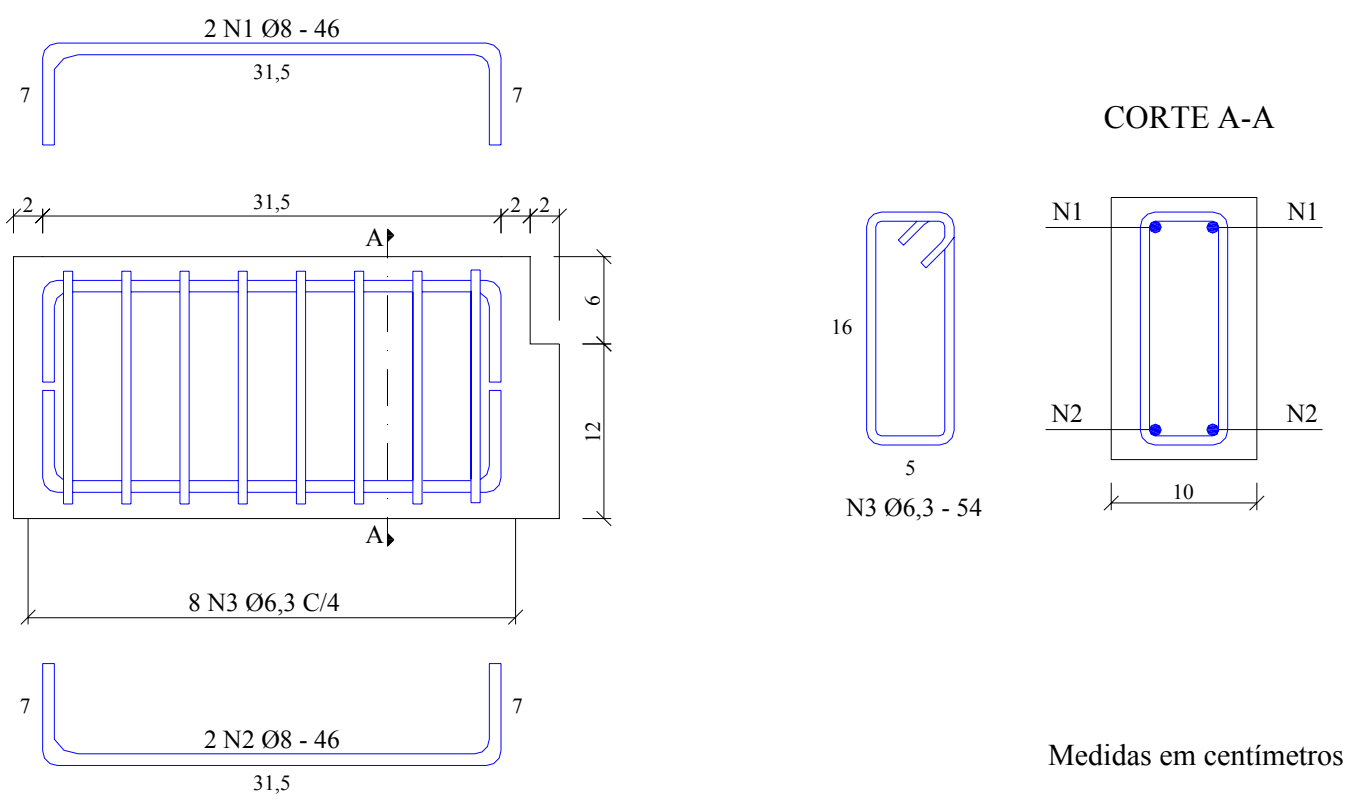

Figura 6.2 - Detalhamento da armadura empregada nos modelos de ensaio de aderência.

\subsection{Propriedades dos materiais}

\subsubsection{Aço}

Utilizou-se aço CA50 para confecção das armaduras. A determinação das propriedades do aço à tração foi realizada e acordo com a NBR 6152 (1980). Não foi feita a caracterização das barras de aço com diâmetro igual a $6,3 \mathrm{~mm}$ usadas na armadura dos modelos da série R1. Foram utilizados três corpos-de-prova de $1 \mathrm{~m}$ de comprimento para a determinação das propriedades de cada tipo de barra. Nos ensaios com as barras de $8 \mathrm{~mm}$ de diâmetro, obteve-se diagrama "tensão x deformação" com patamar de escoamento bem definido, o que não ocorreu para as barras de $6,3 \mathrm{~mm}$ de diâmetro, conforme se pode observar na Figura 6.3-b e na Figura 6.3-a. A tensão de escoamento para as barras de 6,3 mm, apresentada na Tabela 6.1, corresponde a uma tensão sob a qual sendo descarregada a peça restaria uma deformação residual de $2 \%$. A deformação no escoamento $\varepsilon_{\mathrm{y}}{ }^{*}$ foi obtida do diagrama simplificado proposto pela NBR 6118 (2003) (Figura 6.3-a). Os ensaios de caracterização foram realizados na máquina universal de ensaios servo-hidráulica INSTRON com sistema de aquisição de dados System 5000 da Vishay. As deformações foram obtidas por meio de clip gages (calibres instrumentados com extensômetros elétricos). 
Tensão X Deformação (CP2 - R2)

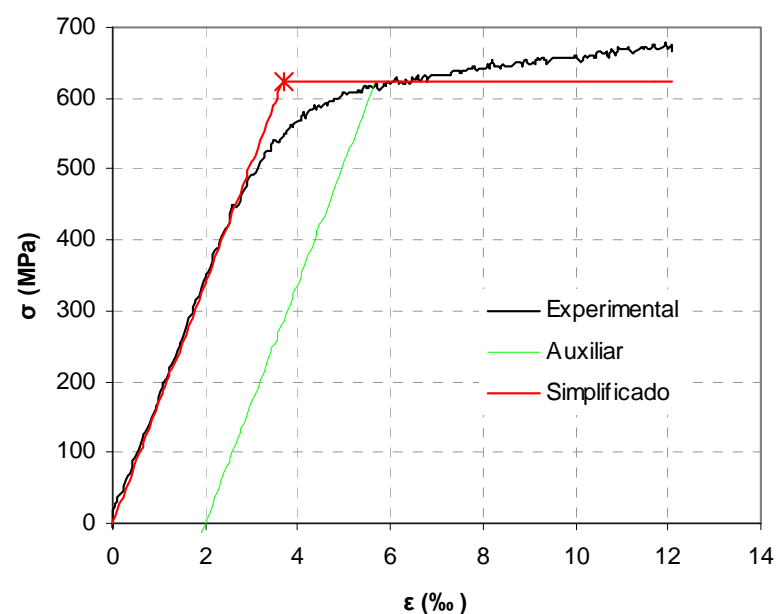

(a)
Tensão X Deformação (CP3 - R2)

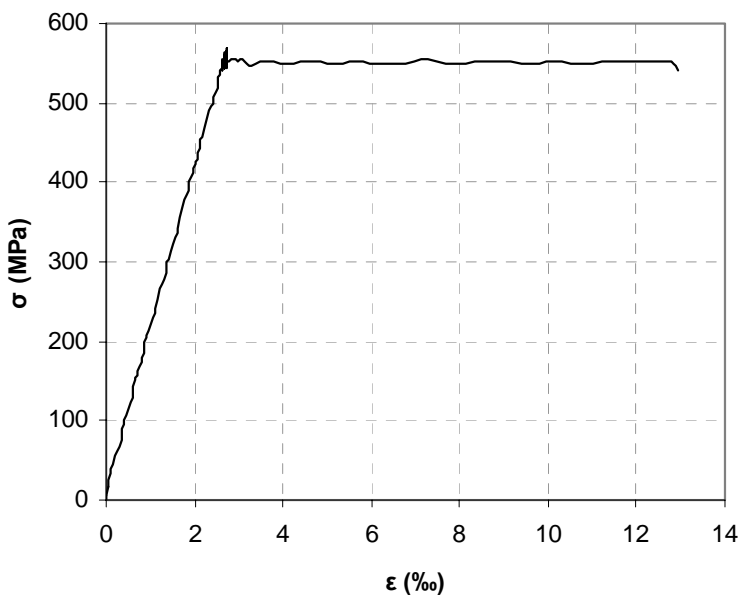

(b)

Figura 6.3 - Diagramas “tensão x deformação": (a) barras de 6,3 mm de diâmetro; (b)barras de 8 mm de diâmetro.

Tabela 6.1 - Propriedades das armaduras de aço utilizadas nos modelos de ensaio de aderência.

\begin{tabular}{|c|c|c|c|c|c|c|c|}
\hline $\begin{array}{l}\text { Série de } \\
\text { ensaios }\end{array}$ & $\begin{array}{c}\text { Diâmetro } \\
\text { (mm) }\end{array}$ & Corpo-de-prova & $\begin{array}{c}\mathbf{E}_{\mathbf{s}} \\
(\mathrm{GPa})\end{array}$ & $\begin{array}{c}\mathbf{f}_{\mathbf{y}} \\
(\mathbf{M P a})\end{array}$ & $\begin{array}{c}\varepsilon_{y} \\
(\% o)\end{array}$ & $\begin{array}{l}\varepsilon_{\mathrm{y}}^{*} \\
(\%)\end{array}$ & $\begin{array}{c}\mathbf{f}_{\mathrm{u}} \\
(\mathrm{MPa})\end{array}$ \\
\hline \multirow{5}{*}{ R1 } & \multirow{5}{*}{8} & 1 & 210 & 548 & 2,61 & - & 669 \\
\hline & & 2 & 218 & 601 & 2,75 & - & 691 \\
\hline & & 3 & 206 & 649 & 3,15 & - & 736 \\
\hline & & Média & 211 & 599 & 2,84 & - & 699 \\
\hline & & $\begin{array}{l}\text { Coeficiente de } \\
\text { variação }\end{array}$ & $3,0 \%$ & $8,4 \%$ & $9,9 \%$ & - & $4,9 \%$ \\
\hline \multirow{10}{*}{$\mathrm{R} 2$} & \multirow{5}{*}{6,3} & 1 & 204 & 646 & 5,18 & 3,18 & 828 \\
\hline & & 2 & 169 & 623 & 5,68 & 3,68 & 812 \\
\hline & & 3 & 176 & 609 & 5,46 & 3,46 & 825 \\
\hline & & Média & 183 & 626 & 5,44 & 3,44 & 822 \\
\hline & & $\begin{array}{l}\text { Coeficiente de } \\
\text { variação }\end{array}$ & $9,9 \%$ & $3,1 \%$ & $4,6 \%$ & $7,3 \%$ & $1,0 \%$ \\
\hline & \multirow{5}{*}{8} & 1 & 212 & 561 & 2,65 & - & 664 \\
\hline & & 2 & 202 & 558 & 2,77 & - & 665 \\
\hline & & 3 & 204 & 556 & 2,73 & - & 625 \\
\hline & & Média & 206 & 558 & 2,71 & - & 651 \\
\hline & & $\begin{array}{l}\text { Coeficiente de } \\
\text { variação }\end{array}$ & $2,5 \%$ & $0,5 \%$ & $2,1 \%$ & - & $3,5 \%$ \\
\hline
\end{tabular}




\subsubsection{Concreto}

Para confecção dos modelos da série de ensaio R1, foi utilizado concreto de cimento comum com traço em massa de 1:1,26:2,27, relação água/cimento de 0,445 e resistência à compressão prevista para $45 \mathrm{MPa}$. $\mathrm{Na}$ elaboração do concreto dos modelos da série R2, utilizou-se cimento de alta resistência inicial. Para esse concreto, o traço foi de 1:2,3:2,3, com relação água/cimento de 0,5 e resistência à compressão prevista para 28 dias de $50 \mathrm{MPa}$. O consumo de materiais por metro cúbico dos concretos usados na série R1 e na R2 estão discriminados respectivamente na Tabela 6.2 e Tabela 6.3.

Tabela 6.2 - Consumo de materiais por metro cúbico para o concreto utilizado na série de ensaio R1.

\begin{tabular}{cc}
\hline Material & Consumo $\left(\mathbf{k g} / \mathbf{~ m}^{\mathbf{3}}\right)$ \\
\hline Cimento CP II E 32 - ITAU & 445,5 \\
Areia seca & 561,33 \\
Brita 1 & 1011,28 \\
Água & 198,25 \\
\hline
\end{tabular}

Tabela 6.3 - Consumo de materiais por metro cúbico para o concreto utilizado na série de ensaio R2.

\begin{tabular}{cc}
\hline Material & Consumo $\left(\mathbf{k g} / \mathbf{~ m}^{\mathbf{3}}\right)$ \\
\hline Cimento CP IV ARI PLUS & 400 \\
Areia seca & 920 \\
Brita 1 & 920 \\
Água & 200 \\
\hline
\end{tabular}

A determinação da resistência à compressão do concreto foi realizada com base na NBR 5739 (1994) e a determinação da resistência à tração com base na NBR 7222 (1994). Para caracterização do concreto utilizado na série de ensaio R1, utilizaram-se corpos-de-prova cilíndricos com dimensões de $15 \mathrm{~cm}$ de diâmetro e $30 \mathrm{~cm}$ de altura. Para caracterização do concreto usado na série R2, foram adotados corpos-de-prova de $10 \mathrm{~cm}$ de diâmetro e $20 \mathrm{~cm}$ de altura. A resistência à compressão calculada para os CPs de $10 \mathrm{~cm}$ x $20 \mathrm{~cm}$ foi multiplicada por um fator de redução de 0,95 para se equivaler à resistência de CPs de $15 \mathrm{~cm}$ x $30 \mathrm{~cm}$ (segundo especificações do Concrete Manual*, 1975 apud MEHTA e MONTEIRO, 1994), que são as dimensões propostas na NBR 5739 (1994). O módulo de elasticidade foi

\footnotetext{
* “Concrete Manual”, US Bureau of Reclamation, 1975, p. 574-75.
} 
determinado apenas para o concreto utilizado na série R2. A determinação do módulo foi feita nos mesmos CPs submetidos a ensaio de compressão. As deformações foram obtidas por meio de extensômetros removíveis, com base de medida de $10 \mathrm{~cm}$, posicionados em pontos diametralmente opostos em relação à seção do $\mathrm{CP}$ com os cursos de leitura centralizados em relação à altura (Figura 6.4). Na elaboração do diagrama "tensão x deformação", utilizou-se a média das deformações lidas nos dois extensômetros. O módulo de elasticidade secante apresentado na Tabela 6.5 foi calculado pela Equação 6.1, proposta pela NBR 8522. Adotouse para $\sigma_{f}$ o valor de tensão correspondente a $40 \%$ da tensão de ruptura, como prescreve a ASTM C-469 (1994). Foram executados três ensaios para cada propriedade aferida. Os ensaios de caracterização do concreto da série R1 foram realizados em na máquina hidráulica ELE Autotest 2000, bem como os ensaios para determinação da resistência à tração do concreto da série R2. Os ensaios para determinação da resistência à compressão e do módulo de elasticidade do concreto da série R2 foram executados na máquina universal de ensaios servo-hidráulica INSTRON com uso do sistema de aquisição de dados System 5000 da Vishay. Os resultados da caracterização estão apresentados na Tabela 6.4 e na Tabela 6.5.

$$
E_{c s}=\frac{\sigma_{f}-\sigma_{a}}{\varepsilon_{f}-\varepsilon_{a}}
$$

Onde:

$\sigma_{f}=$ tensão correspondente a $40 \%$ da tensão de ruptura

$\sigma_{a}=$ tensão igual a $0,5 \mathrm{MPa}$

$\varepsilon_{f}=$ deformação correspondente a $\sigma_{f}$

$\varepsilon_{f}=$ deformação correspondente a $\sigma_{a}$

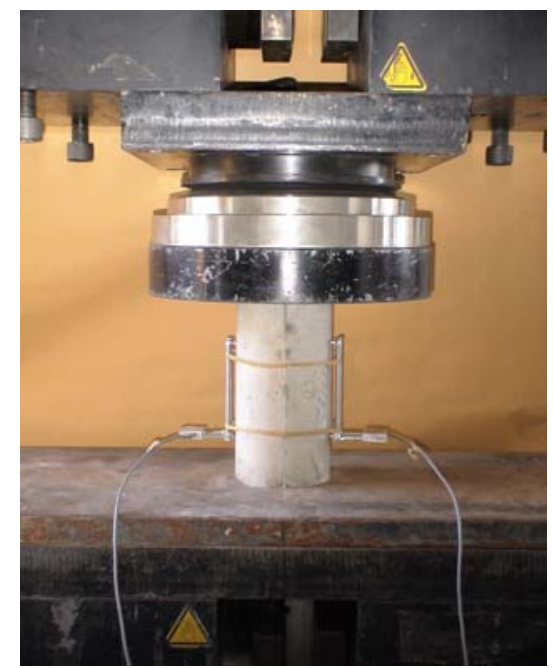

Figura 6.4 - Ensaio para a determinação da resistência à compressão e do módulo de elasticidade. 
Tabela 6.4 - Propriedades do concreto utilizado na série R1.

\begin{tabular}{cccc}
\hline Corpo-de-prova & $\begin{array}{c}\text { Idade } \\
\text { (dias) }\end{array}$ & $\mathbf{f}_{\mathbf{c}}(\mathbf{M P a})$ & $\mathbf{f}_{\mathbf{t}}$ (MPa) \\
\hline 1 & 98 & 46,2 & 3,48 \\
2 & 98 & 46,9 & 2,80 \\
3 & 98 & 42,5 & 2,72 \\
Média & - & $\mathbf{4 5 , 2}$ & $\mathbf{3 , 0 0}$ \\
Coeficiente de variação & - & $\mathbf{5 \%}$ & $\mathbf{1 4} \%$ \\
\hline
\end{tabular}

Tabela 6.5 - Propriedades do concreto utilizado na série R2.

\begin{tabular}{ccccc}
\hline Corpo-de-prova & $\begin{array}{c}\text { Idade } \\
\text { (dias) }\end{array}$ & $\mathbf{f}_{\mathbf{c}}(\mathbf{M P a})$ & $\mathbf{f}_{\mathbf{t}}(\mathbf{M P a})$ & $\mathbf{E}_{\mathbf{c}}(\mathbf{G P a})$ \\
\hline 1 & 31 & 48,2 & $2,17^{*}$ & 29,4 \\
2 & 31 & 50,1 & 3,66 & 29,7 \\
3 & 31 & 51,7 & 3,96 & 31,0 \\
Média & - & $\mathbf{5 0 , 0}$ & $\mathbf{3 , 8 1}$ & $\mathbf{3 0 , 0}$ \\
Coeficiente de variação & - & $\mathbf{3} \%$ & $\mathbf{6 \%}$ & $\mathbf{3} \%$ \\
\hline
\end{tabular}

* valor discrepante desprezado.

\subsubsection{Adesivo}

Para a colagem dos laminados nos entalhes dos modelos da série R1, foi utilizada resina epóxi bi-componente com nome comercial "Epóxi Estruturante FC" fornecida pela empresa "Rogertec". Utilizou-se a resina epóxi bi-componente "Sikadur® 330" para a colagem dos laminados nos entalhes dos modelos da série R2. Não foi realizado qualquer ensaio para caracterização dessas resinas. Suas propriedades físicas, de acordo com informações dos fornecedores, são apresentadas na Tabela 6.6 e Tabela 6.7.

Tabela 6.6 - Propriedades físicas do adesivo utilizado nos modelos da série R1 (dados do fornecedor).

\begin{tabular}{ccccccc}
\hline $\begin{array}{c}\text { Resistência à } \\
\text { tração } \\
(\mathbf{M P a})\end{array}$ & $\begin{array}{c}\text { Deformação } \\
\text { na tração } \\
(\mathbf{\%})\end{array}$ & $\begin{array}{c}\text { Módulo } \\
\text { à tração } \\
(\mathbf{M P a})\end{array}$ & $\begin{array}{c}\text { Resistência à } \\
\text { flexão } \\
(\mathbf{M P a})\end{array}$ & $\begin{array}{c}\text { Módulo à } \\
\text { flexão } \\
\text { (MPa) }\end{array}$ & $\begin{array}{c}\text { Resistência à } \\
\text { Compressão } \\
\text { (MPa) }\end{array}$ & $\begin{array}{c}\text { Módulo à } \\
\text { compressão } \\
\text { (MPa) }\end{array}$ \\
\hline 57 & 2,4 & 2998 & 131 & 3684 & 81 & 2560 \\
\hline
\end{tabular}

Tabela 6.7 - Propriedades físicas do adesivo utilizado nos modelos da série R2 (dados do fornecedor).

\begin{tabular}{cccc}
\hline $\begin{array}{c}\text { Resistência à tração } \\
(\mathbf{M P a})\end{array}$ & $\begin{array}{c}\text { Deformação na ruptura } \\
(\mathbf{\%})\end{array}$ & $\begin{array}{c}\text { Módulo à tração } \\
(\mathbf{M P a})\end{array}$ & $\begin{array}{c}\text { Módulo à flexão } \\
\text { (MPa) }\end{array}$ \\
\hline 30 & 0,9 & 4500 & 3800 \\
\hline
\end{tabular}




\subsubsection{Laminado}

O laminado foi adquirido junto à empresa "Rogertec" e recebe o nome comercial de "Fita de Fibra de Carbono" ou "FITA MFC". O produto foi desenvolvido para aplicação em reforço segundo a técnica NSM, denominada pela empresa por "incorporação por sulco na superfície (ISS)". A largura e a espessura do laminado apresentadas na Tabela 6.9 foram obtidas pela média de vinte medidas aleatórias. Foram feitos ensaios para determinação das propriedades no laminado à tração baseados na ASTM D 3039/D 3039M (1995). Os ensaios foram realizados máquina universal de ensaios servo-hidráulica INSTRON (Figura 6.5) com sistema de aquisição de dados System 5000 da Vishay. Utilizaram-se três corpos-de-prova com $100 \mathrm{~cm}$ de comprimento e largura e espessura do laminado. Na região da garra foram coladas pastilhas (tabs), confeccionadas com o laminado, com comprimento de $15 \mathrm{~cm}$ para impedir o esmagamento do compósito nesta região. Na metade do comprimento dos CPs foram posicionados extensômetros elétricos e extensômetros removíveis que permitiram a obtenção da deformação. Os corpos-de-prova antes e depois dos ensaios podem ser visualizados na Figura 6.6 e na Figura 6.7, respectivamente. Em um dos corpos-de-prova, evidencia-se um modo de ruptura não convencional, com fissura longitudinal do laminado. Os valores da deformação na ruptura e da resistência à tração, obtidos experimentalmente, apresentaram alto coeficiente de variação e ficaram bem abaixo dos fornecidos pela empresa, como se pode notar pela comparação entre a Tabela 6.8 e a Tabela 6.9. Contudo, considerouse válida a determinação do módulo de elasticidade tendo em vista o comportamento linear do diagrama tensão deformação e o baixo coeficiente de variação dos valores obtidos para os três corpos-de-prova (Figura 6.8). Observa-se a proximidade do valor médio do módulo de elasticidade obtido experimentalmente (Tabela 6.9) daquele informado pelo fornecedor (Tabela 6.8).

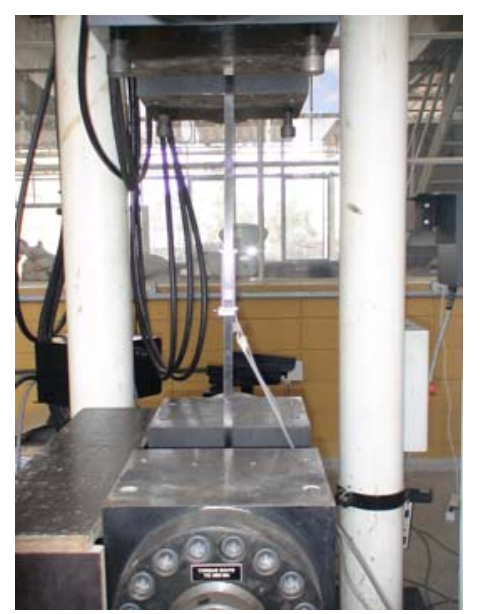

Figura 6.5 - Ensaio para determinação das propriedades no laminado à tração. 
Figura 6.6 - Corpo-de-prova para ensaio de tração.

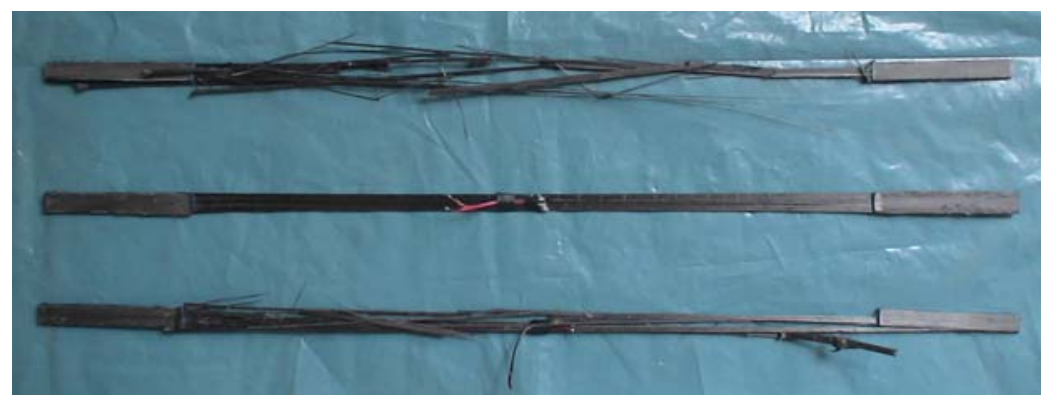

Figura 6.7 - Corpos-de-prova após ensaio de tração.

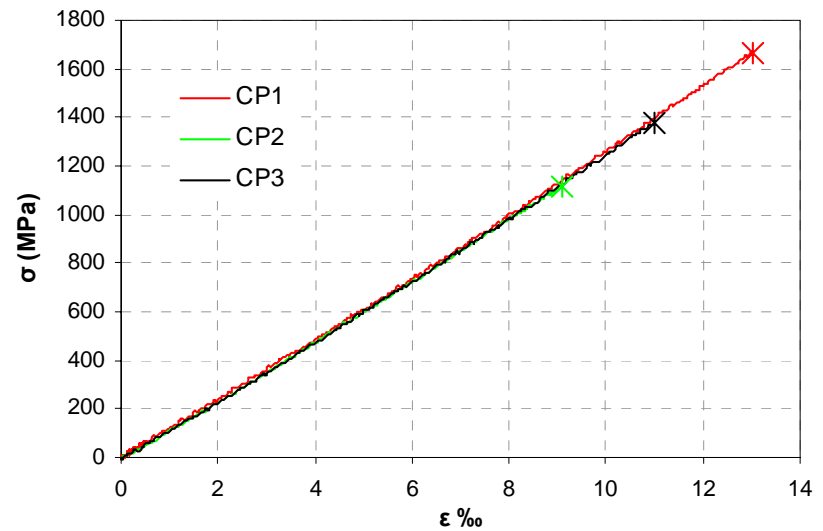

Figura 6.8 - Gráfico “tensão x deformação” para os corpos-de-prova utilizados na caracterização do laminado.

Tabela 6.8 - Propriedades físicas do laminado (dados do fornecedor).

\begin{tabular}{ccccccc}
\hline $\begin{array}{c}\text { Largura } \\
(\mathbf{m m})\end{array}$ & $\begin{array}{c}\text { Espessura } \\
(\mathbf{m m})\end{array}$ & $\begin{array}{c}\text { Resistência } \\
\text { à tração } \\
\mathbf{( M P a )}\end{array}$ & $\begin{array}{c}\text { Módulo de } \\
\text { elasticidade } \\
\mathbf{( G P a )}\end{array}$ & $\begin{array}{c}\boldsymbol{\varepsilon}_{\mathbf{u}} \\
(\mathbf{\%})\end{array}$ & $\begin{array}{c}\text { Coeficiente de dilatação } \\
\text { térmica } \\
\text { Transversal } \\
\left(\mathbf{\times 1 0} /^{\mathbf{0}} \mathbf{C}\right)\end{array}$ & $\begin{array}{c}\text { Longitudinal } \\
\left(\mathbf{x 1 0} / \mathbf{o}^{\mathbf{0}} \mathbf{C}\right)\end{array}$ \\
\hline 16 & 2 & 2068 & 131 & 1,7 & 74 a 104 & 9 a 0,0 \\
\hline
\end{tabular}

Tabela 6.9 - Propriedades físicas do laminado (dados obtidos experimentalmente).

\begin{tabular}{cccccc}
\hline $\begin{array}{c}\text { Largura } \\
(\mathbf{m m})\end{array}$ & $\begin{array}{c}\text { Espessura } \\
(\mathbf{m m})\end{array}$ & $\begin{array}{c}\text { Área } \\
\left(\mathbf{m m}^{\mathbf{2}}\right)\end{array}$ & $\begin{array}{c}\text { Resistência à tração } \\
\mathbf{( M P a )}\end{array}$ & $\begin{array}{c}\text { Módulo de } \\
\text { elasticidade }(\mathbf{G P a})\end{array}$ & $\boldsymbol{\varepsilon}_{\mathbf{u}}(\mathbf{\%})$ \\
\hline $15,69 \pm 0,04$ & $2,11 \pm 0,02$ & 33,11 & 1388 & 126 & 1,1 \\
$(0,2 \%)$ & $(0,7 \%)$ & $(20 \%)$ & $(1,5 \%)$ & $(18 \%)$ \\
\hline
\end{tabular}

Obs.: os valores entre parênteses indicam o coeficiente de variação.

\subsection{Configuração do ensaio e instrumentação}

A configuração do ensaio apresentou simetria em relação ao plano perpendicular que continha o eixo longitudinal da peça. O modelo foi bi-apoiado. Em cada apoio, foram posicionadas células de carga com capacidade de medida de $100 \mathrm{kN}$ que permitiram a 
determinação da reação. Sobre as células, dispositivos prismáticos de seção semicircular simularam a condição de articulação nos apoios. Dois cilindros metálicos foram utilizados para concentração da carga aplicada em dois pontos distantes $250 \mathrm{~mm}$ do apoio mais próximo a cada um deles. Foram posicionados transdutores de deslocamento (LVDT) no laminado, no início da zona de ancoragem (laminado tracionado) e fim da zona de ancoragem (laminado livre de esforços) do bloco A, para medir o deslizamento do laminado em relação ao concreto. Ao total foram utilizados quatro LVDTs com campo de medida de $10 \mathrm{~mm}$, dois para cada laminado. O laminado que pode ser visualizado na vista frontal do modelo (Figura 6.9) é chamado de laminado 1 e os LVDTs posicionados no início e fim da zona de ancoragem deste laminado de LVDT1 e LVDT2, respectivamente. O laminado na face posterior do modelo é chamado de laminado 2 e os LVDTs no início e fim da zona de ancoragem de LVDT3 e LVDT4. Um extensômetro foi colado em cada laminado posicionado a meio vão. A configuração esquemática do ensaio e a instrumentação podem ser visualizadas na Figura 6.9. Maiores informações sobre os equipamentos utilizados nos ensaios são apresentados no APÊNDICE A.

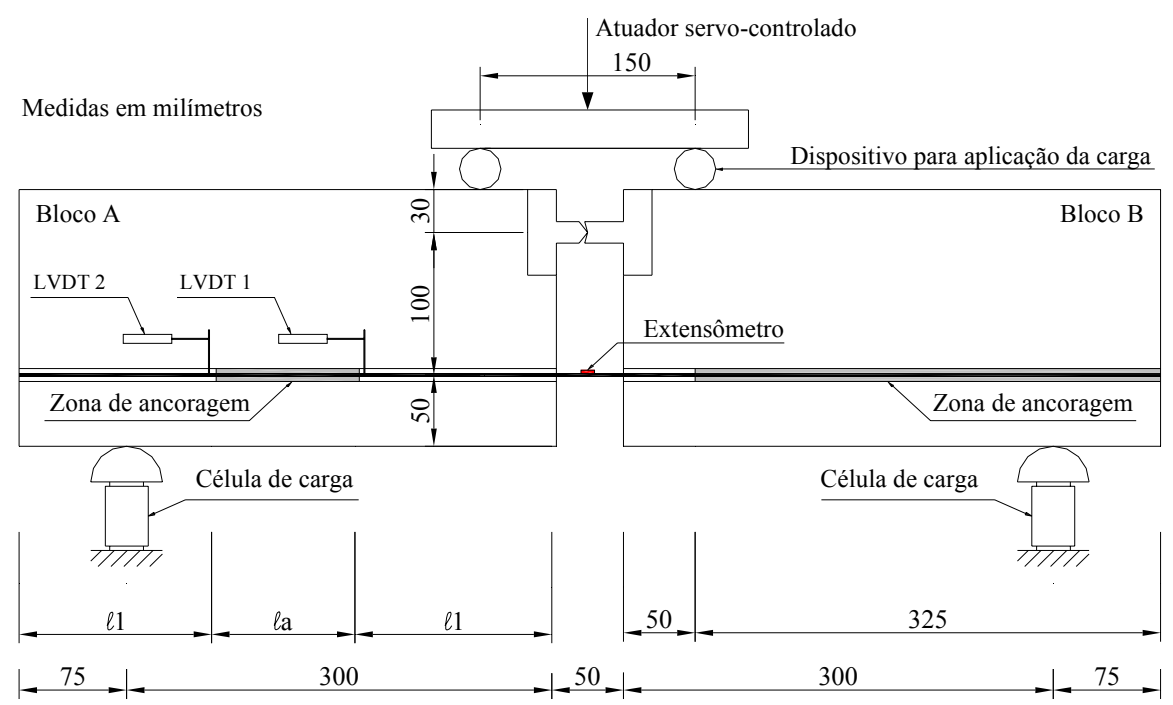

Figura 6.9 - Configuração esquemática do ensaio.

\subsection{Confecção dos modelos}

O procedimento utilizado na confecção dos modelos para as séries de ensaios R1 e R2 foi o mesmo com diferenças nos intervalos entre as etapas. $\mathrm{O}$ concreto foi misturado em betoneira (Figura 6.10-a) colocado nas fôrmas de madeira compensada laminada e adensado em mesa vibratória (Figura 6.10-b). Os modelos foram dispostos em área externa ao Laboratório de Estruturas da EESC (Figura 6.10-c). No dia seguinte procedeu-se a desfôrma e os modelos foram levados à câmara úmida, onde permaneceram até a retirada para execução 
dos entalhes com uso de ferramenta elétrica com disco de corte (Figura 6.10-d). Optou-se pela utilização de dois discos de corte justapostos, o que proporcionou uma largura do entalhe de aproximadamente $5 \mathrm{~mm}$ e profundidade de aproximadamente $18 \mathrm{~mm}$. O corte foi feito por via úmida em todas as peças, que foram posteriormente lavadas com água e deixadas secar ao ar.

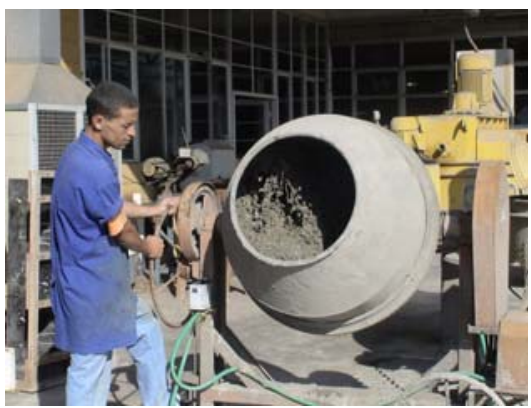

(a)

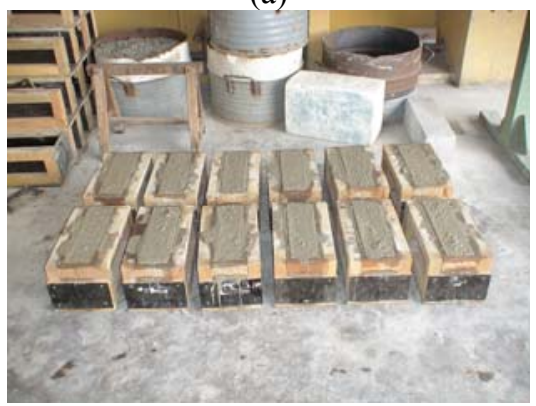

(c)

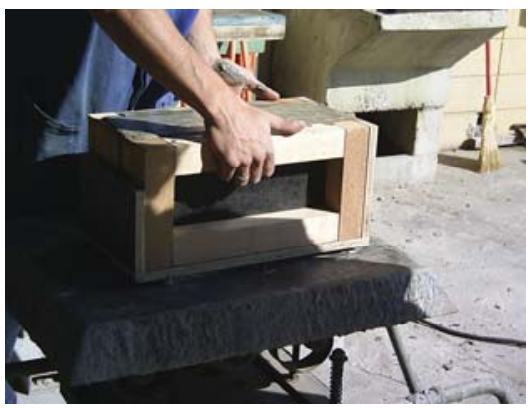

(b)

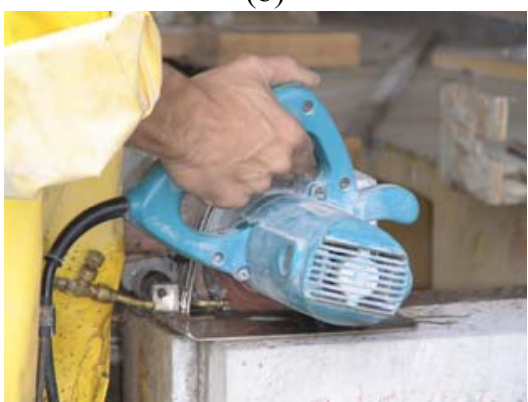

(d)

Figura 6.10 - (a) Mistura do concreto em betoneira; (b) adensamento do concreto em mesa vibratória; (c) modelos após a moldagem na área externa do Laboratório de Estruturas; (d) realização do entalhe.

Mesmo com a lavagem, as peças de concreto apresentavam muito pó depositado em sua superfície e no interior dos entalhes. Na ocasião da colagem do laminado, foi realizada limpeza dos modelos com uso de jato de ar comprimido (Figura 6.12-a) e estopa embebida em álcool (Figura 6.12-b). Os laminados utilizados na confecção dos modelos foram cortados com comprimento de $80 \mathrm{~cm}$. As zonas a serem ancoradas foram delimitadas por fita adesiva. Devido à natureza excessivamente fluida do adesivo utilizado na série R1, foram coladas sobre as fitas placas finas de poliestireno expandido, para prevenir que o adesivo escorresse da zona de ancoragem, ocasionando a existência de vazios entre o laminado e o concreto, ou mesmo a colagem do laminado em zonas indesejadas. As placas de poliestireno expandido proporcionaram a centralização do laminado no entalhe e foram utilizadas também na série R2. No início e fim da zona ancorada, foram coladas chapas metálicas com espessura de aproximadamente $1 \mathrm{~mm}$, comprimento de aproximadamente $5 \mathrm{~cm}$ e largura de $2 \mathrm{~cm}$, nas quais foram fixadas cantoneiras para medição do deslocamento relativo entre o concreto e o laminado. Extensômetros foram colados no laminado em posição correspondente à metade do vão da viga. A Figura 6.11 ilustra os laminados utilizados na série R2 instrumentados. 


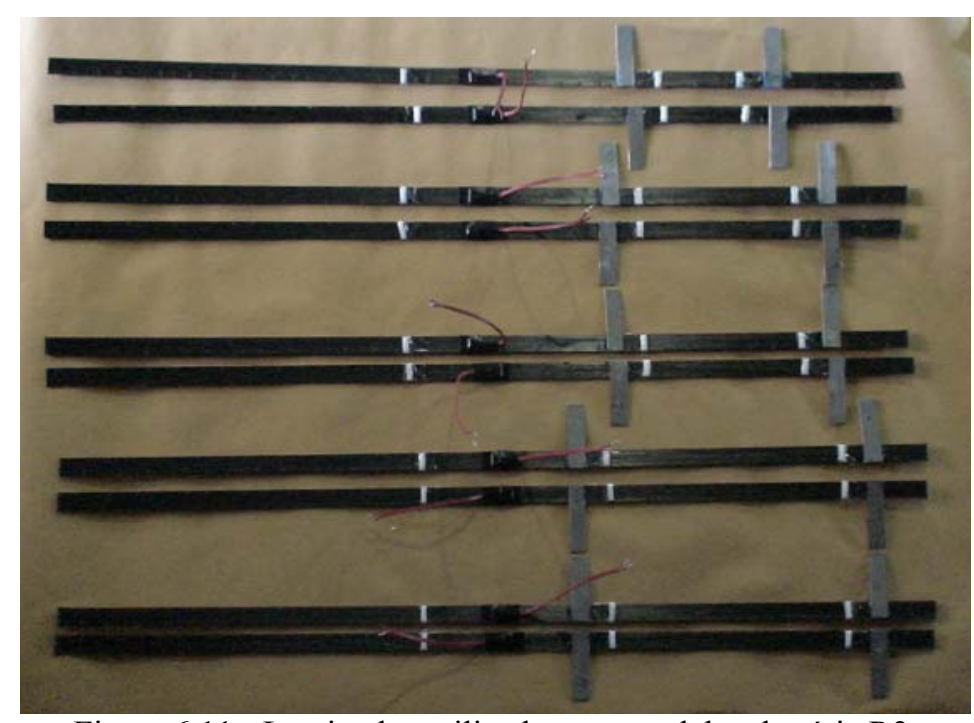

Figura 6.11 - Laminados utilizados nos modelos da série R2.

O laminado foi limpo com acetona. Colocaram-se as duas partes da rótula nos blocos que foram posicionados de forma a apresentar a configuração definitiva do modelo. Procedeuse a mistura dos dois componentes do adesivo conforme orientações do fabricante. Aplicou-se $\mathrm{o}$ adesivo no entalhe (Figura 6.12-c) ao longo do comprimento de ancoragem e nos laminados, com auxílio de uma espátula (Figura 6.12-d). Introduziram-se os laminados nos entalhes (Figura 6.12-e), retirou-se o excesso de adesivo com a espátula (Figura 6.12-f). Na preparação dos modelos da série R1, foi necessária a colagem de fita adesiva ao longo da zona ancorada para que o adesivo não escorresse. Os modelos foram mantidos nas dependências do Laboratório de Estruturas da EESC até a data do ensaio.

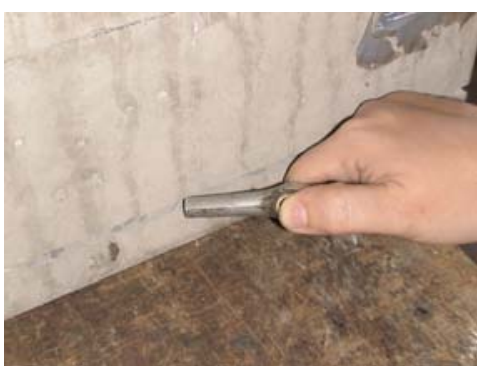

(a)

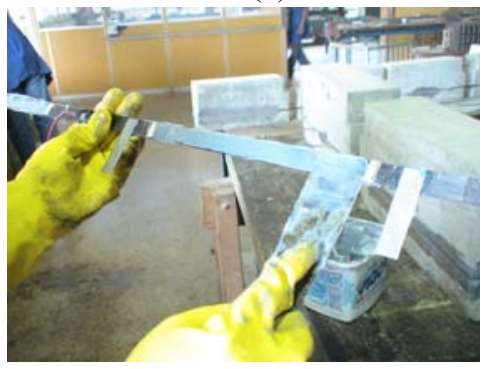

(d)

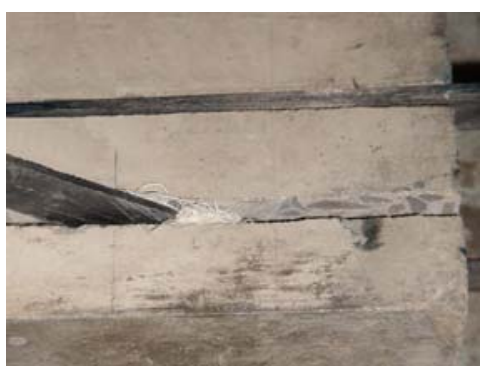

(b)

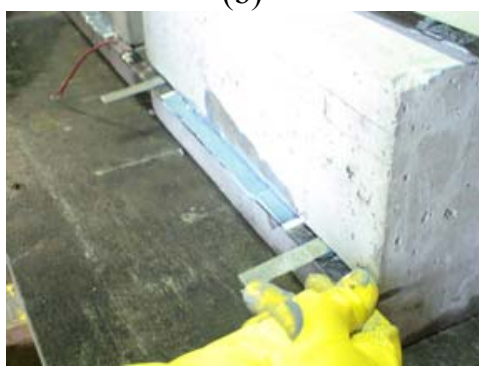

(e)

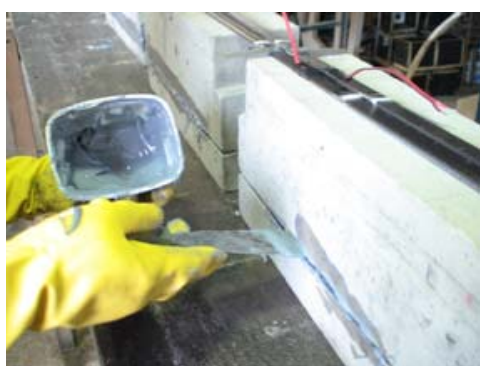

(c)

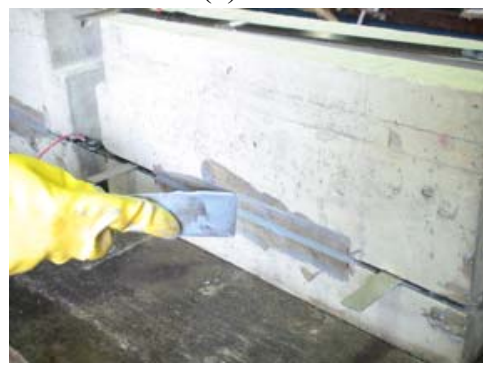

(f)

Figura 6.12 - Etapas principais da colagem dos laminados nos modelos de ensaio de aderência: (a) limpeza do entalhe com jato de ar; (b) limpeza do entalhe com estopa embebida em alcool; (c) aplicação do adesivo no entalhe com uso de espátula; (d) aplicação do adesivo no laminado; (e) introdução do laminado no entalhe; (f) retirada do excesso de adesivo e acabamento. 


\subsection{Execução do ensaio}

Os ensaios foram realizados na máquina universal de ensaios servo-hidráulica INSTRON, sob controle de deslocamento do pistão a uma taxa de $0,005 \mathrm{~mm} / \mathrm{s}$ e interrompidos com o deslizamento de ambos os laminados. O sistema de aquisição de dados utilizado foi o System 5000 da Vishay. Os transdutores de deslocamento foram fixados em dois quadros para suporte da instrumentação (Figura 6.13) presos ao concreto por parafusos. Na Figura 6.14, ilustra-se um dos ensaios da série R2.

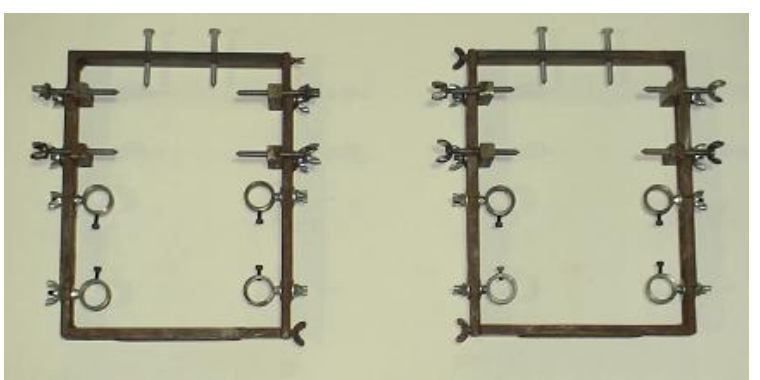

Figura 6.13 - Quadros para suporte da instrumentação.

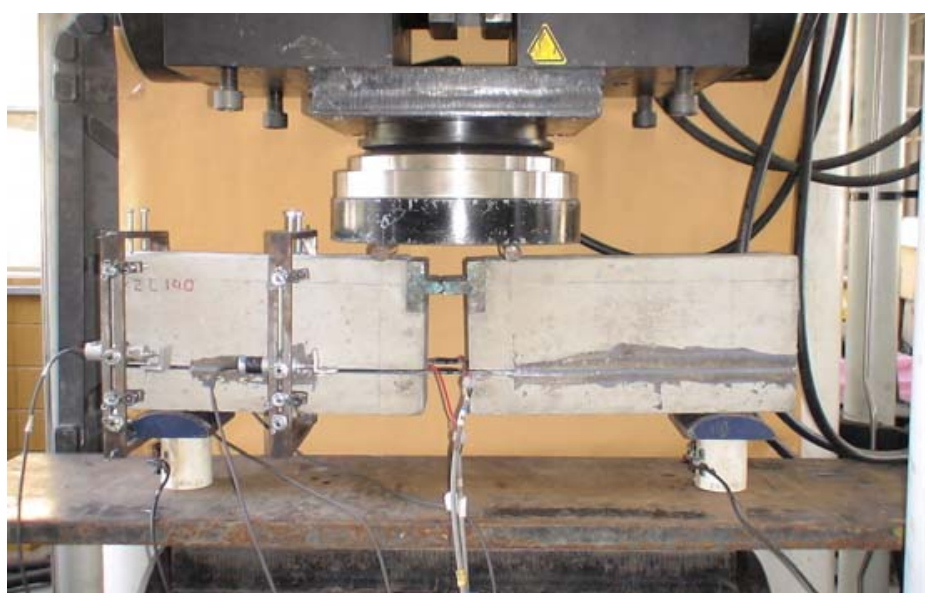

Figura 6.14 - Ensaio de aderência.

\subsection{Resultados e análises}

\subsubsection{Modos de ruptura}

Para os ensaios da série R1 a ruptura ocorreu sempre por deslizamento na interface entre o adesivo e o concreto em direção paralela à do reforço e sem apresentar fissuras (Figura 6.15-a). Essa configuração corresponde à ruptura classificada por EC-I no Item 3.3. Nos ensaios da série R2 a forma de ruptura variou com o comprimento de ancoragem. Para os modelos com comprimento de ancoragem de 70 e $140 \mathrm{~mm}$, a ruptura se deu puramente na interface adesivo/laminado (Figura 6.15-b). Para os modelos com maior comprimento de 
ancoragem estudado $(210 \mathrm{~mm})$, ocorreu fissuração diagonal no adesivo e leve fissuração no concreto adjacente (Figura 6.15-c). As configurações observadas nos ensaios da série R2 são classificadas, de acordo com o Item 3.3, como BE-I e SPC-1.

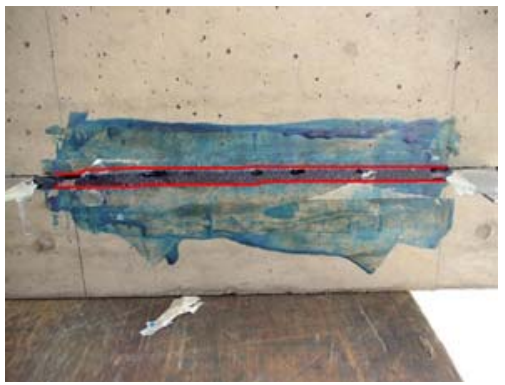

(a)

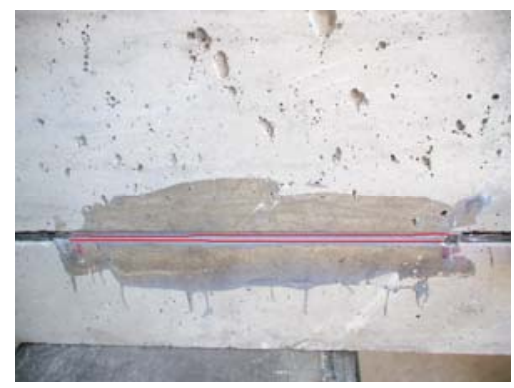

(b)

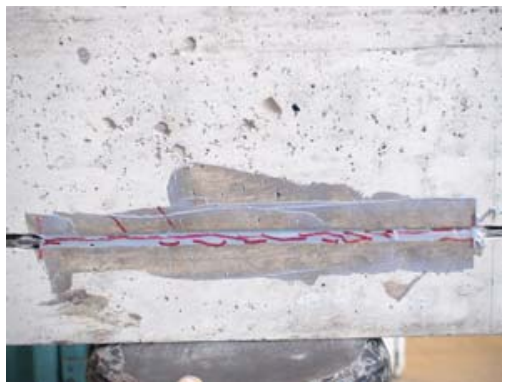

(c)

Figura 6.15 - Padrões de deslizamento observados: (a) ensaios da série R1; (b) ensaios da série R2 com comprimento de 70 e $140 \mathrm{~mm}$; (c) ensaio da série R2 com comprimento de $210 \mathrm{~mm}$.

\subsubsection{Força no laminado}

A configuração do ensaio (Figura 6.9) permitiu o cálculo da força média (por modelo de ensaio) no laminado por meio de duas formas: pela aplicação das condições de equilíbrio (Equação 6.2) e pelo produto da deformação lida nos extensômetros fixados no laminado pelo módulo de elasticidade e pela área do compósito (Equação 6.3).

$$
\begin{aligned}
& F_{\text {medl }}=\left(\frac{C 1+C 2}{2} \times \frac{B}{b}\right) \times \frac{1}{2} \\
& F_{\text {medl }}=\frac{\left(\varepsilon_{l 1}+\varepsilon_{l 2}\right)}{2} \times E_{l} \times e \times L
\end{aligned}
$$

Os símbolos nas Equações 6.2 e 6.3 têm os seguintes significados:

$F_{\text {medl }}$ - Força média por laminado, por modelo;

$C 1$ - Leitura da célula de carga $\mathrm{C} 1$;

C2 - Leitura da célula de carga C2;

$B$ - Distância entre o apoio e o ponto de aplicação da força (Figura 6.16);

$b$ - Braço de alavanca interno (graficamente definido na Figura 6.16);

$\varepsilon_{l 1}$ - Deformação lida no extensômetro colado ao laminado 1;

$\varepsilon_{l 2}$ - Deformação lida no extensômetro colado ao laminado 2;

$E_{l}$ - Módulo de elasticidade do laminado;

$e$ - Espessura do laminado (graficamente definida na Figura 6.16);

$L$ - Largura do laminado (graficamente definida na Figura 6.16). 


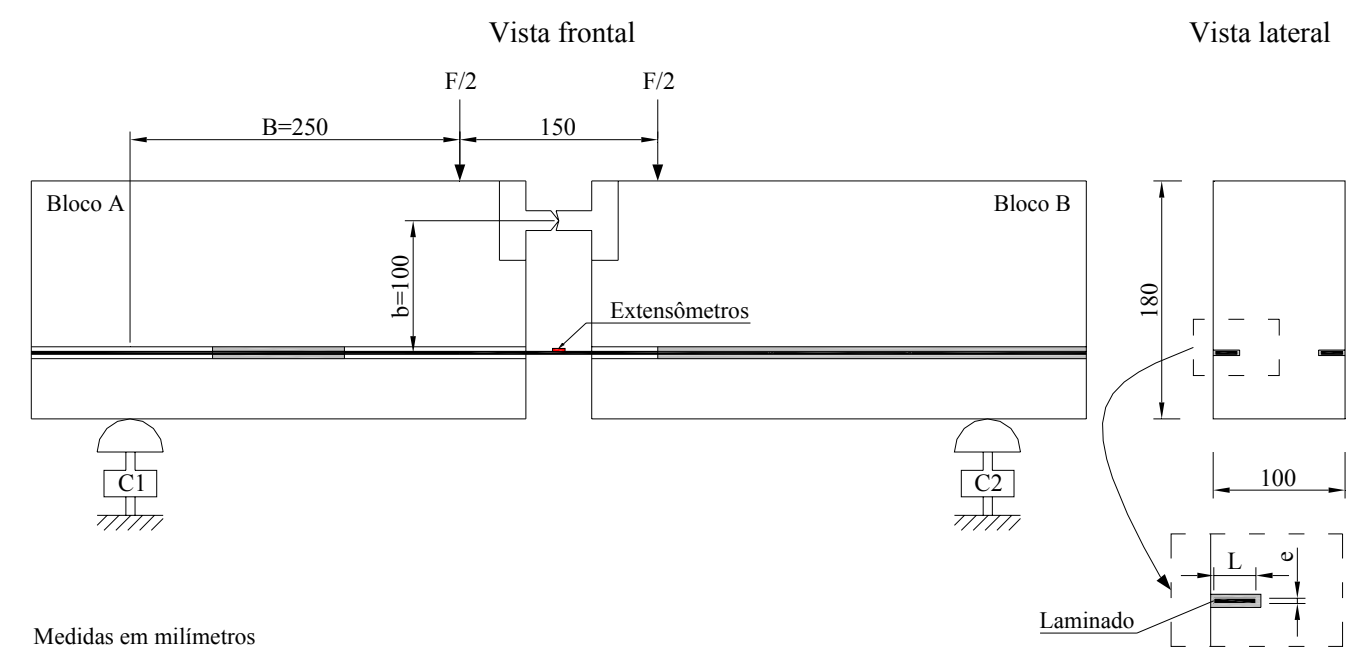

Figura 6.16 - Configuração esquemática usada na determinação da força média no laminado por meio do equilíbrio estático.

O grau de concordância entre as duas formas de cálculo variou nos modelos, o que pode ter sido causado por imperfeições geométricas nos modelos, imprecisão na montagem dos ensaios ou na instrumentação, variação do braço de alavanca interno ao longo do ensaio. Entretanto, de modo geral, pode-se dizer que houve semelhança satisfatória nos resultados para todos os modelos. Na Figura 6.17 (a), destaca-se o resultado do ensaio em que as duas formas de cálculo mais se aproximaram e na Figura 6.17 (b), um resultado em que houve distanciamento entre elas. Os gráficos com os resultados dos ensaios obtidos para todos os modelos são apresentados no APÊNDICE B.

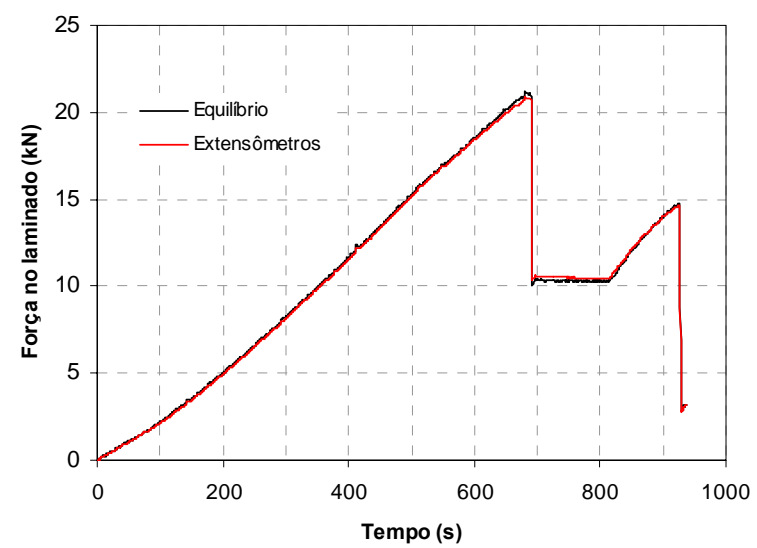

(a)

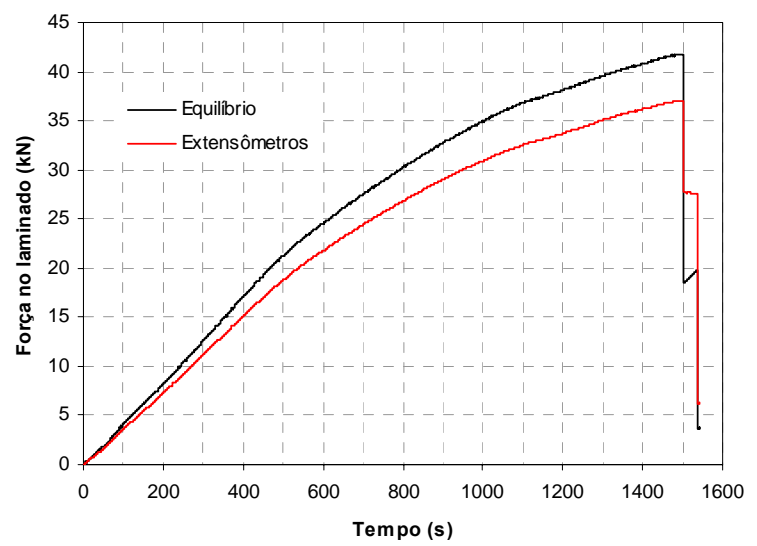

(b)

Figura 6.17 - Gráfico "força x tempo" definido por meio do equilíbrio de forças e dos dados obtidos nos extensômetros: (a) modelo M1L70R2; (b) modelo M1L210R2.

Muitas das análises subseqüentes se fundamentam na determinação da força em cada laminado individualmente pela Equação 6.4 (Figura 6.18 e Figura 6.19).

$$
F_{l i}=\varepsilon_{l i} \times E_{l} \times e \times L
$$

Em que: 
$F_{l i}$ - Força no laminado determinada individualmente $(i=1$ ou 2$)$

$\varepsilon_{l i}$ - Deformação lida no extensômetro colado ao laminado $(i=1$ ou 2$)$

Os gráficos "força no laminado x deslocamento do pistão", para os ensaios das séries R1 e R2, são apresentados na Figura 6.18 e na Figura 6.19, respectivamente.

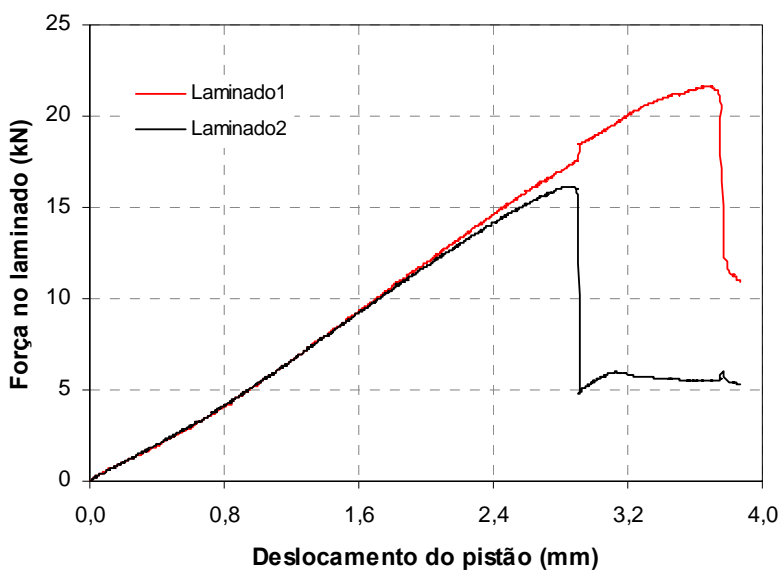

(a)

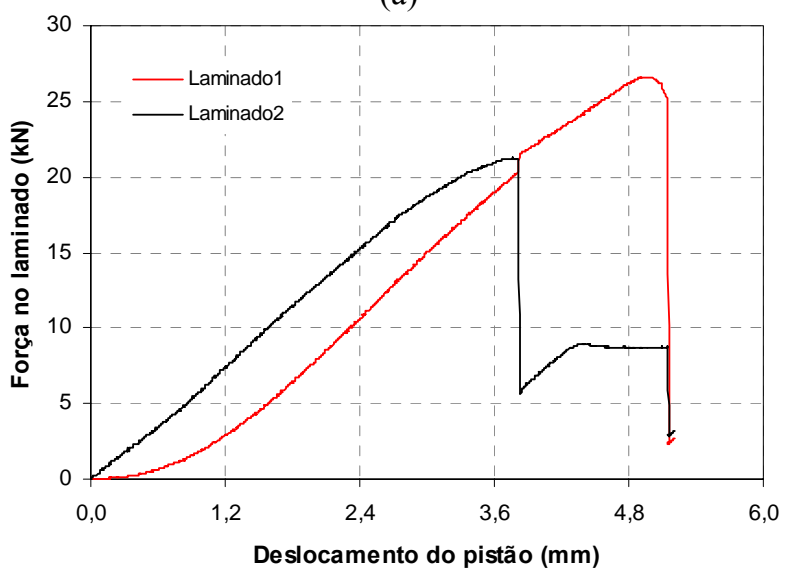

(c)

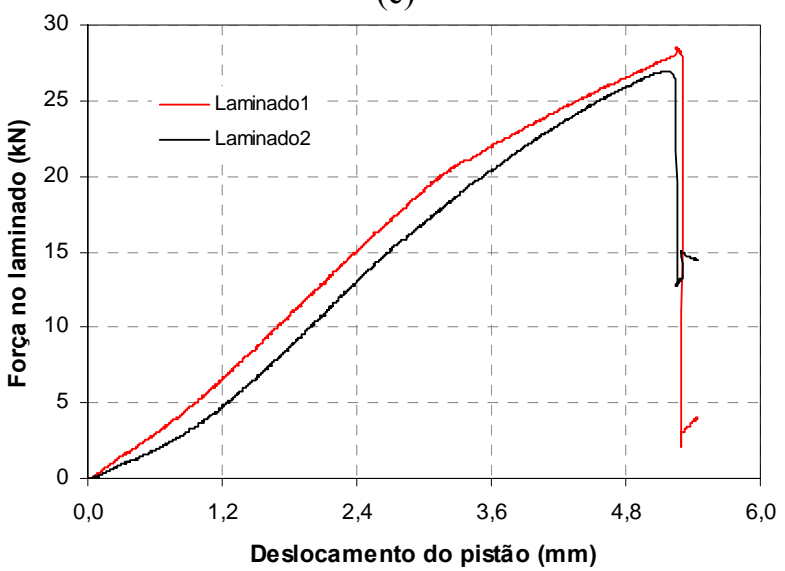

(e)

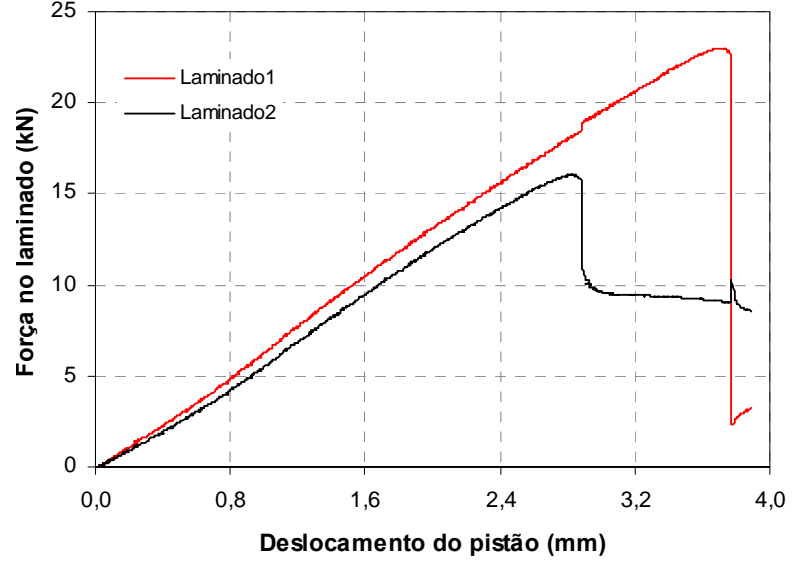

(b)

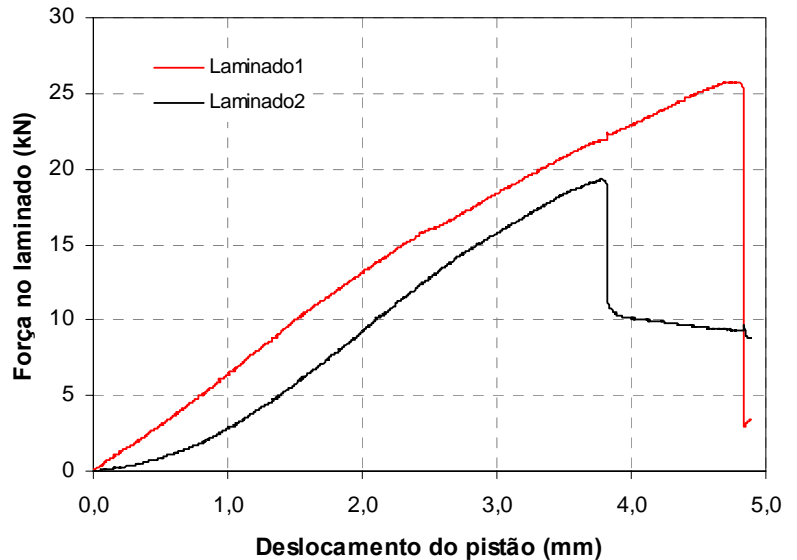

(d)

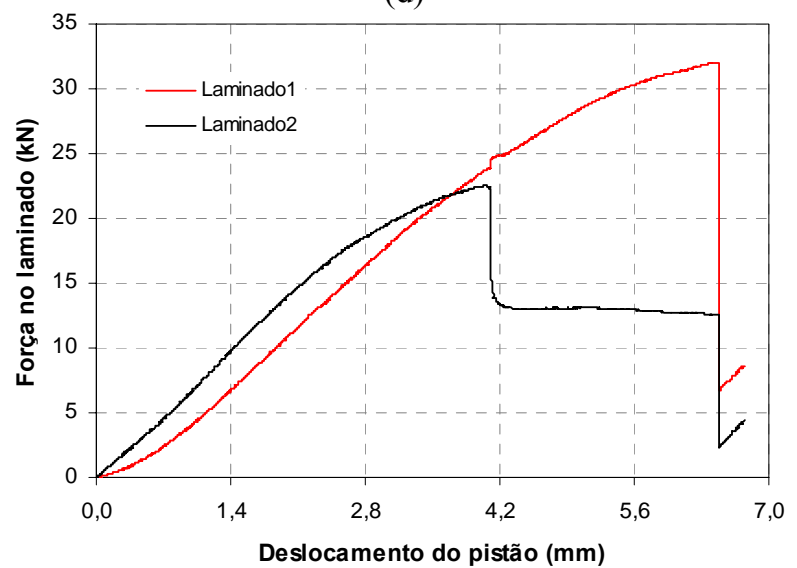

(f)

Figura 6.18 - Gráficos "força nos laminado x deslocamento do pistão" obtidos nos ensaios de aderência da série R1: (a) M1L90R1; (b) M2L90R1; (c) M1L120R1; (d) M2L120R1; (e) M1L150R1; (f) M2L150R1. 


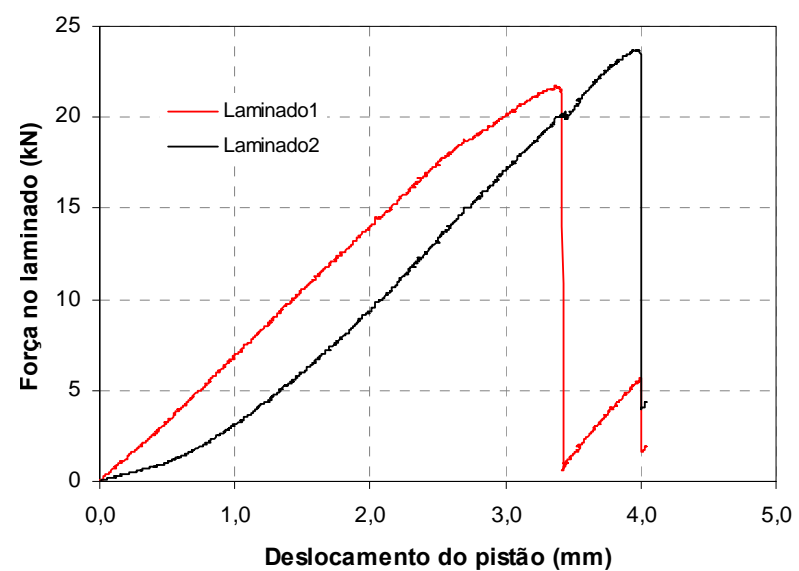

(a)

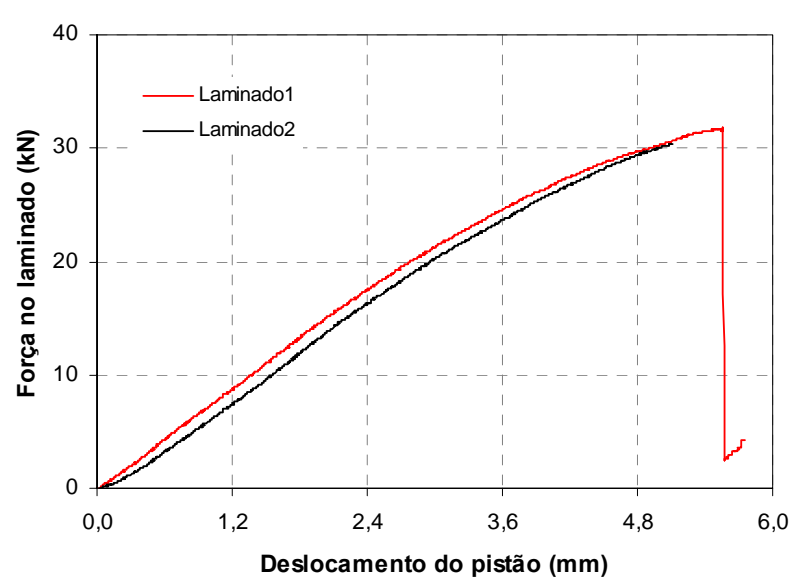

(c)

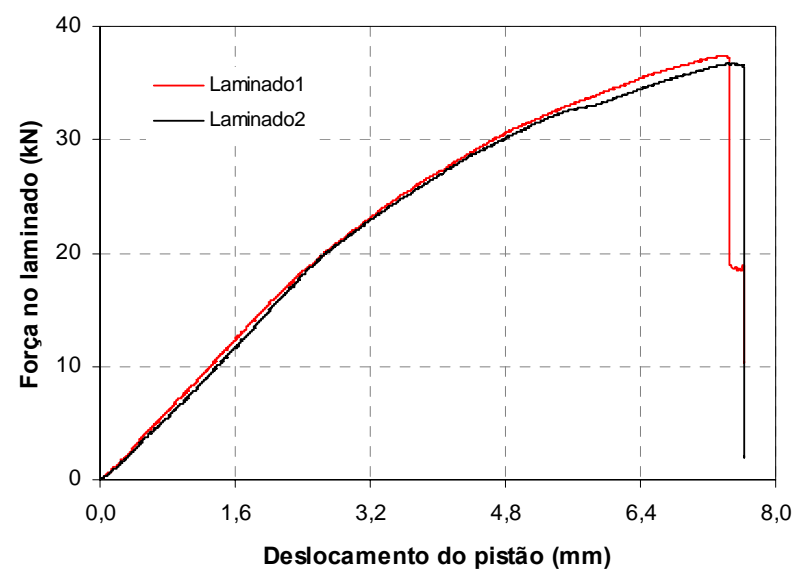

(e)

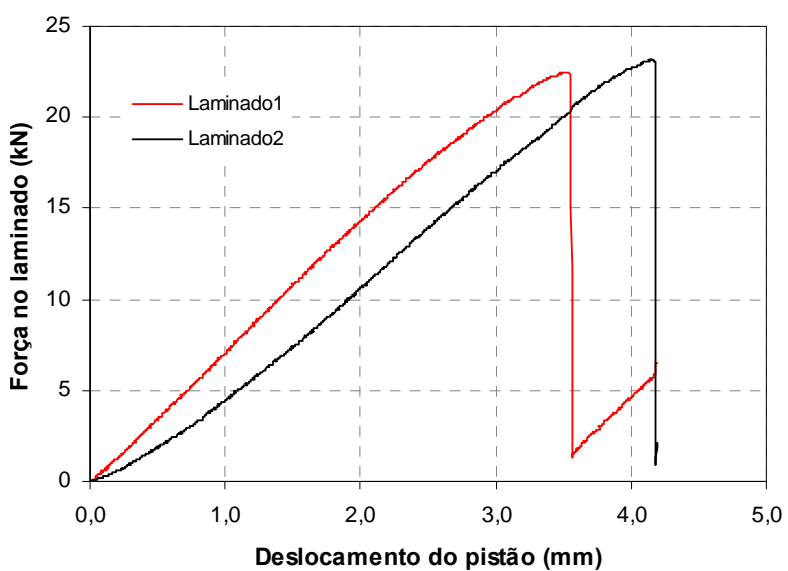

(b)

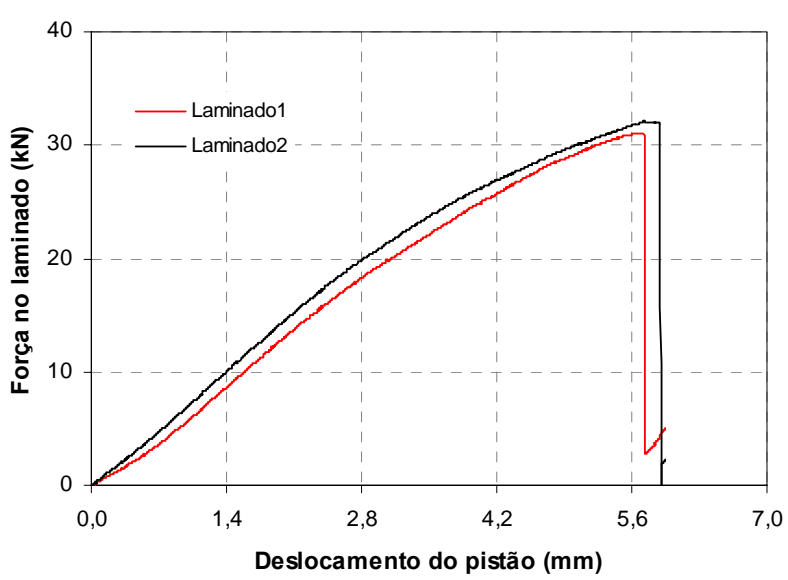

(d)

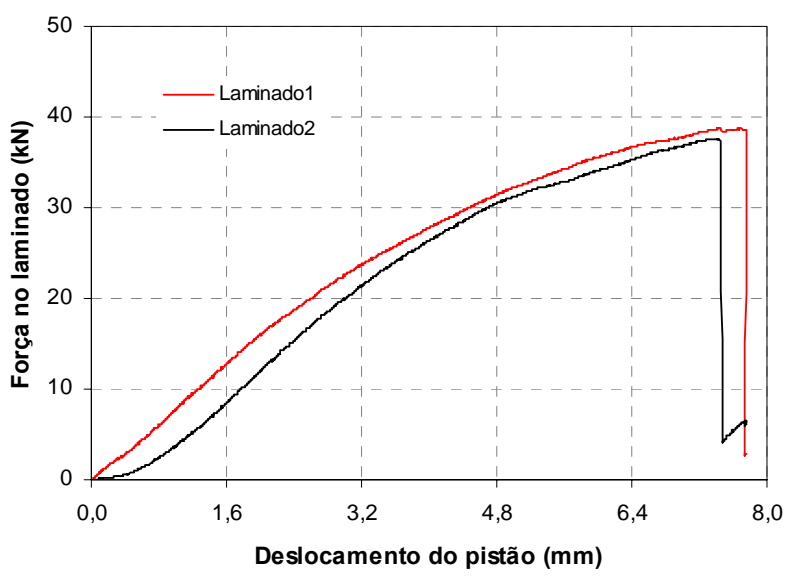

(f)

Figura 6.19 - Gráficos "força no laminados x deslocamento do pistão" obtidos nos ensaios de aderência da série R2: (a) M1L70R2; (b) M2L70R2; (c) M1L140R2; (d) M2L140R2; (e) M1L210R2; (f) M2L210R2.

Em geral, pode-se dizer que comportamento dos laminados se aproxima da linearidade até o deslizamento caracterizado pela queda brusca na força suportada por eles. A proximidade da linearidade é maior para os resultados dos modelos com os menores comprimentos de ancoragem. Esse fato está relacionado à mudança na distribuição das 
tensões com a variação do comprimento de ancoragem também concluída por meio da análise do modo de ruptura. Nos modelos com maior comprimento de ancoragem, se mobilizou mais a resistência do concreto adjacente que exibiu algumas fissuras. $\mathrm{O}$ trecho final não linear dos gráficos "força no laminados x deslocamento do pistão" dos modelos com comprimento de $210 \mathrm{~mm}$ é conseqüência provavelmente do processo de fissuração.

Como se pode observar nos gráficos da Figura 6.18 e Figura 6.19, em muitos dos ensaios houve comportamento diferente entre os laminados colados em um mesmo modelo. Considerando a simetria imposta ao esquema de ensaio, seria esperado um comportamento similar. Entretanto, muitos fatores contribuem para que essa simetria não seja ideal. Qualquer imperfeição nos dentes em que se encaixam a rótula ou na própria rótula, o mau posicionamento das células de carga ou dos dispositivos para aplicação da carga, diferença na qualidade da colagem dos laminados são exemplos desses fatores. Percebe-se que a divergência entre o comportamento dos laminados é mais evidente para os ensaios da série de ensaios R1. Isso pode denotar a diferença de qualidade na colagem dos laminados dispostos nas laterais de cada modelo para essa série. A obtenção de uniformidade na colagem dos laminados nos modelos da série R1 foi prejudicada pelas características de trabalhabilidade da resina, que apresentou fluidez excessiva para a finalidade em questão.

\subsubsection{Tensão de aderência e deslizamento}

A formulação proposta pela RILEM-CEB-FIB (1973) para o cálculo da tensão de aderência foi modificada em função da utilização de um reforço de seção retangular enquanto originalmente a norma se aplica às barras de seção circular e em função do cálculo da tensão no laminado ter sido baseado na leitura dos extensômetros e não no equilíbrio estático do ensaio. A lógica do cálculo, entretanto se manteve a mesma, em que, se assumiu uma distribuição uniforme de tensões ao longo do comprimento de ancoragem. A tensão de aderência foi calculada como a razão entre a força no laminado e a área superficial ao longo do comprimento de ancoragem, por meio da Equação 6.5.

$$
\tau_{l i}=\frac{F_{l i}}{2 \times(e+L) \times \ell_{a}}
$$

Procurou-se obter o deslizamento em dois trechos do laminado, como já foi detalhado no Item 6.3. As curvas "tensão x deslizamento" no início da zona de ancoragem obtidas no ensaio do modelo M2L150R1 podem ser visualizadas na Figura 6.20. 


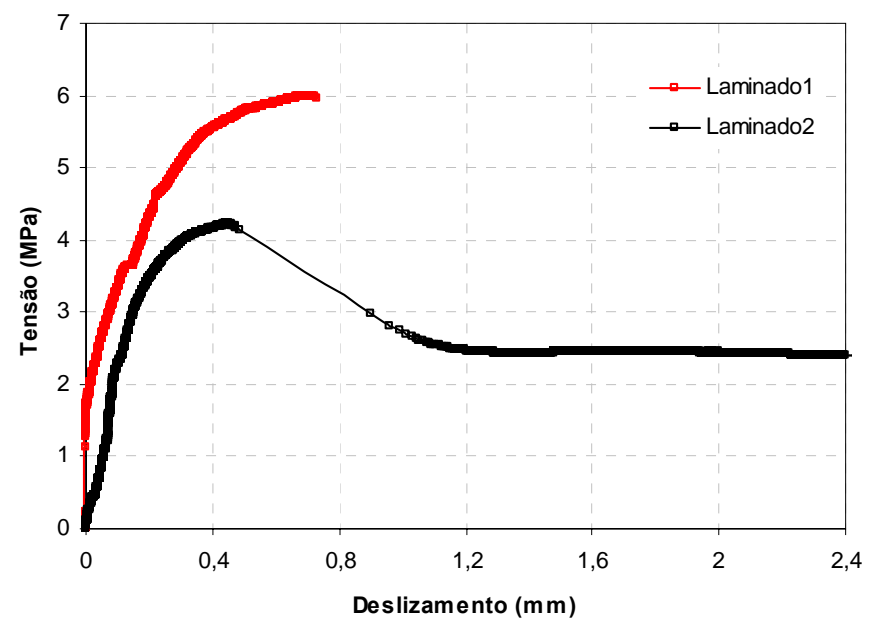

Figura 6.20 - Curva "tensão x deslizamento", no início da zona de ancoragem - M2L150R1.

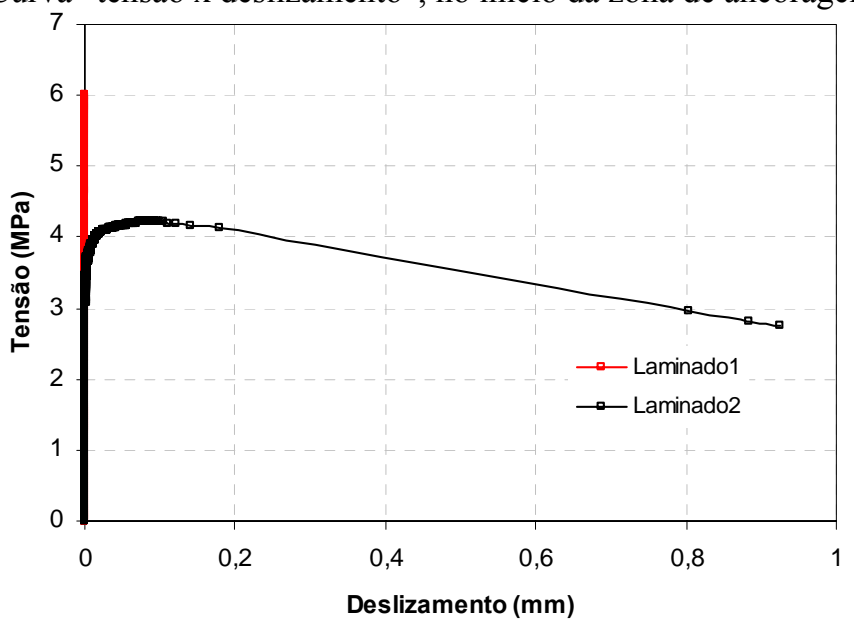

Figura 6.21 - Curva “tensão x deslizamento", no final da zona de ancoragem- M2L150R1.

A curva "tensão x deslizamento", no início da zona de ancoragem para o laminado 2 do modelo M2L150R1 tem a forma típica, observada em ensaio de laminados ou barras de PRF. Apresenta um trecho ascendente até um pico de tensão (resistência de aderência). Após o pico observa-se um trecho descendente até que se alcança um patamar para determinada tensão residual. Para a maioria dos laminados (gráficos dos demais modelos estão no APÊNDICE C), como para o laminado 1 do modelo M2L150R1, foi possível a obtenção apenas do trecho ascendente da curva "tensão x deslizamento", no início da zona ancorada. $\mathrm{Na}$ maior parte dos casos, a interrupção prematura ocorreu em função da perda de leitura do deslizamento pelo desprendimento do dispositivo de referência colado ao laminado. Esse desprendimento ocorria entre a cantoneira e a chapa metálica (Figura 6.22-a) ou entre a chapa metálica e o laminado (Figura 6.22-b) e se dava de forma brusca ao se atingir ou pouco depois de se atingir a carga máxima do ensaio. Em geral, o trecho final da zona de ancoragem sofria arrancamento brusco com deslizamento desprezível até que se atingia a carga máxima do ensaio (laminado 2 na Figura 6.21). Também se observou desprendimento do dispositivo de referência colado ao laminado no final da zona de ancoragem (laminado 1 na Figura 6.21). 


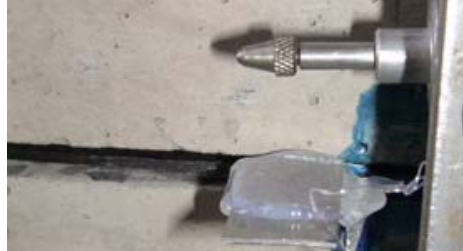

(a)

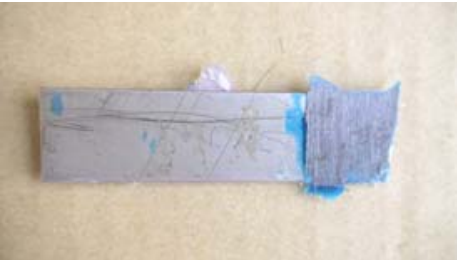

(b)

Figura 6.22 - Desprendimento do dispositivo de referência para obtenção do deslizamento: (a) desprendimento entre a cantoneira e a chapa; (b) desprendimento entre a chapa e o laminado.

\subsubsection{Variação da força máxima no laminado com o comprimento de ancoragem}

Os gráficos na Figura 6.23 ilustram a variação da força máxima no laminado com o comprimento de ancoragem para os ensaios das séries R1 e R2, respectivamente.

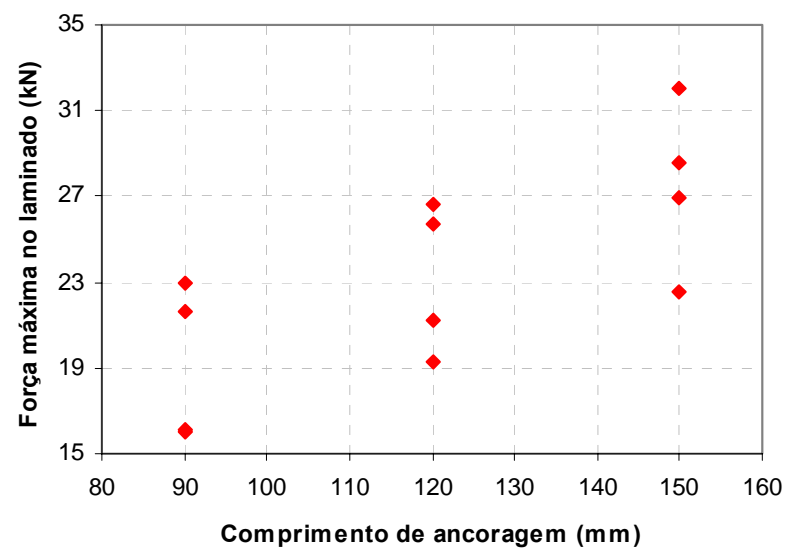

(a)

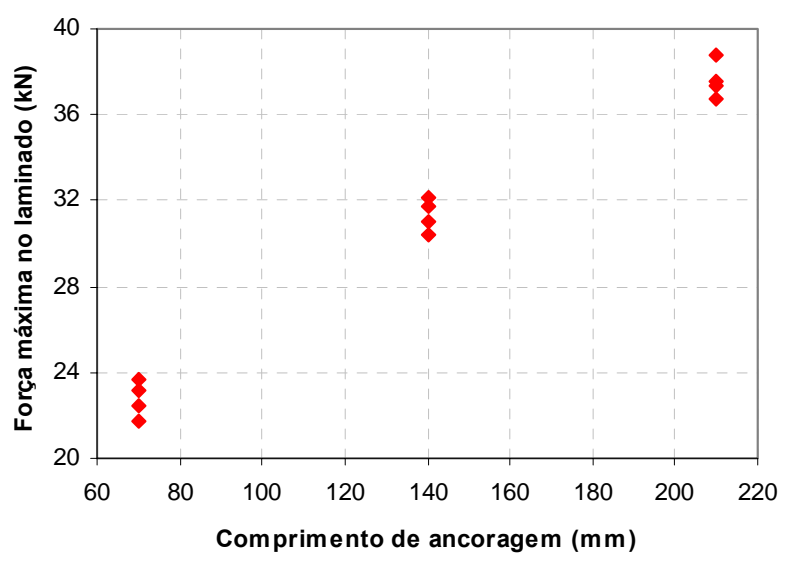

(b)

Figura 6.23 - Variação da força máxima no laminado com comprimento de ancoragem: (a) série R1; (b) série R2.

\subsubsection{Variação da tensão máxima de aderência com o comprimento de ancoragem}

Os gráficos na Figura 6.24 ilustram a variação da tensão máxima de aderência com o comprimento de ancoragem.

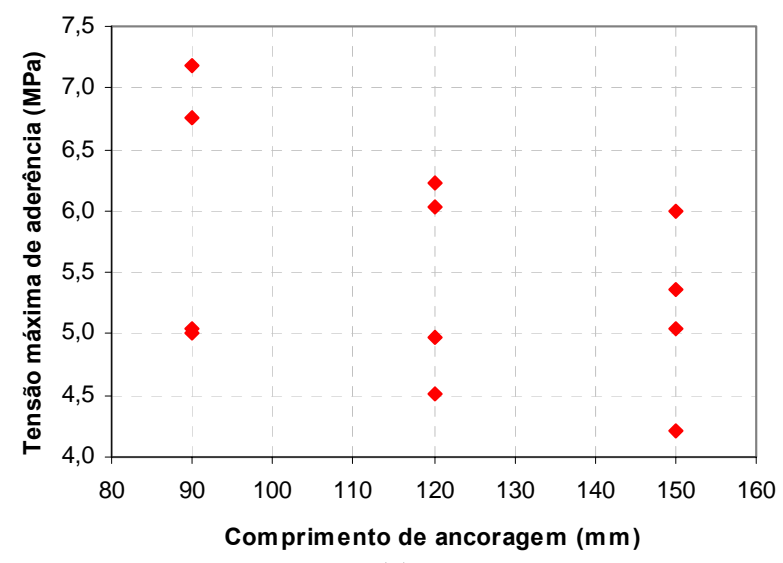

(a)

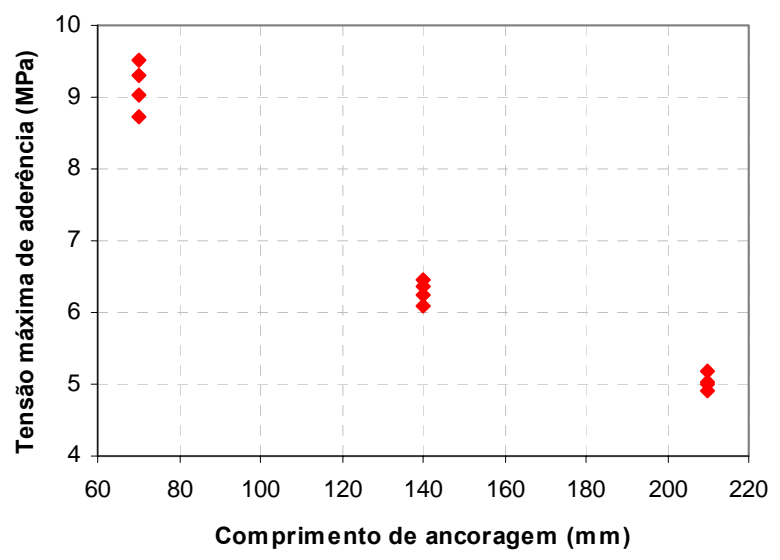

(b)

Figura 6.24 - Variação da tensão máxima de aderência com o comprimento de ancoragem: (a) série R1; (b) série R2. 


\subsubsection{Considerações acerca dos materiais}

A resina de colagem do laminado não era uma variável que se pretendia investigar nos ensaios de aderência. A idéia inicial era utilizar apenas o "Epóxi estruturante FC" fornecido pela mesma empresa do laminado, a "Rogertec". No site da empresa, essa resina é indicada para o reforço por colagem de laminados em entalhes, informação confirmada pela equipe de atendimento técnico da "Rogertec". Com base nessa informação, utilizou-se essa resina na preparação dos ensaios de aderência da serie R1, seguindo as recomendações do fabricante quanto à proporção dos componentes na mistura e ao tempo de mistura. A resina apresentou consistência muito fluida o que acarretou em dificuldade no preenchimento do entalhe (procurou-se preencher o entalhe na mesma posição em que ele estaria no caso do reforço em uma ligação de estrutura real, ou seja, em um plano horizontal). Mesmo com o cuidado de se confinar o adesivo pela colagem de fita adesiva, observou-se um mau acabamento do reforço, que apresentou vazios. Comparando-se os resultados dos ensaios em relação à força máxima de arrancamento com outros semelhantes presentes na literatura técnica (CRUZ, 2004), constatou-se que eles foram muito baixos. Além desses fatores mencionados, acrescenta-se que problemas na utilização dessa resina foram relatados por outros pesquisadores do SET e também por Oliveira Junior (2005). Por tudo isso, se decidiu realizar uma nova série de ensaios com uma outra resina. A escolha recaiu sobre a resina epóxi bi-componente "Sikadur ${ }^{\circledR}$ 330”. Na série de ensaios R2, optou-se pela utilização de cimento alta resistência inicial no concreto usado na elaboração dos modelos a fim de minimizar prejuízos em relação ao cronograma da pesquisa. Como não se observou fissuração do concreto na ruptura nos ensaios de aderência da série R1, considerou-se que a adoção de um concreto com resistência igual ou superior para confecção dos modelos da série R2 seria apropriada para que se pudessem efetuar comparações entre os resultados das duas séries.

\subsubsection{Comparações entre as duas séries de ensaio}

Os resultados obtidos para as séries de ensaios R1 e R2 estão resumidos na Tabela 6.10 e Tabela 6.11, respectivamente. 
Tabela 6.10 - Resultados obtidos na série de ensaios R1.

\begin{tabular}{|c|c|c|c|c|c|c|c|c|}
\hline Modelo & Laminado & $\begin{array}{l}\text { Idade do } \\
\text { adesivo } \\
\text { (dias) }\end{array}$ & $\begin{array}{c}\text { Idade do } \\
\text { concreto } \\
\text { (dias) }\end{array}$ & $\begin{array}{l}F_{1 \text { máx }} \\
(\mathbf{k N})\end{array}$ & $\begin{array}{c}\sigma_{\text {máx }} \\
(\mathbf{M P a})\end{array}$ & $\begin{array}{c}\tau_{\text {máx }} \\
\text { (MPa) }\end{array}$ & $\begin{array}{l}\mathcal{E}_{\text {máx }} \\
(\%)\end{array}$ & $\begin{array}{c}\Delta_{\text {máx }} \\
(\mathbf{m m})\end{array}$ \\
\hline \multirow{2}{*}{ M1L90R1 } & 1 & 33 & 97 & 22,99 & 694,32 & 7,17 & 5,51 & 0,339 \\
\hline & 2 & 33 & 97 & 16,03 & 484,07 & 5,00 & 3,84 & 0,194 \\
\hline \multirow{2}{*}{ M2L90R1 } & 1 & 33 & 97 & 21,64 & 653,59 & 6,75 & 5,19 & 0,148 \\
\hline & 2 & 33 & 97 & 16,15 & 487,73 & 5,04 & 3,87 & 0,248 \\
\hline Média & & & & 19,20 & $\mathbf{5 7 9 , 9 3}$ & 5,99 & 4,60 & 0,23 \\
\hline Desvio & & & & 3,64 & 109,85 & 1,14 & $\mathbf{0 , 8 7}$ & 0,08 \\
\hline $\begin{array}{c}\text { Coeficiente } \\
\text { de } \\
\text { variação }\end{array}$ & & & & $18,94 \%$ & $18,94 \%$ & $18,94 \%$ & $18,94 \%$ & $35,34 \%$ \\
\hline \multirow{2}{*}{ M1L120R1 } & 1 & 34 & 98 & 26,62 & 803,99 & 6,23 & 6,38 & 0,428 \\
\hline & 2 & 34 & 98 & 21,27 & 642,63 & 4,98 & 5,10 & 0,110 \\
\hline \multirow{2}{*}{ M2L120R1 } & 1 & 34 & 98 & 25,75 & 777,71 & 6,03 & 6,17 & 0,577 \\
\hline & 2 & 34 & 98 & 19,31 & 583,23 & 4,52 & 4,63 & 0,248 \\
\hline Média & & & & 23,24 & 701,89 & 5,44 & $\mathbf{5 , 5 7}$ & 0,34 \\
\hline Desvio & & & & 3,51 & 106,09 & $\mathbf{0 , 8 2}$ & 0,84 & 0,20 \\
\hline $\begin{array}{c}\text { Coeficiente } \\
\text { de } \\
\text { variação }\end{array}$ & & & & $15,12 \%$ & $15,12 \%$ & $15,12 \%$ & $15,12 \%$ & $59,97 \%$ \\
\hline \multirow{2}{*}{ M1L150R1 } & 1 & 31 & 98 & 28,59 & 863,52 & 5,35 & 6,85 & 0,547 \\
\hline & 2 & 31 & 98 & 26,97 & 814,53 & 5,05 & 6,46 & 0,713 \\
\hline \multirow{2}{*}{ M2L150R1 } & 1 & 30 & 97 & 32,00 & 966,53 & 5,99 & 7,67 & 0,700 \\
\hline & 2 & 30 & 97 & 22,51 & 679,90 & 4,22 & 5,40 & 0,456 \\
\hline Média & & & & 27,51 & 831,12 & 5,15 & 6,60 & 0,60 \\
\hline Desvio & & & & 3,94 & 119,07 & 0,74 & 0,94 & 0,12 \\
\hline $\begin{array}{c}\text { Coeficiente } \\
\text { de } \\
\text { variacão }\end{array}$ & & & & $14,33 \%$ & $14,33 \%$ & $14,33 \%$ & $14,33 \%$ & $20,56 \%$ \\
\hline
\end{tabular}


Tabela 6.11 - Resultados obtidos na série de ensaios R2.

\begin{tabular}{|c|c|c|c|c|c|c|c|c|}
\hline Modelo & Laminado & $\begin{array}{c}\text { Idade do } \\
\text { adesivo } \\
\text { (dias) }\end{array}$ & $\begin{array}{c}\text { Idade do } \\
\text { concreto } \\
\text { (dias) }\end{array}$ & $\begin{array}{l}\mathbf{F}_{\text {Imáx }} \\
(\mathbf{k N})\end{array}$ & $\begin{array}{c}\sigma_{\operatorname{máx}} \\
(\mathrm{MPa})\end{array}$ & $\begin{array}{c}\tau_{\text {máx }} \\
(\mathbf{M P a})\end{array}$ & $\begin{array}{l}\varepsilon_{\text {máx }} \\
(\% 0)\end{array}$ & $\begin{array}{c}\Delta_{\text {máx }} \\
(\mathbf{m m})\end{array}$ \\
\hline \multirow{2}{*}{ M1L70R2 } & 1 & 7 & 16 & 21,71 & 655,83 & 8,71 & 5,21 & $*$ \\
\hline & 2 & 7 & 16 & 23,72 & 716,57 & 9,52 & 5,69 & 0,159 \\
\hline \multirow{2}{*}{ M2L70R2 } & 1 & 7 & 30 & 22,47 & 678,75 & 9,02 & 5,39 & $*$ \\
\hline & 2 & 7 & 30 & 23,15 & 699,22 & 9,29 & 5,55 & 0,411 \\
\hline Média & & & & 22,76 & 687,59 & 9,13 & 5,46 & 0,285 \\
\hline Desvio & & & & 0,87 & 26,22 & 0,35 & 0,21 & 0,18 \\
\hline $\begin{array}{c}\text { Coeficiente } \\
\text { de } \\
\text { variação }\end{array}$ & & & & $3,81 \%$ & $3,81 \%$ & $3,81 \%$ & $3,81 \%$ & $62,52 \%$ \\
\hline \multirow{2}{*}{ M1L140R2 } & 1 & 7 & 30 & 31,77 & 959,75 & 6,38 & 7,62 & 1,020 \\
\hline & 2 & 7 & 30 & 30,38 & 917,68 & 6,10 & 7,28 & 0,830 \\
\hline \multirow{2}{*}{ M2L140R2 } & 1 & 7 & 30 & 31,05 & 938,02 & 6,23 & 7,44 & $*$ \\
\hline & 2 & 7 & 30 & 32,14 & 970,68 & 6,45 & 7,70 & 0,909 \\
\hline Média & & & & 31,34 & 946,53 & 6,29 & 7,51 & 0,92 \\
\hline Desvio & & & & 0,78 & 23,54 & 0,16 & 0,19 & 0,10 \\
\hline $\begin{array}{c}\text { Coeficiente } \\
\text { de } \\
\text { variaçãa }\end{array}$ & & & & $2,49 \%$ & $2,49 \%$ & $2,49 \%$ & $2,49 \%$ & $10,38 \%$ \\
\hline \multirow{2}{*}{ M1L210R2 } & 1 & 7 & 30 & 37,35 & 1128,25 & 5,00 & 8,95 & 1,420 \\
\hline & 2 & 7 & 30 & 36,75 & 1110,11 & 4,92 & 8,81 & 1,430 \\
\hline \multirow{2}{*}{ M2L210R2 } & 1 & 7 & 30 & 38,76 & 1170,80 & 5,18 & 9,29 & 1,730 \\
\hline & 2 & 7 & 30 & 37,55 & 1134,18 & 5,02 & 9,00 & 1,420 \\
\hline Média & & & & 37,60 & 1135,84 & 5,03 & 9,01 & 1,50 \\
\hline Desvio & & & & 0,84 & 25,46 & 0,11 & 0,20 & 0,15 \\
\hline $\begin{array}{c}\text { Coeficiente } \\
\text { de } \\
\text { variação }\end{array}$ & & & & $2,24 \%$ & $2,24 \%$ & $2,24 \%$ & $2,24 \%$ & $10,23 \%$ \\
\hline
\end{tabular}

Comparando-se os valores médios obtidos para força máxima no laminado ( $\mathrm{F}_{1}$ máx $)$, tensão máxima no laminado $\left(\sigma_{\text {máx }}\right)$, tensão máxima de aderência $\left(\tau_{\text {máx }}\right)$, deformação máxima $\left(\varepsilon_{\text {máx }}\right)$, observa-se um melhor desempenho do adesivo utilizado na série R2. Isso fica mais claro nos gráficos da Figura 6.25, Figura 6.26, Figura 6.27 e Figura 6.28, visto que não foram utilizados os mesmos comprimentos de ancoragem nas duas séries. A força máxima no laminado, a tensão máxima no laminado, o deslizamento no inicio da zona de ancoragem correspondente à força máxima no laminado $\left(\Delta_{\text {máx }}\right)$ (Figura 6.29) e a deformação máxima 
apresentaram a tendência de crescimento com o aumento do comprimento de ancoragem, para ambas as séries de ensaios $\left(\mathrm{F}_{1 \text { máx }}, \sigma_{\text {máx }}\right.$ e $\varepsilon_{\text {máx }}$ têm seus valores atrelados e obrigatoriamente deveriam apresentar a mesma tendência, uma vez que $F_{1 \text { máx }}$ e $\sigma_{\text {máx }}$ são resultantes da multiplicação de $\varepsilon_{\text {máx }}$ por valores constantes e positivos). A tensão máxima de aderência $\left(\tau_{\text {máx }}\right)$ apresentou decréscimo com o aumento do comprimento de ancoragem.

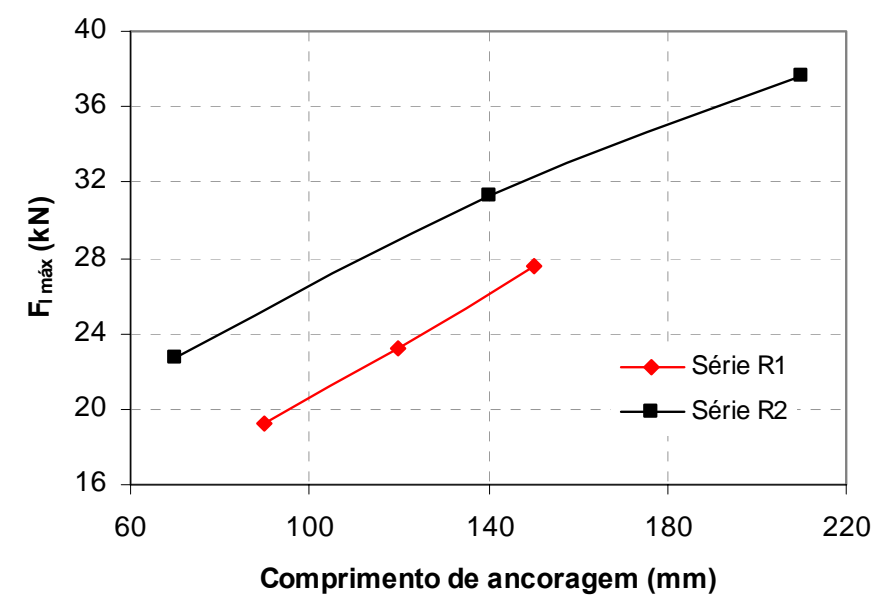

Figura 6.25 - Variação da força máxima no laminado (valores médios) com o comprimento de ancoragem.

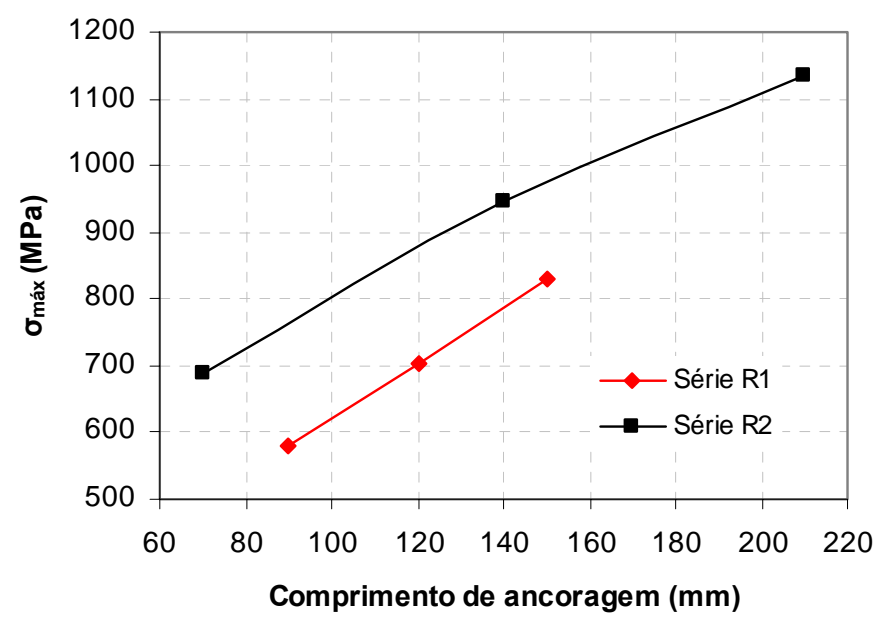

Figura 6.26 - Variação tensão máxima no laminado (valores médios) com o comprimento de ancoragem.

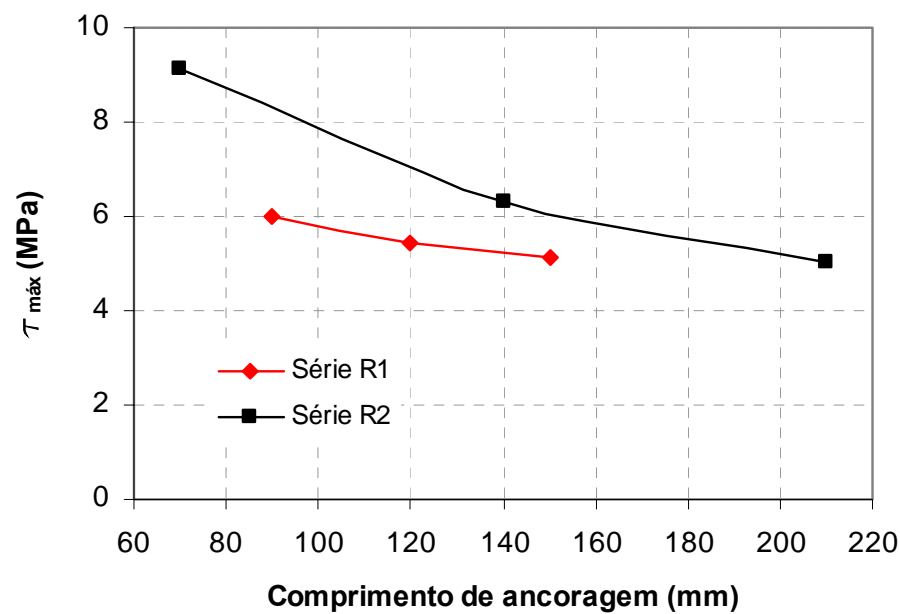

Figura 6.27 - Variação tensão de aderência máxima (valores médios) com o comprimento de ancoragem. 


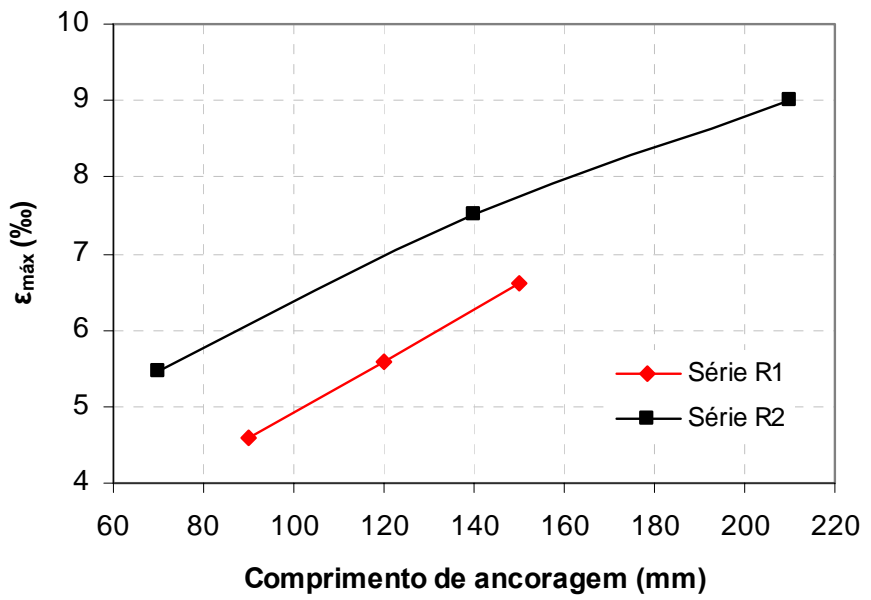

Figura 6.28 - Variação deformação máxima no laminado (valores médios) com o comprimento de ancoragem.

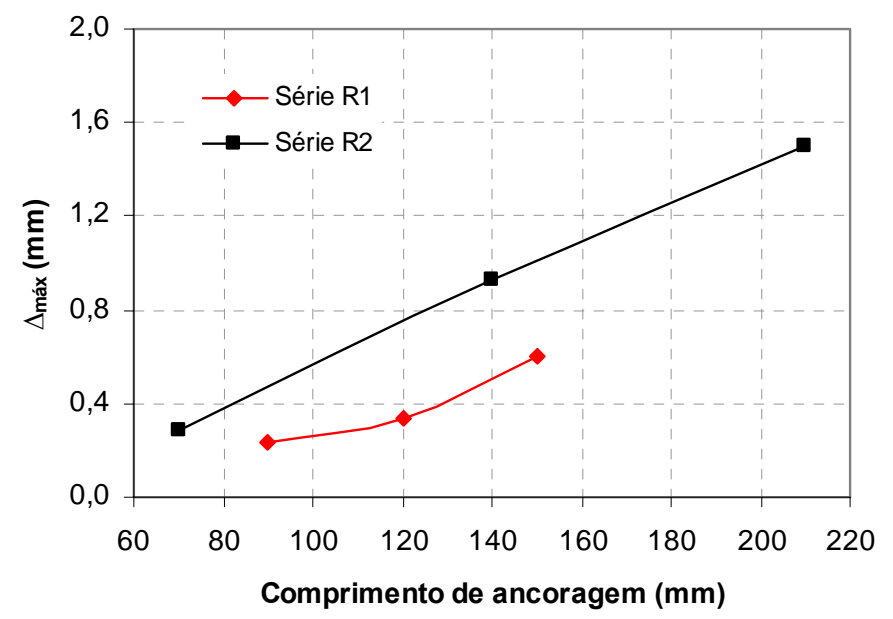

Figura 6.29 - Variação do deslizamento no inicio da zona de ancoragem correspondente à força máxima no laminado (valores médios) com o comprimento de ancoragem.

$\mathrm{O}$ adesivo utilizado na série $\mathrm{R} 2$ teve um desempenho superior também em relação à facilidade de execução do reforço. A fluidez excessiva do adesivo utilizado na série R1 já foi mencionada ao longo do trabalho. A consistência do adesivo utilizado na série R2 foi bastante satisfatória, de modo que o entalhe foi preenchido com facilidade e não foi necessária a proteção do reforço para que o adesivo não escorresse. Essas características dos adesivos interferiram na uniformidade dos resultados obtidos. A maior dispersão dos resultados da série R1 pode ser comprovada pela comparação dos coeficientes de variação na Tabela 6.10 e Tabela 6.11. A trabalhabilidade dos adesivos interferiu também na qualidade final do reforço. Conforme se pode observar na Figura 6.30-a, o reforço com o adesivo utilizado na série R1 apresentou vazios na superfície, enquanto que o reforço com o adesivo da série R2, teve um bom acabamento superficial (Figura 6.30-b). 


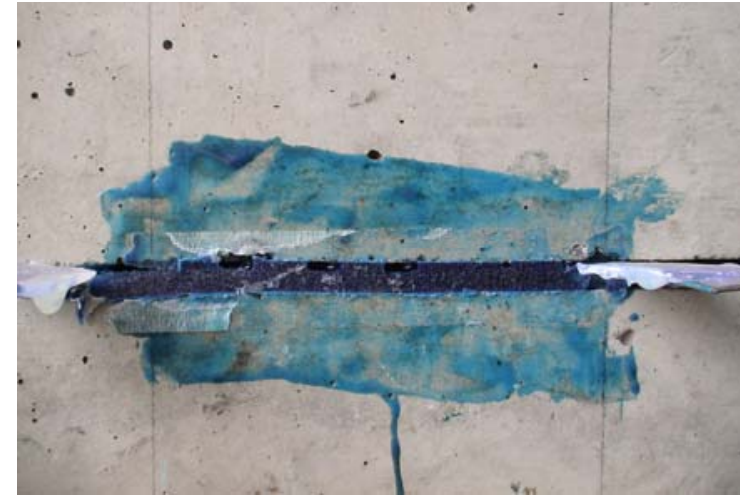

(a)

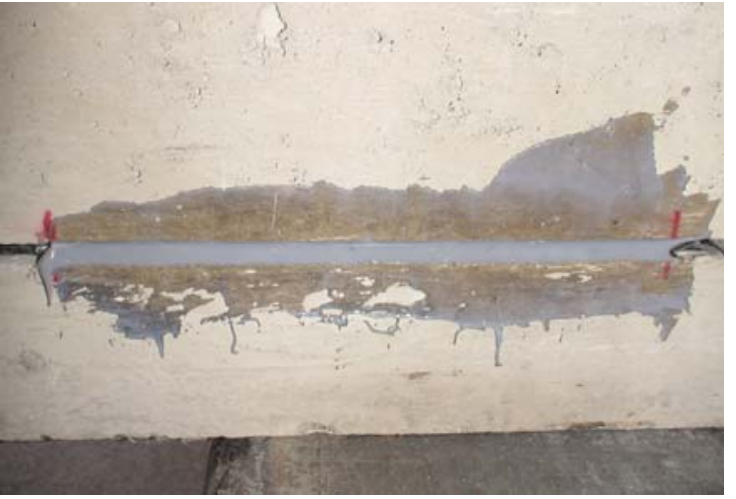

(b)

Figura 6.30 - Acabamento superficial do reforço: (a) série R1; (b) série R2.

A ruptura do laminado não foi alcançada em nenhum dos ensaios das duas séries. A máxima deformação observada foi de 9,29 \%o, apenas 55\% da deformação na ruptura (17 \%o). Com base nos resultados dos ensaios da serie R2 elaborou-se um gráfico "deformação $\mathrm{x}$ comprimento de ancoragem". Determinou-se uma linha de tendência que se adequasse aos dados experimentais e se aproximasse da origem do sistema cartesiano. Foi adotada uma função exponencial. De acordo com essa função, só se alcançaria a deformação na ruptura do laminado para um comprimento de ancoragem de $2600 \mathrm{~mm}$ (Figura 6.31-a). Estimou-se por meio dessa função a deformação que se obteria ao utilizar-se para ancoragem todo o comprimento da viga (375 mm) dos modelos de ligação (Figura 6.31-b), descritos no Capítulo 7. Alerta-se que não se pretende assumir que esta é uma lei que relaciona as duas variáveis em questão, mas apenas uma extrapolação dos dados experimentais, adequada ás condições específicas dos ensaios realizados. Salienta-se a imprecisão em relação à estimativa do comprimento de ancoragem que proporcionaria a ruptura do laminado (Figura 6.31-a), uma vez que, a extrapolação conduziu a um valor de $2600 \mathrm{~mm}$, muito superior ao valor máximo utilizado nos ensaios experimentais $(210 \mathrm{~mm})$.

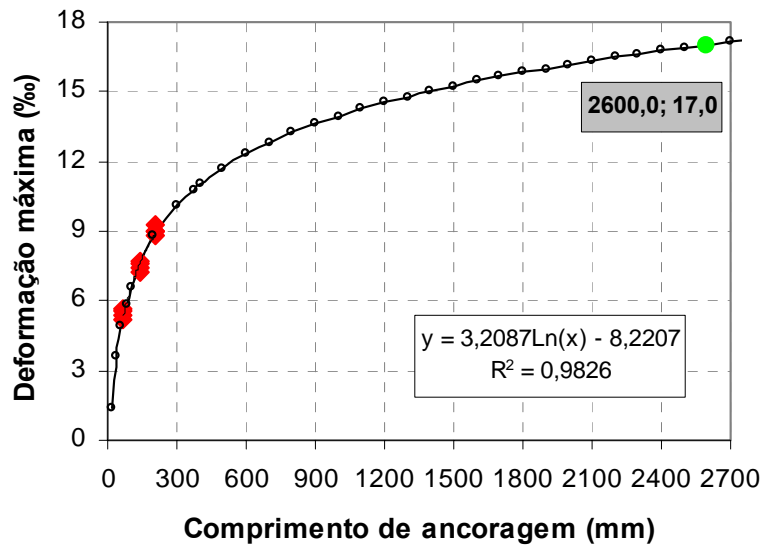

(a)

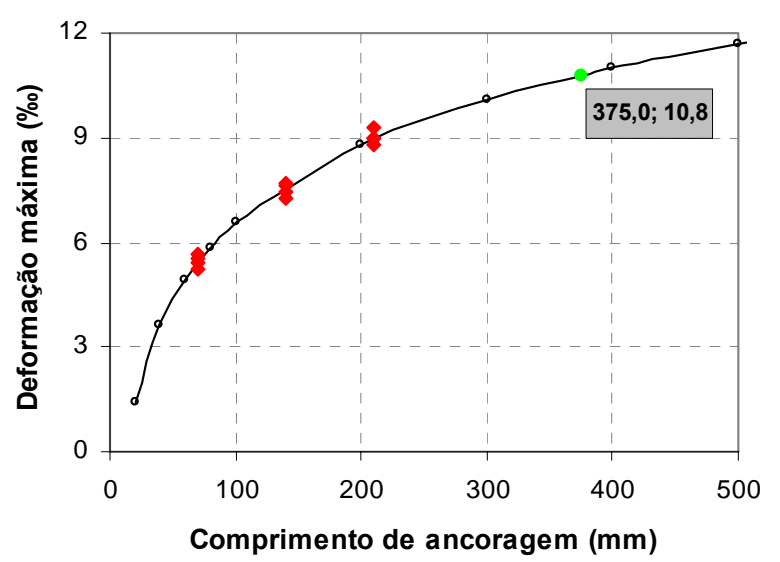

(b)

Figura 6.31 - Gráfico “deformação máxima x comprimento de ancoragem” com linha de tendência: (a) para estimativa do comprimento de ancoragem correspondente a deformação na ruptura; (b) para estimativa da deformação correspondente ao comprimento de ancoragem de $375 \mathrm{~mm}$. 


\section{CAPÍTULO 7}

\section{ENSAIOS EM MODELOS REDUZIDOS DE LIGAÇÃO}

\subsection{Características dos modelos}

Os modelos de ligação estudados foram concebidos para se assemelhar a um trecho de estrutura real (destacado na Figura 7.1). As dimensões dos elementos conectados, trechos de vigas e de pilar, foram reduzidas num fator de aproximadamente 1:3. A folga entre viga e pilar e o furo do chumbador não puderam ser reduzidos na mesma proporção, pois isso dificultaria a montagem do modelo e inviabilizaria o preenchimento por graute. A rigor, pela Teoria da Semelhança, o modelo não pode ser considerado representativo de uma ligação real. Seria necessário, para tanto, que não somente as dimensões dos elementos fossem reduzidas, mas também as dimensões dos materiais empregados na confecção dos modelos, como os agregados do concreto e as barras de aço. Embora a utilização de modelos reduzidos possa representar prejuízo em relação à equivalência a estruturas reais, alguns aspectos favoreceram a sua adoção nesta pesquisa a destacar: a possibilidade de caracterização dos mecanismos resistentes da ligação, a sua adequação aos ensaios dinâmicos, a possibilidade de execução de vários modelos, o caráter exploratório do estudo, a facilidade de manuseio dos elementos.

À exceção do modelo-piloto, os modelos de ensaio são referenciados por nomenclatura com quatro campos, por exemplo, " $\underline{\mathrm{N} 1} \underline{\mathrm{CJ}}$ ". O primeiro campo a define o tipo de reforço. A letra "N" significa reforço a momento fletor Negativo e "P" significa reforço a momento fletor Positivo. O segundo campo designa o número do modelo, podendo ser igual a 1 ou 2. O terceiro e o quarto campos (CJ ou SJ) definem se o modelo foi confeccionado Com 


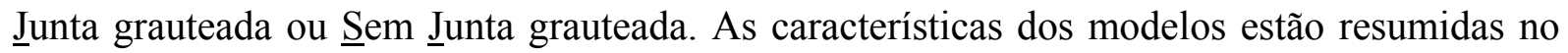
Quadro 7.1.

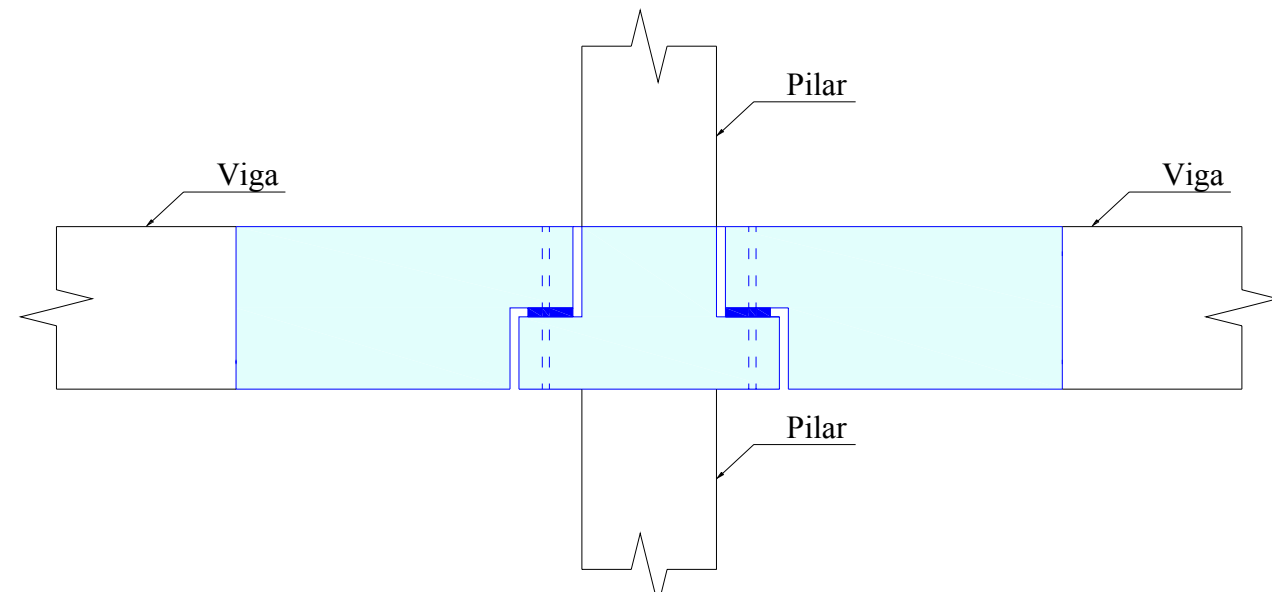

Figura 7.1 - Porção de uma estrutura com trecho equivalente ao modelo de ensaio em destaque.

Em três dos cinco tipos de modelos de ensaio, foram mantidos os mecanismos originais de transferência de esforços da ligação (almofada de apoio, chumbador, graute do furo do chumbador) e acrescentaram-se outros mecanismos para que ele se tornasse resistente à flexão (reforço com laminados colados em entalhes e graute no espaço entre o consolo e a viga, destacados na Figura 7.2, Figura 7.3 e Figura 7.4). Em um dos modelos (modelo-piloto), executou-se reforço a momento fletor positivo e negativo (Figura 7.2). Nos outros modelos, o reforço com laminado foi realizado com vistas ao incremento de resistência a momento fletor positivo ou negativo (Figura 7.3 e Figura 7.4).

Executaram-se também dois modelos com juntas perfeitamente conjugadas. Esses modelos não representam trechos de estruturas reais e foram idealizados para investigação da influência da almofada de apoio e do grauteamento das juntas no comportamento da ligação. Eles foram confeccionados em duas etapas de concretagem. Primeiramente, concretaram-se os trechos de pilar e consolos e posteriormente, os trechos de vigas. Um desses modelos foi reforçado a momento fletor negativo (Figura 7.5) e o outro a momento fletor positivo (Figura 7.6).

Para todos os modelos, o entalhe foi realizado a uma distância de $30 \mathrm{~mm}$ da face superior ou inferior, com espessura de aproximadamente $5 \mathrm{~mm}$ e profundidade de $18 \mathrm{~mm}$ (detalhe na Figura 7.2). 


\begin{tabular}{|c|c|c|c|c|c|}
\hline 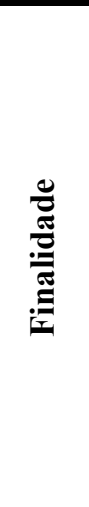 & 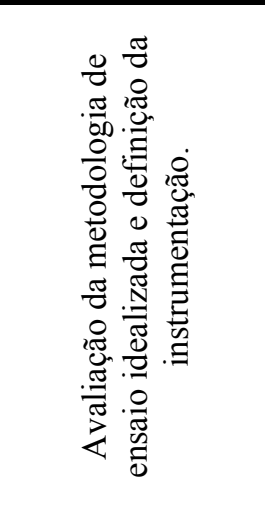 & 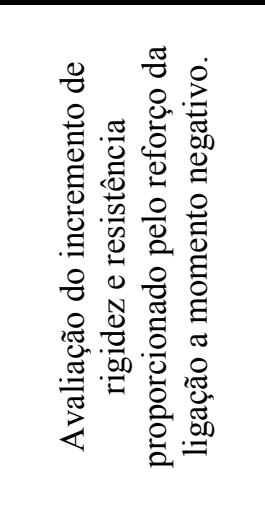 & 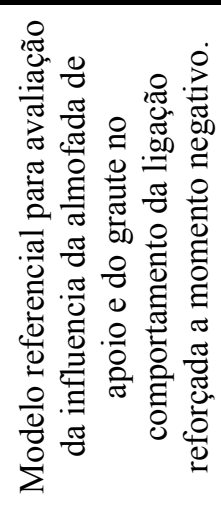 & 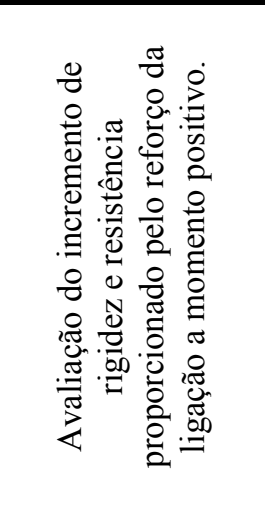 & 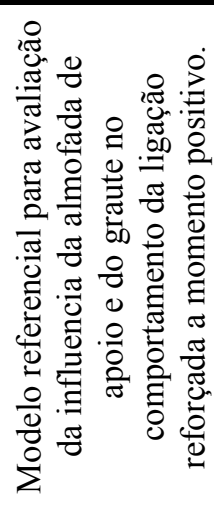 \\
\hline 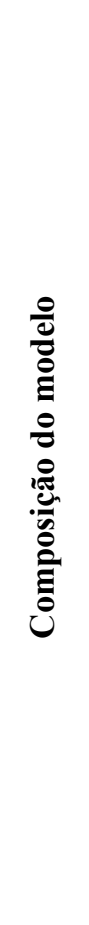 & 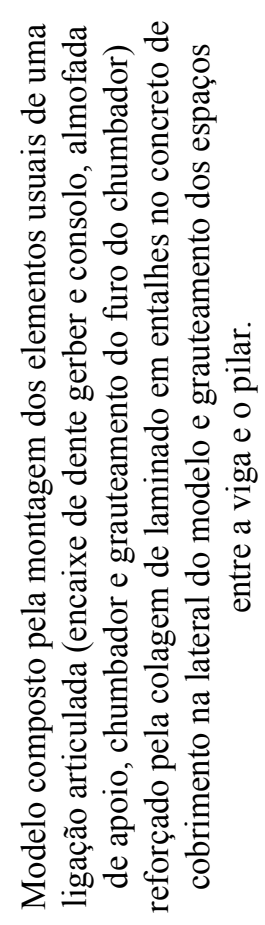 & 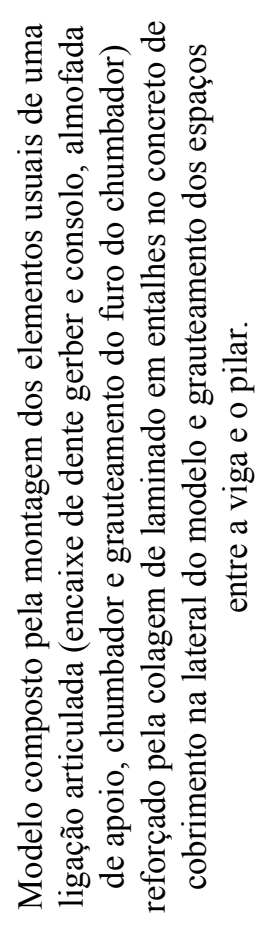 & 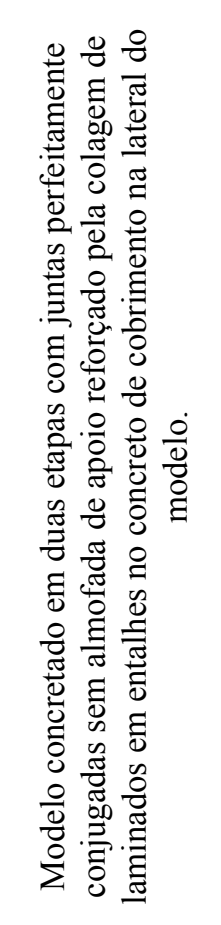 & 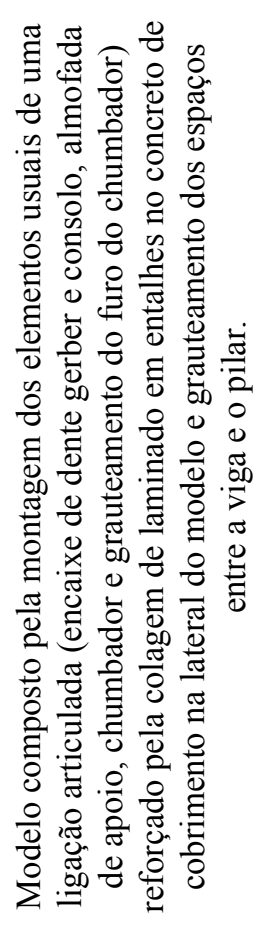 & 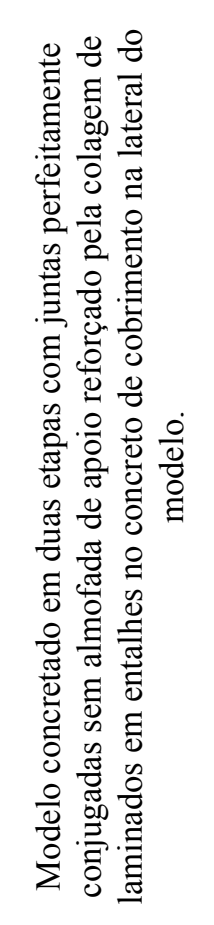 \\
\hline 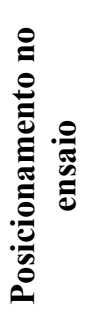 & 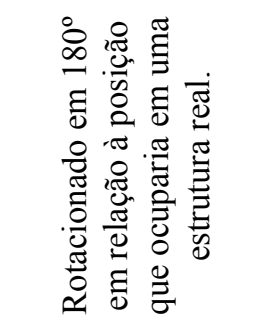 & 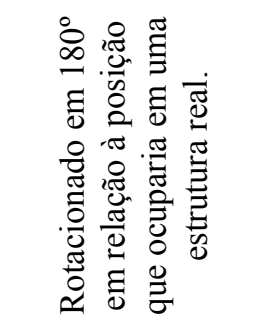 & 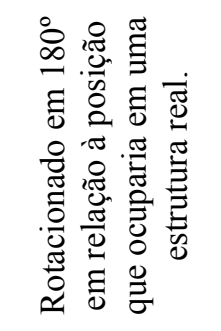 & 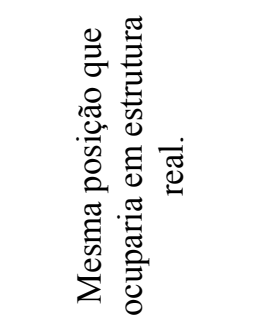 & 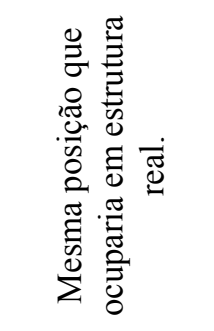 \\
\hline 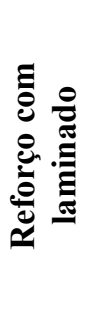 & 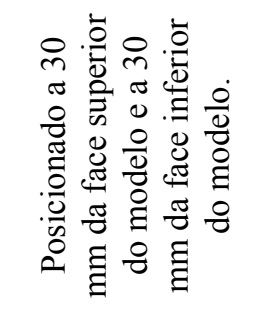 & 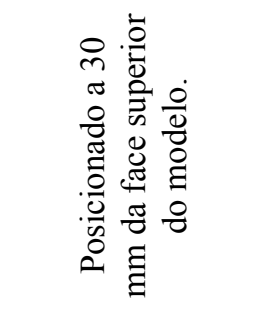 & 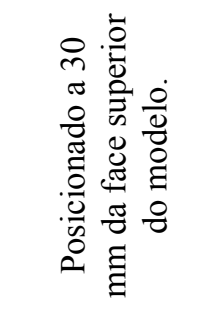 & 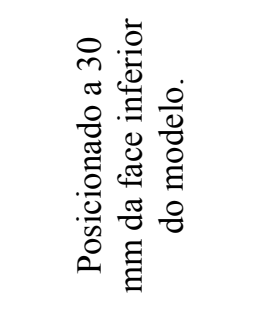 & 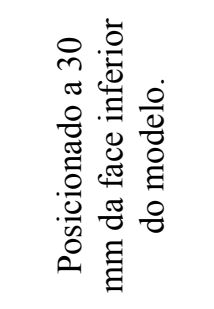 \\
\hline$\frac{e}{\frac{e}{g}}$ & $\frac{\theta}{\stackrel{\theta}{*}}$ & $\begin{array}{l}Z \widetilde{U} \\
Z \mathbf{Z}\end{array}$ & $\vec{Z}$ & $\underline{a}$ & $\tilde{a}$ \\
\hline
\end{tabular}




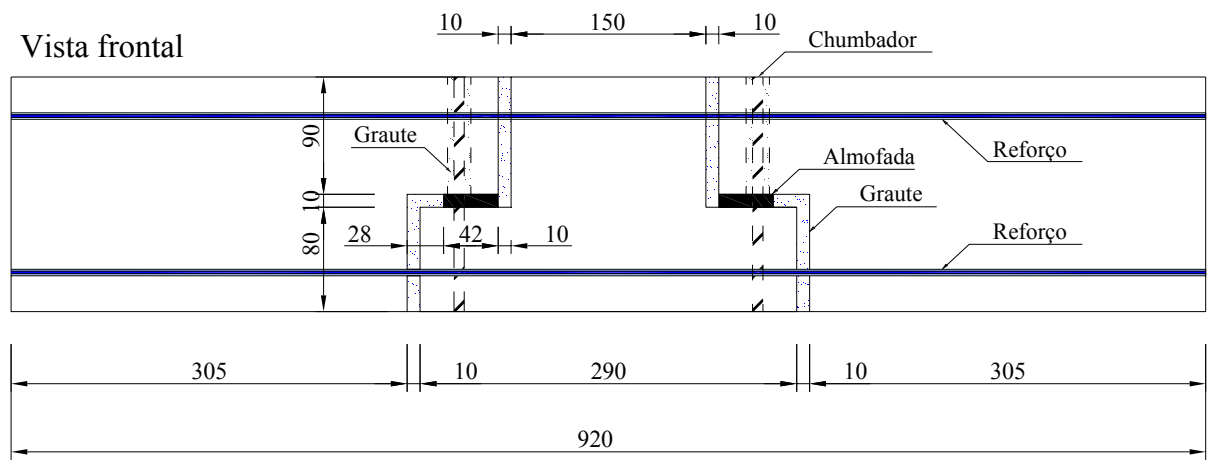

Medidas em milímetros

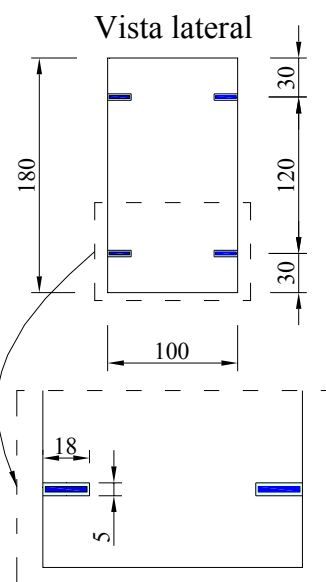

Figura 7.2 - Características do modelo-piloto.
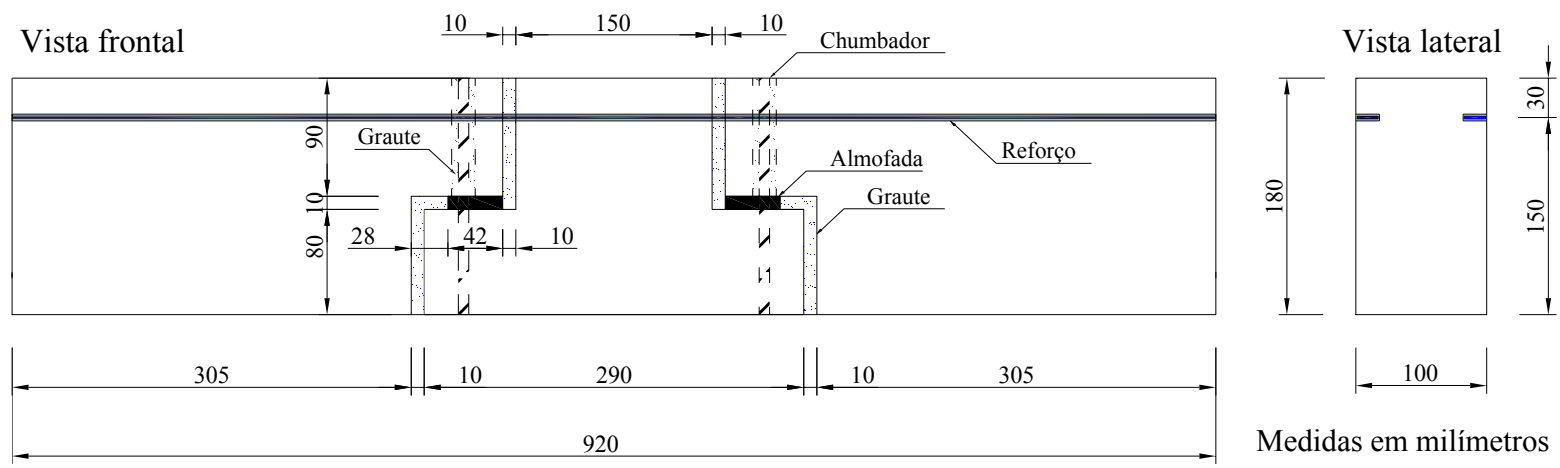

Figura 7.3 - Características dos modelos N1 CJ e N2 CJ.
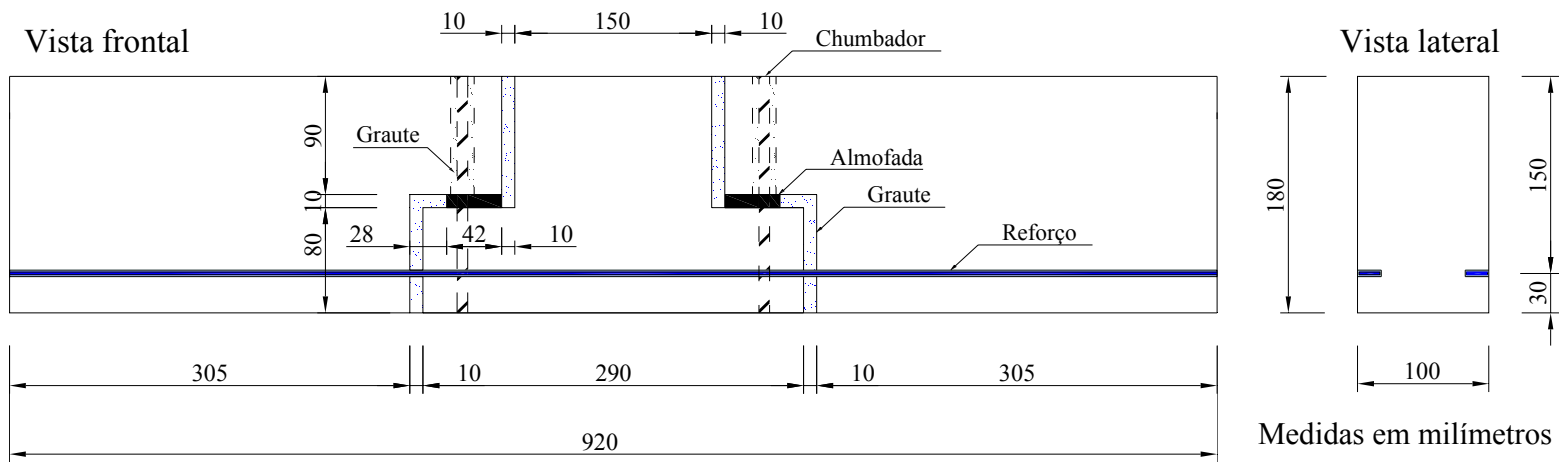

Figura 7.4 - Características do modelo P1 CJ.
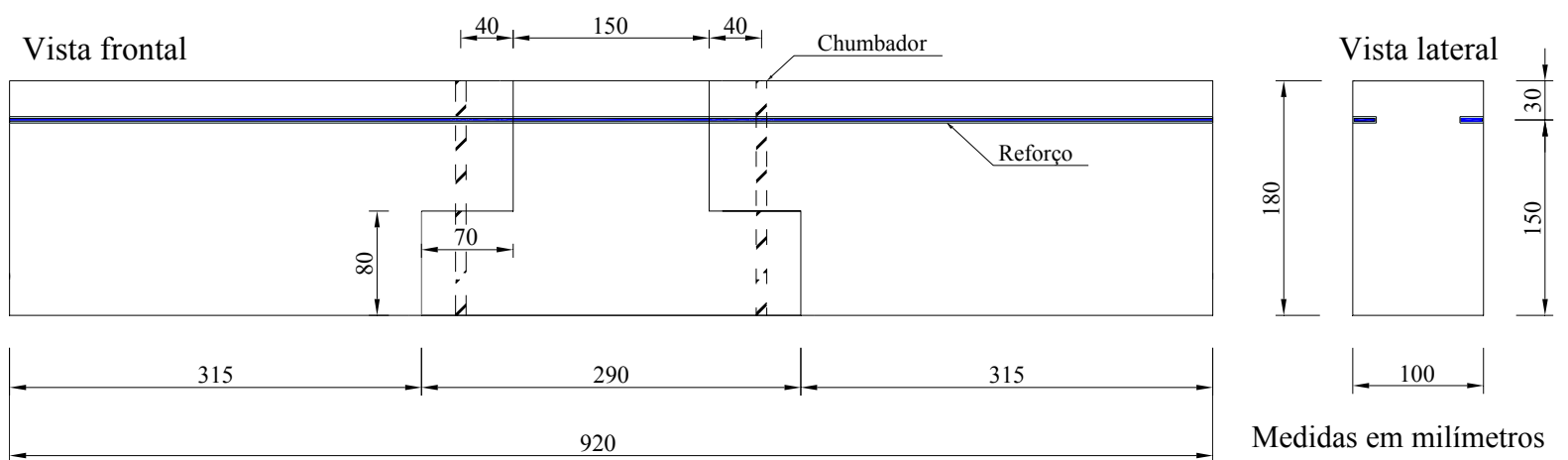

Figura 7.5 - Características do modelo N1 SJ. 

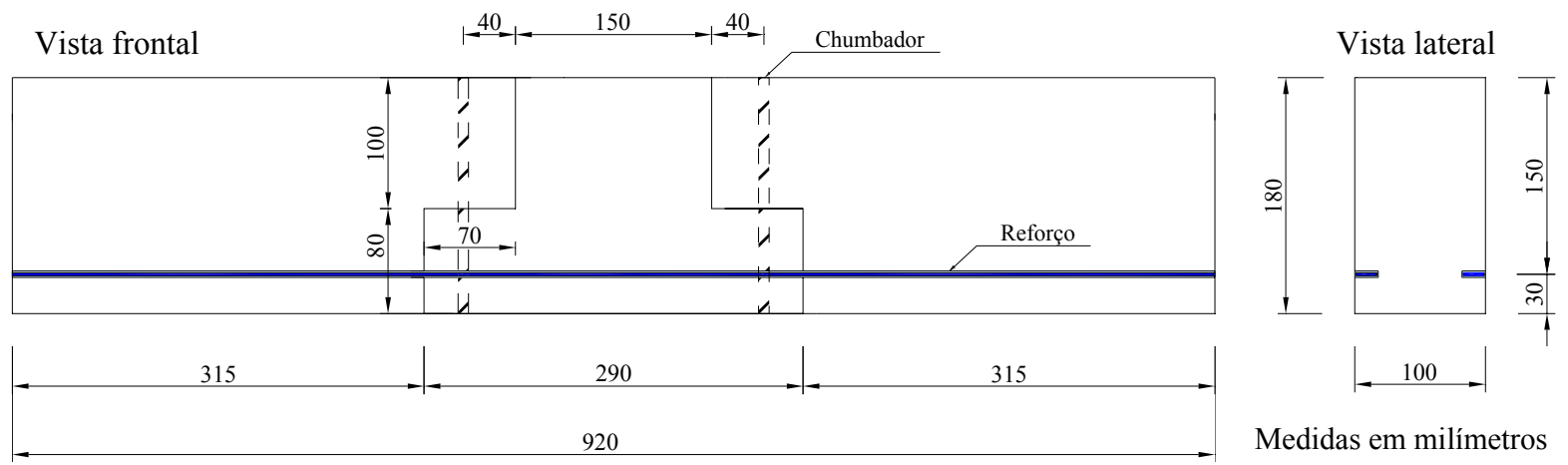

Figura 7.6 - Características do modelo P1 SJ.

Medidas em milímetros

Adotaram-se para as armaduras longitudinais e transversais das vigas as mesmas taxas dos blocos dos ensaios de aderência. As armaduras longitudinais são armaduras construtivas e a taxa de armadura transversal é mais que o suficiente para impedir a ruptura por cisalhamento na viga. As armaduras adotadas no consolo e dente do trecho de pilar e viga foram calculadas com base nas recomendações de El Debs (2000). A armadura N2 na Figura 7.7 foi calculada da mesma forma que a armadura de suspensão da viga. Os detalhes de todas as armaduras dos modelos constam na Figura 7.7 e na Figura 7.8.

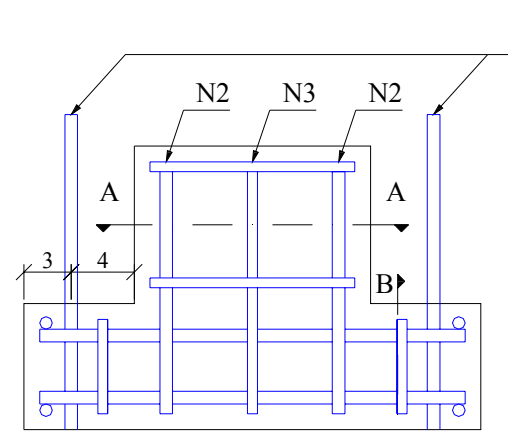

B,

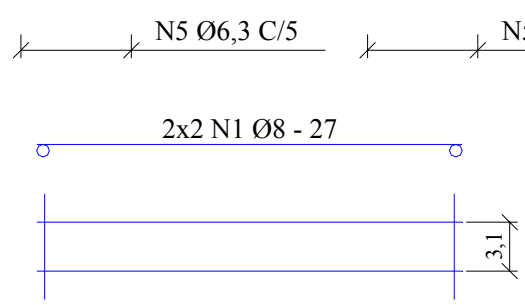

Medidas em centímetros

Barra Ø8 - 20

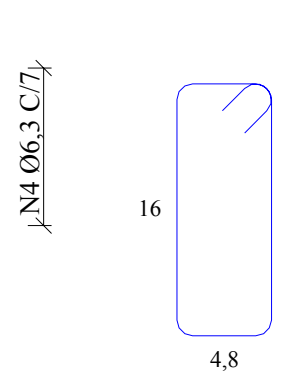

N2 Ø8- 54

$\mathrm{N} 5 \varnothing 6,3 \mathrm{C} / 5$

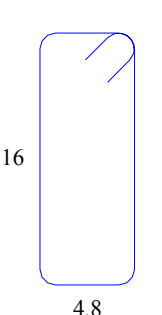

N3 Ø6,3 - 54

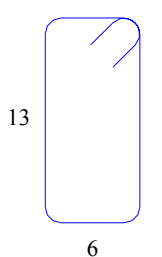

N4 Ø6,3- 50

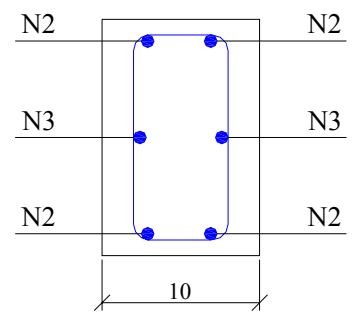

CORTE B-B

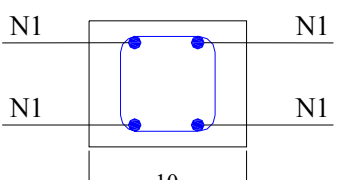

10

Figura 7.7 - Detalhamento da armadura do consolo. 


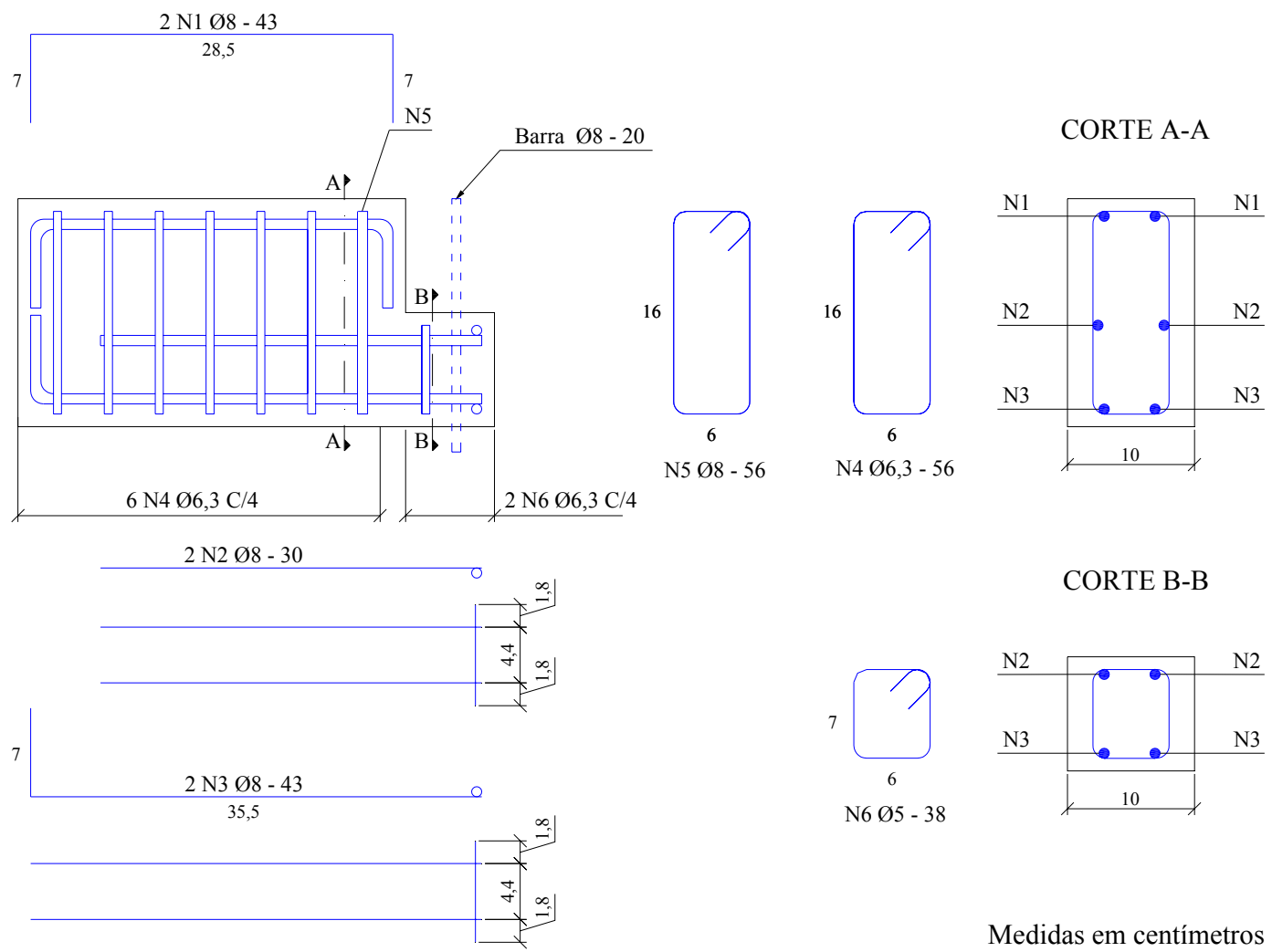

Figura 7.8 - Detalhamento da armadura da viga.

\subsection{Propriedades dos materiais}

Para o aço utilizado na armadura e como chumbador nos modelos de ligação, valem os mesmos ensaios de caracterização efetuados para o aço utilizado nos modelos dos ensaios de aderência da série R2, como apresentados no item 6.2.1. O laminado utilizado no reforço do modelo de ligação foi o mesmo descrito no item 6.2.4. Para a colagem do laminado, utilizouse resina epóxi bi-componente "Sikadur ${ }^{\circledR} 330 "$ cujas propriedades constam no item 6.2.3.

\subsubsection{Concreto}

Utilizou-se cimento de alta resistência inicial na elaboração do concreto com traço de $1: 2,3: 2,3$, relação água/cimento de 0,5 e resistência à compressão prevista para 28 dias de 50 $\mathrm{MPa}$. O consumo de materiais por metro cúbico está discriminado na Tabela 7.1.

Tabela 7.1 - Consumo de materiais por metro cúbico para o concreto utilizado no modelo de ligação.

\begin{tabular}{cc}
\hline Material & Consumo $\left(\mathbf{k g} / \mathbf{~ m}^{\mathbf{3}}\right)$ \\
\hline Cimento CP IV ARI PLUS & 400 \\
Areia seca & 920 \\
Brita 1 & 920 \\
Água & 200 \\
\hline
\end{tabular}


As determinações das resistências à compressão e à tração do concreto foram realizadas com base na NBR 5739 (1994) e NBR 7222 (1994). Utilizaram-se corpos-de-prova cilíndricos com dimensões de $10 \mathrm{~cm}$ de diâmetro e $20 \mathrm{~cm}$ de altura. A resistência à compressão calculada para os CPs de $10 \mathrm{~mm}$ x $20 \mathrm{~mm}$ foi multiplicada por um fator de redução de 0,95 para se equivaler à resistência de CPs de $15 \mathrm{~mm}$ x $30 \mathrm{~mm}$. O procedimento para a obtenção do módulo de elasticidade foi o mesmo descrito no item 6.2.2. Os ensaios para determinação da resistência a tração do concreto foram realizados em na máquina hidráulica ELE Autotest 2000. Os ensaios para determinação da resistência à compressão e do módulo de elasticidade do concreto foram executados na máquina universal de ensaios servohidráulica INSTRON com uso do sistema de aquisição de dados System 5000 da Vishay. Os resultados da caracterização do concreto utilizado nos trechos de pilar e viga do modelopiloto, trechos de pilar e viga dos modelos N1 CJ, N2 CJ, P1 CJ e trecho de pilar dos modelos N1 SJ e P1 SJ estão reunidos na Tabela 7.2 e na Tabela 7.3, respectivamente. As propriedades do concreto utilizado nos trechos de viga dos modelos N1 SJ e P1 SJ estão dispostas na Tabela 7.4.

Tabela 7.2 - Propriedades do concreto utilizado no modelo-piloto de ligação.

\begin{tabular}{ccccc}
\hline Corpo-de-prova & $\begin{array}{c}\text { Idade } \\
\text { (dias) }\end{array}$ & $\mathbf{f}_{\mathbf{c}}(\mathbf{M P a})$ & $\mathbf{f}_{\mathbf{t}}(\mathbf{M P a})$ & $\mathbf{E}_{\mathbf{c}}(\mathbf{G P a})$ \\
\hline 1 & 20 & 34,7 & 3,28 & 28,3 \\
2 & 20 & 24,3 & 2,74 & 30,4 \\
3 & 20 & 32,6 & 2,89 & 27,5 \\
Média & - & $\mathbf{3 0 , 5}$ & $\mathbf{2 , 9 7}$ & $\mathbf{2 8 , 7}$ \\
Coeficiente de variação & - & $\mathbf{1 8} \%$ & $\mathbf{9 \%}$ & $\mathbf{5 \%}$ \\
\hline
\end{tabular}

Tabela 7.3 - Propriedades do concreto utilizado nos trechos de pilar e viga dos modelos N1 CJ, N2 CJ, P1 CJ e trecho de pilar dos modelos N1 SJ e P1 SJ.

\begin{tabular}{ccccc}
\hline Corpo-de-prova & $\begin{array}{c}\text { Idade } \\
\text { (dias) }\end{array}$ & $\mathbf{f}_{\mathbf{c}}(\mathbf{M P a})$ & $\mathbf{f}_{\mathbf{t}}(\mathbf{M P a})$ & $\mathbf{E}_{\mathbf{c}}(\mathbf{G P a})$ \\
\hline 1 & 32 & 48,1 & 4,33 & 36,7 \\
2 & 32 & 48,3 & 4,60 & 41,9 \\
3 & 32 & 45,6 & 4,06 & 36,2 \\
Média & - & $\mathbf{4 7 , 3}$ & $\mathbf{4 , 3 3}$ & $\mathbf{3 8 , 3}$ \\
Coeficiente de variação & - & $\mathbf{3} \%$ & $\mathbf{6 \%}$ & $\mathbf{8 \%}$ \\
\hline
\end{tabular}


Tabela 7.4 - Propriedades do concreto utilizado nos trechos de viga dos modelos N1 SJ e P1 SJ.

\begin{tabular}{ccccc}
\hline Corpo-de-prova & Idade (dias) & $\mathbf{f}_{\mathbf{c}}(\mathbf{M P a})$ & $\mathbf{f}_{\mathbf{t}}(\mathbf{M P a})$ & $\mathbf{E}_{\mathbf{c}}(\mathbf{G P a})$ \\
\hline 1 & 30 & 52,8 & 3,18 & 39,1 \\
2 & 30 & 46,6 & 3,09 & 35,7 \\
3 & 30 & 45,1 & 3,90 & 35,3 \\
Média & - & $\mathbf{4 8 , 2}$ & $\mathbf{3 , 3 9}$ & $\mathbf{3 6 , 7}$ \\
Coeficiente de variação & - & $\mathbf{9 \%}$ & $\mathbf{1 3} \%$ & $\mathbf{6 \%}$ \\
\hline
\end{tabular}

\subsubsection{Almofada de apoio}

Utilizou-se almofada de apoio de borracha natural "NR 1087" da marca "ORION", dureza Shore 70 A. Este é um material adequado para uso em estruturas de concreto prémoldado, ainda que o mais comum seja a utilização de almofada de apoio em elastômero ao invés de borracha natural. A Figura 7.9 ilustra as características geométricas da almofada de apoio.

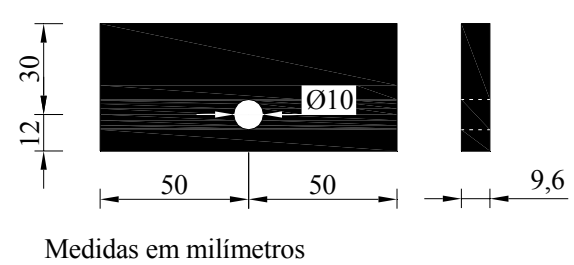

(a)

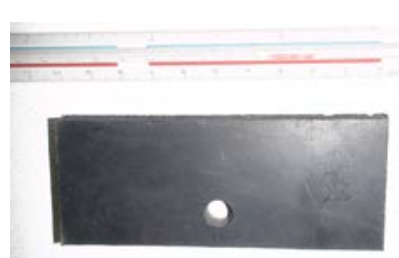

(b)

Figura 7.9 - Características geométricas da almofada de apoio: (a) desenho; (b) fotografia.

\subsubsection{Graute}

Utilizou-se graute auto adensável “Masterflow ${ }^{\circledR} 885$ grout”. A relação água/graute para o preenchimento do furo do chumbador do modelo-piloto de ligação foi de 0,18 . Houve dificuldade no preenchimento do furo com o graute elaborado com essa proporção e, portanto decidiu-se adotar nos grauteamentos subseqüentes a relação água/graute de 0,20 , que é a máxima indicada no manual do produto.

Foram adotados corpos-de-prova de $5 \mathrm{~cm}$ de diâmetro e $10 \mathrm{~cm}$ de altura para a caracterização do graute. Os ensaios para determinação da resistência à compressão e módulo foram realizados na máquina universal de ensaios servo-hidráulica INSTRON com uso do sistema de aquisição de dados System 5000 da Vishay. As deformações utilizadas na determinação do módulo de elasticidade foram obtidas por meio de extensômetros removíveis com base de leitura de $5 \mathrm{~cm}$. Os ensaios para determinação da resistência à tração foram realizados na máquina hidráulica ELE Autotest 2000. Os resultados da caracterização dos 
grautes utilizados na confecção do modelo-piloto estão dispostos na Tabela 7.5 e Tabela 7.6. As propriedades dos grautes utilizados nos modelos estão reunidas na Tabela 7.7 e Tabela 7.8. Moldou-se apenas um corpo-de-prova do graute utilizado no preenchimento dos vazios dos modelos N1 CJ, N2 CJ e P1 CJ. Ele foi utilizado para ensaio de compressão e determinação do módulo de elasticidade. A resistência à tração constante na Tabela 7.8 foi calculada segundo a Equação 7.1 da NBR 6118 (2003).

$$
f_{c t m}=0,3 \cdot f_{c k}^{2 / 3}
$$

Tabela 7.5 - Propriedades do graute para preenchimento do furo do chumbador do modelo-piloto de ligação.

\begin{tabular}{ccccc}
\hline Corpo-de-prova & Idade (dias) & $\mathbf{f}_{\mathbf{c}}(\mathbf{M P a})$ & $\mathbf{f}_{\mathbf{t}}(\mathbf{M P a})$ & $\mathbf{E}_{\mathbf{c}}(\mathbf{G P a})$ \\
\hline 1 & 9 & 41,7 & 3,62 & 38,8 \\
2 & 9 & 39,2 & 3,58 & 38,0 \\
3 & 9 & 40,0 & 3,44 & 38,7 \\
Média & - & $\mathbf{4 0 , 3}$ & $\mathbf{3 , 5 4}$ & $\mathbf{3 8 , 4}$ \\
Coeficiente de variação & - & $\mathbf{3} \%$ & $\mathbf{9 \%}$ & $\mathbf{1 \%}$ \\
\hline
\end{tabular}

Tabela 7.6 - Propriedades do graute para preenchimento dos vazios do modelo-piloto de ligação.

\begin{tabular}{ccccc}
\hline Corpo-de-prova & Idade (dias) & $\mathbf{f}_{\mathbf{c}}(\mathbf{M P a})$ & $\mathbf{f}_{\mathbf{t}}(\mathbf{M P a})$ & $\mathbf{E}_{\mathbf{c}}(\mathbf{G P a})$ \\
\hline 1 & 8 & 37,3 & 4,01 & 36,0 \\
2 & 8 & 40,6 & 3,35 & 37,1 \\
3 & 8 & 38,2 & 3,08 & 30,3 \\
Média & - & $\mathbf{3 8 , 7}$ & $\mathbf{3 , 4 8}$ & $\mathbf{3 4 , 5}$ \\
Coeficiente de variação & - & $\mathbf{4} \%$ & $\mathbf{1 4} \%$ & $\mathbf{1 1} \%$ \\
\hline
\end{tabular}

Tabela 7.7 - Propriedades do graute para preenchimento do furo do chumbador - modelos N1 CJ, N2 CJ e P1 CJ.

\begin{tabular}{ccccc}
\hline Corpo-de-prova & Idade (dias) & $\mathbf{f}_{\mathbf{c}}(\mathbf{M P a})$ & $\mathbf{f}_{\mathbf{t}}(\mathbf{M P a})$ & $\mathbf{E}_{\mathbf{c}}(\mathbf{G P a})$ \\
\hline 1 & 9 & 33,0 & 4,93 & 34,9 \\
2 & 9 & 38,8 & 3,68 & 49,4 \\
3 & 9 & 45,5 & 3,59 & 43,5 \\
Média & - & $\mathbf{3 9 , 1}$ & $\mathbf{4 , 0 7}$ & $\mathbf{4 2 , 6}$ \\
Coeficiente de variação & - & $\mathbf{1 6} \%$ & $\mathbf{1 8} \%$ & $\mathbf{1 7} \%$ \\
\hline
\end{tabular}

Tabela 7.8 - Propriedades do graute para preenchimento dos vazios da ligação - modelos N1 CJ, N2 CJ e P1 CJ.

\begin{tabular}{ccccc}
\hline Corpo-de-prova & Idade (dias) & $\mathbf{f}_{\mathbf{c}}(\mathbf{M P a})$ & $\mathbf{f}_{\mathbf{t}}(\mathbf{M P a})$ & $\mathbf{E}_{\mathbf{c}}(\mathbf{G P a})$ \\
\hline 1 & 8 & 37,3 & $3,35^{*}$ & 39,9 \\
\hline
\end{tabular}

* valor teórico 


\subsection{Confecção do modelo}

As fôrmas para os elementos de concreto (trechos de viga e pilar) que compuseram o modelo de ligação foram confeccionadas em madeira laminada colada. Nas fôrmas dos trechos de pilar, foram feitos furos para posicionamento dos chumbadores (Figura 7.10-a). As fôrmas dos trechos de viga também continham furos em que se colocaram mangueiras plásticas com diâmetro externo de $20 \mathrm{~mm}$, previamente untadas com desmoldante (Figura 7.10-b). A colocação dessas mangueiras visou à confecção do espaço em que se encaixou o chumbador no processo de montagem do modelo. No interior da mangueira, introduziram-se barras de aço para que ela se mantivesse reta no interior da fôrma. As folgas entre os furos nas fôrmas e o chumbador e entre os furos e a mangueira foram vedadas com borracha de silicone. A extremidade do chumbador foi fixada a fôrma com cola de silicone para prevenir sua movimentação no processo de concretagem. As fôrmas para a segunda etapa de concretagem dos modelos P1 SJ e N1 SJ foram feitas com as dimensões finais do modelo.

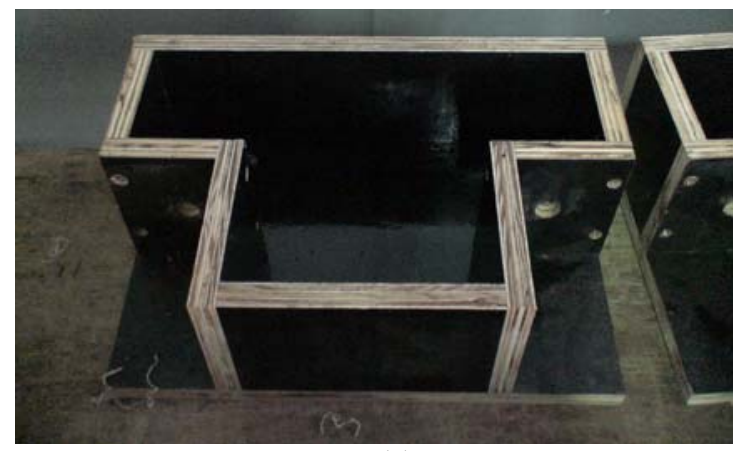

(a)

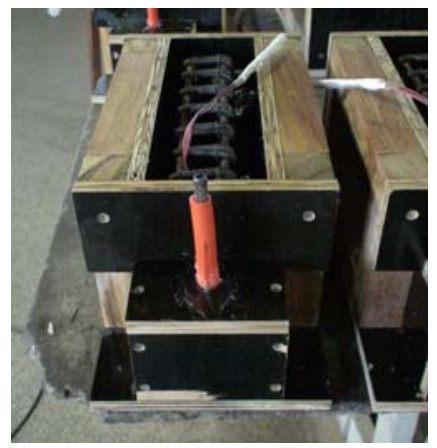

(b)

Figura 7.10 - Fôrmas para concretagem dos elementos do modelo de ligação: (a) fôrma do trecho de pilar; (b) fôrma do trecho de viga.

O concreto para confecção dos elementos do modelo de ligação foi misturado em betoneira, em área externa ao Laboratório de Estruturas do SET, colocado nas fôrmas e adensado em mesa vibratória. Os trechos de pilar utilizados para confecção dos modelos P1 SJ e N1 SJ foram desformados no dia seguinte à concretagem, limpos com álcool e posicionados na fôrma com as dimensões finais do modelo, juntamente com as armaduras dos trechos de viga (Figura 7.12). As outras peças foram levadas à câmara úmida onde permaneceram em cura até a data de realização dos entalhe. Uma primeira tentativa de concretagem dos trechos de viga foi frustrada, pois, no processo de adensamento, os trechos de pilar se deslocaram verticalmente permitindo que pasta de cimento se infiltrasse no vazio que surgiu entre o trecho de pilar e o fundo da fôrma. O concreto foi despejado e os trechos de pilar, as armaduras e as fôrmas foram lavados. No processo de lavagem, alguns extensômetros foram danificados o que atrasou a concretagem em mais um dia, para colocação de novos 
extensômetros. Dois dias após a concretagem dos trechos de pilar, procedeu-se a concretagem dos trechos de viga dos modelos P1 SJ e N1 SJ. Para essa concretagem, se tomou a precaução de instalar travas de madeira na parte superior das fôrmas que impediram a movimentação vertical dos trechos de pilar durante o adensamento em mesa vibratória. Os modelos P1 SJ e N1 SJ foram levados no dia seguinte à câmara úmida onde permaneceram até a data de realização dos entalhe.

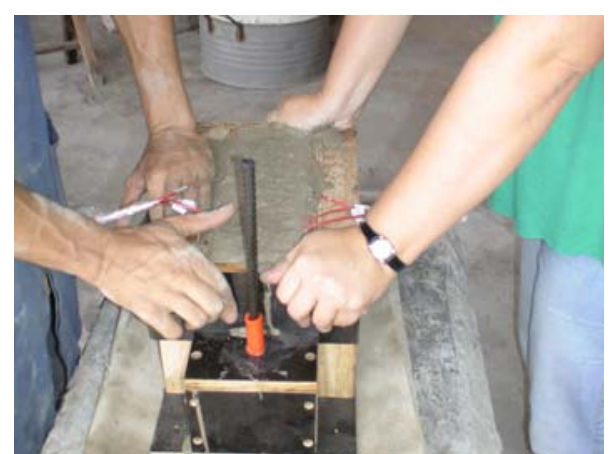

(a)

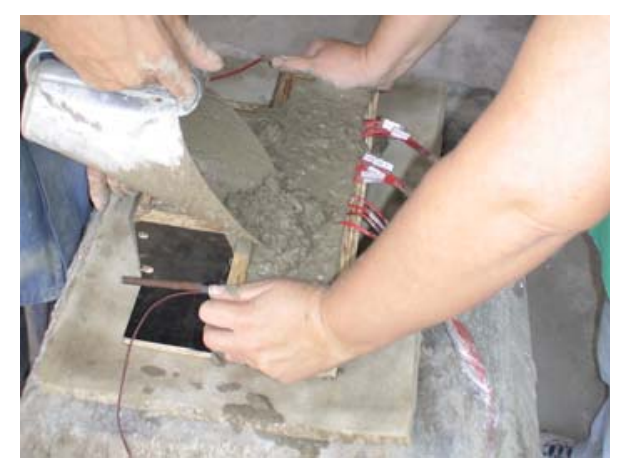

(b)

Figura 7.11 - Adensamento do concreto em mesa vibratória: (a) trecho de viga; (b) trecho de pilar.

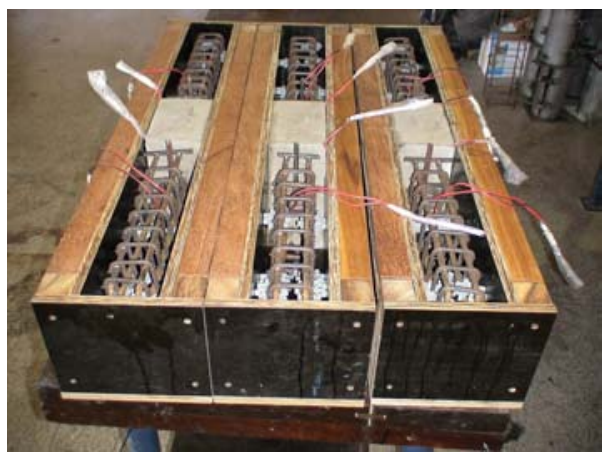

Figura 7.12 - Fôrmas para segunda etapa de concretagem dos modelos P1 SJ e N1 SJ com o trecho de pilar e com as armaduras dos trechos de viga posicionados em seu interior.

Os entalhes foram realizados com uso de ferramenta elétrica com dois discos de corte justapostos, por via úmida. Foi necessário o alargamento da sua seção nas regiões em que havia extensômetros colados ao laminado. As peças entalhadas foram lavadas com água e deixadas secar ao ar. Na data da execução do reforço, os entalhes foram limpos com jato de ar comprimido e estopa embebida em álcool isopropílico. A superfície dos elementos também foi limpa com álcool para retirada do resquício de desmoldante. Para montagem dos modelos com juntas grauteadas, posicionaram-se as almofadas de apoio nos consolos, introduzindo-se os chumbadores nos furos das almofadas. Posicionaram-se os trechos de vigas apoiados sobre as almofadas de apoio e em peças de madeira, verificando o prumo (Figura 7.13-a) e o alinhamento (Figura 7.13-b). Executou-se a solidarização do modelo pela colagem do 
laminado (Figura 7.13-c). O furo do chumbador foi umedecido e preenchido com graute. Dois dias depois, deitou-se o modelo sobre pedaços de placas de madeira compensada. Vedaram-se as extremidades superior e inferior dos vazios entre os elementos da ligação com placas de madeira compensada. Umedeceram-se as superfícies a serem grauteadas (Figura 7.13-d). Efetuou-se o grauteamento dos vazios (Figura 7.13-e). As etapas de montagem e grauteamento não foram necessárias para os modelos P1 SJ e N1 SJ que tiveram sua confecção concluída pela execução do reforço (Figura 7.13-f). Na Tabela 7.9, estão contidas informações acerca da dos intervalos entre algumas das etapas e a realização dos ensaios.

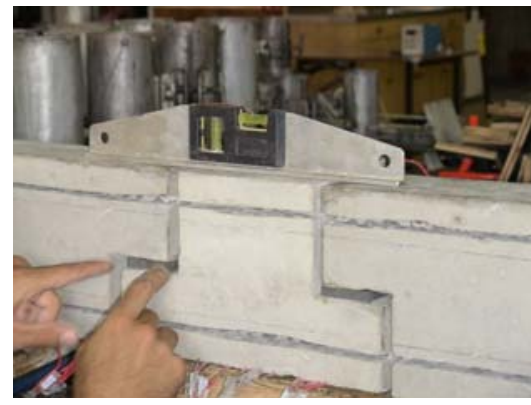

(a)

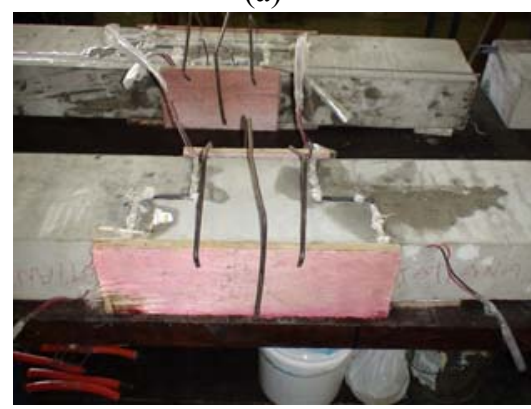

(d)

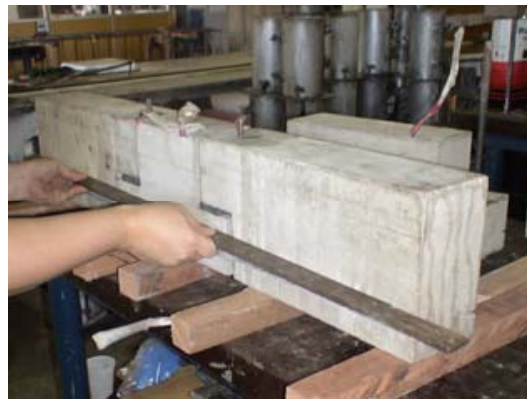

(b)

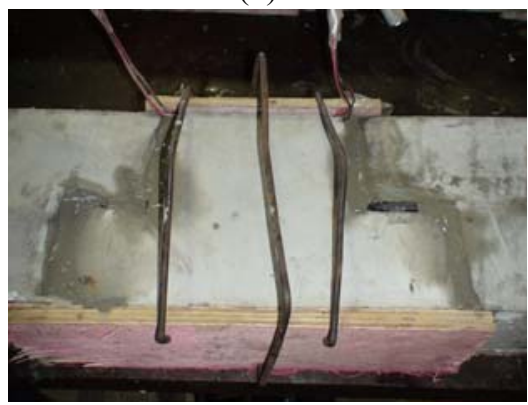

(e)

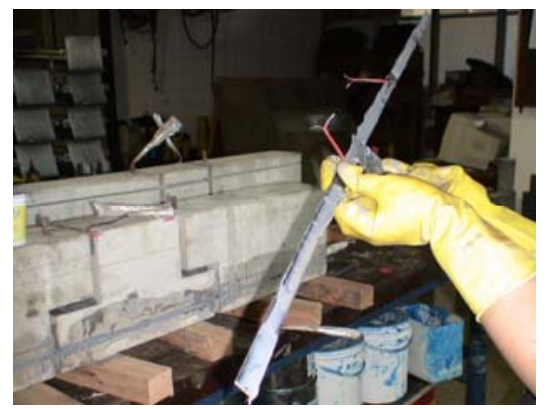

(c)

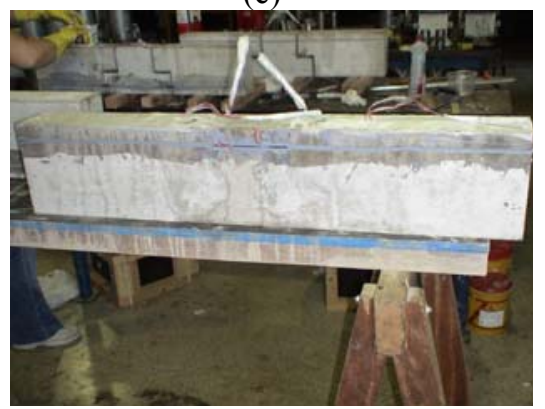

(f)

Figura 7.13 - Confecção dos modelos de ligação reforçados: (a) conferência do prumo; (b) conferência do alinhamento; (c) execução do reforço; (d) umedecimento dos vazios entre os elementos da ligação; (e) vazios preenchidos com graute; (f) modelo P1 SJ.

Tabela 7.9 - Intervalos entre etapas de confecção dos modelos.

\begin{tabular}{cccccc}
\hline \multirow{2}{*}{ Modelo } & Período de cura & \multicolumn{4}{c}{ Idade na data do ensaio (dias) } \\
\cline { 3 - 6 } & 10 & Adesivo & Graute do furo & Graute da junta & Concreto \\
\hline Piloto & 9 & 7 & 7 & 6 & 18 \\
N1 CJ & 9 & 15 & 14 & 13 & 29 \\
N2 CJ & 9 & 16 & 15 & 14 & 30 \\
N1 SJ & 9 & 16 & 15 & 12 & $28 * / 30$ \\
P1 CJ & 9 & 14 & 13 & 13 & $27 * / 29$ \\
\hline
\end{tabular}

* Idade do concreto das vigas. 


\subsection{Instrumentação e configuração dos ensaios estáticos}

O modelo-piloto foi dotado de farta extensometria interna para se conhecer a distribuição de tensões nas armaduras do modelo ao longo do carregamento (Figura 7.14). A princípio, pretendia-se submeter o modelo a momentos fletores positivos e negativos, entretanto, por questões de ordem prática, o modelo foi submetido apenas a momento fletor negativo. Na Figura 7.14, o modelo se encontra na posição em que foi ensaiado e invertido em relação à posição original que ocuparia em uma estrutura. Extensômetros foram colados também nos laminados. No laminado superior (reforço a momento fletor positivo), foi posicionado um extensômetro a meio vão. No laminado inferior (reforço a momento fletor negativo), foram posicionados extensômetros nos intervalo entre o consolo e os trechos da viga e a meio vão. A instrumentação apresenta simetria em relação ao plano vertical que intercepta o eixo longitudinal da peça. O primeiro número na nomenclatura dos extensômetros apresentada na Figura 7.14 particulariza o extensômetro na parte posterior do modelo e o segundo o extensômetro na parte anterior. Nos demais modelos, foram mantidos os extensômetros em que se observaram as maiores deformações no ensaio-piloto (Figura 7.15 e Figura 7.16).

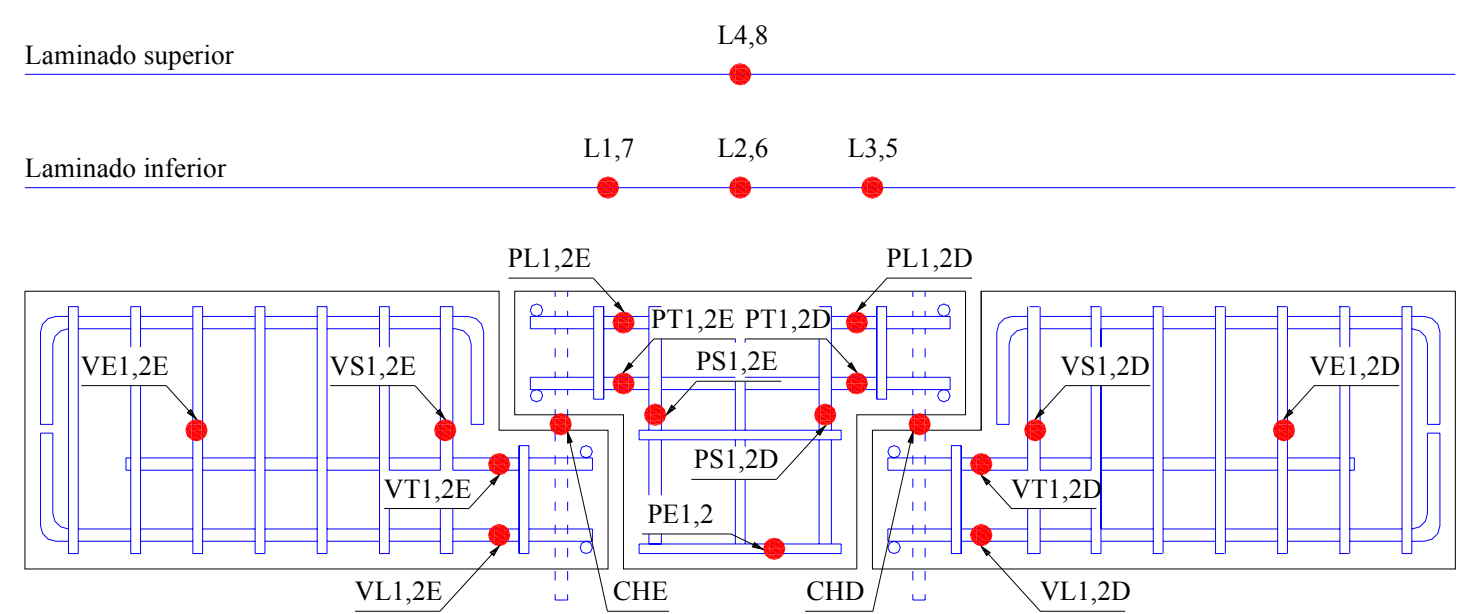

Figura 7.14 - Posicionamento da instrumentação na armadura e laminados do modelo-piloto.

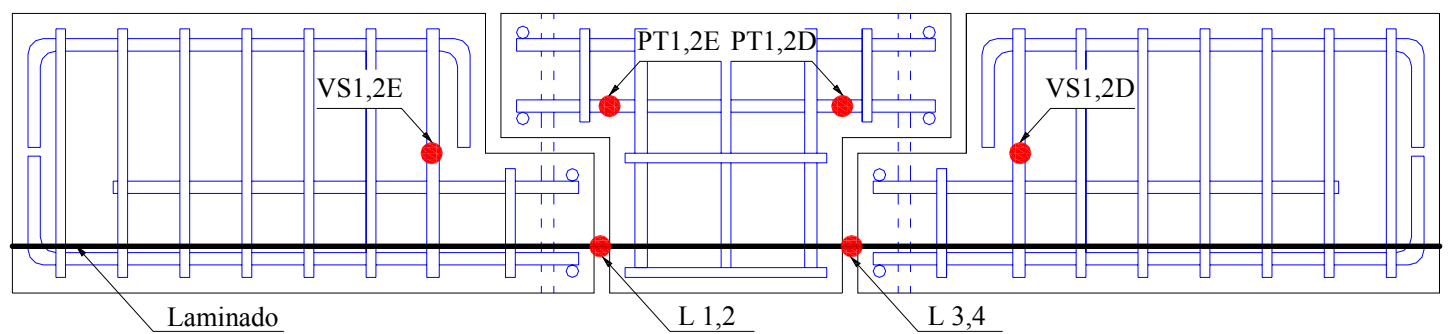

Figura 7.15 - Posicionamento da instrumentação na armadura e laminado do ensaio dos modelos N1 CJ, N1 CJ e N1 SJ. 


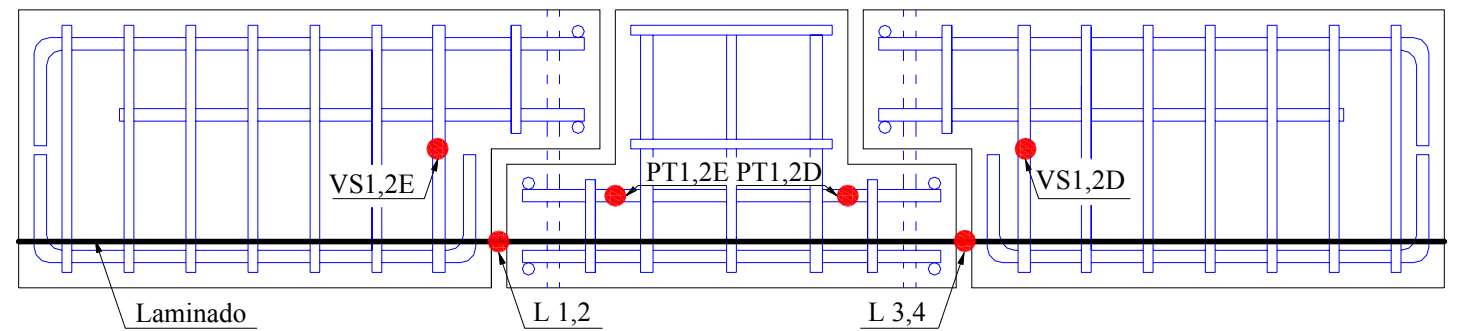

Figura 7.16 - Posicionamento da instrumentação na armadura e laminado do ensaio dos modelos P1 CJ e P1 SJ.

Os modelos foram dotados também de instrumentação externa. Utilizou-se um transdutor de deslocamento posicionado verticalmente a meio vão da viga para medição da flecha. As reações nos apoios foram obtidas nas leituras de células de carga posicionadas sob os apoios. Foram utilizados transdutores de deslocamento, fixados em quadros para suporte da instrumentação (Figura 6.13) presos ao concreto por parafusos, para obtenção do deslocamento relativo entre as seções descontínuas. Assim como a instrumentação interna, a instrumentação externa apresenta simetria em relação ao plano perpendicular que contém o eixo longitudinal da peça. O primeiro número na nomenclatura dos transdutores posicionados horizontalmente (Figura 7.17) particulariza o transdutor na parte posterior do modelo e o segundo, o transdutor na parte anterior. No modelo-piloto, duas seções foram tomadas como referenciais, uma à direita e uma à esquerda da junta vertical inferior (tracionada). A distância horizontal entre elas foi de $3 \mathrm{~cm}$. A distância vertical entre os transdutores foi de $8 \mathrm{~cm}$ e entre os parafusos de fixação de $12 \mathrm{~cm}$ (Figura 7.17). Nos demais modelos, buscou-se um posicionamento dos transdutores que permitisse a aferição da deformação tanto das juntas tracionadas quanto das juntas comprimidas. O quadro para suporte da instrumentação foi posicionado em um plano eqüidistante a dois outros planos de referencia no concreto em que foram coladas cantoneiras metálicas, conforme Figura 7.18 e Figura 7.19. Mantiveram-se as distâncias verticais de $11 \mathrm{~cm}$ entre os transdutores e $17 \mathrm{~cm}$ entre os parafusos de fixação do quadro para suporte da instrumentação e a distância horizontal de $4 \mathrm{~cm}$ entre os planos referenciais.

O esquema estático do ensaio foi o mesmo para todos os modelos (Figura 7.17, Figura 7.18 e Figura 7.19). O modelo de ligação foi bi-apoiado em dispositivos prismáticos de seção semicircular. O carregamento foi aplicado por atuador servo-hidráulico e distribuído, com a utilização de blocos metálicos em uma área que corresponderia à seção do pilar. A Figura 7.20 ilustra a configuração do ensaio. Cabe observar que os modelos reforçados a momento fletor negativo foram submetidos a ensaio em posição inversa (rotacionados em $180^{\circ}$ ) à que ocupariam em uma estrutura real. 


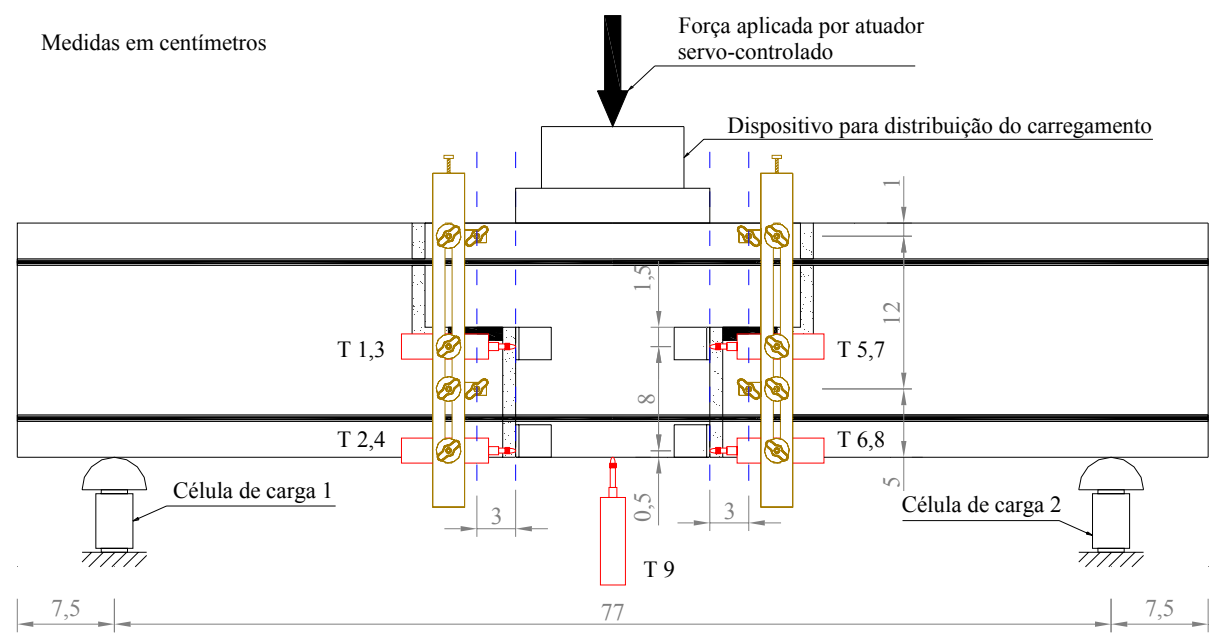

Figura 7.17 - Configuração esquemática do ensaio e instrumentação externa para o modelo-piloto.

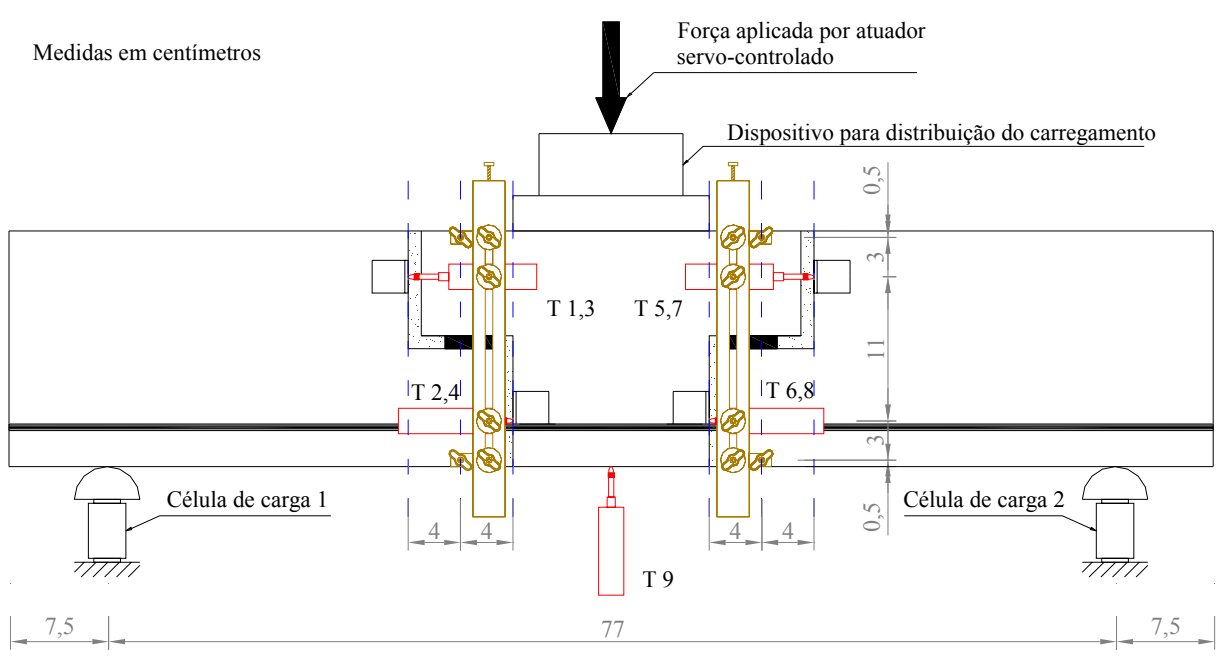

Figura 7.18 - Configuração esquemática do ensaio e instrumentação externa dos modelos N1 CJ, N2 CJ e N1 SJ.

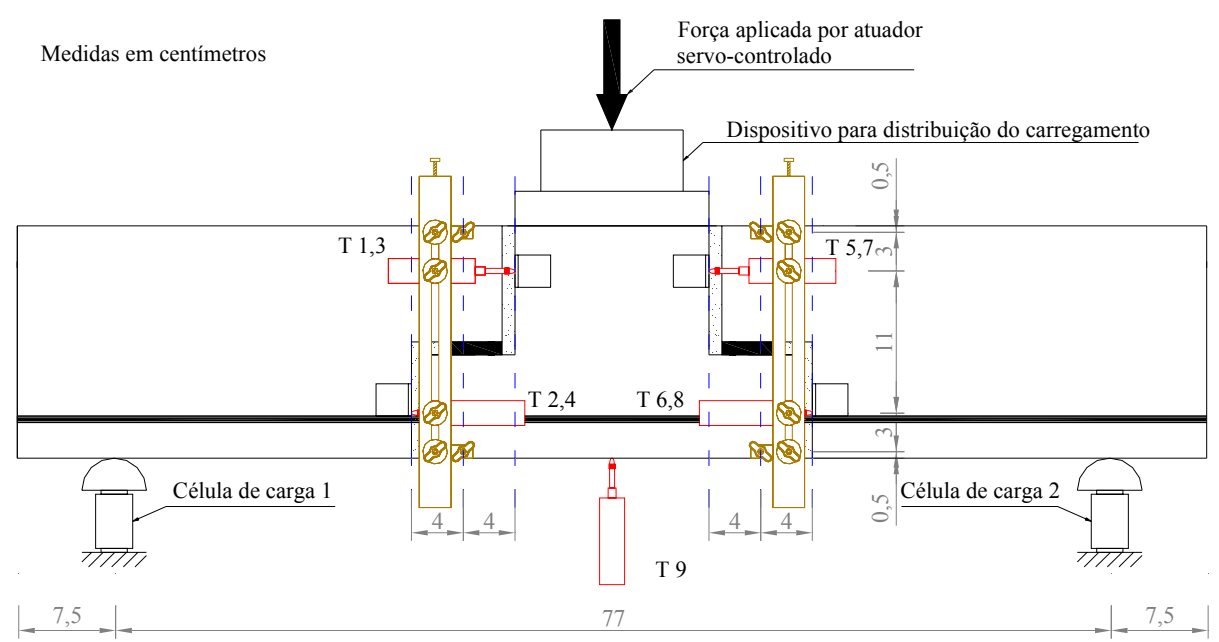

Figura 7.19 - Configuração esquemática do ensaio e instrumentação externa para os modelos P1 CJ e P1 SJ. 


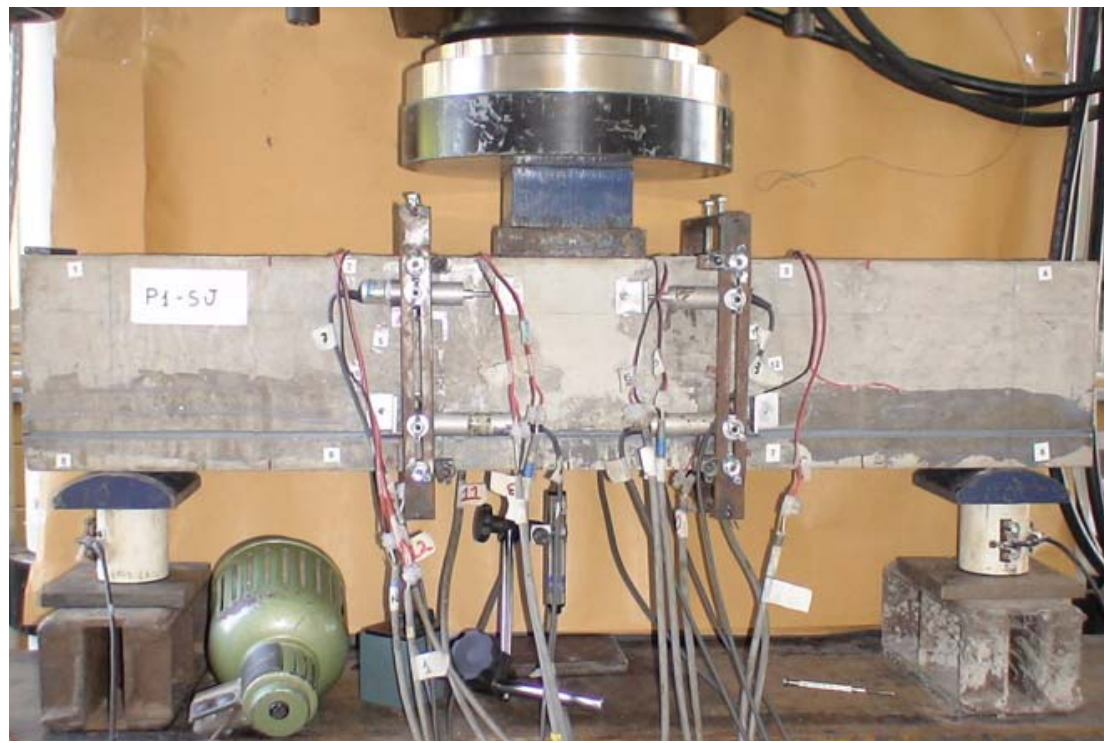

Figura 7.20 - Configuração do ensaio e instrumentação externa para o modelo P1 SJ.

\subsection{Execução dos ensaios estáticos}

Os ensaios foram realizados em ciclos de carga e descarga na máquina universal de ensaios servo-hidráulica INSTRON, sob controle de deslocamento do pistão a uma taxa de $0,005 \mathrm{~mm} / \mathrm{s}$. O sistema de aquisição de dados utilizado foi o System 5000 da Vishay. A realização do carregamento em ciclos visou à detecção da queda da rigidez com o processo de fissuração dos modelos. No ensaio do modelo-piloto, realizaram-se dois ciclos para um de carregamento de $8 \mathrm{kN}$ (10\% da carga de ruptura estimada, conforme APÊNDICE D ) dois ciclos para um de carregamento de $16 \mathrm{kN}$ (20\% da carga de ruptura estimada) e um ciclo para um de carregamento de $24 \mathrm{kN}$ (30\% da carga de ruptura estimada) ao fim do qual o ensaio estático foi interrompido. Modificou-se a vinculação do modelo e realizou o ensaio dinâmico. Após o ensaio dinâmico, restaurou-se a configuração do ensaio estático e realizou-se um ciclo de carregamento de $36 \mathrm{kN}$ ( $40 \%$ da carga de ruptura estimada) e um ciclo de carregamento de $40 \mathrm{kN}$ (50\% da carga de ruptura estimada). No oitavo ciclo de carregamento, o modelo foi levado à ruptura. Para os demais modelos, modificou-se o esquema de carregamento. Nos dois primeiros ciclos de carregamento, aplicou-se uma força de $12 \mathrm{kN}$ (aproximadamente $15 \%$ da força máxima estimada). No terceiro e quarto ciclos, aplicou-se uma força de $24 \mathrm{kN}$ (aproximadamente $30 \%$ da força máxima estimada). Nesse ponto, o carregamento estático foi interrompido, modificou-se a vinculação do modelo e realizou-se o ensaio dinâmico. Após o ensaio dinâmico, restaurou-se a configuração do ensaio estático e realizou-se um ciclo de carregamento com uma força de $36 \mathrm{kN}$ (aproximadamente $45 \%$ da força máxima estimada). $\mathrm{O}$ modelo foi levado à ruptura no sexto ciclo de carregamento. 


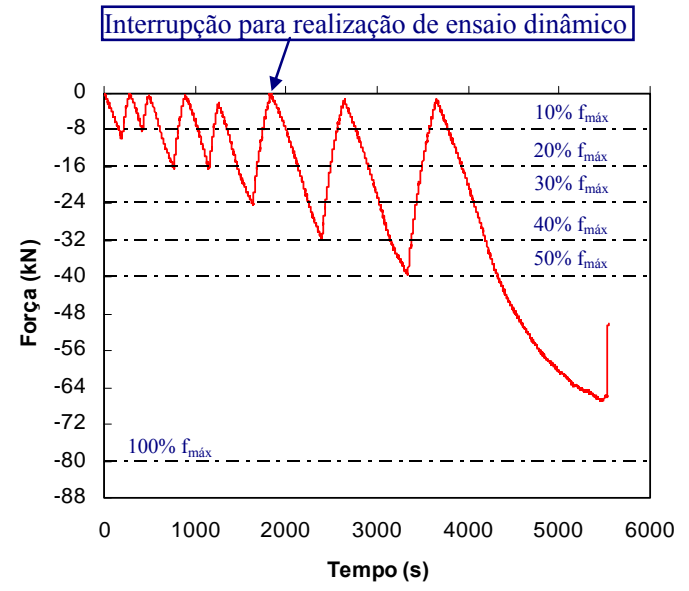

(a)

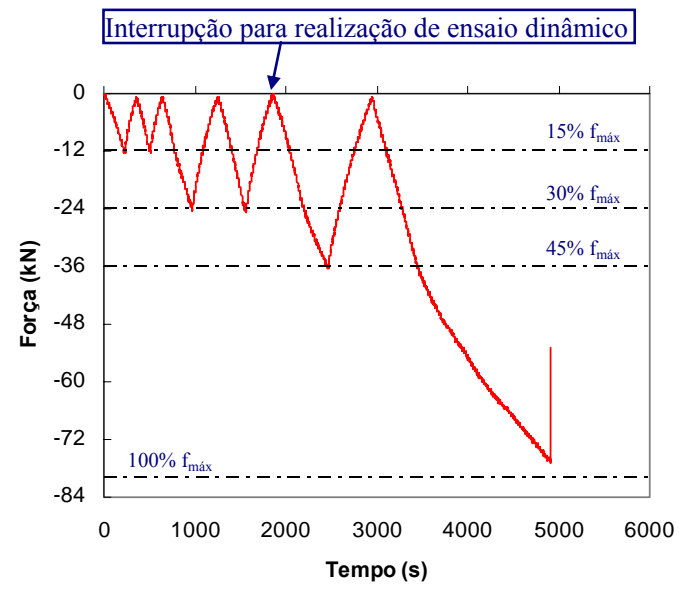

(b)

Figura 7.21 - Ciclos de carregamento: (a) aplicados ao modelo-piloto; (b) aplicados ao modelo P1-SJ.

\subsection{Resultados e análises dos ensaios estáticos}

Os resultados estão apresentados separadamente conforme os itens que se julgaram mais importantes na avaliação do reforço: fissuração e modo de ruptura, deformação nos laminados, deformação na armadura do tirante do consolo, deformação na armadura de suspensão da viga, rigidez à flexão e deslocamento vertical. São apresentados os valores absolutos de força, momento, deslocamento e rotação para facilitar a comparação entre os resultados dos ensaios nos diversos modelos.

Os resultados dos ensaios no modelo-piloto são apresentados numa seqüência com os demais modelos. Contudo, enfatiza-se que ele foi realizado antes, para avaliar a eficiência da metodologia de ensaio idealizada. Alguns ajustes foram feitos a partir dessa primeira experiência (já citadas as diferenças na instrumentação interna e externa e no ciclo de carregamento). Quanto à instrumentação interna, só serão apresentados os resultados dos extensômetros que foram mantidos para os demais modelos, visto que eles foram considerados os mais relevantes. Particularmente, nesse ensaio, somente se registraram as deformações das armaduras e do reforço nos ciclos efetuados após a interrupção do ensaio estático para realização do ensaio dinâmico, quando se percebeu que os canais dos extensômetros não estavam configurados no sistema de aquisição de dados. 


\subsubsection{Fissuração e modo de ruptura}

\subsubsection{Modelo-piloto}

A fissuração se iniciou a um nível baixo de carregamento $(7 \mathrm{kN})$ ao longo da interface entre o graute e o concreto, partindo da fibra mais tracionada. Para uma força de $17 \mathrm{kN}$, surgiram fissuras a partir do canto reentrante do consolo e fissuras diagonais de aderência nas proximidades das juntas. Com o aumento do carregamento, surgiram fissuras na região central do modelo e fissuras de aderência mais distantes da região das juntas. Para uma força aplicada de $66 \mathrm{kN}$, fissuras diagonais nos dentes das vigas originadas na linha do reforço atingiram a superfície do dente, o que provocou uma queda brusca na força aplicada. A Figura 7.22 ilustra a evolução da fissuração ao longo do ensaio e a Figura 7.23, a configuração pós-ruptura do modelo. 

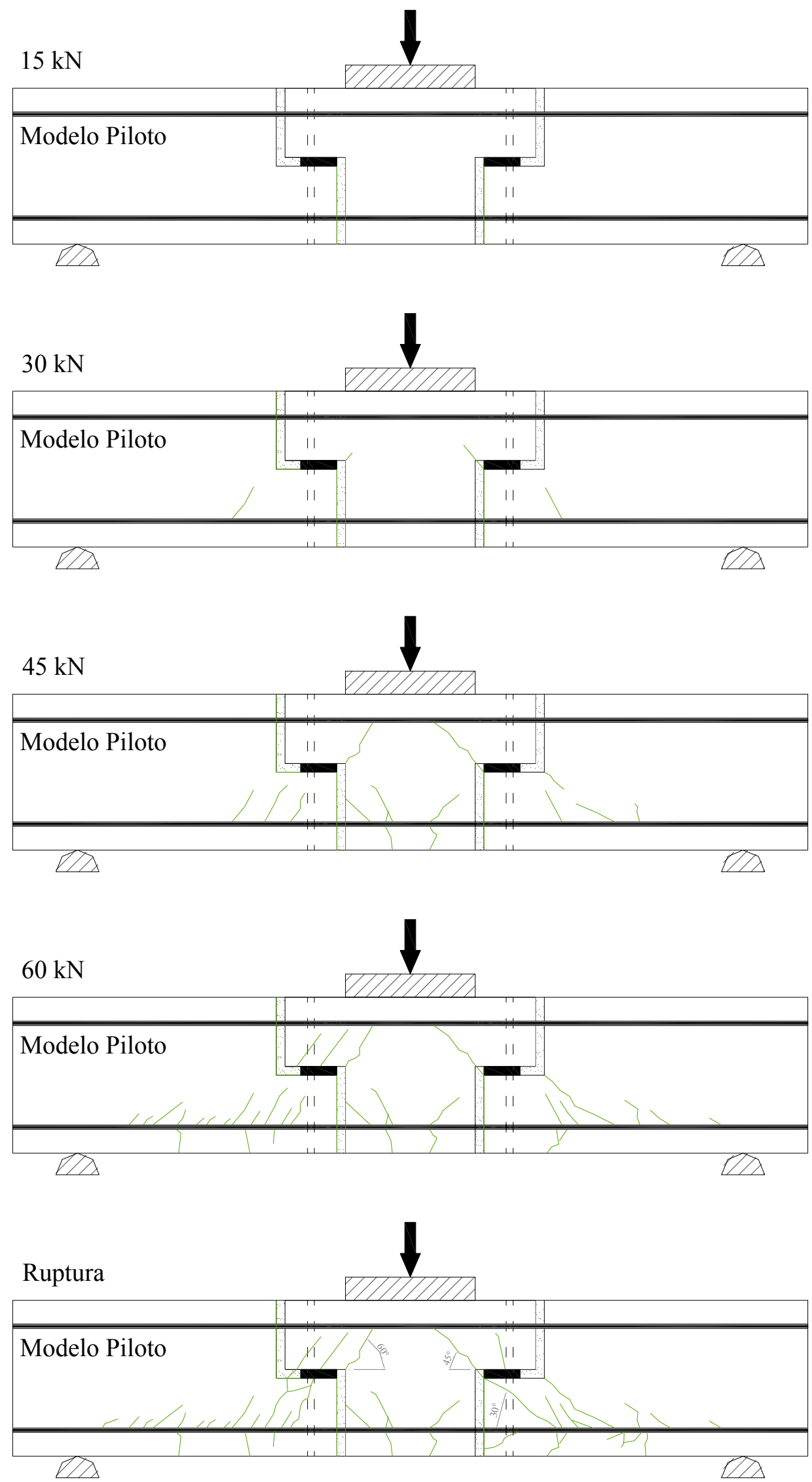

Figura 7.22 - Evolução da fissuração em uma das faces do modelo-piloto. 


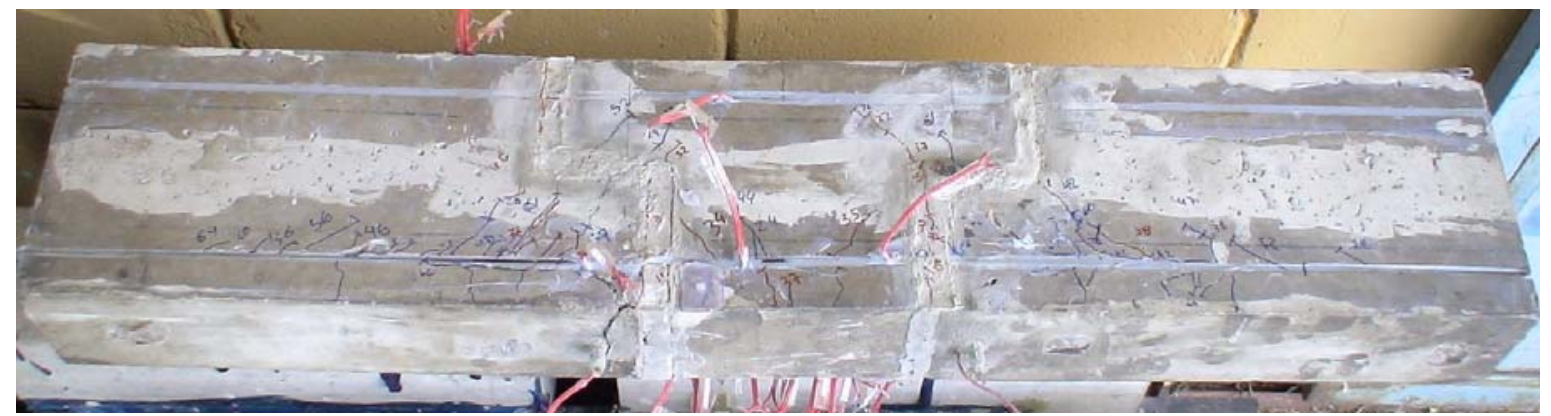

Figura 7.23 - Configuração das fissuras após a ruptura do modelo-piloto de ligação.

\subsubsection{Modelo N1 CJ}

As primeiras fissuras surgiram com o carregamento de $15 \mathrm{kN}$ na interface entre o concreto da viga e o graute da junta tracionada e partindo do canto reentrante do consolo. Para um carregamento de $33 \mathrm{kN}$, apareceram as primeiras fissuras de aderência nas proximidades das juntas tracionadas. Com o aumento do carregamento, foram surgindo novas fissuras de aderência, mais distantes das juntas, e as fissuras já existentes aumentaram. Com o carregamento de $59 \mathrm{kN}$, surgiram fissuras partindo da quina do consolo. A ruptura ocorreu quando fissuras de aderência evoluíram até a superfície horizontal do dente, numa linha coincidente a posição do chumbador, isolando uma porção de concreto. O comprimento de ancoragem foi reduzido e houve um arrancamento brusco do laminado. Houve destacamento de pedaços de concreto com finas camadas de laminado ainda aderidas e exposição da armadura longitudinal da viga (Figura 7.25-b). A Figura 7.24 ilustra a evolução da fissuração ao longo do ensaio e a Figura 7.25, a configuração pós-ruptura do modelo. 

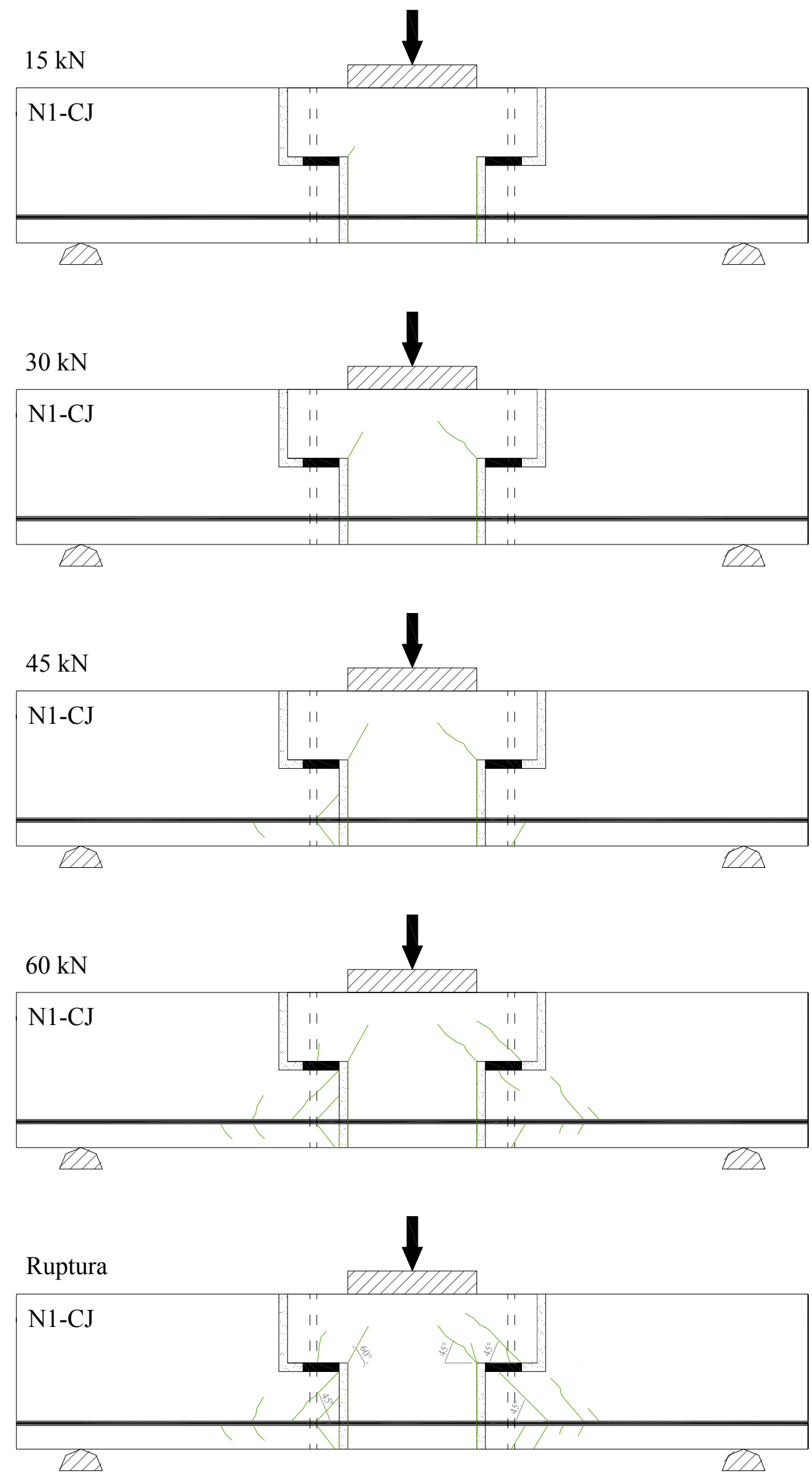

Figura 7.24 - Evolução da fissuração em uma das faces do modelo N1 CJ. 


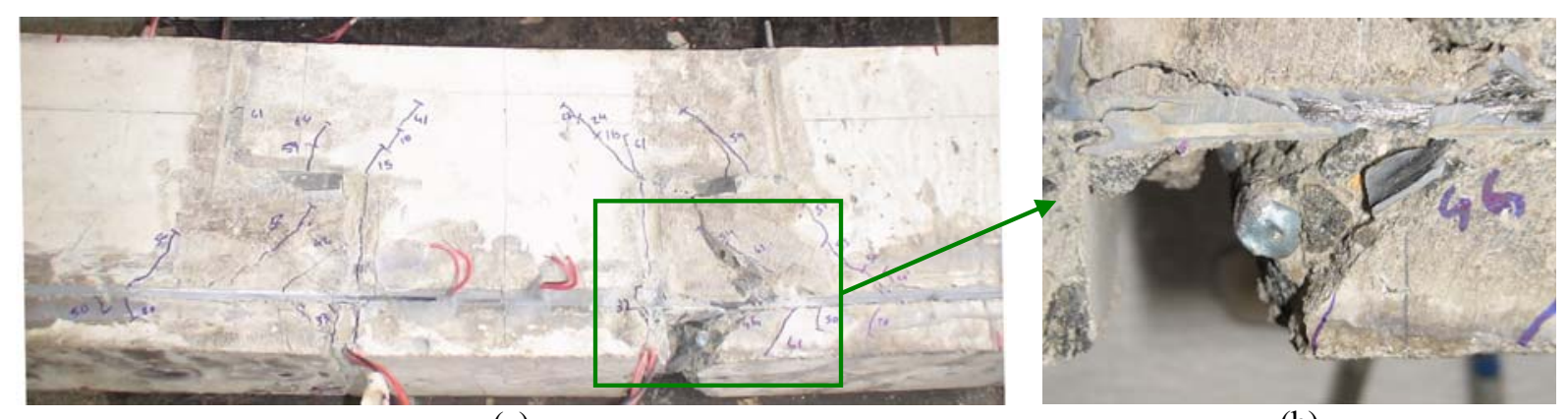

(a) (b)

Figura 7.25 - (a) Configuração das fissuras após a ruptura; (b) detalhe da armadura exposta - modelo N1 CJ.

\subsubsection{Modelo N2 CJ}

As primeiras fissuras surgiram com o carregamento de $20 \mathrm{kN}$ na interface entre o concreto da viga e o graute da junta tracionada. Para o carregamento de $23 \mathrm{kN}$, partiram fissuras do canto reentrante do consolo e para o de $24 \mathrm{kN}$ surgiram fissuras de flexão a meio vão do modelo. Para o carregamento de $35 \mathrm{kN}$, apareceram as primeiras fissuras de aderência nas proximidades das juntas tracionadas. Com o aumento do carregamento, foram surgindo novas fissuras de aderência e as fissuras já existentes aumentaram. As fissuras de aderência se intensificaram no sentido das juntas aos apoios. Para o carregamento de $40 \mathrm{kN}$, surgiram fissuras partido da quina do consolo. A ruptura ocorreu quando fissuras de aderência evoluíram até a superfície vertical do dente da viga, isolando uma porção de concreto. $\mathrm{O}$ comprimento de ancoragem foi reduzido e houve um arrancamento brusco do laminado. A Figura 7.26 ilustra a evolução da fissuração ao longo do ensaio e a Figura 7.27, a configuração pós-ruptura do modelo. 

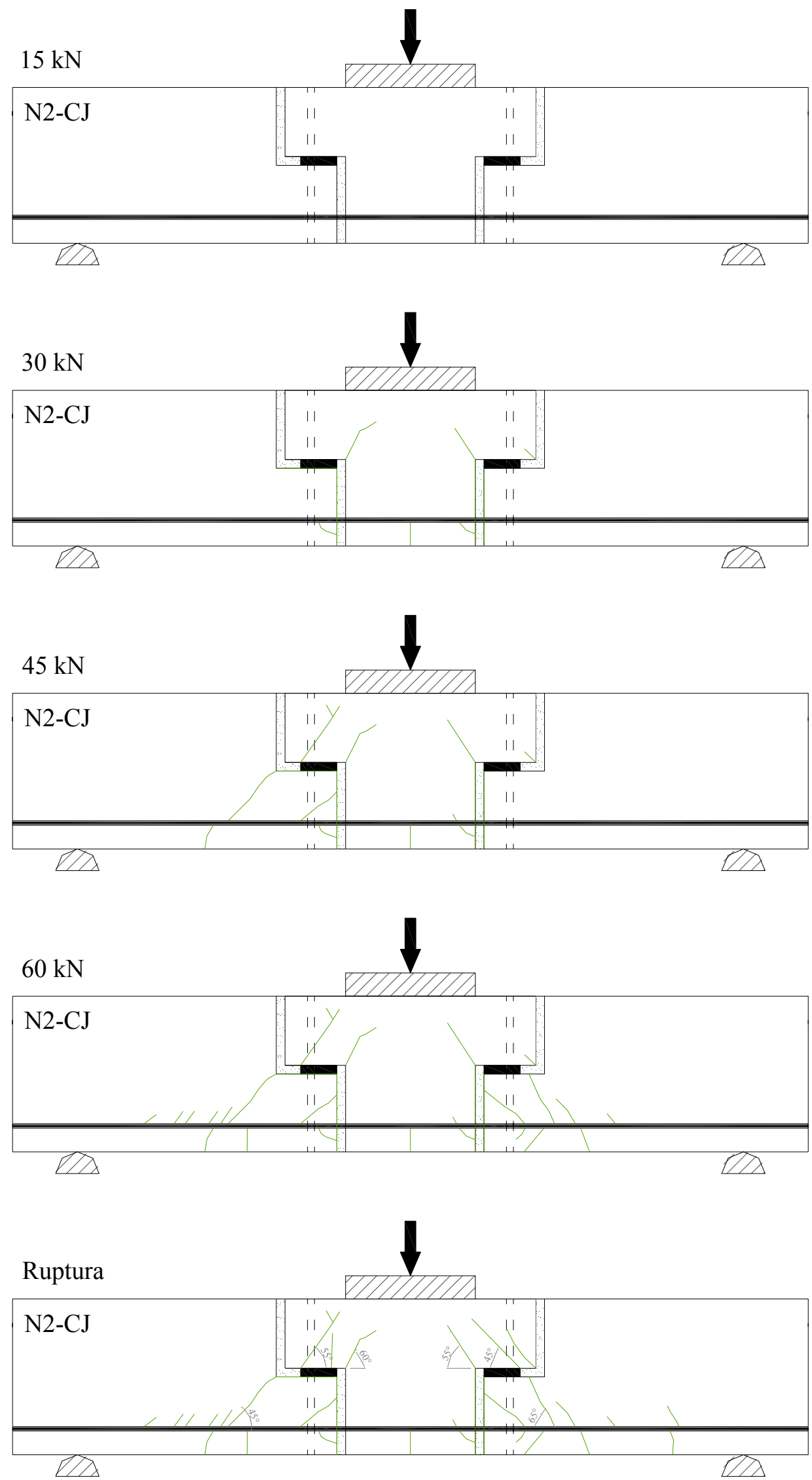

Figura 7.26 - Evolução da fissuração em uma das faces do modelo N2 CJ. 


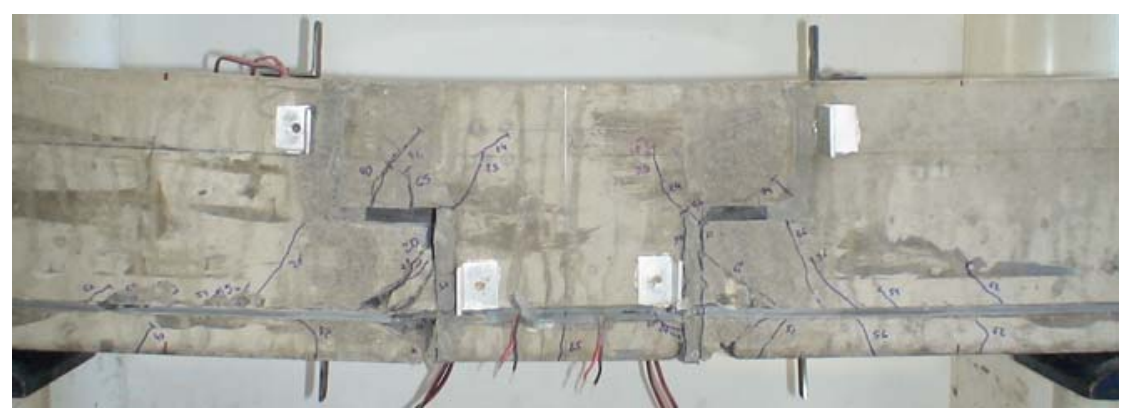

(a)

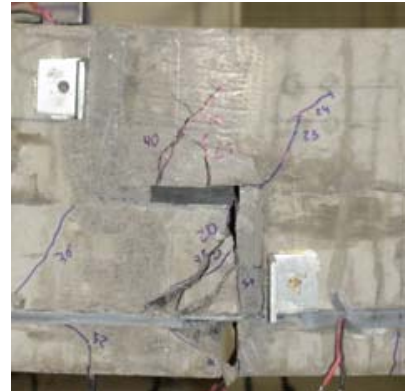

(b)

Figura 7.27 - (a) Configuração das fissuras após a ruptura; (b) detalhe da ruptura - modelo N2 CJ.

\subsubsection{Modelo N1 SJ}

A fissuração se iniciou na interface entre os concretos da viga e do pilar para um carregamento de $12 \mathrm{kN}$. Para o carregamento de $33 \mathrm{kN}$, partiram fissuras do canto reentrante do consolo. Com $40 \mathrm{kN}$ de carregamento, surgiram fissuras de flexão a meio vão do modelo. Para o carregamento de $36 \mathrm{kN}$, surgiram fissuras de aderência nas proximidades da junta tracionada. Novas fissuras de aderência surgiram e as fissuras existentes se intensificaram com o aumento no carregamento. A ruptura ocorreu quando fissuras de aderência encontraram a quina da viga, isolando uma porção de concreto. O comprimento de ancoragem foi reduzido e houve arrancamento brusco do laminado. Houve destacamento de uma grande porção de concreto (Figura 7.29-a), exposição da armadura (Figura 7.29-b) e delaminação do reforço (Figura 7.29-c). A Figura 7.28 ilustra a evolução da fissuração ao longo do ensaio e a Figura 7.29, a configuração pós-ruptura do modelo. 

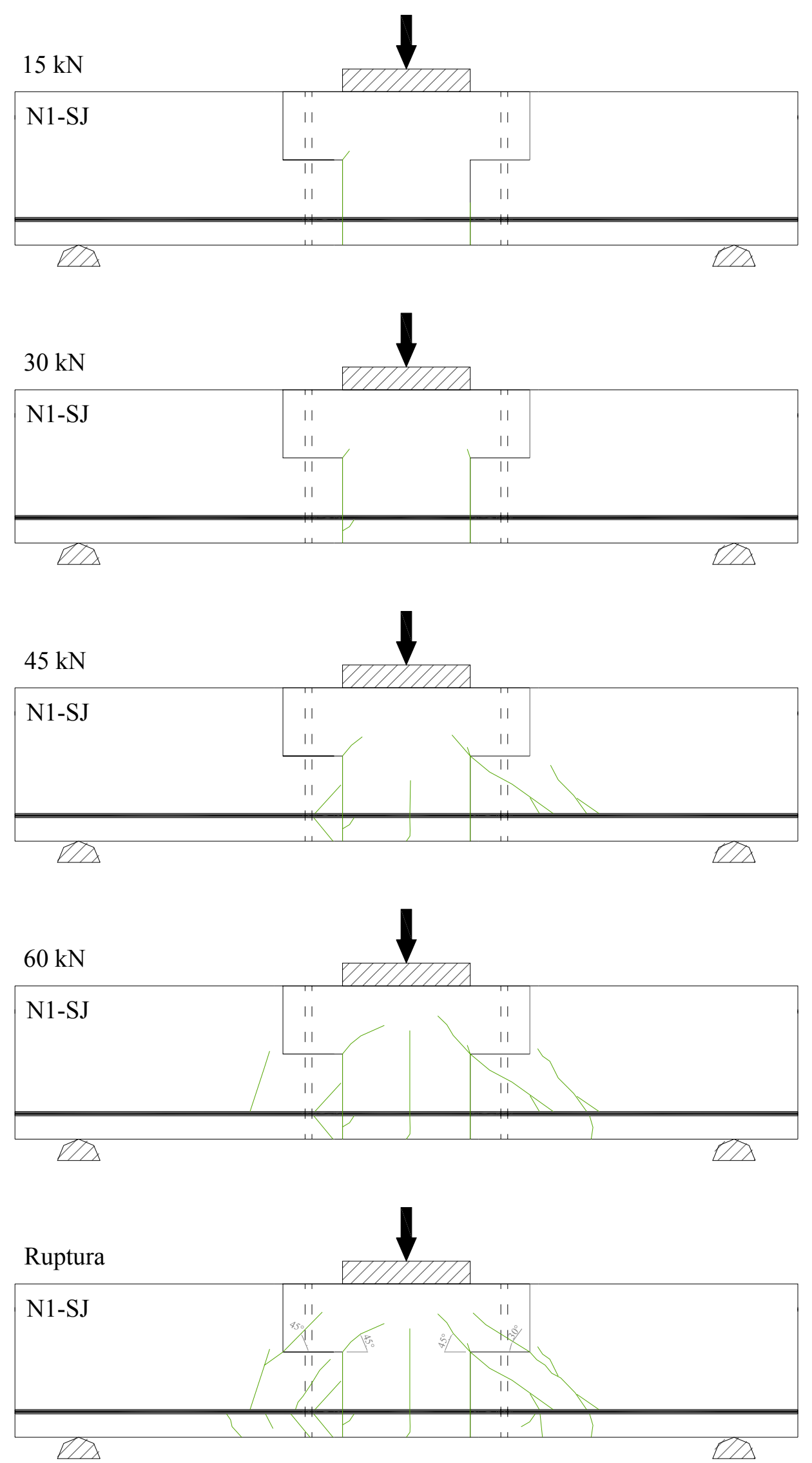

Figura 7.28 - Evolução da fissuração em uma das faces do modelo N1 SJ. 


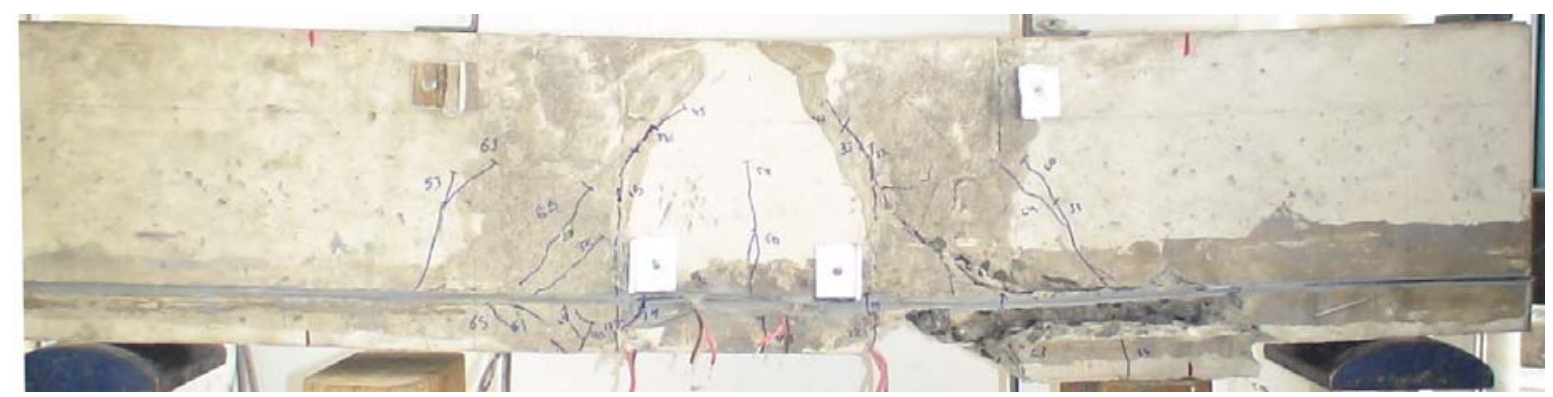

(a)

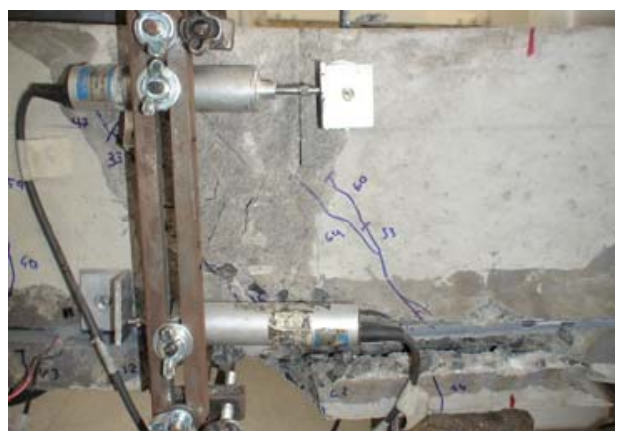

(b)

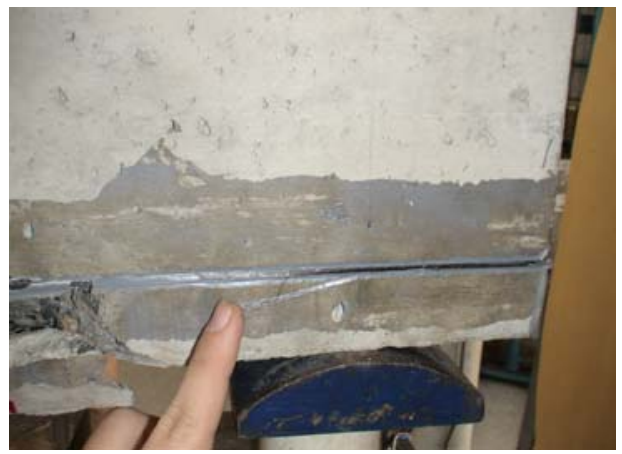

(c)

Figura 7.29 - Configuração das fissuras após a ruptura; (b) desprendimento de porção de concreto; (c) delaminação do reforço - modelo N1 SJ.

\subsubsection{Modelo P1 CJ}

As primeiras fissuras surgiram com carregamento de $12 \mathrm{kN}$ na interface entre o concreto da viga e o graute. Para o carregamento $24 \mathrm{kN}$, apareceram fissuras na base da viga aproximadamente nos limites da área de aplicação da carga. Com $32 \mathrm{kN}$ de carregamento, surgiram fissuras a meio vão do modelo. Para a força aplicada de $35 \mathrm{kN}$ apareceram as primeiras fissuras de aderência nas proximidades das juntas. Com o aumento do carregamento, foram surgindo novas fissuras de aderência e as fissuras já existentes aumentaram. A ruptura ocorreu quando fissuras de aderência encontraram o canto reentrante da viga, isolando uma porção de concreto (Figura 7.31-b). Houve arrancamento brusco do laminado. Observou-se o esmagamento da região mais comprimida do dente da viga (Figura 7.31-a). Houve destacamento de pedaços de concreto na região tracionada. Alguns traziam uma fina camada de laminado ainda aderida (Figura 7.31-d). A Figura 7.30 ilustra a evolução da fissuração ao longo do ensaio. 

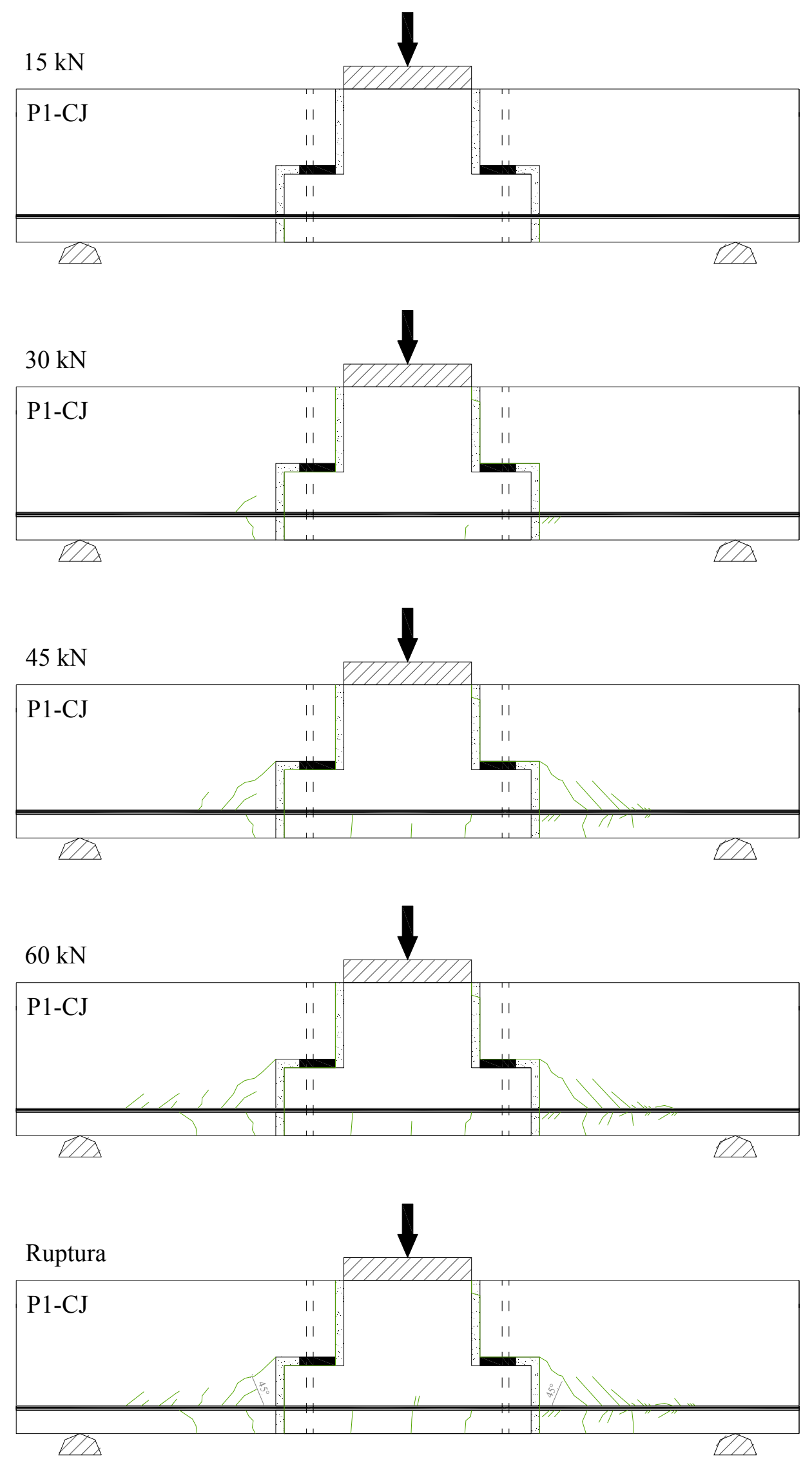

Figura 7.30 - Evolução da fissuração em uma das faces do modelo P1 CJ. 


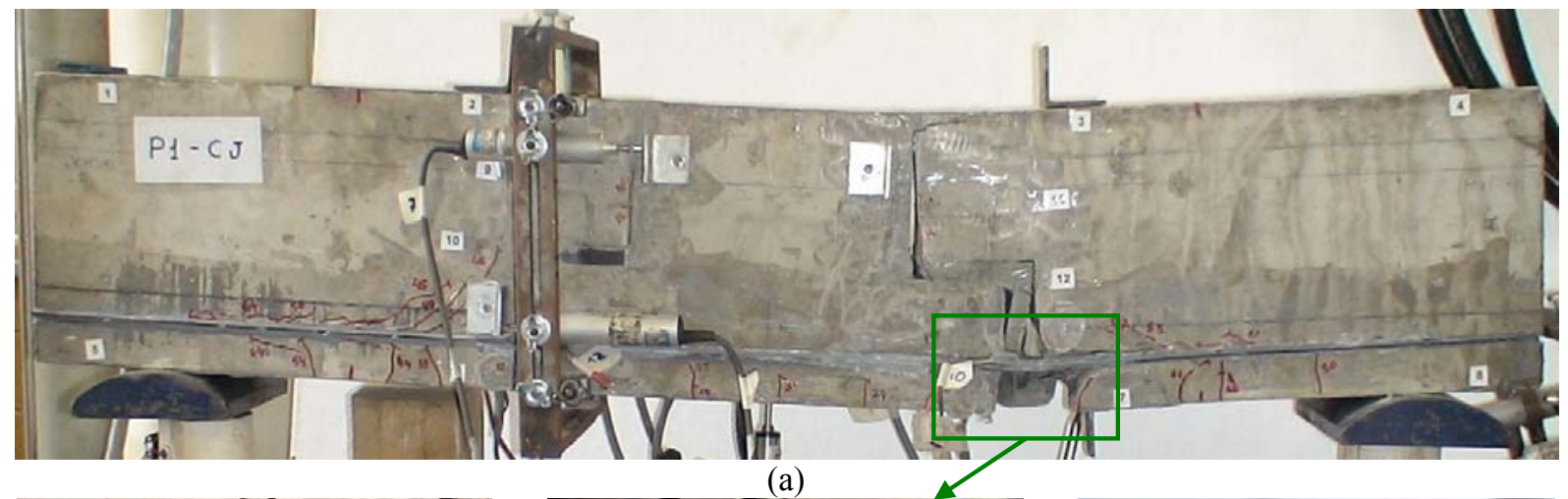

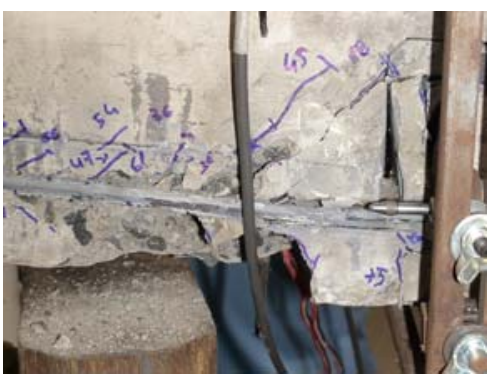

(b)

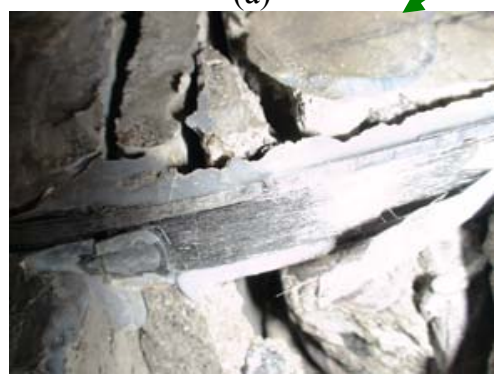

(c)

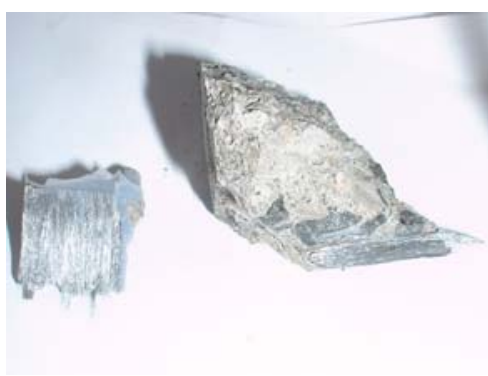

(d)

Figura 7.31 - (a) Configuração das fissuras após a ruptura; (b) detalhe da ruptura; (c) delaminação do reforço; (d) fragmentos de concreto com lâminas de reforço ainda aderidas - modelo P1 CJ.

\subsubsection{Modelo P1 SJ}

A fissuração se iniciou na interface entre os concretos da viga e do pilar para carregamento de $18 \mathrm{kN}$. Para o carregamento de $31 \mathrm{kN}$, surgiram fissuras de aderência nas proximidades da junta tracionada e de flexão a partir da base do modelo, aproximadamente nos limites da área de aplicação da carga. Novas fissuras de aderência surgiram e as fissuras existentes se intensificaram com o aumento no carregamento. A ruptura ocorreu quando fissuras de aderência encontraram o canto reentrante da viga, isolando uma porção de concreto (Figura 7.33-b). O comprimento de ancoragem foi reduzido e houve arrancamento brusco do laminado (Figura 7.33-d). Houve destacamento de pedaços de concreto, alguns deles com uma fina camada de laminado ainda aderida (Figura 7.33-c). A Figura 7.32 ilustra a evolução da fissuração ao longo do ensaio. 

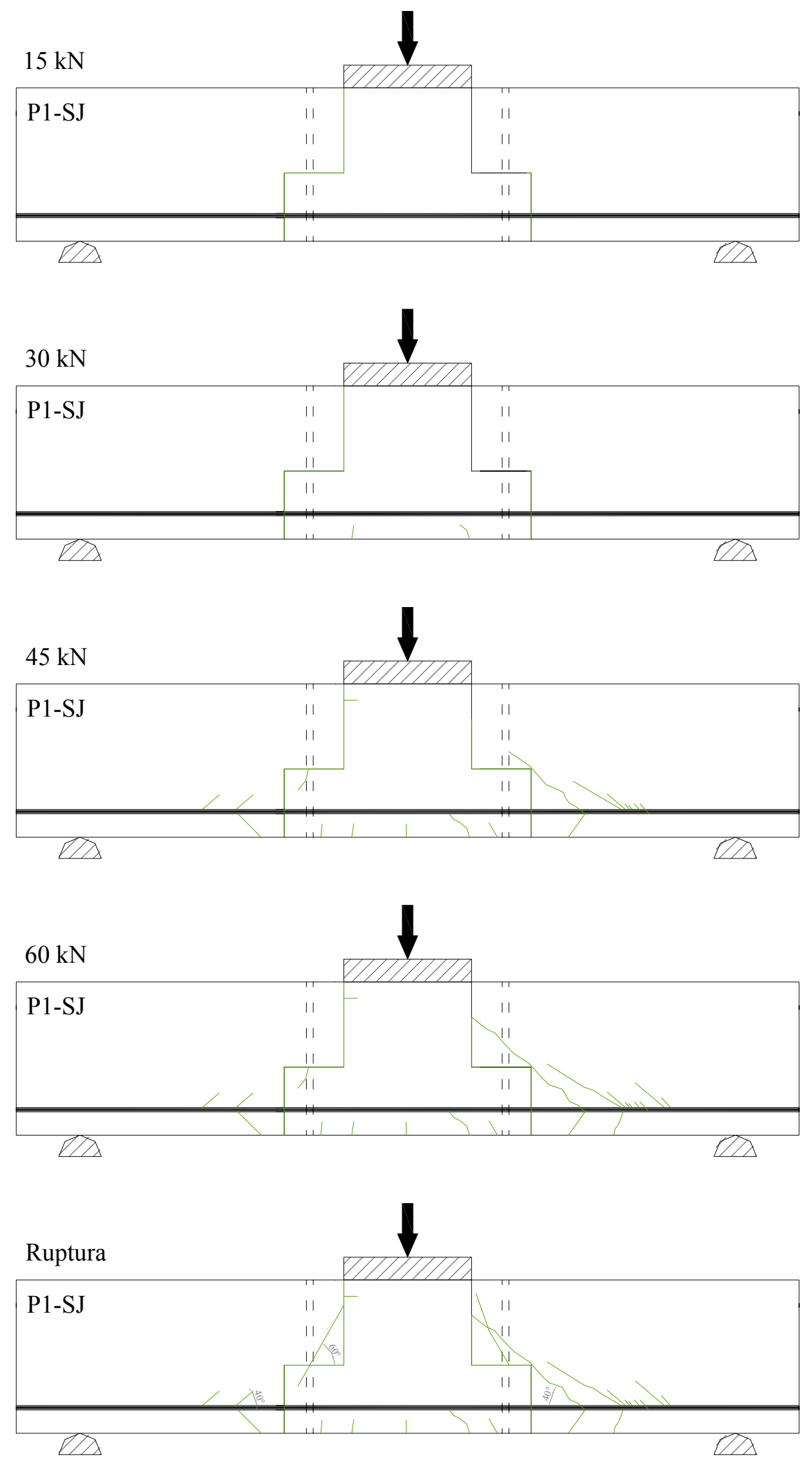

Figura 7.32 - Evolução da fissuração em uma das faces do modelo P1 SJ. 


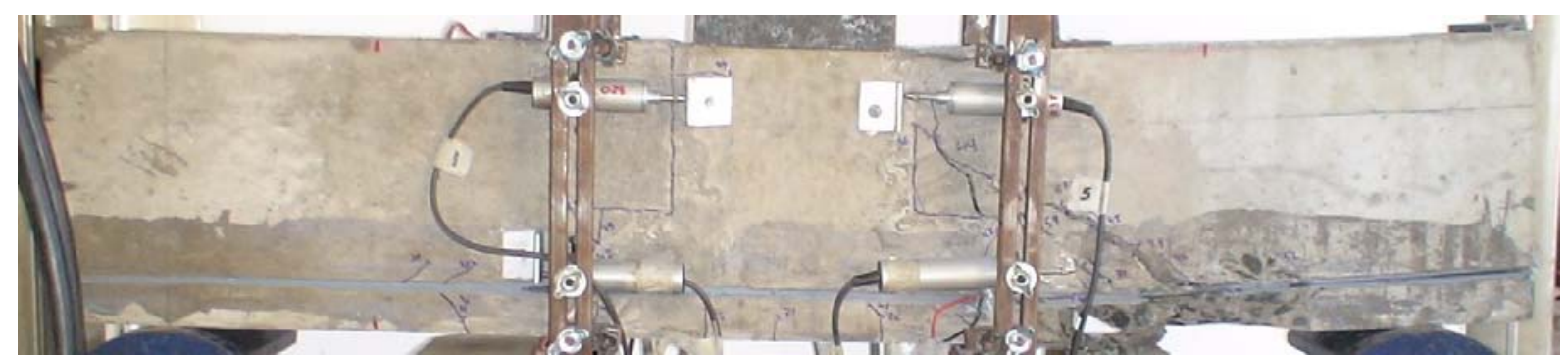

(a)

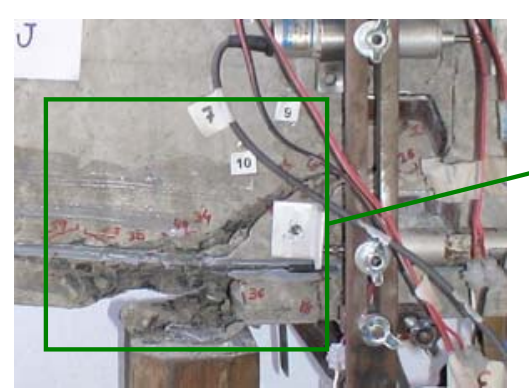

(b)

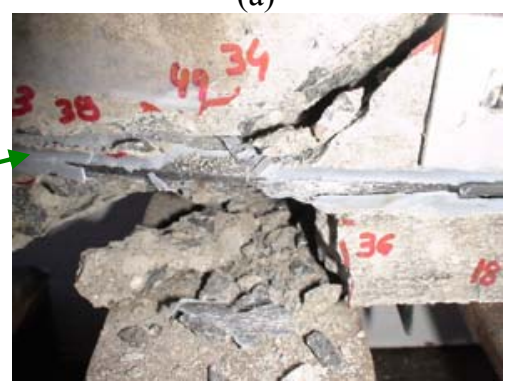

(c)

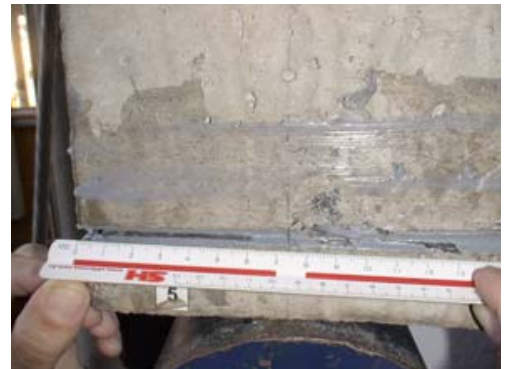

(d)

Figura 7.33 - (a) Configuração das fissuras após a ruptura; (b) ruptura; (c) do desprendimento de concreto e laminas do reforço; (d) deslizamento do reforço - modelo P1 SJ.

\subsubsection{Deformação nos laminados}

Os gráficos "força $\mathrm{x}$ deformação" nos laminados para todos os modelos são apresentados nas Figura 7.34, Figura 7.35, Figura 7.36, Figura 7.37, Figura 7.38 e Figura 7.39. Os laminados tiveram um comportamento uniforme e linear ao longo da maior parte do carregamento. A partir do ponto em que a força atingiu aproximadamente $60 \mathrm{kN}$, observa-se uma perturbação nos gráficos. $\mathrm{Na}$ Tabela 7.10, estão reunidos os valores das deformações máximas de cada laminado. Observa-se que a máxima deformação não variou muito nos ensaios, tendo um valor médio de 9,21\%. O coeficiente de variação, indicador da dispersão dos dados, foi de 9,4 \%. Não se apresentam as curvas dos laminados L1E e L2D do modelo P1 CJ e L2E e L1D do modelo P1 SJ em função de deficiências na extensometria.

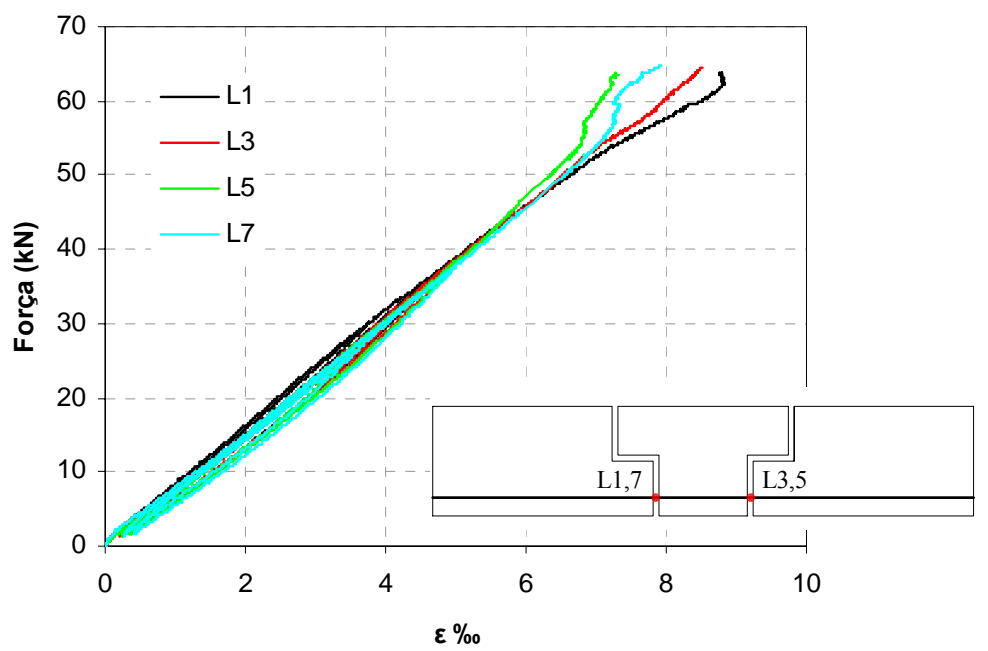

Figura 7.34 - Gráfico “força x deformação” nos laminados - modelo-piloto. 


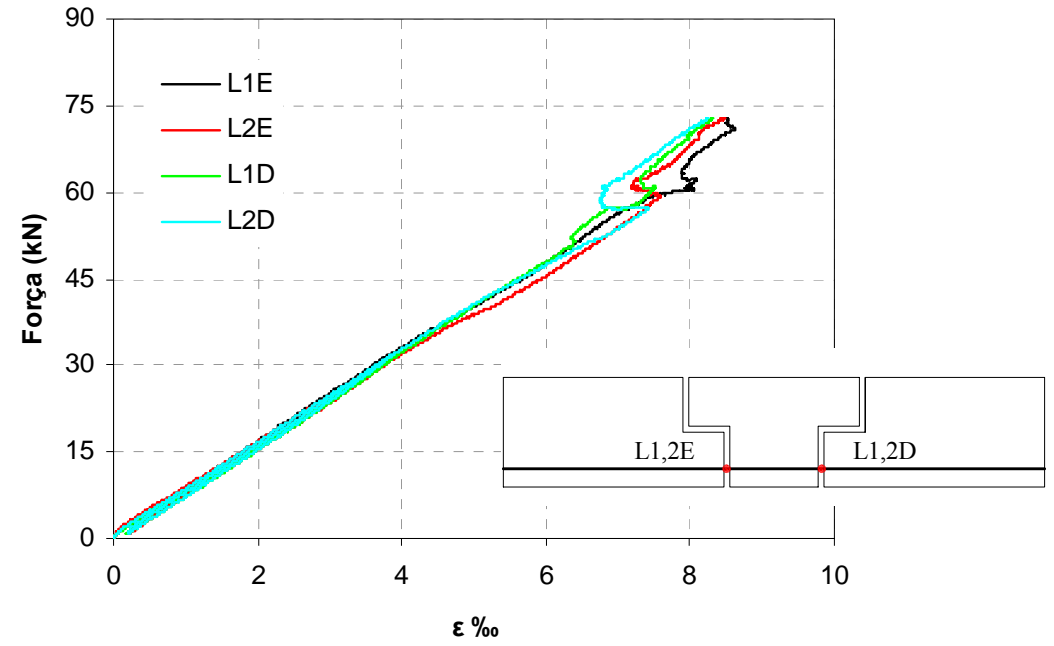

Figura 7.35 - Gráfico "força x deformação" nos laminados - modelo N1 CJ.

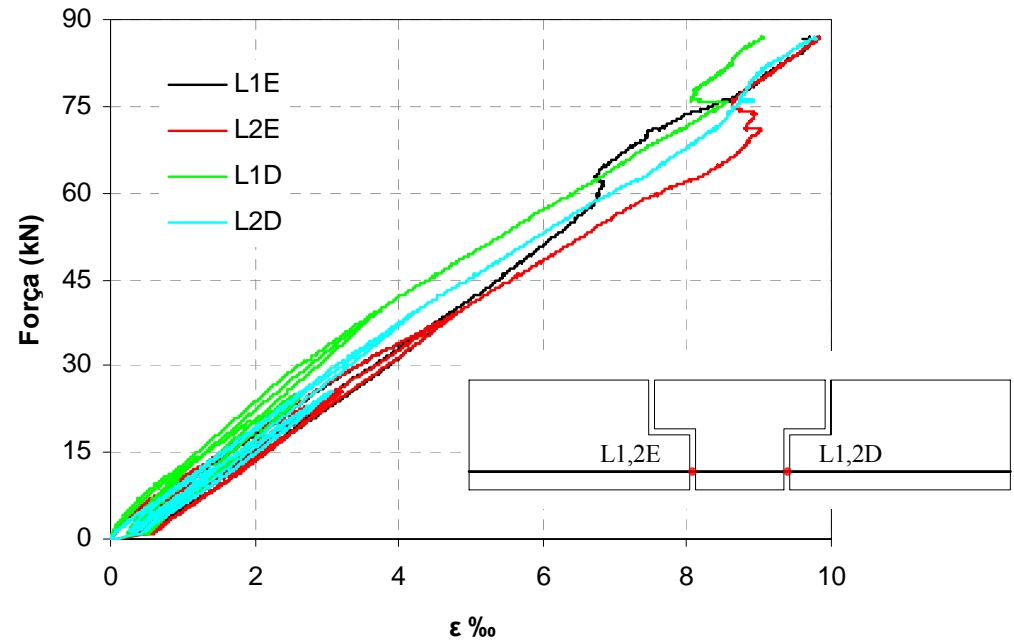

Figura 7.36 - Gráfico "força x deformação" nos laminados - modelo N2 CJ.

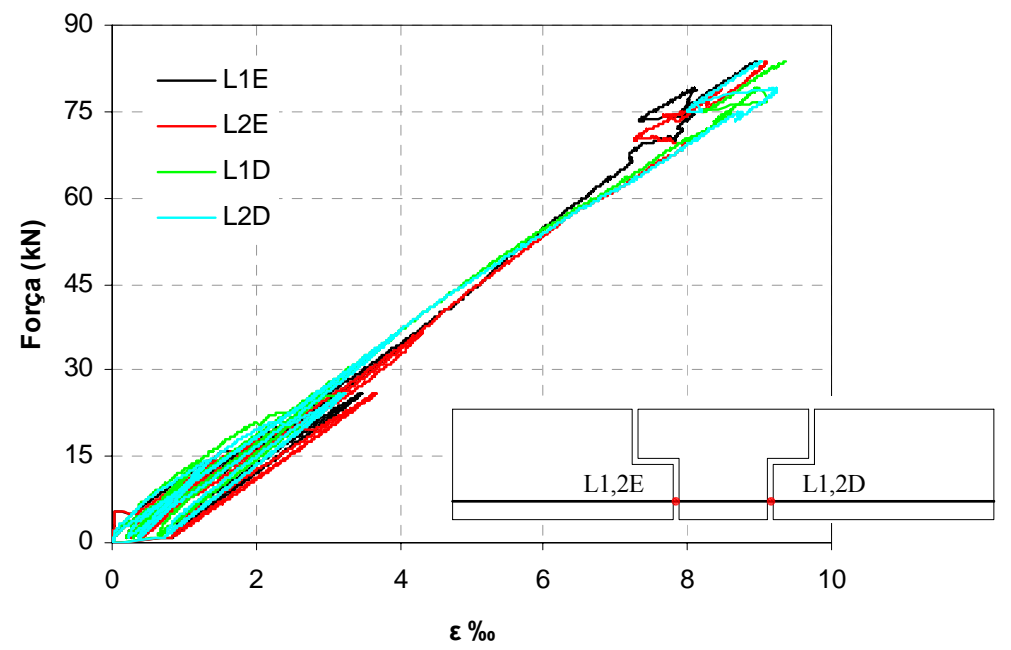

Figura 7.37 - Gráfico "força x deformação" nos laminados - modelo N1 SJ. 


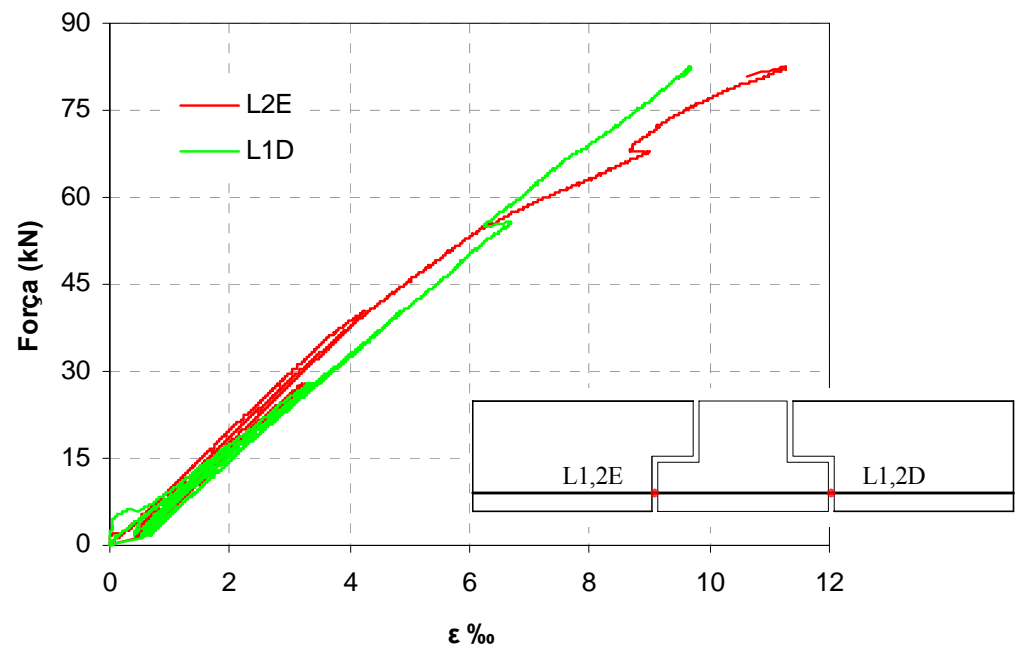

Figura 7.38 - Gráfico "força x deformação" nos laminados - modelo P1 CJ.

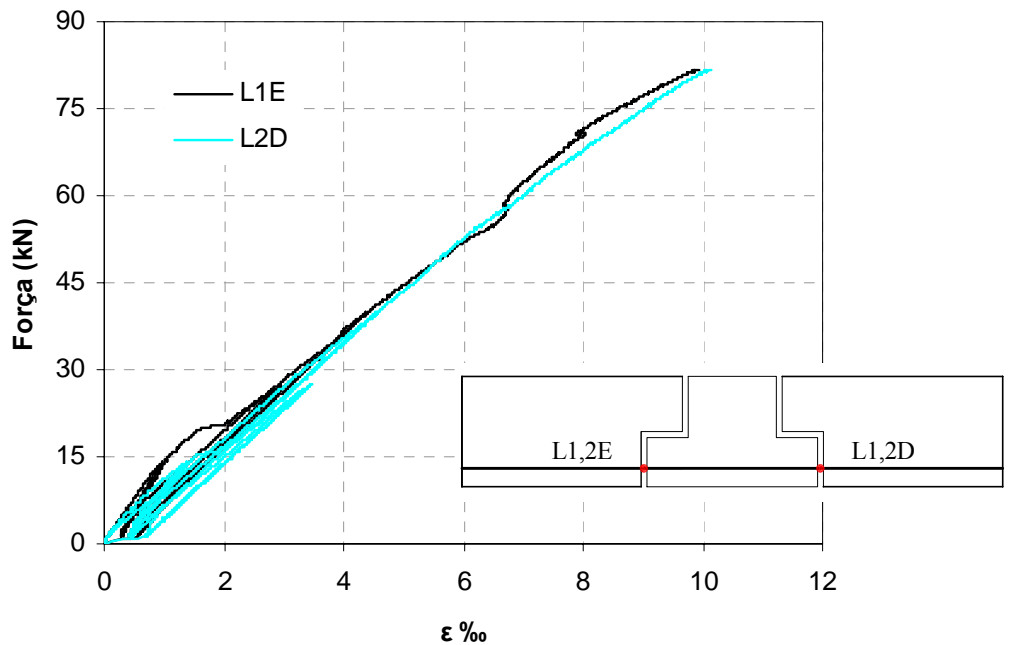

Figura 7.39 - Gráfico "força x deformação" nos laminados - modelo P1 SJ.

Tabela 7.10 - Deformações máximas nos laminados.

\begin{tabular}{cccccc}
\hline \multirow{2}{*}{ Modelo } & \multirow{2}{*}{$\begin{array}{c}\text { Força máxima } \\
(\mathbf{k N})\end{array}$} & L1E & L2E & L1D & L2D \\
\cline { 3 - 6 } & 66,30 & 8,83 & 8,24 & 9,12 & 7,63 \\
\hline Piloto* $^{*}$ & 72,89 & 8,62 & 8,57 & 8,33 & 8,25 \\
N1 CJ & 86,93 & 9,71 & 9,83 & 9,07 & 9,79 \\
N2 CJ & 83,66 & 8,97 & 9,10 & 9,35 & 9,24 \\
N1 SJ & 82,46 & - & 11,27 & 9,68 & - \\
P1 CJ & 81,81 & 10,57 & - & - & 10,13 \\
P1 SJ & & & - & - & \\
\hline
\end{tabular}

*Adotou-se para a nomenclatura dos extensômetros do modelo-piloto as equivalências: L1E=L1, L2E=L7, $\mathrm{L} 1 \mathrm{D}=\mathrm{L} 3, \mathrm{~L} 2 \mathrm{D}=\mathrm{L} 5$. 


\subsubsection{Deformação na armadura do tirante do consolo}

Os gráficos "força x deformação" na armadura do tirante do consolo são apresentados nas Figura 7.40, Figura 7.41, Figura 7.42, Figura 7.43, Figura 7.44 e Figura 7.45. As armaduras do tirante dos consolos foram as que apresentaram as maiores deformações (dentre as armaduras de aço). Entretanto, apenas em um dos ensaios se atingiu o escoamento (PT1E na Figura 7.43). O trecho inicial na curva que relaciona a força e a deformação é aproximadamente linear. No trecho final da curva de alguns dos gráficos, observa-se o decréscimo da deformação com o aumento da força, que indica o descolamento do extensômetro ou a abertura de fissuras próximas ao ponto de sua fixação. Na Tabela 7.11, estão reunidos os valores das deformações máximas nas armaduras do tirante do consolo. Observa-se uma grande dispersão dos valores de deformação que variaram de $0,50 \%$ a 3,04\% . As deformações nessas armaduras foram maiores para os modelos reforçados a momento fletor negativo (média de 1,81\%) que para os modelos reforçados a momento fletor positivo (média de 0,88\%). Não se apresentam as curvas PT1E e PT2E do modelo N1 CJ em função de deficiências constatadas na extensometria.

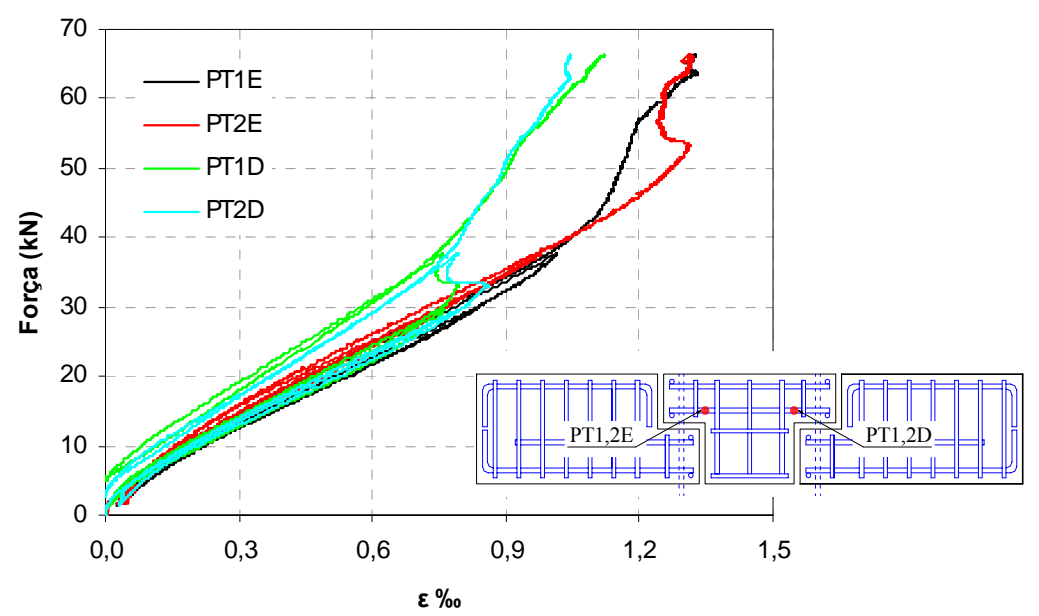

Figura 7.40 - Gráfico "força x deformação" na armadura do tirante do consolo - modelo-piloto.

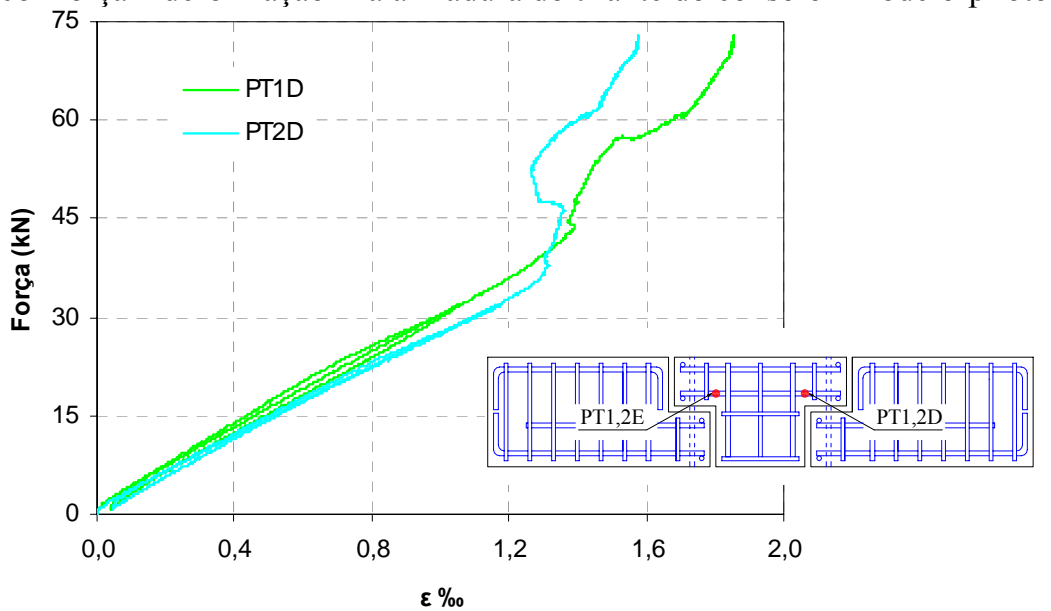

Figura 7.41 - Gráfico "força x deformação" na armadura do tirante do consolo - modelo N1 CJ. 


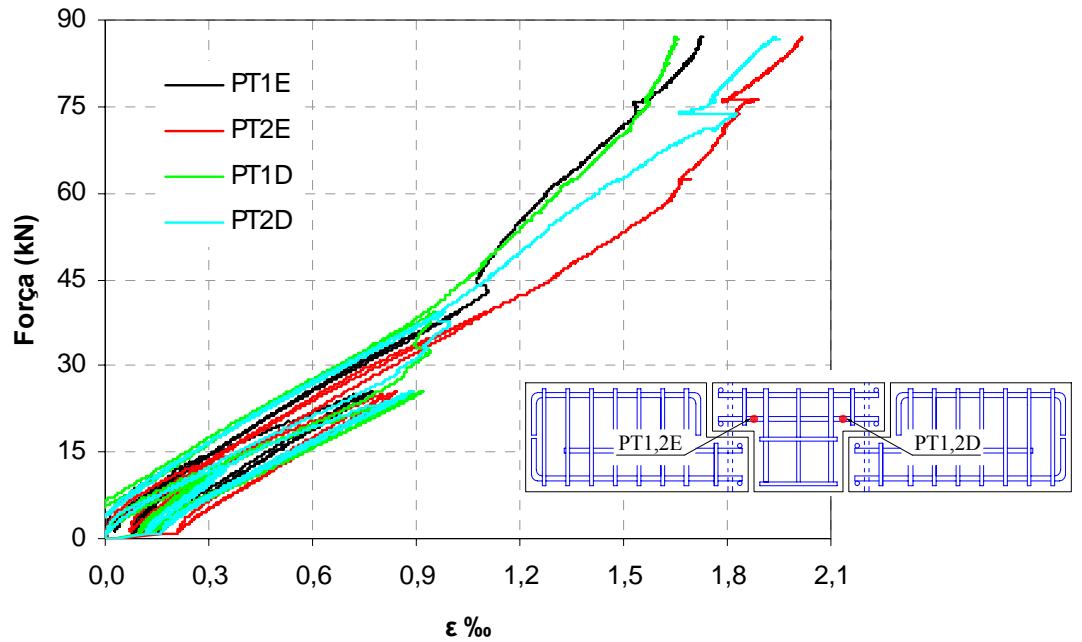

Figura 7.42 - Gráfico "força x deformação" na armadura do tirante do consolo - modelo N2 CJ.

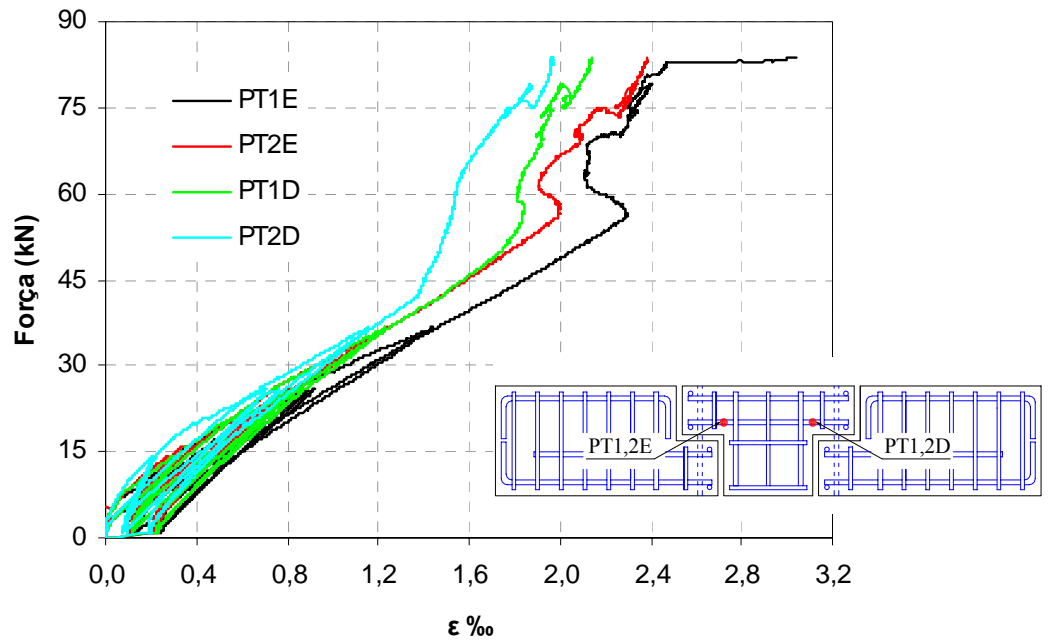

Figura 7.43 - Gráfico "força x deformação" na armadura do tirante do consolo - modelo N1 SJ.

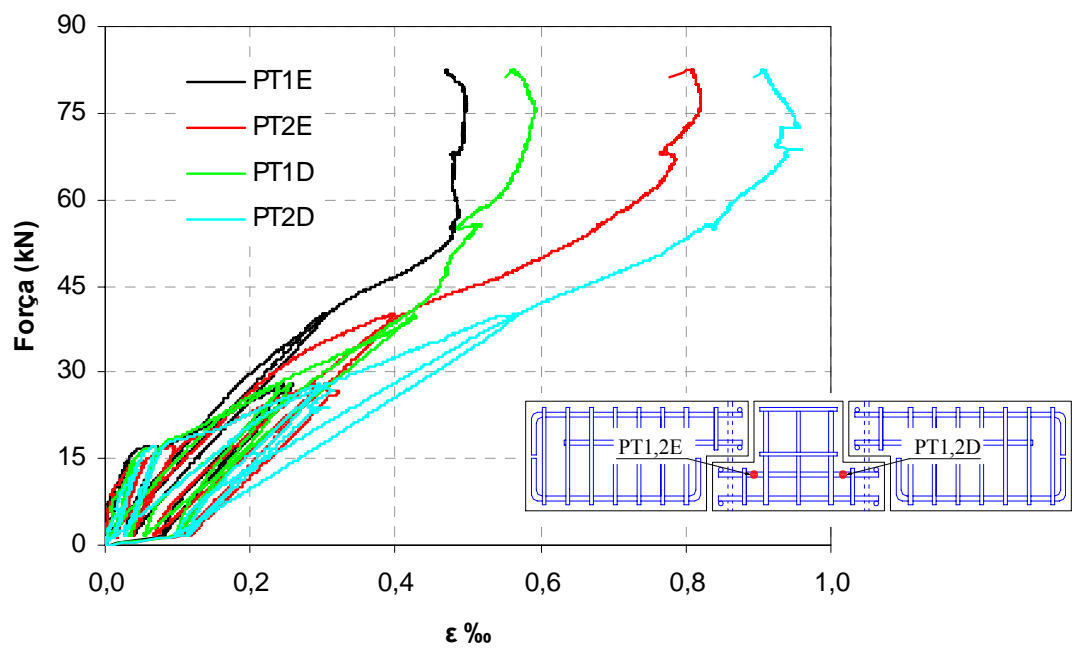

Figura 7.44 - Gráfico "força x deformação" na armadura do tirante do consolo - modelo P1 CJ. 


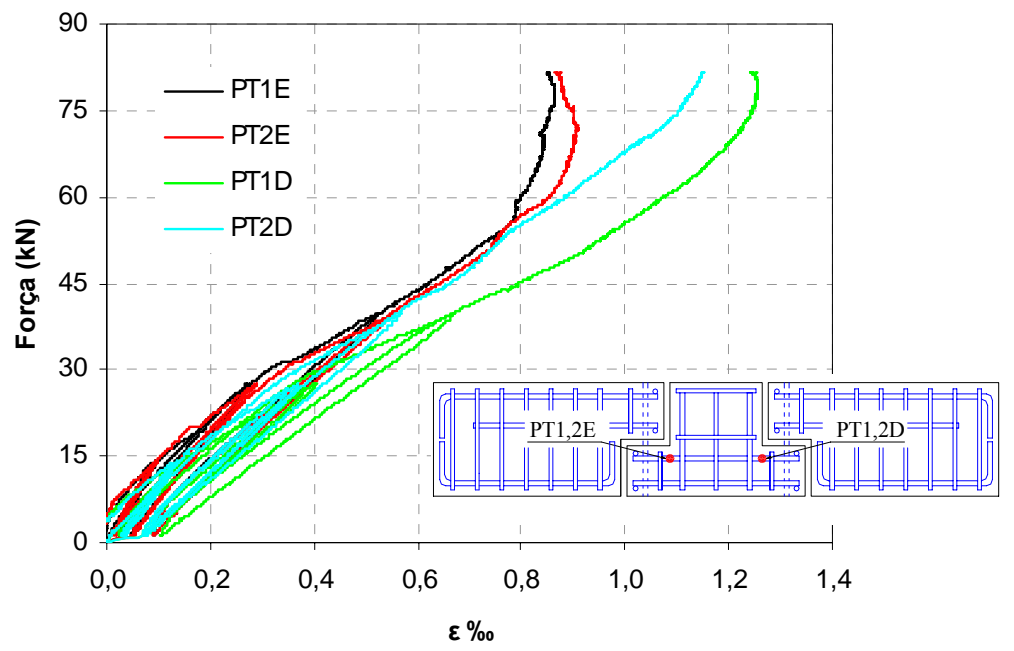

Figura 7.45 - Gráfico "força x deformação" na armadura do tirante do consolo - modelo P1 SJ.

Tabela 7.11 - Deformações máximas nas armaduras do tirante do consolo.

\begin{tabular}{cccccc}
\hline \multirow{2}{*}{ Modelo } & \multirow{2}{*}{$\begin{array}{c}\text { Força máxima } \\
(\mathbf{k N})\end{array}$} & PT1E & PT2E & PT1D & PT2D \\
\cline { 3 - 6 } & 66,30 & 1,33 & 1,29 & 1,32 & 1,07 \\
\hline Piloto & 72,89 & - & - & 1,86 & 1,58 \\
N1 CJ & 86,93 & 1,73 & 2,02 & 1,66 & 1,95 \\
N2 CJ & 83,66 & 3,04 & 2,39 & 2,14 & 1,97 \\
N1 SJ & 82,46 & 0,50 & 0,82 & 0,59 & 0,96 \\
P1 CJ & 81,81 & 0,86 & 0,91 & 1,26 & 1,15 \\
P1 SJ & & & & & \\
\hline
\end{tabular}

\subsubsection{Deformação na armadura de suspensão}

As armaduras de suspensão das vigas não apresentaram deformação até que se atingiu carregamento em torno de 25 a $45 \mathrm{kN}$. Essa faixa do carregamento corresponde ao início do surgimento de fissuras de aderência diagonais, o que provavelmente está relacionado ao início da solicitação das armaduras de suspensão. Observou-se um trecho de baixa inclinação da curva em que um pequeno acréscimo de força correspondeu a grande acréscimo na deformação. Em alguns dos gráficos observa-se, no trecho final da curva, a diminuição da deformação com o aumento da força. Isso pode indicar o descolamento dos extensômetros ou a abertura de fissuras próximas aos pontos de sua fixação. Na Tabela 7.12, estão reunidos os valores das deformações máximas nas armaduras de suspensão. Observa-se uma grande discrepância entre os valores de deformação que variaram de $0,04 \%$ a $1,10 \%$. Não se apresenta as curva de VS1D do modelo P1 SJ em função de deficiências constatadas na 
extensometria. Aparentemente, os extensômetros VS2E e VS2D também tiveram um desempenho deficiente, dada ordem de grandeza da deformação acusada por eles, inferior ao observado nos demais extensômetros.

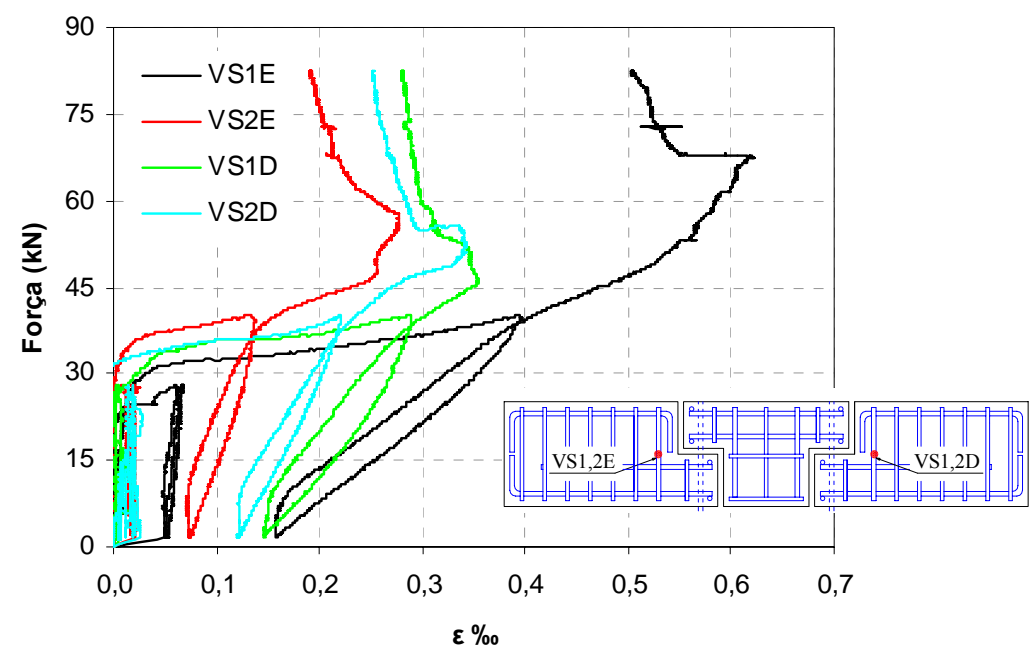

Figura 7.46 - Gráfico "força x deformação" na armadura de suspensão - modelo-piloto.

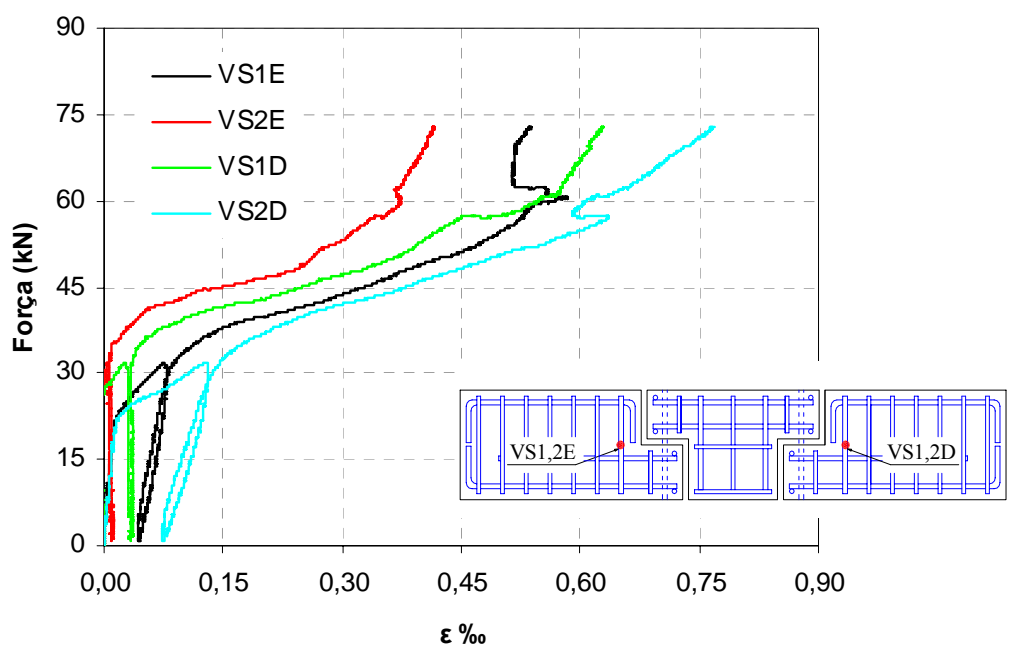

Figura 7.47 - Gráfico "força x deformação" na armadura de suspensão - modelo N1 CJ.

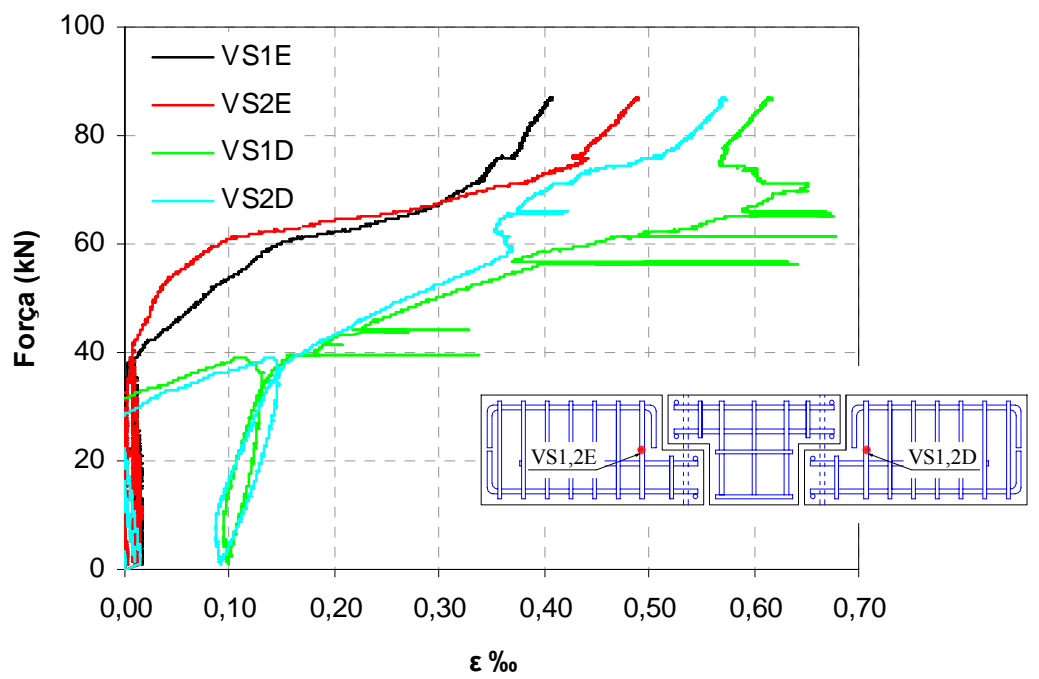

Figura 7.48 - Gráfico "força x deformação" na armadura de suspensão - modelo N2 CJ. 


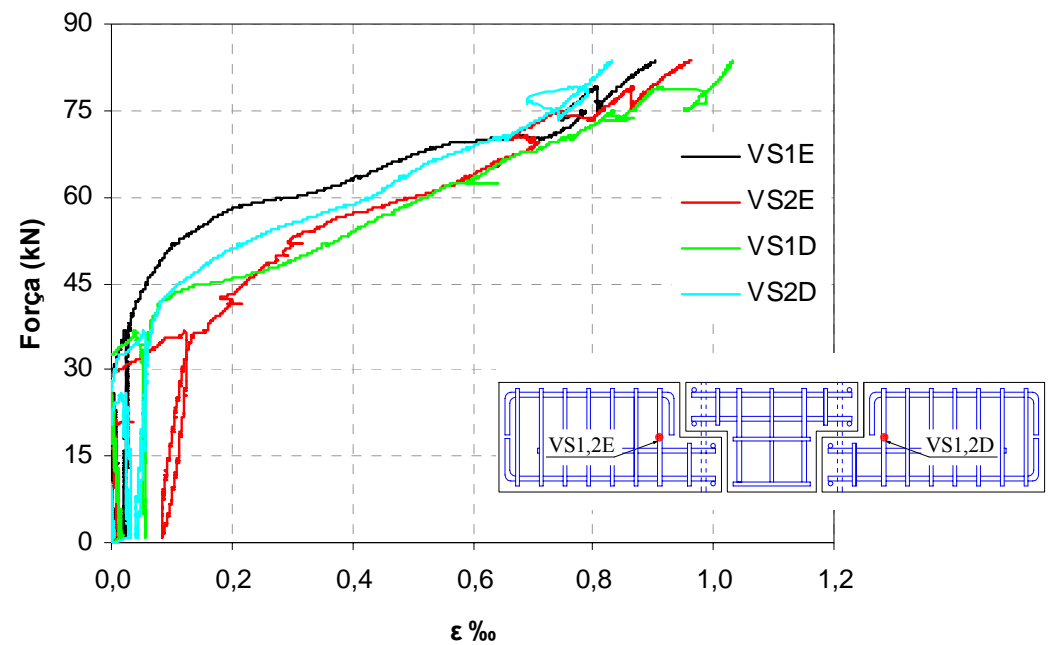

Figura 7.49 - Gráfico "força x deformação" na armadura de suspensão - modelo N1 SJ.

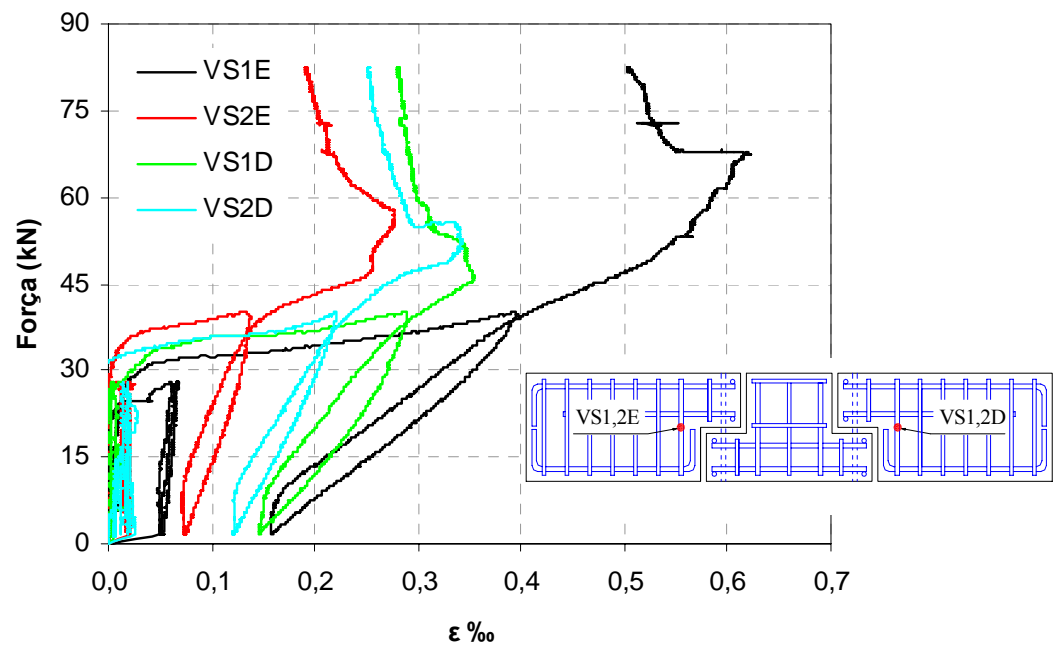

Figura 7.50 - Gráfico "força x deformação" na armadura de suspensão - modelo P1 CJ.

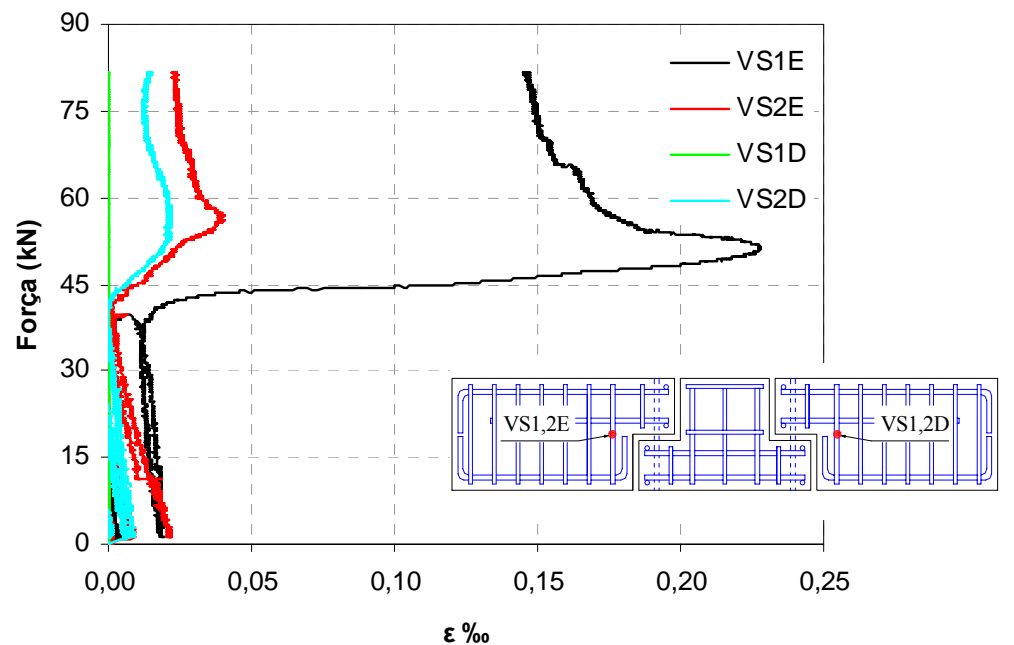

Figura 7.51 - Gráfico "força x deformação" na armadura de suspensão - modelo P1 SJ. 
Tabela 7.12 - Deformações máximas nas armaduras de suspensão.

\begin{tabular}{lccccc}
\hline \multirow{2}{*}{ Modelo } & \multirow{2}{*}{$\begin{array}{c}\text { Força máxima } \\
(\mathbf{k N})\end{array}$} & VS1E & VS2E & VS1D & VS2D \\
\cline { 3 - 6 } & 66,30 & 0,55 & 1,10 & 0,49 & 0,51 \\
\hline Piloto & 72,89 & 0,58 & 0,43 & 0,63 & 0,79 \\
N1 CJ & 86,93 & 0,41 & 0,49 & 0,68 & 0,57 \\
N2 CJ & 83,66 & 0,93 & 0,96 & 1,03 & 0,83 \\
N1 SJ & 82,46 & 0,62 & 0,28 & 0,35 & 0,34 \\
P1 CJ & 81,81 & 0,23 & 0,04 & - & 0,04 \\
P1 SJ & & & & & \\
\hline
\end{tabular}

\subsubsection{Rigidez à flexão}

As rigidezes dos modelos de ligação foram avaliadas em função das curvas "momento x rotação". Para o modelo-piloto, o momento foi calculado em relação à face do pilar, distante $31 \mathrm{~cm}$ do apoio, por meio da Equação 7.2. A distância vertical entre os transdutores $\left(\mathrm{d}_{\mathrm{v}}\right)$ foi de $8 \mathrm{~cm}$ (Figura 7.52). Para os demais modelos, o momento foi calculado na seção intermediária em relação às juntas, ou seja, a seção em que se fixou o quadro para suporte da instrumentação. Os valores da distância entre o apoio e a seção referencial para a determinação do momento fletor $\left(\ell_{\mathrm{m}}\right)$ e da distância vertical entre os transdutores $\left(\mathrm{d}_{\mathrm{v}}\right)$ foram de $11 \mathrm{~cm}$ e $27 \mathrm{~cm}$, respectivamente (Figura 7.53). A rotação foi calculada pela Equação 7.3 em função da leitura dos transdutores de deslocamento e da distância vertical entre eles. É uma média das rotações obtidas para os dois lados da ligação de cada modelo.

$$
\begin{aligned}
& M=-\frac{F}{2} \cdot l_{m} \\
& \phi=\frac{\text { média }(T 1 / 3 / 5 / 7)-\text { média }(T 2 / 4 / 6 / 8)}{d_{v}}
\end{aligned}
$$

Onde:

$M$ - momento fletor na seção

F - Força aplicada (soma das leituras das células de carga posicionadas nos apoios)

$\ell_{m}$ - distância do apoio à seção referencial

$\phi$ - rotação

média(T1/3/5/7) - média das leituras dos transdutores superiores média(T2/4/6/8) - média das leituras dos transdutores inferiores 
$d_{v}$ - distância vertical entre os transdutores superiores e inferiores

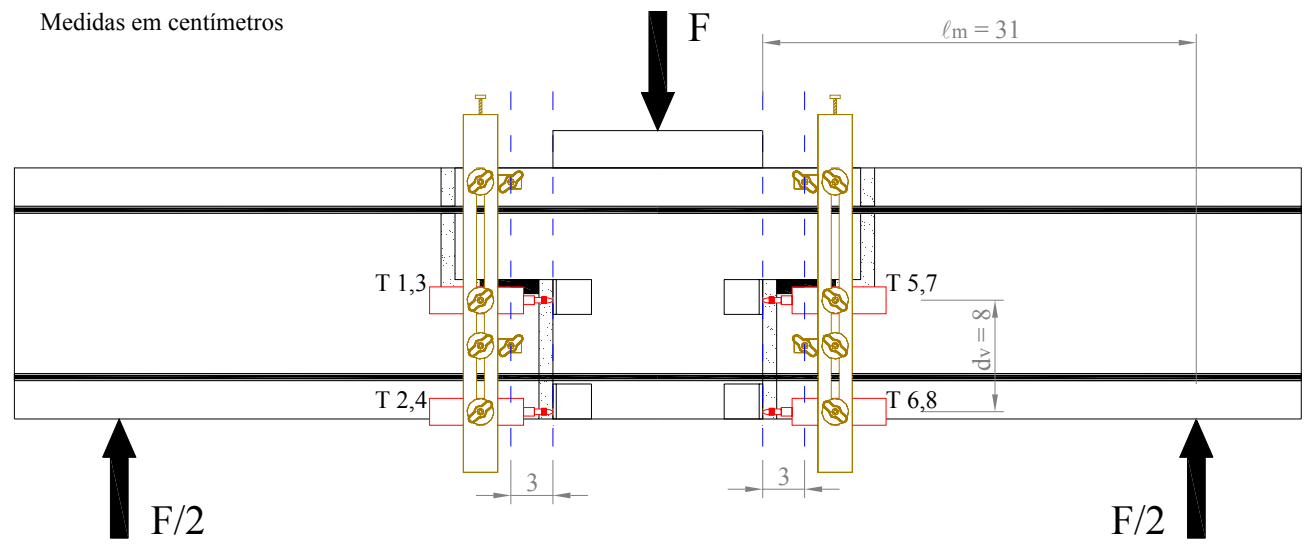

Figura 7.52 - Configuração esquemática do ensaio do modelo-piloto.

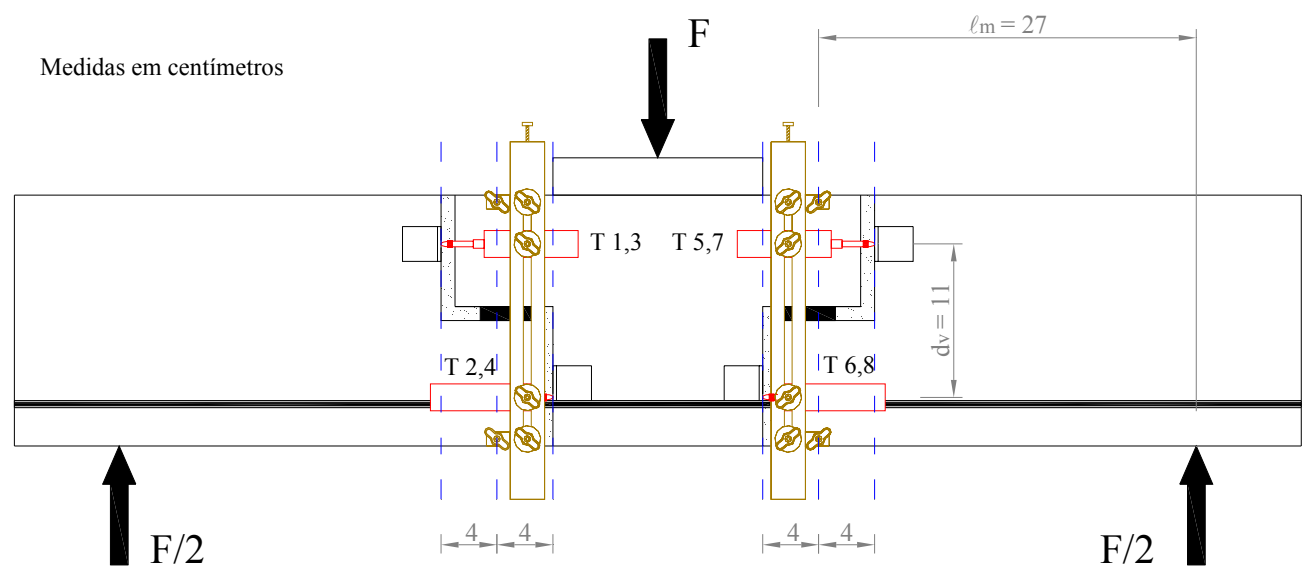

Figura 7.53 - Configuração valida para os modelos N1CJ, N2 CJ, N1 SJ, P1 CJ e P1 SJ.

Descontaram-se das leituras dos transdutores os deslocamentos que ocorreriam em uma viga monolítica no trecho entre a seção que se fixou o quadro para suporte da instrumentação e a seções para a qual se calculou o momento fletor (seção em que se colaram as cantoneiras). Dessa forma, computa-se na determinação da rigidez apenas o acréscimo de deformabilidade introduzido pela descontinuidade na ligação. A maneira como foram calculados esses descontos está descrita no APÊNDICE E. Na Figura 7.54, ilustram-se a curva original e a curva com os valores de rotação corrigidos obtidas para o modelo-piloto, apenas para fornecer uma noção da defasagem entre elas. 


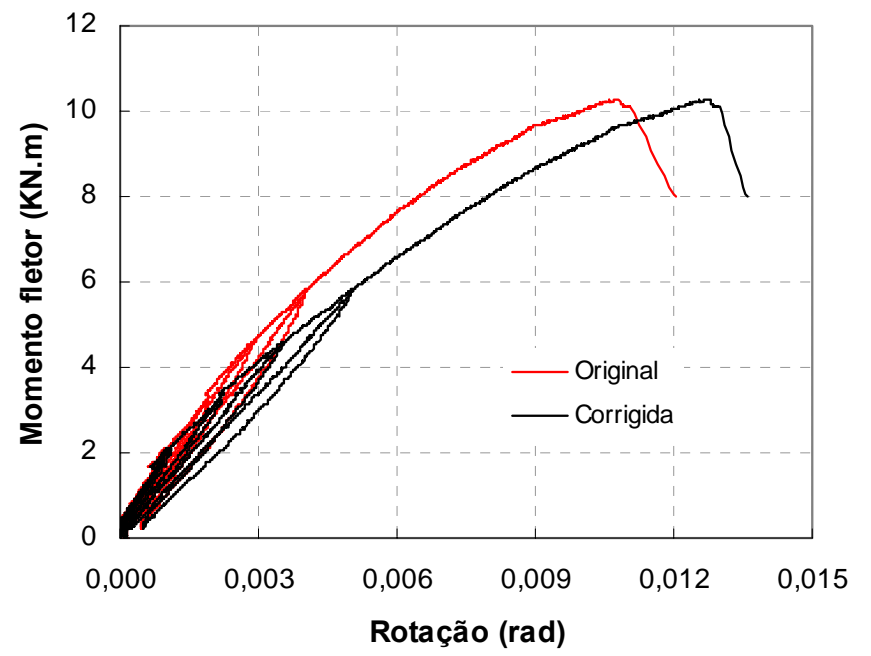

Figura 7.54 - Curvas "momento x rotação" original e corrigida do modelo-piloto.

A curva "momento x rotação" é notadamente não-linear com os trechos inicial e final próximos da linearidade (Figura 7.55, Figura 7.56, Figura 7.57, Figura 7.58, Figura 7.59 e Figura 7.60). Em vista disso se adotou uma simplificação do comportamento da ligação dividindo-o em dois estágios. Aproximou-se a curva a um comportamento bi-linear. As inclinações dos trechos inicial $\left(\mathrm{K}_{\mathrm{i}}\right)$ e final $\left(\mathrm{K}_{\mathrm{f}}\right)$ foram definidas pela regressão linear (Figura 7.55). No primeiro caso, de 0 a $30 \%$ da carga de ruptura. No segundo, de $70 \%$ até a carga de ruptura. O momento atuante na transição do primeiro para o segundo estágio é, por simplificação, denominado momento de transição da ligação $\left(\mathrm{M}_{\mathrm{tr}}\right)$. Os valores do momento de transição variaram de 54\% a 64\% do momento máximo na face do pilar (Tabela 7.13).

A curva do modelo P1 SJ apresentou um trecho inicial com rigidez muito baixa, caracterizando uma fase de acomodação das deformações. Ela foi, por essa razão, dividida em três estágios. O primeiro estágio definiu a rigidez do trecho de acomodação de 960,5 $\mathrm{kN} . \mathrm{m} / \mathrm{rad}$. O segundo estágio definiu a rigidez inicial, $\mathrm{K}_{\mathrm{i}}$, alvo de comparação com os demais modelos e o terceiro estágio, a rigidez final, $\mathrm{K}_{\mathrm{f}}$.

Os valores das rigidezes inicial e final, das rotações máximas, momentos máximos (a meio vão e na face do pilar) e momento de transição estão reunidos na Tabela 7.13. 


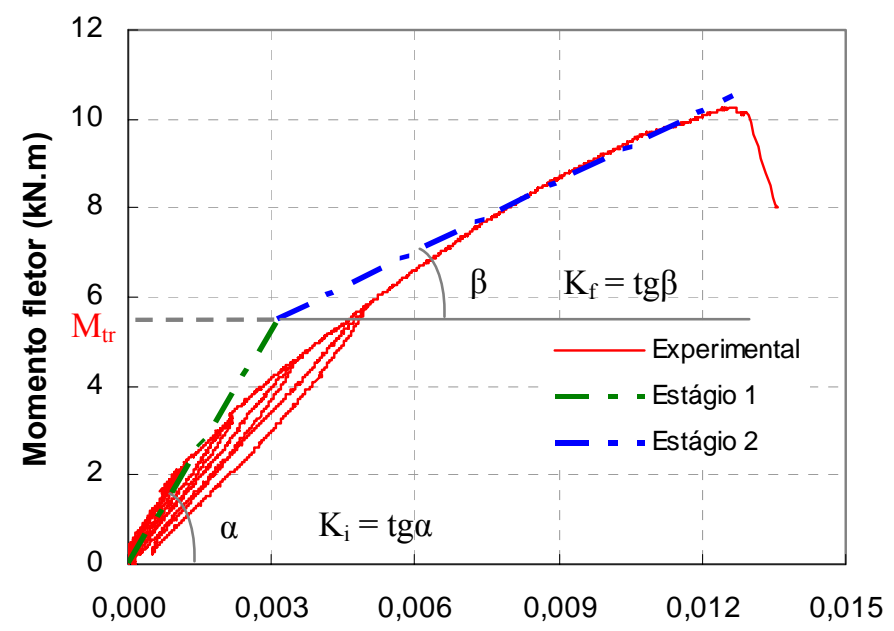

Rotação (rad)

Figura 7.55 - Curva "momento x rotação" do modelo-piloto e a aproximação bi-linear.

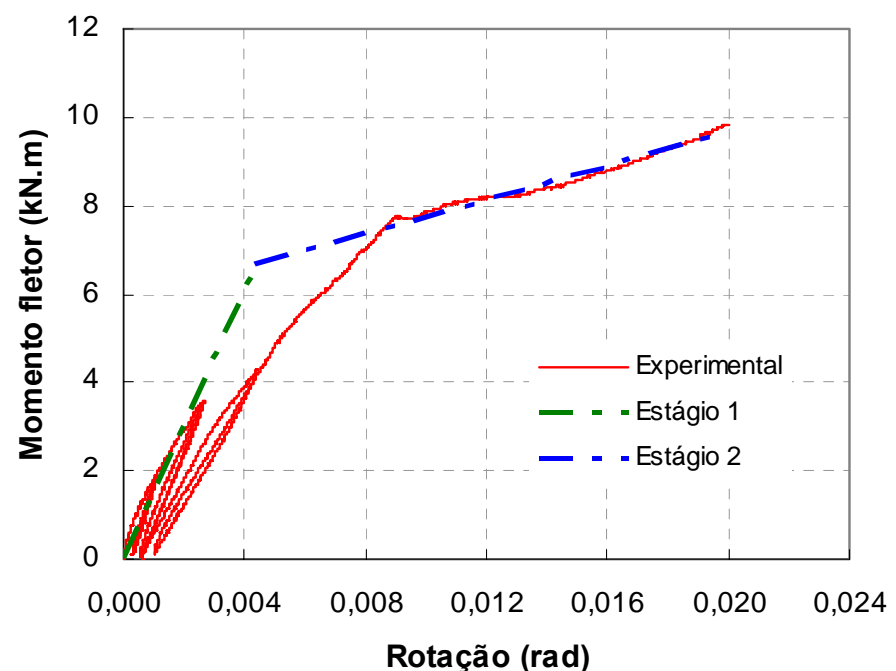

Figura 7.56 - Curva "momento x rotação" do modelo N1 CJ e a aproximação bi-linear.

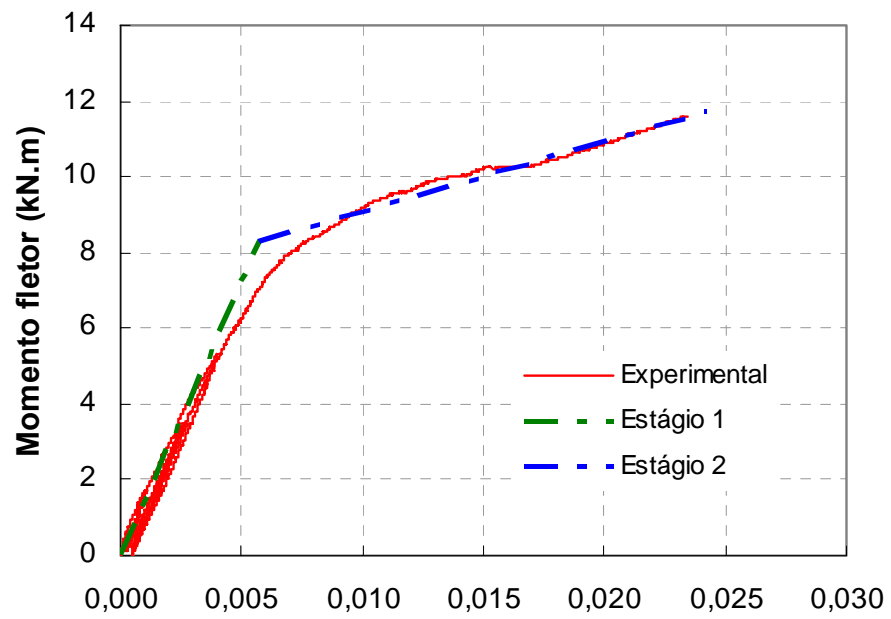

Rotação (rad)

Figura 7.57 - Curva "momento x rotação" do modelo N2 CJ e a aproximação bi-linear. 


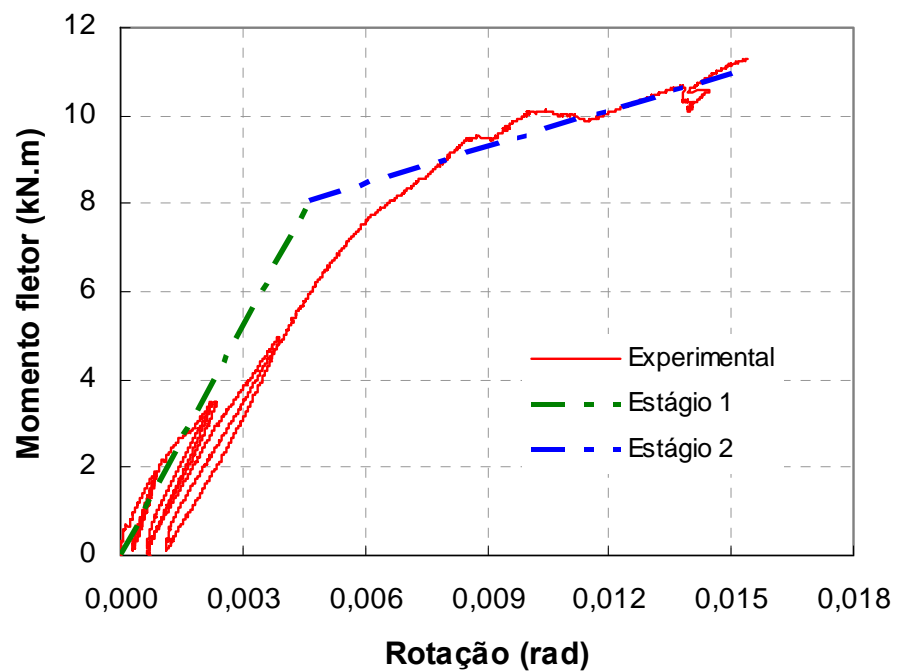

Figura 7.58 - Curva "momento x rotação" do modelo N1 SJ e a aproximação bi-linear.

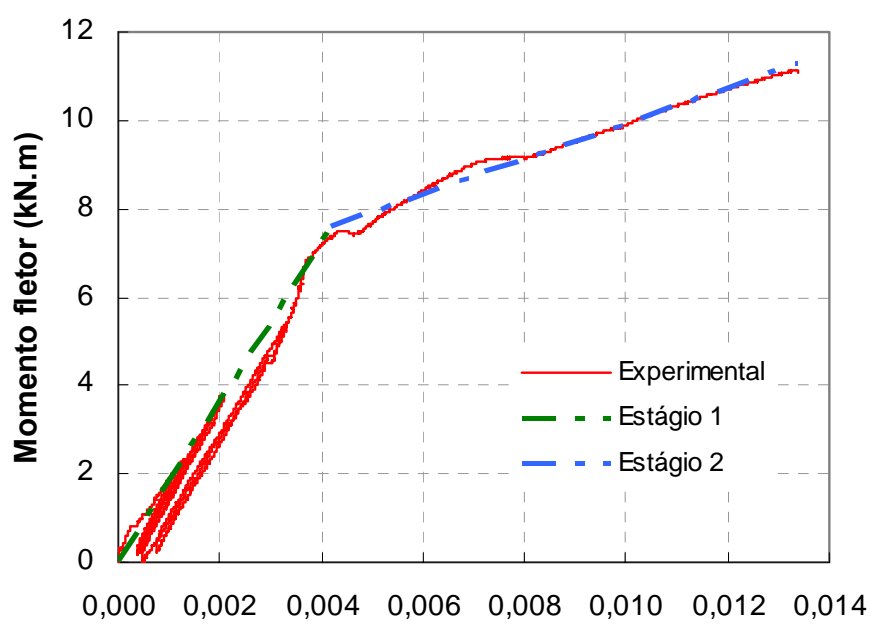

Rotação (rad)

Figura 7.59 - Curva "momento x rotação" do modelo P1 CJ e a aproximação bi-linear.

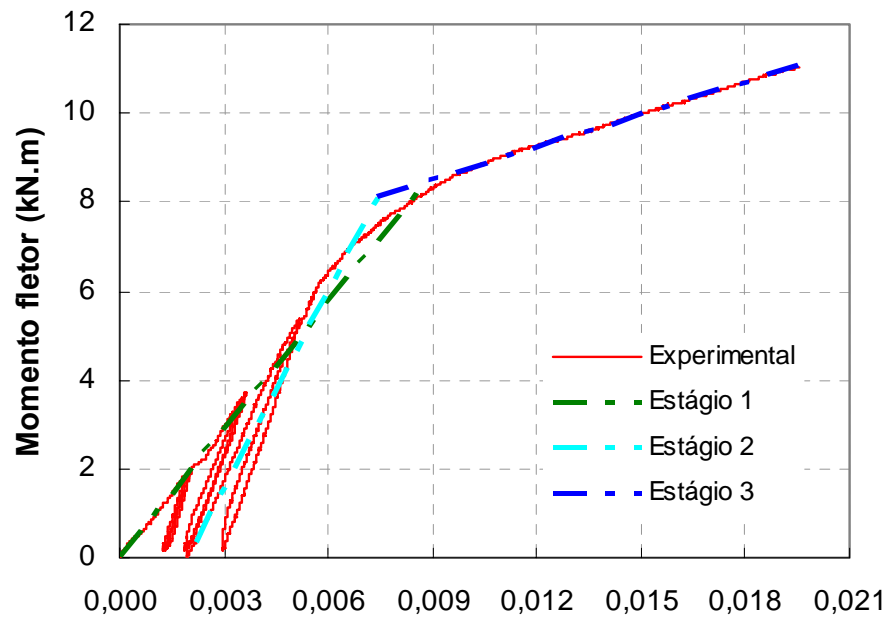

Rotação (rad)

Figura 7.60 - Curva "momento x rotação" do modelo P1 SJ e a aproximação bi-linear. 
Tabela 7.13 - Resultados relacionados à curva "momento x rotação".

\begin{tabular}{|c|c|c|c|c|c|c|c|}
\hline Modelo & $\begin{array}{c}\mathbf{M}_{\mathrm{f}, \mathrm{máx}} \\
(\mathbf{k N} \cdot \mathbf{m})\end{array}$ & $\begin{array}{l}M_{v, \text { máx }} \\
\text { (kN.m) }\end{array}$ & $\begin{array}{l}\Phi_{\text {máx }} \\
(\mathbf{r a d})\end{array}$ & $\begin{array}{c}\mathbf{K}_{\mathrm{i}} \\
(\mathbf{k N} \cdot \mathrm{m} / \mathrm{rad})\end{array}$ & $\begin{array}{c}\mathbf{K}_{\mathrm{f}} \\
(\mathbf{k N} \cdot \mathbf{m} / \mathbf{r a d})\end{array}$ & $\begin{array}{c}\mathbf{M}_{\mathrm{tr}} \\
\text { (kN.m) }\end{array}$ & $\begin{array}{c}\mathbf{M}_{\mathrm{tr}} / \mathbf{M}_{\mathrm{f} \text {,máx }} \\
\quad(\mathbf{\%})\end{array}$ \\
\hline Piloto & 10,28 & 11,52 & 0,0108 & 1756,20 & 524,69 & 5,51 & 54 \\
\hline N1 CJ & 11,30 & 12,66 & 0,0200 & 1514,10 & 191,70 & 6,67 & 59 \\
\hline N2 CJ & 13,47 & 15,10 & 0,0243 & 1489,70 & 185,45 & 8,31 & 62 \\
\hline N1 SJ & 12,97 & 14,54 & 0,0180 & 1736,30 & 279,59 & 8,06 & 62 \\
\hline P1 CJ & 12,78 & 14,33 & 0,0160 & 1814,80 & 398,20 & 7,61 & 60 \\
\hline P1 SJ & 12,68 & 14,21 & 0,0227 & 1484,10 & 243,55 & 8,13 & 64 \\
\hline
\end{tabular}

Na Tabela 7.13, os símbolos têm os seguintes significados:

$\mathrm{M}_{\mathrm{f}}$ máx - momento máximo na face do pilar

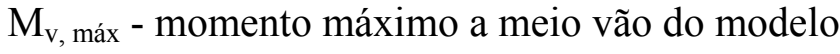

$\Phi_{\text {máx }}$ - rotação máxima

$\mathrm{K}_{\mathrm{i}}$ - rigidez inicial

$\mathrm{K}_{\mathrm{f}}$ - rigidez final

$\mathrm{M}_{\mathrm{tr}}$ - momento de transição

Os limites de classificação quanto à rigidez descritos no Capítulo 4 têm como variável o comprimento, L, da viga conectada pela ligação. Para que se possam classificar as ligações estudadas, pode-se estimar que o comprimento de uma viga compatível com a seção do trecho de viga do modelo $(10 \mathrm{~cm}$ x18 cm) seria em torno de 1,80 m. Os limites de classificação segundo o Eurocode 3 (2002) e o fator $\gamma$ na Tabela 7.14 foram calculados para esse comprimento de viga. Como todos os valores experimentais de rigidez foram menores que o limite superior $\left(\mathrm{K}_{\text {superior }}\right)$ e maiores que o limite inferior $\left(\mathrm{K}_{\text {inferior }}\right)$ do Eurocode 3 (2002), as ligações podem ser classificadas como semi-rígidas. De acordo com a proposta de classificação de Ferreira, El Debs e Elliot (2002), a maioria das ligações pertence à Zona II. São consideradas semi-rígidas com baixa resistência à flexão $(0,14<\gamma<0,40)$. Apenas o modelo-piloto pode ser classificado semi-rígido com média resistência à flexão (Zona III $0,40<\gamma<0,67)$. 
Tabela 7.14 - Classificação das ligações quanto à rigidez.

\begin{tabular}{ccccc}
\hline Modelo & $\mathbf{K}_{\mathbf{i}}(\mathbf{k N . m} / \mathbf{r a d})$ & $\mathbf{K}_{\text {superior }}(\mathbf{k N . m} / \mathbf{r a d})$ & $\mathbf{K}_{\text {inferior }}(\mathbf{k N . m} / \mathbf{r a d})$ & $\gamma$ \\
\hline Piloto & 1756,2 & 19601,07 & 392,02 & 0,43 \\
N1 CJ & 1514,1 & 26141,13 & 522,82 & 0,33 \\
N2 CJ & 1489,7 & 26141,13 & 522,82 & 0,32 \\
N1 SJ & 1736,3 & 25572,58 & 511,45 & 0,36 \\
P1 CJ & 1814,8 & 26141,13 & 522,82 & 0,37 \\
P1 SJ & 1484,1 & 25572,58 & 511,45 & 0,33 \\
\hline
\end{tabular}

Para efeito de comparação, calcularam-se a deformação no laminado e o momento teóricos para uma viga armada com PRF, de acordo com o ACI 440.1R-03 (2003) e FIB 9.3 TG (2003) (Tabela 7.15 e Tabela 7.16, respectivamente). Para os modelos com juntas grauteadas adotaram-se nos cálculos as propriedades do concreto, desprezando-se a não homogeneidade dos modelos em função dos trechos grauteados e da almofada de apoio. Para os modelos sem grauteamento das juntas, adotou-se uma média ponderada entre as propriedades dos dois concretos. Buscou-se, também, um meio teórico de estimar a rigidez inicial da ligação (Tabela 7.17). Considerou-se para isso que a rigidez da ligação é função da deformabilidade do concreto no trecho em que se verifica a descontinuidade. Definiu-se que a rigidez poderia ser estimada por meio da Equação 7.11.

A rotação da ligação, $\phi$, foi considerada como a razão entre o encurtamento da fibra mais comprimida do concreto, $\Delta \ell_{c}$, ao longo do comprimento $\ell_{L}$ (Figura 7.61) e a distância à linha neutra, $x$.
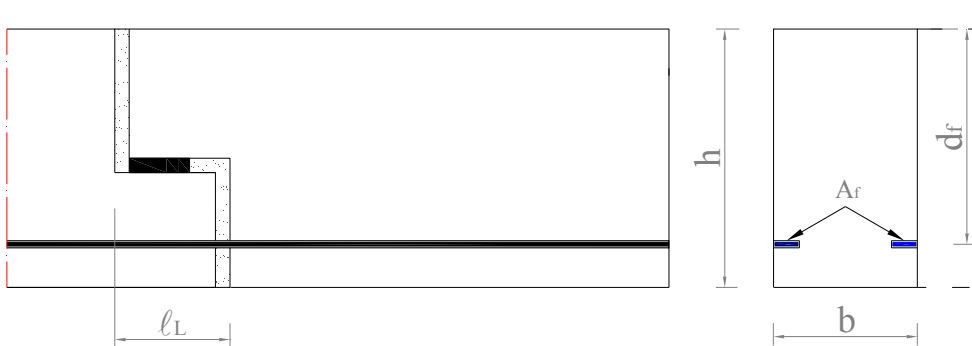

Figura 7.61 - Aspectos geométricos em que se baseou a formulação para estimativa da rigidez inicial.

$$
\phi=\frac{\Delta \ell_{c}}{x}
$$

O encurtamento na fibra mais comprimida pode ser determinado por:

$\Delta \ell_{c}=\ell_{L} \varepsilon_{c}$

Onde:

$\varepsilon_{c}$ - deformação no concreto 
Admite-se a Equação 7.6 para cálculo da deformação

$\varepsilon_{c}=\frac{\sigma_{c}}{E_{c}}$

Onde:

$E_{c}$ - módulo de elasticidade do concreto

$\sigma_{c}$ - tensão no concreto

Adotando-se a inércia da seção fissurada, $I_{I I}$, calcula-se a tensão no concreto.

$\sigma_{c}=\frac{M x}{I_{I I}}$

Onde:

$M$ - momento atuante na seção

A expressão para o cálculo do encurtamento resulta em:

$\Delta \ell_{c}=\frac{\ell_{L} M x}{E_{c} I_{I I}}$

Substituindo na Equação 7.4.

$\phi=\frac{\ell_{L} M}{E_{c} I_{I I}}$

A rigidez é a razão entre o momento e a rotação.

$K_{i}=\frac{M}{\phi}$

Por fim, define-se a Equação 7.11 para estimativa da rigidez inicial da ligação.

$K_{i}=\frac{E_{c} I_{I I}}{\ell_{L}}$

Tabela 7.15 - Estimativas teóricas pelo ACI 440.1R-03 (2003).

\begin{tabular}{ccccc}
\hline \multirow{4}{*}{ Modelo } & \multicolumn{4}{c}{ ACI 440.1R-03 (2003) } \\
\cline { 2 - 5 } & $\begin{array}{c}\mathbf{\Phi} \mathbf{M}_{\mathbf{n}} \\
(\mathbf{k N . m )}\end{array}$ & $\mathbf{\Phi M}_{\mathbf{n}} / \mathbf{M}_{\mathbf{f} \text { máx }}$ & $\begin{array}{c}\boldsymbol{\varepsilon}_{\mathbf{f}} \\
\mathbf{( \% o )}\end{array}$ & $\boldsymbol{\varepsilon}_{\mathbf{f}} / \boldsymbol{\varepsilon}_{\mathbf{L m a ́ x}}$ \\
\hline Piloto & 8,41 & 0,82 & 10,87 & 1,19 \\
N1 CJ & 9,98 & 0,88 & 12,47 & 1,45 \\
N2 CJ & 9,98 & 0,74 & 12,47 & 1,27 \\
N1 SJ & 10,01 & 0,77 & 12,50 & 1,34 \\
P1 CJ & 9,98 & 0,78 & 12,47 & 1,11 \\
P1 SJ & 10,01 & 0,79 & 12,50 & 1,18 \\
\hline
\end{tabular}


Tabela 7.16 - Estimativas teóricas pelo FIB 9.3 TG (2003).

\begin{tabular}{ccccc}
\hline \multirow{4}{*}{ Modelo } & \multicolumn{4}{c}{ FIB 9.3 TG (2003) } \\
\cline { 2 - 5 } & $\begin{array}{c}\mathbf{M}_{\mathbf{u}} \\
(\mathbf{k N . m})\end{array}$ & $\mathbf{M}_{\mathbf{u}} / \mathbf{M}_{\text {f,máx }}$ & $\begin{array}{c}\boldsymbol{\varepsilon}_{\text {FRP }} \\
(\mathbf{\%})\end{array}$ & $\boldsymbol{\varepsilon}_{\text {FRP }} / \boldsymbol{\varepsilon}_{\text {Lmáx }}$ \\
\hline Piloto & 9,75 & 0,95 & 8,84 & 0,97 \\
N1 CJ & 12,83 & 1,14 & 11,37 & 1,32 \\
N2 CJ & 12,83 & 0,95 & 11,37 & 1,16 \\
N1 SJ & 12,90 & 0,99 & 11,42 & 1,22 \\
P1 CJ & 12,83 & 1,00 & 11,37 & 1,01 \\
P1 SJ & 12,90 & 1,02 & 11,42 & 1,08 \\
\hline
\end{tabular}

Tabela 7.17 - Comparação entre os valores teóricos e experimentais da rigidez inicial.

\begin{tabular}{ccc}
\hline Modelo & $\mathbf{K}_{\mathbf{i}, \text { teórico }}(\mathbf{k N . m} / \mathbf{r a d})$ & $\mathbf{K}_{\mathbf{i}, \text { teórico }} / \mathbf{K}_{\mathbf{i}}$ \\
\hline Piloto & 1813,17 & 1,03 \\
N1 CJ & 1875,65 & 1,24 \\
N2 CJ & 1875,65 & 1,26 \\
N1 SJ & 1871,32 & 1,08 \\
P1 CJ & 1875,65 & 1,03 \\
P1 SJ & 1871,32 & 1,26 \\
\hline
\end{tabular}

As estimativas teóricas para o momento máximo e para a deformação apresentaram coerência com os valores experimentais, considerando o momento na face do pilar. A diferença percentual entre os valores de momento e deformação teóricos em relação aos experimentais, calculados conforme ACI 440.1R-03 (2003), foram de -26 a -12\% e de 11 a 45\%, respectivamente. Para os cálculos conforme FIB 9.3 TG (2003), as diferenças percentuais foram de -5 a 14\% para os momentos e de -3 a $32 \%$ para as deformações. As diferenças percentuais entre os valores de $\mathrm{K}_{\mathrm{i}}$, calculados pela Equação 7.11 e obtidos experimentalmente, variaram de 3 a 26\%. Cabe observar a variação no posicionamento dos extensômetros nos laminados que pode ter influenciado em maior ou menor divergência entre valores experimentais e teóricos. A formulação para o cálculo da rigidez inicial conduziu a valores coerentes e aceitáveis considerando-se a simplicidade da idealização do comportamento da ligação.

O cálculo teórico das rotações para solicitações superiores ao momento fletor de transição não é simples, posto que envolve deformações e deslocamentos que sofrem forte influência da força cortante. As fissuras inclinadas nos modelos de ligação (Figura 7.22, 
Figura 7.24, Figura 7.26, Figura 7.28, Figura 7.30 e Figura 7.32) indicam efeitos do cisalhamento. Isto é comprovado pela análise das deformações na armadura de suspensão, que passam a crescer consideravelmente a partir de um determinado nível de carregamento, como resultado da formação de fissuras inclinadas por cisalhamento-tração, como ocorre no caso de estribos em vigas.

Não se propõe como resultado do presente trabalho um método de cálculo da rotação no caso de solicitações no estágio 2 (momentos fletores superiores ao de transição), uma vez que ele envolveria, direta ou indiretamente, a consideração dos mecanismos secundários de resistência e deformabilidade, no caso de cisalhamento, como por exemplo o atrito entre superfícies das fissuras, efeito de pino, engastamento de bielas comprimidas, etc. Para isso, haveria necessidade de outros tipos de ensaios e uma investigação mais aprofundada dos parâmetros influentes, o que fica como sugestão para pesquisas futuras.

\subsubsection{Deslocamento vertical}

As considerações acerca da não-linearidade da curva "momento x rotação" são válidas também para a curva "força x deslocamento" (Figura 7.62). Adotou-se a mesma aproximação bi-linear para o comportamento desta curva. As inclinações dos trechos inicial e final, denominadas por $\left(\mathrm{K}_{\mathrm{i}}^{\prime}\right)$ e $\left(\mathrm{K}_{\mathrm{f}}^{\prime}\right)$, respectivamente, foram definidas pela regressão linear. No primeiro caso, de 0 a $30 \%$ da carga de ruptura. No segundo, de $70 \%$ até a carga de ruptura. A inclinação K' é a rigidez que relaciona o deslocamento vertical a meio vão do modelo com a força vertical aplicada. A força atuante na transição do estágio 1 para o 2 é denominada força de transição $\left(\mathrm{F}_{\text {tr }}\right)$. A força de transição variou de 53 a $73 \%$ da força máxima. A Tabela 7.18 reúne os valores da força máxima $\left(\mathrm{F}_{\text {máx }}\right)$, deslocamento máximo $\left(\delta_{\text {máx }}\right), \mathrm{K}_{\mathrm{i}}, \mathrm{K}_{\mathrm{f}}{ }_{\mathrm{f}}$ e $\mathrm{F}_{\text {tr }}$ para todos os modelos. 


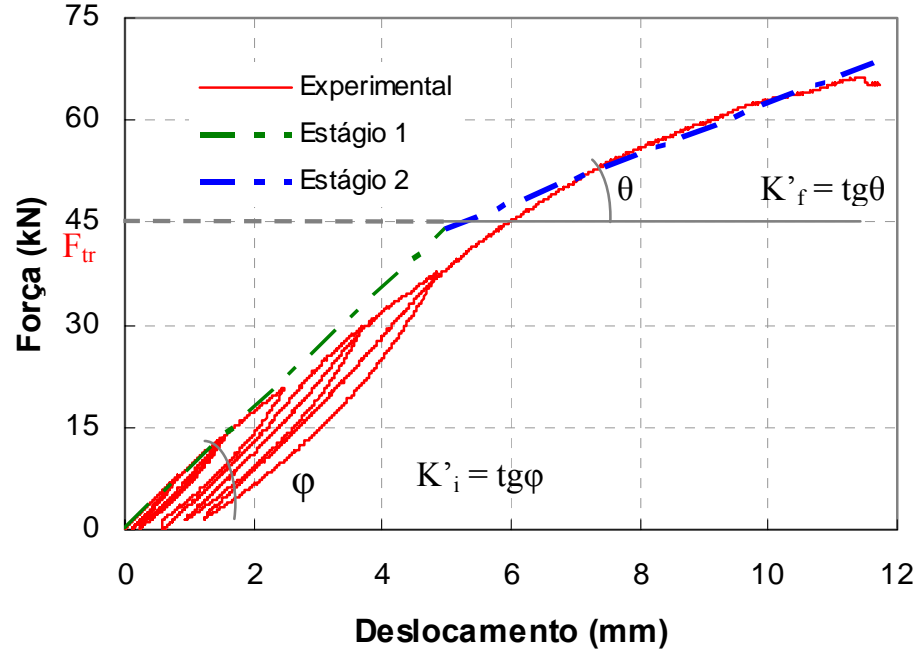

Figura 7.62 - Gráfico "força x deslocamento" no meio do vão - modelo-piloto.

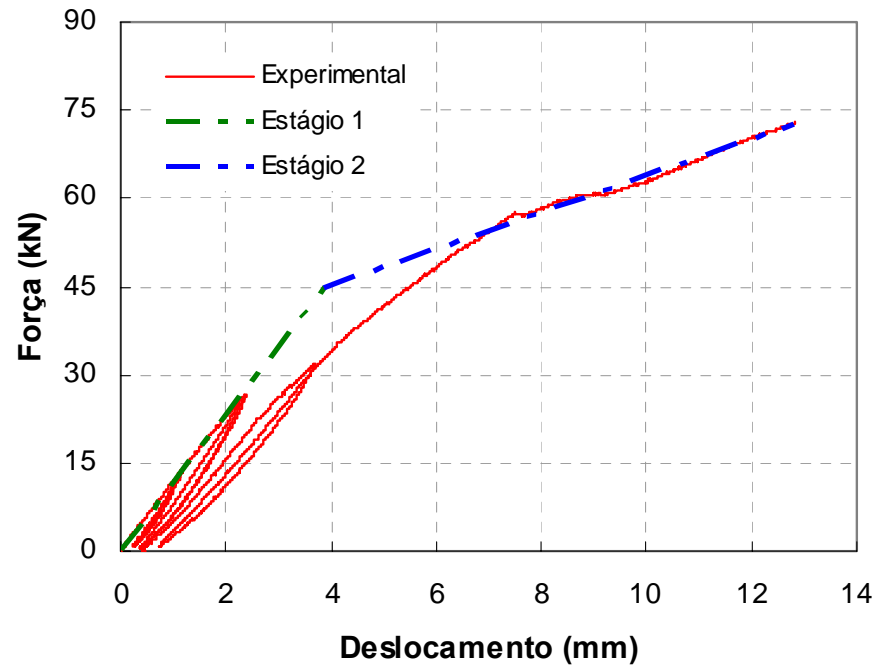

Figura 7.63 - Gráfico "força x deslocamento" no meio do vão - modelo N1 CJ.

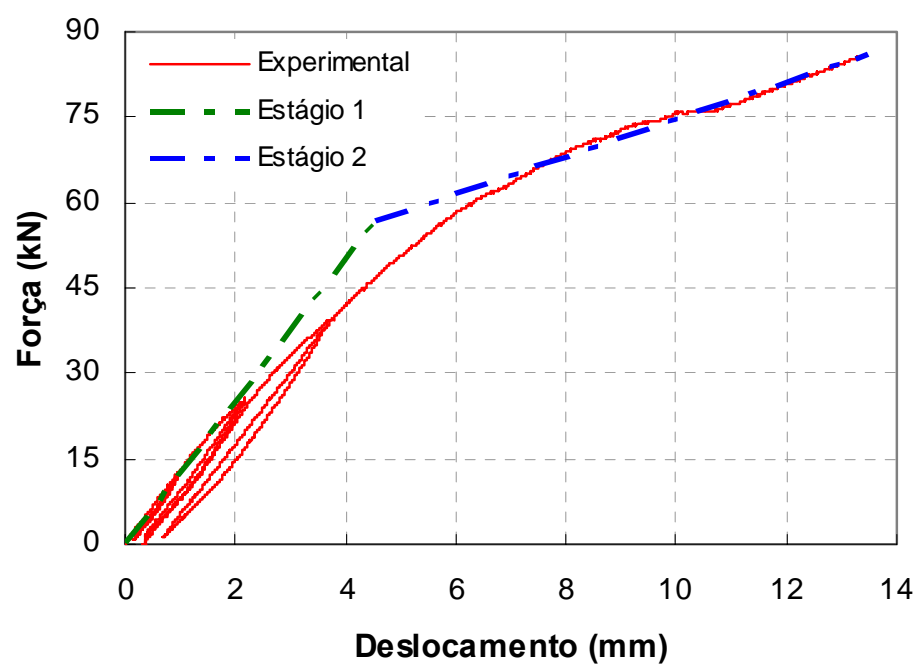

Figura 7.64 - Gráfico "força x deslocamento" no meio do vão - modelo N2 CJ. 


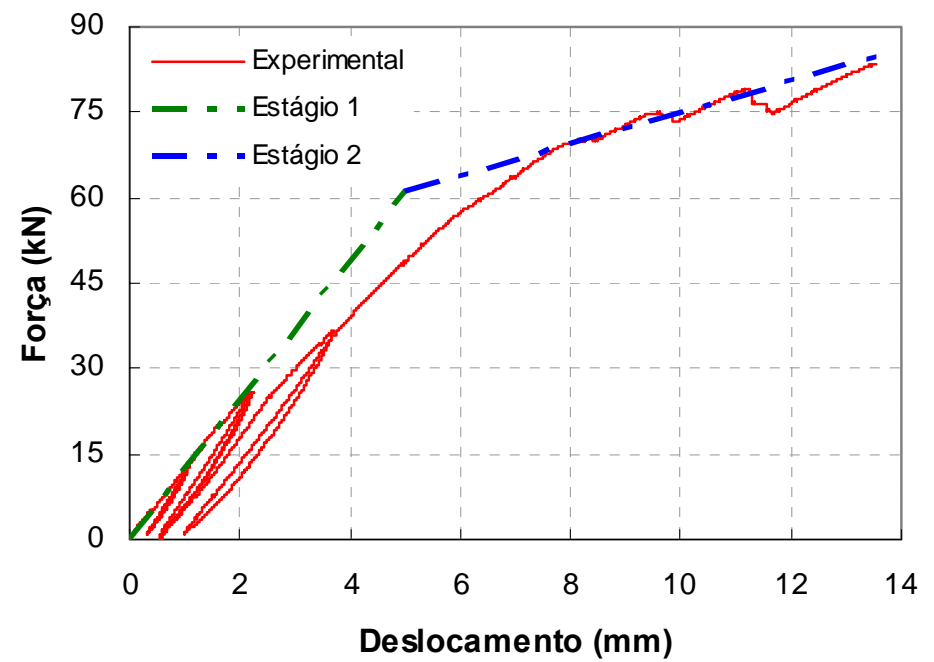

Figura 7.65 - Gráfico "força x deslocamento" no meio do vão - modelo N1 SJ.

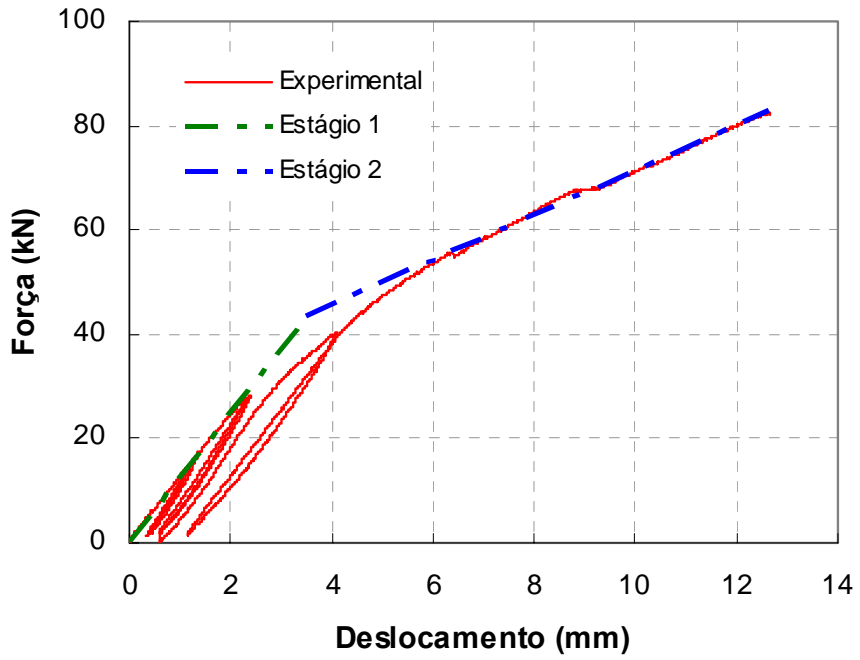

Figura 7.66 - Gráfico “força x deslocamento" no meio do vão - modelo P1 CJ.

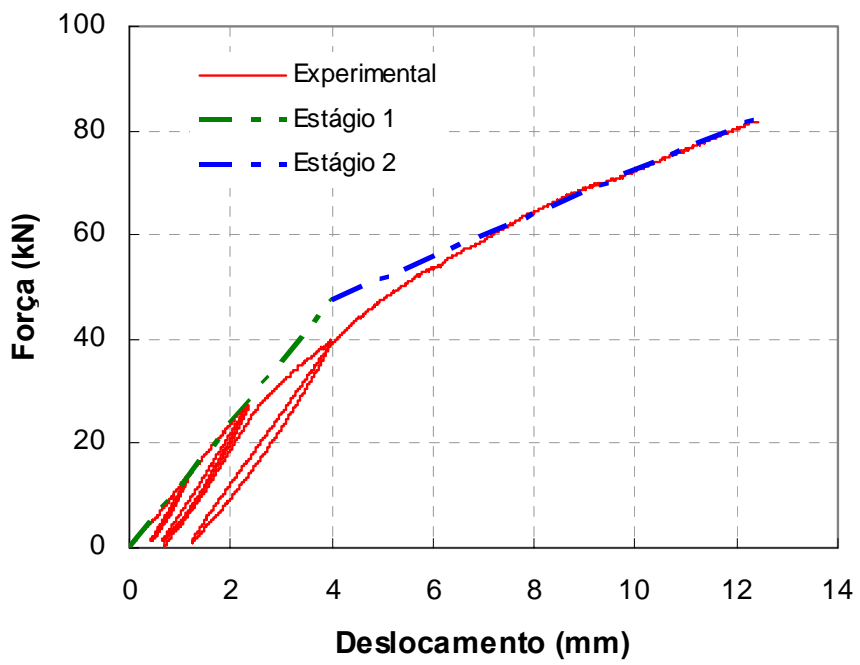

Figura 7.67 - Gráfico “força x deslocamento" no meio do vão - modelo P1 SJ. 
Tabela 7.18 - Resultados relacionados à curva "força x deslocamento".

\begin{tabular}{|c|c|c|c|c|c|c|c|c|}
\hline Modelo & $\begin{array}{l}\mathbf{F}_{\text {máx }} \\
(\mathbf{k N})\end{array}$ & $\begin{array}{l}\delta_{\text {máx }} \\
(\mathbf{m m})\end{array}$ & $\begin{array}{c}\mathbf{K}_{i} \\
(\mathbf{k N} / \mathbf{m m})\end{array}$ & $\begin{array}{c}\mathbf{K}_{\mathbf{f}}^{\prime} \\
(\mathbf{k N} / \mathbf{m m})\end{array}$ & $\begin{array}{c}\mathbf{F}_{\mathrm{tr}} \\
(\mathbf{k N})\end{array}$ & $\begin{array}{c}\mathbf{K}_{\mathrm{i}, \text { teórico }} \\
(\mathbf{k N} / \mathbf{m m})\end{array}$ & $\begin{array}{c}\mathbf{F}_{\mathrm{tr}} / \mathbf{F}_{\text {máx }} \\
(\%)\end{array}$ & $\left(\mathbf{K}_{\mathrm{i}, \text { teórico }}^{\prime}\right) /\left(\mathbf{K}_{\mathrm{i}}^{\prime}\right.$ \\
\hline Piloto & 66,30 & 11,44 & 8,80 & 3,70 & 44,07 & 12,71 & 66 & 1,44 \\
\hline N1 CJ & 72,89 & 12,83 & 11,54 & 3,08 & 44,95 & 13,15 & 62 & 1,14 \\
\hline N2 CJ & 86,93 & 13,78 & 12,45 & 3,28 & 56,79 & 13,15 & 65 & 1,06 \\
\hline N1 SJ & 83,66 & 13,54 & 12,23 & 2,76 & 61,30 & 13,12 & 73 & 1,07 \\
\hline P1 CJ & 82,46 & 12,62 & 12,50 & 4,26 & 43,71 & 13,15 & 53 & 1,05 \\
\hline P1 SJ & 81,81 & 12,06 & 11,85 & 4,14 & 47,46 & 13,12 & 58 & 1,11 \\
\hline
\end{tabular}

A flecha de uma viga monolítica submetida às mesmas condições de carregamento que os modelos de ligação (Figura 7.68) seria calculada por meio da Equação 7.12. A expressão para o cálculo da flecha poderia ser simplificada para a Equação 7.13 considerando ao invés da força distribuída p, a força concentrada F. A Figura 7.69 demonstra ser essa uma simplificação razoável haja vista a semelhança entre as duas curvas.

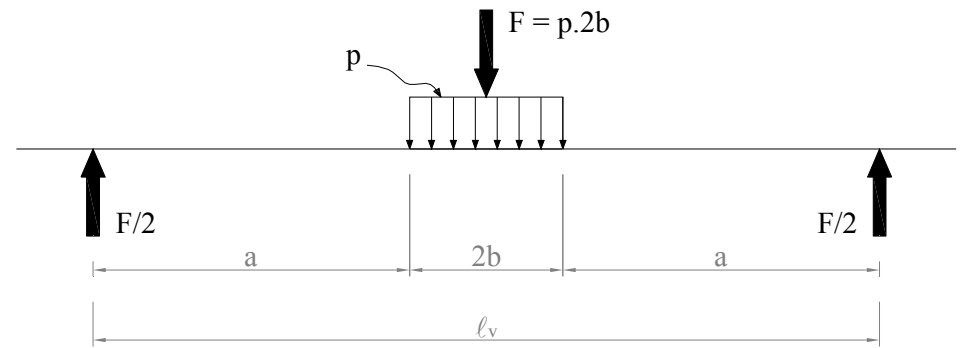

Figura 7.68 - Esquema estático para determinação da flecha teórica.

$f=\left[\frac{b(a+b)^{3}}{3}-\frac{b^{3}(a+3 / 4 . b)}{6}\right] \cdot \frac{p}{E_{c} I}$

$f=\frac{F \cdot \ell_{v}{ }^{3}}{48 E_{c} I}$

Onde:

$f$ - flecha

$b$ - metade do comprimento do trecho ao longo do qual se distribui a carga

$a$ - distância do apoio ao início do trecho carregado

$p$ - carregamento distribuído

$F$ - força concentrada equivalente ao carregamento distribuído

$\ell_{v}$ - vão da viga 


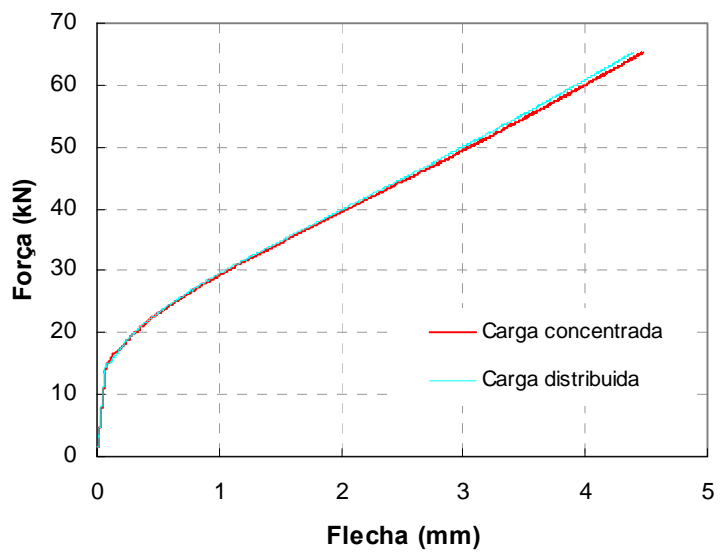

Figura 7.69 - Gráficos "força x flecha" com a consideração de carga distribuída e concentrada.

A curva teórica para o cálculo da flecha não representa bem o que ocorre para os modelos de ligação, pois apresenta um trecho inicial em que se considera a inércia bruta da seção (Figura 7.70). Nos modelos de ligação já se têm, a princípio, dois trechos, correspondentes às juntas, que se podem considerar fissurados. Assumindo que a inércia do modelo é a inércia do estádio II puro e utilizando, no cálculo da flecha, a Equação 7.13 majorada pelo coeficiente $\lambda$, proposto por Castro (2005) para vigas reforçadas com PRF no estádio II, alcança-se uma boa aproximação da curva teórica à curva experimental no estágio 1. A rigidez $\mathrm{K}^{\prime}$ i pode então ser estimada teoricamente pela Equação 7.15. Os valores obtidos para a rigidez teórica estão dispostos na Tabela 7.18. A formulação para o calculo da rigidez inicial conduziu a valores superestimados, mas bastante próximos dos experimentais. A maior diferença percentual de $44 \%$ se observou para o modelo-piloto. Para os demais modelos, a diferença não excedeu os 14\%.

$\lambda=1,2$ (viga retangular)

$$
K_{i}^{\prime}=\frac{48 E_{c} I_{I I}}{\lambda \cdot \ell_{v}^{3}}
$$

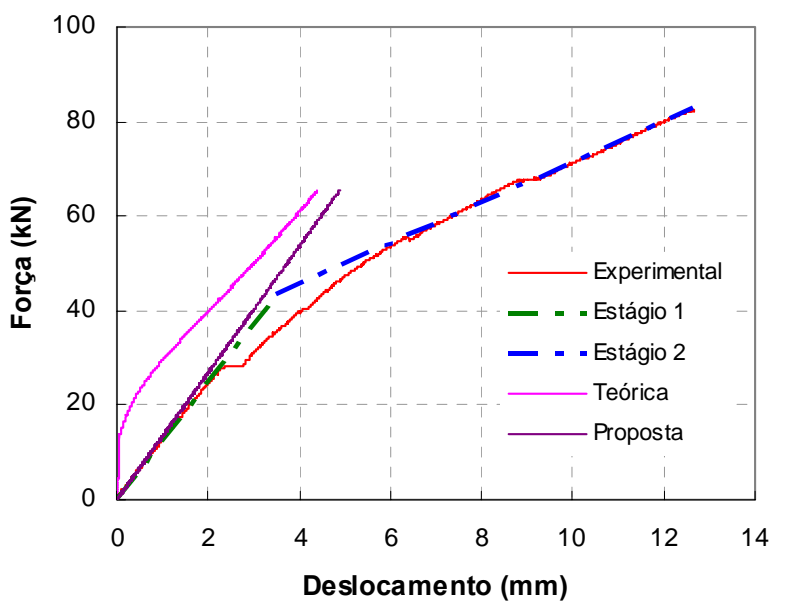

Figura 7.70 - Envoltória da curva experimental "força x deslocamento", aproximação bi-linear e curva teóricas do modelo P1 CJ. 
Assim como no cálculo teórico das rotações, não se propõe como resultado do presente trabalho um método de cálculo de deslocamentos para solicitações no estágio 2 (forças atuante superiores à de transição). Como se justificou no caso de rotações, o cálculo de deslocamentos envolveria, direta ou indiretamente, a consideração dos mecanismos secundários de resistência e deformabilidade no caso de cisalhamento. Uma investigação mais aprofundada dos parâmetros influentes e a proposta de métodos de avaliação dos deslocamentos fica como sugestão para pesquisas futuras.

\subsubsection{Comparações entre os modelos}

A despeito das diferenças geométricas e constitutivas dos modelos, eles apresentaram comportamento bastante semelhante entre si. A semelhança é bastante notável na Figura 7.71b, que reúne as curvas "força $\mathrm{x}$ deslocamento" resultantes dos ensaios. Em relação às curvas "momento x rotação" (Figura 7.71-a) parece haver um maior distanciamento que deve estar relacionado à complexidade da instrumentação por meio da qual se obtiveram os resultados que permitiram o traçado das curvas. Aparentemente os modelos exibiram um comportamento de viga com seção previamente fissurada. Não se averiguou, portanto, influência da presença da almofada de apoio no desempenho da ligação.
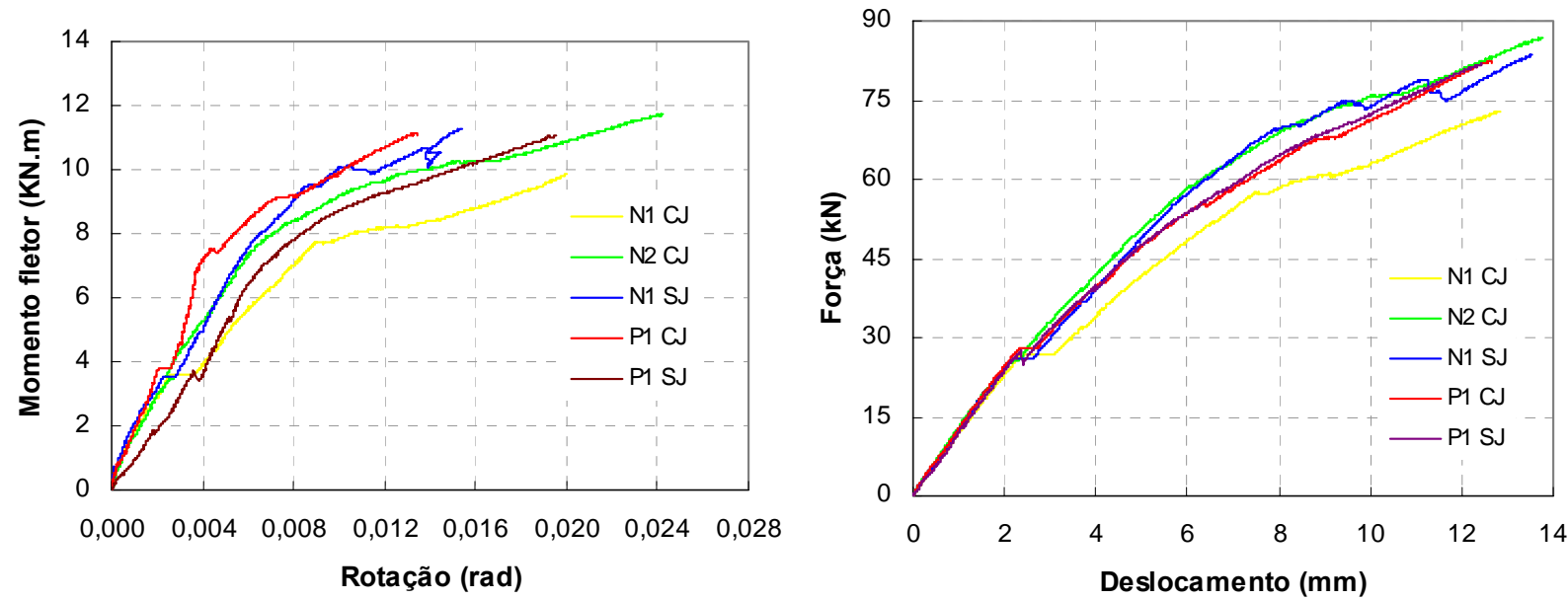

Figura 7.71 - (a) Curvas "momento rotação"; (b) curvas "força x deslocamento".

\subsection{Ensaios dinâmicos em modelos reduzidos de ligação}

Os ensaios de vibração tiveram por objetivo a determinação da rigidez da ligação para efeito de comparação com os resultados obtidos nos ensaios estáticos. Eles foram realizados em cooperação com a doutoranda Sandra Freire de Almeida, que avalia em sua pesquisa métodos diretos para a obtenção da rigidez de ligações viga-pilar de estruturas de concreto pré-moldado. Os resultados das análises iniciais mostraram-se inconsistentes e não serão, 
portanto, apresentados nesta dissertação. Contudo, mantém-se esse item em que são abordados os ensaios dinâmicos realizados, pois eles interferiram na idealização dos modelos de ligação e na execução dos ensaios estáticos.

A metodologia dos ensaios de vibração foi baseada em Nóbrega (2004) que apresenta um método direto para determinação da rigidez de ligações pilar-fundação. Nóbrega (2004) discute brevemente a dificuldade na obtenção da reposta rotacional de uma estrutura frente a uma excitação dinâmica e fundamenta a opção por uma técnica em que são utilizados sensores e equipamentos convencionais.

A técnica consiste em usar um par de acelerômetros uniaxiais colocados a uma pequena distância um do outro, fixados à estrutura, ou fixados a um acessório auxiliar na forma de "T", que é solidarizado à estrutura. Neste caso, torna-se necessário um cuidado adicional em relação à flexibilidade das barras em balanço do acessório, com vistas à peça comportar-se como um corpo rígido e não influencie, pelo seu próprio movimento, a resposta dos sensores. (NÓBREGA, 2004, p. 211-212).

A Figura 7.72 ilustra os esquemas de instrumentação descritos. A partir das acelerações $\ddot{x}_{A}$ e $\ddot{x}_{B}$, medidas pelos acelerômetros, calculam-se os deslocamentos $x_{A}$ e $x_{B}$. A translação e a rotação no ponto P, na Figura 7.72, são determinados pelas Equações 7.16 e 7.17 , respectivamente.
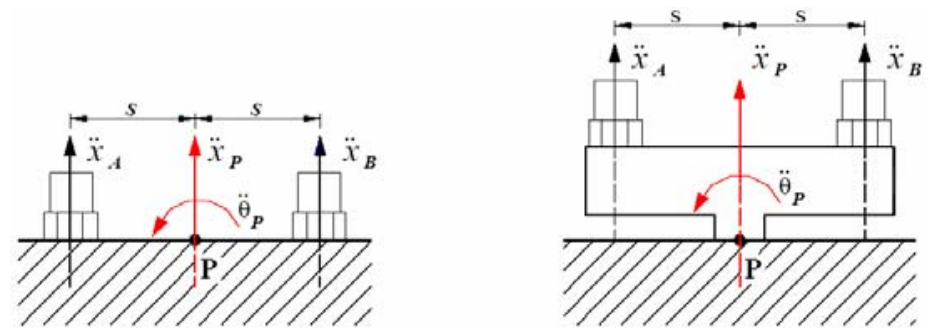

Figura 7.72 - Arranjo para medição da resposta rotacional (Fonte: Nóbrega (2004)).

$$
\begin{aligned}
& x_{p}=\frac{x_{B}+x_{A}}{2} \\
& \theta_{P}=\frac{x_{B}-x_{A}}{2 s}
\end{aligned}
$$

A determinação da rotação por meio dessa técnica e por meio da utilização dos transdutores, no ensaio estático, parte de uma mesma fundamentação. A rotação é a razão entre a diferença dos deslocamentos obtidos por meio dos instrumentos de medida (acelerômetros ou transdutores de deslocamento) e a distância entre eles. No ensaio dinâmico, dispondo-se os acelerômetros ao longo de uma linha contida no plano da seção do elemento, elimina-se a distorção do resultado em função da deformação do concreto entre as seções referenciais, que ocorre para o ensaio estático. 
A seqüência de procedimentos adotada nesta pesquisa, adaptada de Nóbrega (2004), é descrita por Almeida (2007):

- Fixação de acelerômetros, um no dente da viga e o outro no consolo, com seus eixos axiais paralelos ao eixo axial do modelo (Figura 7.73);

- Excitação da estrutura com um sinal senoidal de freqüência igual à freqüência natural da estrutura, para majorar as rotações e reduzir o ruído;

- Medição da excitação imposta (força) e das respostas dos acelerômetros (aceleração) no domínio do tempo;

- Cálculo das respostas dos sensores, em termos de deslocamento, no domínio do tempo. A expressão que relaciona a aceleração e o deslocamento de cada acelerômetro é dada por $x=\frac{\ddot{x}}{\omega^{2}}$, onde $\omega$ é a freqüência da excitação imposta (em $\mathrm{rad} / \mathrm{s})$

- Cálculo do ângulo de rotação na seção de interesse (seção da ligação instrumentada por acelerômetros), $\theta=\frac{\Delta x}{2 s}$, onde $\Delta x$ é o deslocamento relativo entre os dois acelerômetros, e $2 s$ a distância entre eles;

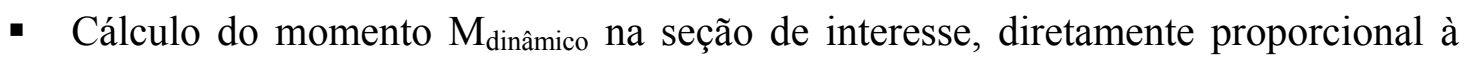
amplitude da força de excitação e à distância entre as seções de aplicação da excitação e de medição da resposta. O fator de amplificação dinâmica $(D)$, função da freqüência natural, freqüência de excitação e do amortecimento estrutural, também é considerado nesse cálculo;

- Cálculo da rigidez à flexão $K$ pela expressão $K=\frac{M}{\theta}$, onde $M$ é o momento dinâmico aplicado, e $\theta$ é o ângulo de rotação calculado no passo anterior.

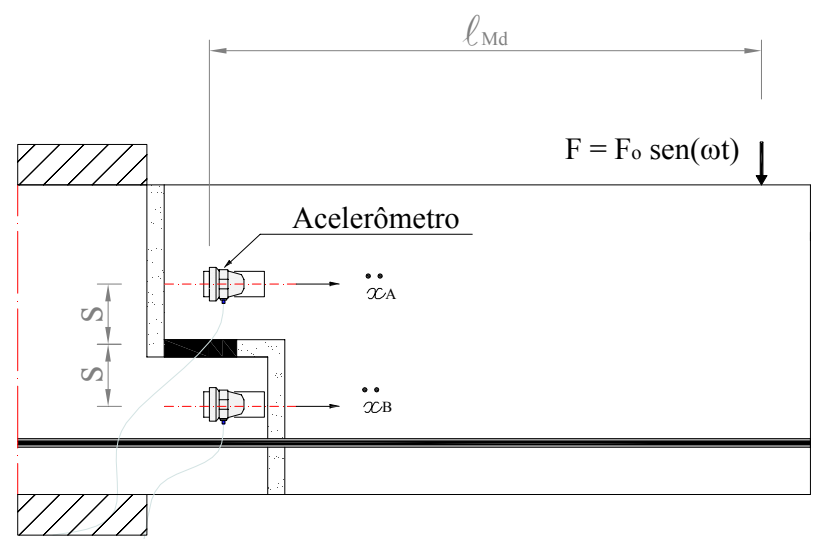

Figura 7.73 - Arranjo esquemático para determinação da resposta rotacional e momento dinâmico. 


\subsubsection{Instrumentação, configuração e execução dos ensaios dinâmicos}

Realizaram-se dois tipos de ensaios dinâmicos: ensaio de vibração livre, no modelo com condição de contorno "livre-livre" e ensaio de vibração forçada, com o modelo fixado pelo trecho de pilar e com as vigas em balanço. Os ensaios de vibração livre foram realizados nos modelos íntegros (antes dos ensaios estáticos) e nos modelos rompidos. Os ensaios de vibração forçada foram executados nos modelos em três diferentes condições: modelo íntegro, modelo com fissuração leve (após carregamento estático de $24 \mathrm{kN}$, aproximadamente $30 \%$ da carga de ruptura) e modelo rompido.

\subsubsection{Ensaio de vibração livre}

No ensaio de vibração livre o modelo ficou suspenso em fios de nylon simulando a condição de contorno livre-livre. A posição dos fios de nylon corresponde aos nós do primeiro modo de vibração (distância aos apoios de 0,224 vezes o comprimento do modelo). A vinculação nos nós minimiza a influência da rigidez do nylon, que idealisticamente seria nula, na restrição ao movimento do modelo. Foram coladas chapas metálicas para que se pudesse fixar o acelerômetro piezelétrico por meio de sua base magnética nos pontos em que se desejava obter a resposta do sistema (ponto 1 na Figura 7.74). Posicionou-se o acelerômetro na posição 1 e alternou-se o ponto de aplicação da excitação entre os pontos 1 e 4 (Figura 7.74). A excitação dos modelos foi imposta manualmente com uso de martelo de impacto instrumentado. Os sinais de entrada (impacto) e de saída (aceleração) foram ambos obtidos no domínio do tempo. Os ensaios foram repetidos para diferentes limites de freqüência de aquisição $(2.000 \mathrm{~Hz}$ e $10.000 \mathrm{~Hz})$. A partir dos dados obtidos nesses ensaios foi possível a determinação dos fatores de amortecimento.

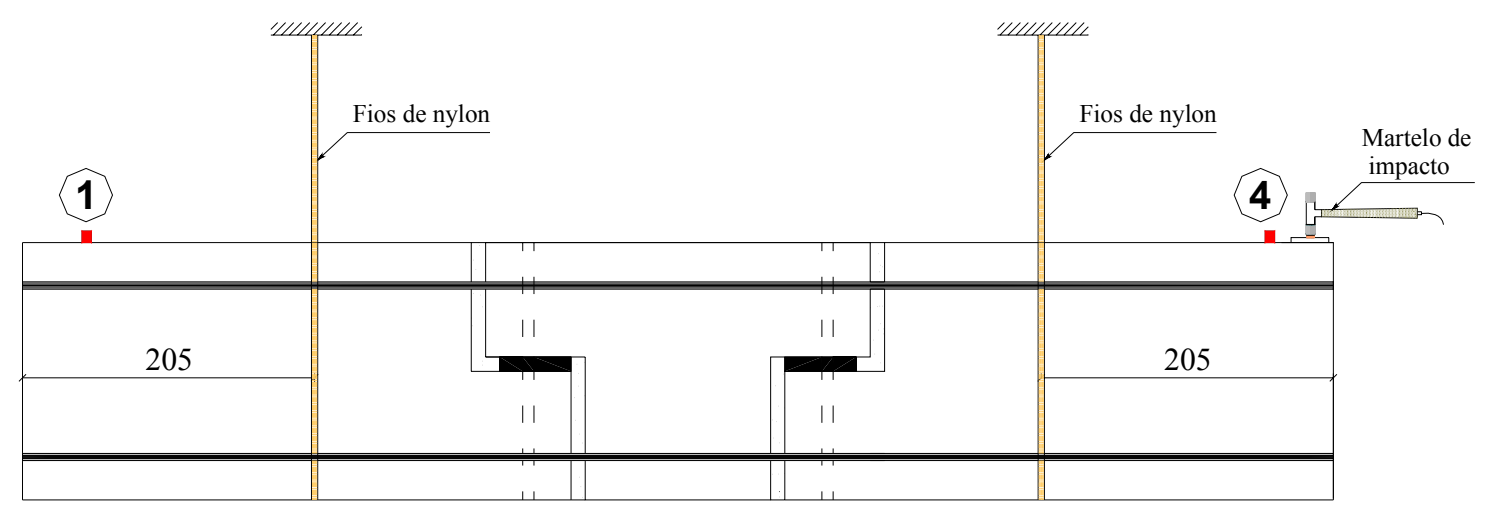

Figura 7.74 - Desenho esquemático do ensaio de vibração livre - condição de contorno livre-livre (Fonte: Almeida (2007)). 


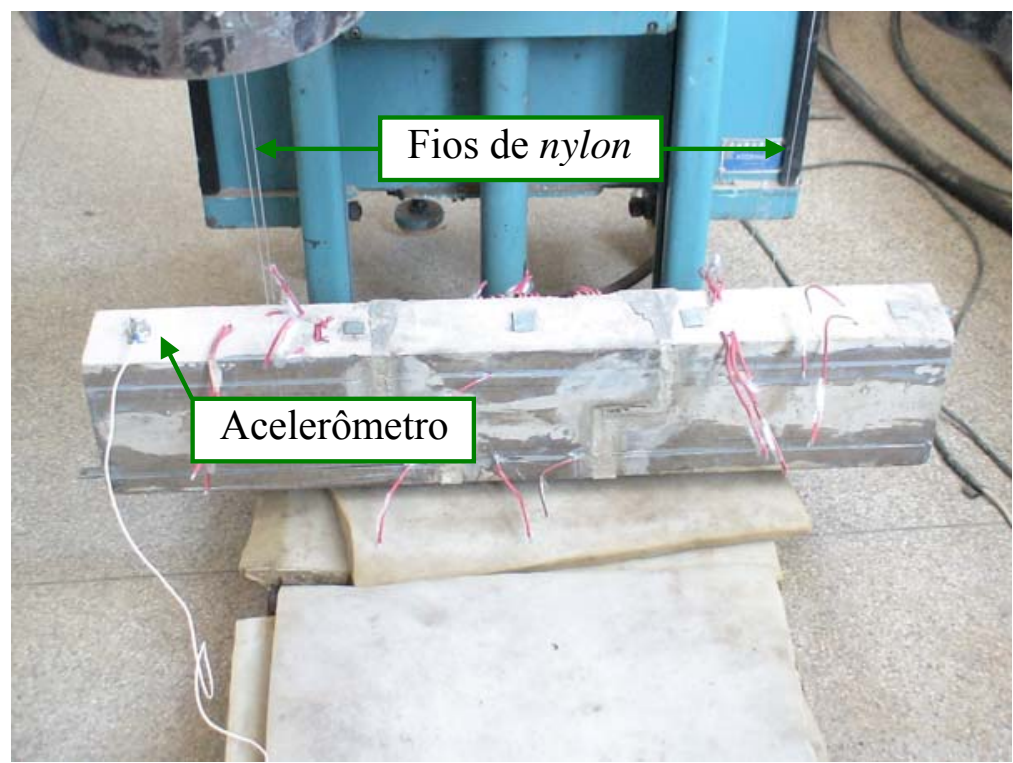

Figura 7.75 - Vinculação do ensaio de vibração livre.

\subsubsection{Ensaio de vibração forçada}

Para a realização do ensaio de vibração forçada, o modelo foi apoiado em um perfil metálico apenas na base do trecho de pilar. Na parte superior do trecho de pilar, aplicou-se uma força de $10 \mathrm{kN}$. Buscou-se, dessa forma, simular uma situação de vigas em balanço engastadas no pilar. Fixaram-se no modelo placas metálicas nos pontos em que se desejava obter a resposta da estrutura. Apenas as respostas (aceleração no domínio do tempo) dos pontos 9, 10, 11 e 12 foram necessárias ao cálculo da rigidez das ligações. A obtenção das respostas dos demais pontos visou à determinação dos modos de vibrar da estrutura. Em uma das extremidades do modelo, se fixou uma chapa metálica na qual se parafusou uma célula de carga dinâmica. Acoplou-se a esta célula o excitador dinâmico (shaker) suspenso por cabos de aço.

Os ensaios de vibração forçada foram divididos em duas etapas em função do tipo de excitação imposta. Na primeira etapa, foi feita uma varredura de freqüências, com um sinal de excitação do tipo aleatório ("random"), gerado pelo sistema ACE Dataphysics. O sinal de resposta foi obtido com um acelerômetro piezelétrico, instalado na extremidade livre da viga, próximo ao ponto de aplicação da força (ponto 01) ou na extremidade oposta (ponto 04), conforme a Figura 7.76. O sistema ACE Dataphysics realiza a aquisição dos dados e converte o sinal no domínio do tempo para o domínio da freqüência, além de calcular a Função de Resposta em Freqüência. A primeira freqüência natural do modelo foi determinada da análise das FRFs. 
$\mathrm{Na}$ segunda etapa do ensaio, impôs-se ao modelo uma excitação forçada com sinal senoidal de freqüência constante e igual à primeira freqüência natural (determinada na etapa anterior). Ajustou-se a amplificação do sinal até que se alcançou a amplitude da força de excitação desejada, que foi mantida constante ao longo de todo o restante do ensaio. Obtevese a resposta (aceleração no domínio do tempo) para os dois acelerômetros fixados à estrutura, um no ponto 09 e outro no ponto 10. Os acelerômetros foram reposicionados nos pontos $11 \mathrm{e}$ 12, a estrutura foi novamente excitada e obteve-se a resposta (aceleração no domínio do tempo) para esses outros pontos.

Ainda utilizando um sinal de freqüência e amplitude de força constantes, variou-se a posição de um acelerômetro, percorrendo a parte superior e a parte inferior ao longo do comprimento do modelo (pontos 1 a 8 da Figura 7.76), com a intenção de obter as amplitudes e fases da aceleração em pontos distintos e determinar os modos de vibração.

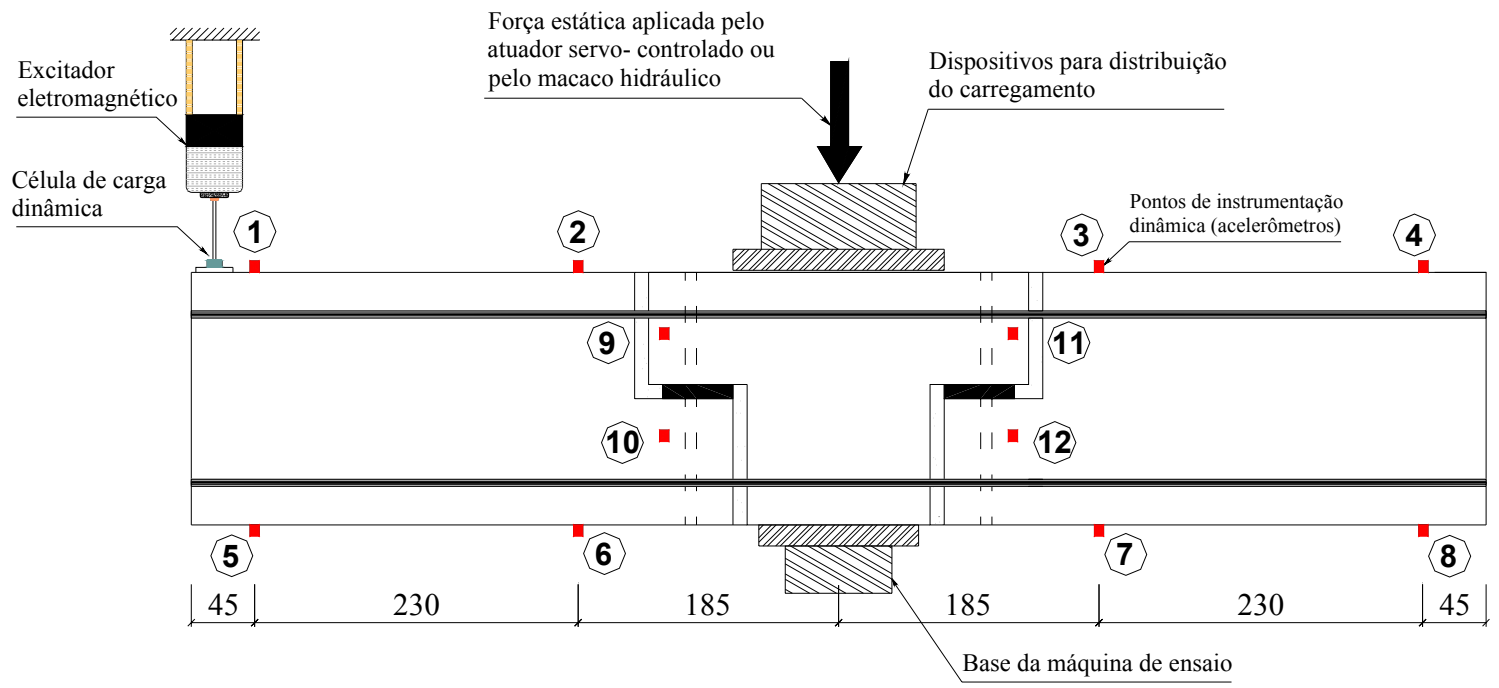

Figura 7.76 - Desenho esquemático da instrumentação e da aplicação do carregamento do ensaio dinâmico de vibração forçada (Fonte: Almeida (2007)).

Para o modelo-piloto, os ensaios nas três condições (íntegro, fissurado e rompido) foram realizados na máquina universal de ensaios INSTRON (Figura 7.77). Para os demais modelos, os ensaios nas condições íntegro e rompido foram realizados em um pórtico montado na laje de reação do Laboratório de Estruturas da EESC (Figura 7.78). A força nesse caso foi aplicada por um macaco hidráulico. Todos os ensaios de vibração forçada, intermediários aos ensaios estáticos (modelo fissurado), foram realizados na máquina universal de ensaios servo-hidráulica INSTRON. 


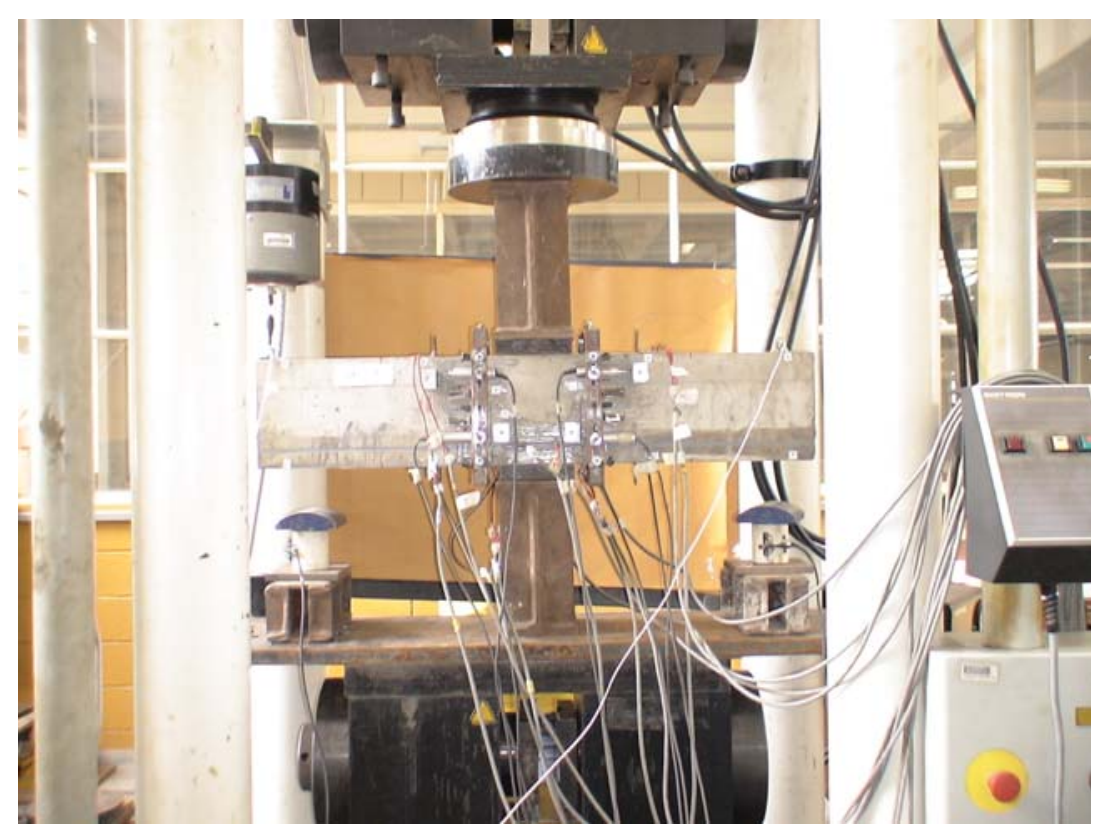

Figura 7.77 - Ensaio de vibração forçada realizado na maquina universal de ensaios INSTRON.

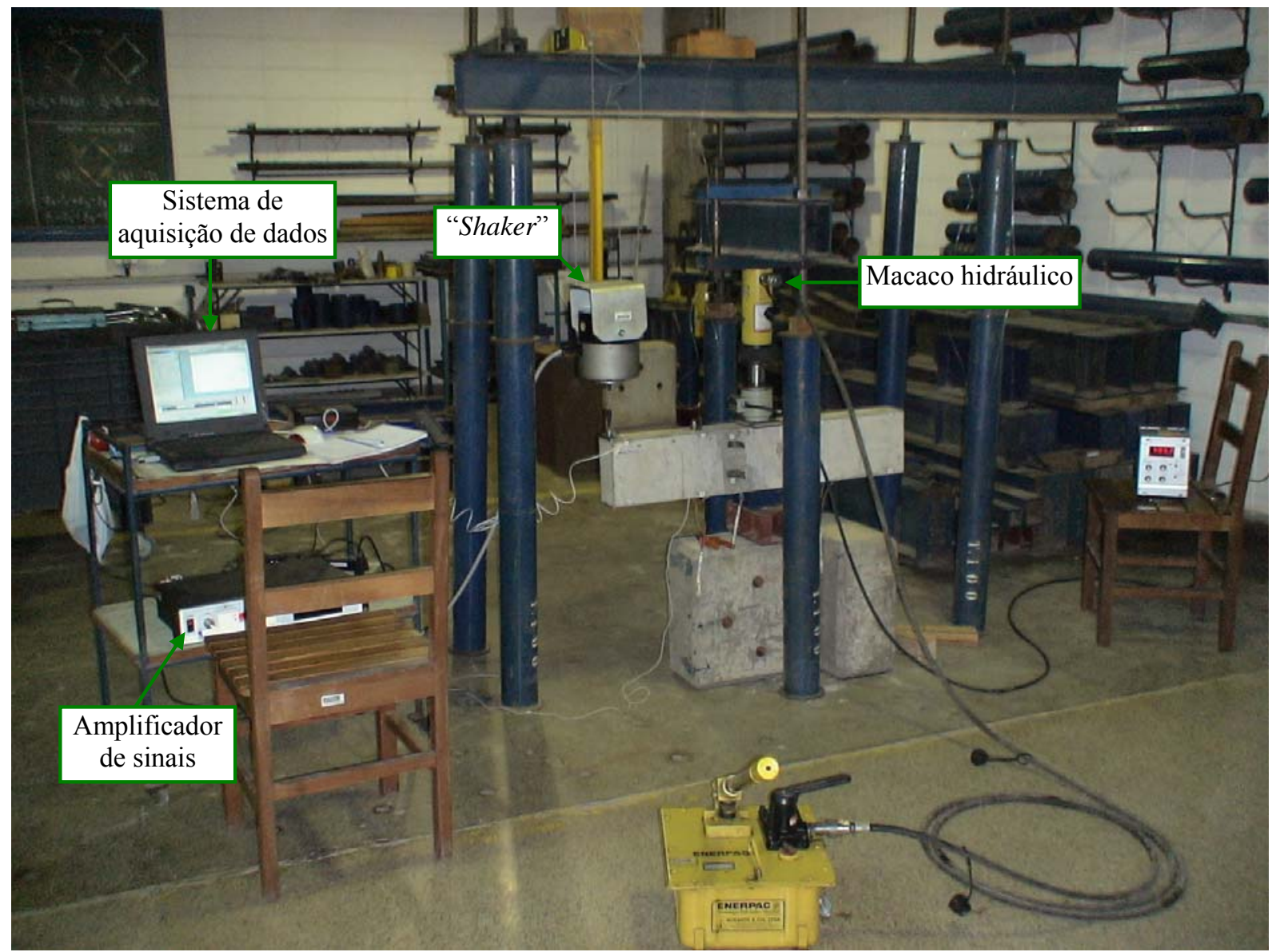

Figura 7.78 - Ensaio de vibração forçada em um modelo íntegro realizado no pórtico de reação.

Reafirma-se que as análises iniciais dos resultados dos ensaios dinâmicos não ofereceram conclusões consistentes e, portanto não serão apresentadas. Possivelmente, as 
dificuldades enfrentadas no devido condicionamento dos ensaios físicos às condições de contorno idealizadas acabaram levando a resultados questionáveis, que devem ainda ser mais bem analisados. No entanto, ressalta-se que o método de análise dinâmica tem se mostrado eficiente em diversas situações. 


\section{CAPÍTULO 8}

\section{CONCLUSÕES E SUGESTÕES PARA TRABALHOS FUTUROS}

\subsection{Conclusões acerca dos ensaios de aderência}

A realização do reforço pode ser prática e eficiente, compatível com a rapidez executiva característica das construções de concreto pré-moldado, desde que observadas as recomendações técnicas específicas, especialmente a escolha adequada da resina. As resinas aplicadas neste estudo apresentaram diferenças na trabalhabilidade, no modo de ruptura, na mobilização da capacidade resistente do laminado, no acabamento superficial e na homogeneidade do reforço. Nos testes particularmente realizados, uma das resinas apresentou desempenho superior à outra, que se mostrou imprópria para utilização no reforço por colagem de laminados em entalhes realizados nas laterais ou fundo de elementos estruturais. Sua consistência excessivamente fluida acarretou grande dificuldade no preenchimento dos entalhes, mesmo nas condições de laboratório, mais favoráveis que as condições de obra. Não se conseguiu, nos ensaios de aderência, mobilizar toda a capacidade resistente do laminado.

Fica registrada a necessidade de caracterização cuidadosa dos materiais constituintes do compósito polimérico e das condições de sua aplicação, para evitar resultados de desempenho muito abaixo do esperado. Sabe-se que, na prática da Engenharia, o uso de adesivos à base de resina epóxi é frequentemente considerado eficiente, sem restrições ou condições mais específicas sobre a sua formulação. Como se constatou no presente trabalho e também em outras pesquisas concomitantemente desenvolvidas no Laboratório de Estruturas da EESC - o emprego de uma resina inadequada pode levar a resultados desastrosos. 
De modo geral, os resultados permitiram, entretanto, uma boa estimativa da deformação máxima que se poderia alcançar nos ensaios dos modelos de ligação. A deficiência na instrumentação para obtenção do deslizamento do laminado não permitiu que análises conclusivas fossem feitas em relação à curva "tensão x deslizamento", fato que deve ser investigado em pesquisas futuras.

\subsection{Conclusões acerca dos ensaios de ligações}

A praticidade da execução e a eficiência do reforço averiguadas nos ensaios de aderência com uma das resinas se confirmaram no reforço dos modelos de ligação. Os modelos apresentaram comportamento semelhante entre si, a despeito das diferenças geométricas e mecânicas e dos materiais neles empregados.

A presença da almofada de apoio - na configuração particularmente adotada - não influenciou o desempenho da ligação, demonstrando-se que o grauteamento das juntas pode levar a ligação a uma condição próxima da monolítica no tocante à resistência à flexão.

As curvas "momento x rotação" e "força x deslocamento" apresentaram característica tipicamente não-linear, mas com possibilidade de representação satisfatória por diagrama bilinear. O momento fletor e a força para os quais ocorreu a passagem entre o primeiro e o segundo estágio da aproximação bi-linear, foram em torno de $60 \%$ dos valores máximos. $\mathrm{O}$ comportamento dos modelos de ligação mostrou-se próximo ao de vigas com seções fissuradas. Partindo dessa hipótese, foram estimados teoricamente os valores de rigidez à flexão no trecho inicial. Os valores dos momentos máximos alcançados nas ligações foram compatíveis com os momentos calculados pelo ACI 440.1R-03 (2003) e pelo FIB 9.3 TG (2003), aplicáveis a vigas monolíticas armadas com barras de PRF. Disso se conclui a grande eficiência do reforço no tocante ao incremento de resistência à flexão das ligações.

$\mathrm{O}$ incremento da rigidez à flexão também foi logrado e as ligações puderam ser classificadas como semi-rígidas. A ruptura no laminado não foi observada em nenhum dos ensaios. Ao longo do carregamento os modelos apresentaram predominantemente fissuras de aderência. A ruptura dos modelos ocorreu sempre de forma brusca e em função do mecanismo de arrancamento do reforço. 


\subsection{Conclusão final}

O objetivo geral deste trabalho, apresentado no item 1.2, foi avaliar a aplicabilidade da técnica NSM no reforço e incremento de rigidez de ligações viga-pilar de estruturas prémoldadas. Para tanto, foram realizados ensaios experimentais de aderência e ensaios em modelos reduzidos de ligação reforçados pela técnica proposta. Os resultados dos ensaios foram avaliados e permitiram algumas conclusões. Como síntese final das conclusões da presente pesquisa, destacam-se os seguintes aspectos, ainda que sujeitos a novas investigações e aperfeiçoamentos.

- O estudo realizado demonstrou que a técnica NSM é aplicável ao incremento da rigidez e da resistência de ligações de estruturas de concreto pré-moldado, com rapidez e eficiência compatíveis com o processo industrializado;

- O estudo da aderência dos laminados colados em entalhes demonstrou a sua efetividade e forneceu parâmetros confiáveis para avaliação da capacidade resistente do reforço em configuração semelhante à de uma situação de uso corrente na prática. O método de ensaio mostrou-se adequado;

- O processo de execução inerente à técnica de reforço foi testado, concluindo-se que ele tem condições de ser assimilado sem grandes dificuldades pelos agentes executores;

- No tipo de ligação e configuração particularmente analisada, a aplicação do graute mostrou-se satisfatória, praticamente reconstituindo a condição de ligação monolítica, em relação aos esforços de compressão. A existência da almofada não teve influência significativa no comportamento da ligação reforçada;

- Os resultados da Análise Dinâmica Modal na obtenção experimental da rigidez de ligações não se mostraram consistentes e, portanto, não permitiram uma avaliação segura da metodologia, o que não significa que ela não possa ser aperfeiçoada e seu campo de aplicação bem delimitado.

\subsection{Sugestões para trabalhos futuros}

As lacunas identificadas na pesquisa bibliográfica e a experiência adquirida ao longo desta pesquisa conduzem às seguintes sugestões para trabalhos futuros: 
- Estudo da influência da resina na eficiência do reforço, focalizando a identificação das propriedades da resina que podem definir sua adequação ou não ao emprego na colagem dos laminados em entalhes no concreto de cobrimento;

- Estudo do reforço por meio da técnica NSM em estruturas de concreto com fibras;

- Estudo da técnica de reforço proposta em modelos representativos de estruturas reais;

- Estudo do mecanismo de ruptura das ligações reforçadas;

- Análise modal das ligações reforçadas;

- Investigação acerca das conseqüências do reforço das ligações na estabilidade global das estruturas;

- Desenvolvimento de métodos de cálculo para avaliação teórica de deslocamentos verticais e rotações da ligação, especialmente no caso de solicitações mais elevadas, superiores aos esforços de fissuração ou transição;

- Avaliação do comportamento da ligação reforçada quando submetida a solicitações cíclicas;

- Modelagem numérica dos modelos de ligação reforçados. 


\section{REFERÊNCIAS BIBLIOGRÁFICAS}

ALMEIDA, S. F. Análise experimental estática e dinâmica da rigidez de ligações de elementos pré-moldados de concreto sujeitas a danificação progressiva. Relatório Científico n² - FAPESP - Bolsa de Doutorado, São Carlos, 2007.

AMERICAN CONCRETE INSTITUTE COMMITTEE 440. ACI 440.1R-03: Guide for the design and construction of concrete reinforced with FRP bars. 2003.

AMERICAN CONCRETE INSTITUTE COMMITTEE 440. ACI 440.2R-02: Guide for the design and construction of externally bonded FRP systems for strengthening concrete structures. 2002.

AMERICAN CONCRETE INSTITUTE COMMITTEE 440. ACI 440R-96: State-of-the-art report on fiber reinforced plastic (FRP) reinforcement for concrete structures. 1996.

AMERICAN SOCIETY FOR TESTING AND MATERIALS. C469-94: Standard test method for static modulus of elasticity and Poisson's ratio of concrete I compression. West Conshohocken, PA, 1994.

AMERICAN SOCIETY FOR TESTING AND MATERIALS. D 3039/D 3039M-95a: Standard test method for tensile properties of polymer matrix composite materials. West Conshohocken, PA, 1995.

ASSOCIAÇÃO BRASILEIRA DE NORMAS TÉCNICAS. NBR 5739: Concreto - Ensaio á compressão de corpos-de-prova cilíndricos. Rio de Janeiro, 1994.

ASSOCIAÇÃO BRASILEIRA DE NORMAS TÉCNICAS. NBR 6118: Projeto e execução de obras em concreto, Rio de Janeiro, 2003. 
ASSOCIAÇÃO BRASILEIRA DE NORMAS TÉCNICAS. NBR 6152: Materiais metálicos Determinação das propriedades mecânicas à tração. Rio de Janeiro, 1992.

ASSOCIAÇÃO BRASILEIRA DE NORMAS TÉCNICAS. NBR 7222: Argamassas e concreto - Determinação da resistência à tração por compressão diametral de corpos-de-prova cilíndricos, Rio de Janeiro, 1994.

ASSOCIAÇÃO BRASILEIRA DE NORMAS TÉCNICAS. NBR 8522: Concreto Determinação dos módulos estáticos de elasticidade e de deformação e da curva tensãodeformação. Rio de Janeiro, 2003.

BALDISSERA, A. Estudo experimental de uma ligação viga-pilar de concreto prémoldado parcialmente resistente a momento fletor. 2006. Dissertação (Mestrado), Escola de engenharia de São Carlos, Universidade de São Paulo, São Carlos, 2006.

BALLARIN, A.W. Desempenho das ligações de elementos estruturais pré-moldados de concreto. 1993. Dissertação (Mestrado), Escola de Engenharia de São Carlos, Universidade de São Paulo, São Carlos, 1993.

BARBOZA, A. S. R. Comportamento de juntas de argamassa solicitadas à compressão na ligação entre elementos pré-moldados. 2001. Tese (Doutorado), Escola de Engenharia de São Carlos, Universidade de São Paulo, São Carlos, 2001.

BARROS, J. A. O.; DIAS, S. J. E. Near surface mounted CFRP laminates for shear strengthening of concrete beams. Cement \& Concrete Composites, 28, p. 276-292, 2006.

BARROS, J. A. O.; FORTES, A. S. Flexural strengthening of concrete beam with CFRP laminates bonded into slits. Cement \& Concrete Composites, 27, p. 471-480, 2005.

BARROS, J.A.O.; FERREIRA, D. R. S. M.; LOURENÇO, P. B. Comportamento de pilares de betão armado reforçados com laminados de fibras de carbono. Encontro Nacional de Betão Estrutural, 2000, FEUP, p. 393-402, Novembro, 2000.

BEBER, A. J. Comportamento estrutural de vigas reforçadas com compósitos de fibra de carbono. 2003. Dissertação (Mestrado), Universidade Federal do Rio Grande do Sul, Porto Alegre, 2003. 
CANHA, R. M. F. Estudo teórico-experimental da ligação pilar-fundação por meio de cálice em estruturas de concreto pré-moldado. 2004. Tese (Doutorado), Escola de Engenharia de São Carlos, Universidade de São Paulo, São Carlos, 2004.

CAROLIN, A. Carbon fibre reinforced polymers for strengthening of structural elements. 2003. Tese (Doutorado), Division of structural engineering, Department of civil and mining engineering, Lulea University of technology, Lulea, 2003.

CARVALHO et al. Cálculo e detalhamento de estruturas usuais de concreto armado segundo a NBR 6118: 2003. EdUFSCar, São Carlos, 2004.

CASTRO, E. K. Reforço em Vigas "T" de Concreto Armado com Vários Tipos de Compósitos em Entalhes no Cobrimento de Concreto (CEC). 2005. Tese (Doutorado), Universidade de Brasília, Distrito Federal, 2005.

COMITE EURO-INTERNATIONAL DU BETON. CEB-FIP Model Code for Concrete Structures. Paris, 1990.

CRUZ, J. M. S. Reforço de estruturas com laminados de CFRP inseridos no betão de recobrimento. 2004. Tese (Doutorado), Universidade do Minho, Guimarães, 2004.

DE LORENZIS, L.; NANNI, A. Characterization of FRP rods as near-surface mounted reinforcement. Journal of composites for construction, v. 5, n. 2, p. 114-121, May, 2001a.

DE LORENZIS, L.; NANNI, A. Shear strengthening of reinforced concrete beams with nearsurface mounted fiber-reinforced polymers rods. ACI structural journal, v. 98, n. 1, p. 6068, Jan./Feb., $2001 b$.

DE LORENZIS, L.; TENG, J. G. Near-surface mounted FRP reinforcement: An emerging technique for strengthening structures. Composites: Part B, 38, Available online 18 October 2006. www.sciencedirect.com/locate/compositesb

DIAS, S. J. E.; BARROS, J. A. O. NSM CFRP laminates for the shear strengthening of T section RC beams. Proceedings of the $2^{\text {th }}$ international congress, Naples, Italy, 2006.

EBELING, E. B. Análise da base de pilares pré-moldados na ligação com cálice de fundação. 2006. Dissertação (Mestrado), Escola de Engenharia de São Carlos, Universidade de São Paulo, São Carlos, 2006. 
EL DEBS, M. K. Concreto pré-moldado: fundamentos e aplicações. Escola de Engenharia de São Carlos, Universidade de São Paulo, São Carlos, 2000.

ENGINDENIZ, M.; KAHN L. F.; ZUREICK A. H. Repair and strengthening of reinforced concrete beam-column joints: state of art. ACI structural journal, v. 102, n. 2, Mar./Apr., 2005.

EUROCODE 3. Design of steel structures, part 1.8: design of joints. European committee for standardization, Brussels, 2003.

FEDERATION INTERNATIONALE DU BETON. FIB: Externally bonded FRP reinforcement for RC structures - Design and use of externally bonded fibre reinforced polymer reinforcement (FRP EBR) for reinforced concrete structures. CEB-FIP-grupo 9.3, Stuttgart, 2001.

FEDERATION INTERNATIONALE DU BETON. FIB 9.3 TG - FRP as reinforcement in concrete (proposta de norma). Sheffield, Inglaterra, 2003.

FERREIRA, M. A. Deformabilidade de ligações viga-pilar de concreto pré-moldado. 1999. Tese (Doutorado), Escola de Engenharia de São Carlos, Universidade de São Paulo, São Carlos. 1999.

FERREIRA, M. A; EL DEBS, M. K.; ELLIOTT, K. S. Modelo teórico para projeto de ligações semi-rígidas em estruturas de concreto pré-moldado. In: Congresso Brasileiro do Concreto, 44, 2002, Belo Horizonte. Anais. CD ROM.

FERREIRA, M. A. Estudo de deformabilidades de ligações para análise linear em pórticos planos de elementos pré-moldados de concreto. 1993. Dissertação (Mestrado), Escola de Engenharia de São Carlos, Universidade de São Paulo, São Carlos, 1993.

FORTES, A. S. Estruturas de concreto submetidas à flexão reforçadas com laminados de CFRP colados em entalhes. 2004. Tese (Doutorado), Universidade Federal de Santa Catarina, Florianópolis, 2004.

FRENCH, C. W.; THORP, G. A.; TSAI, W. J. Epoxy repair techniques for moderate earthquake damage. ACI Structural Journal, V. 87, n. 4, p. 416-424, July/Aug., 1990. 
HELENE, P. R. L. Manual para Reparo, Reforço e Proteção de Estruturas de Concreto. PINI, São Paulo, 1992.

HYER, M.W.; WHITE, S. R. Stress analysis of fiber-reinforced composite materials. McGraw-Hill, Boston, 1998.

JUVANDES, L. F. P. Reforço e reabilitação de estruturas de betão usando materiais compósitos de CFRP. 1999. Tese (Doutorado), Departamento de Engenharia Civil, Faculdade de Engenharia da Universidade do Porto (FEUP), Porto, 1999.

JUVANDES, L. F. P. Reforço e reabilitação de estruturas. Módulo 2 do curso de formação profissional promovido pela Ordem dos Engenheiros - Seção Regional da Madeira. Departamento de Engenharia Civil, Faculdade de Engenharia da Universidade do Porto (FEUP), Porto, 2002.

KANG, J. Y. et al. Analytical Evaluation of RC Beams Strengthened with Near Surface Mounted CFRP Laminates. In: 7th international symposium - Fiber-reinforced polymer reinforcement for concrete structures (FRPRCS - 7), p.779-794, Kansas City, 2005. Proceedings. CD ROM.

LIU, I. S. T.; OEHLERS, D. J.; SERACINO, R. Tests on the ductility of reinforced concrete beams retrofitted with FRP and steel near-surface mounted plates. Journal of composites for construction, v.10, n. 2, p. 106-114, April, 2006.

LIU, I. S. T. Intermediate crack debonding of plated reinforced concrete beams. 2006. Ph.D. thesis, School of Civil and Environmental Engineering, Univ. of Adelaide, Adelaide, Australia, 2006.

METHA, P. K.; MONTEIRO, P. J. M. Concreto: estrutura, propriedades e materiais. São Paulo, Pini, 1994.

MIOTTO, A. M. Ligações viga-pilar de estruturas de concreto pré-moldado: análise com ênfase na deformabilidade ao momento fletor. 2002. Tese (Doutorado), Escola de Engenharia de São Carlos, Universidade de São Paulo, São Carlos. 2002.

NÓBREGA, P. G. B. Análise dinâmica de estruturas de concreto: estudo experimental e numérico das condições de contorno de estruturas pré-moldadas. 2004. Tese (Doutorado), Escola de Engenharia de São Carlos, Universidade de São Paulo, São Carlos, 2004. 
OLIVEIRA JUNIOR, F. S. de. Reforço à Flexão de Vigas "T" de Concreto Armado com Colagem Externa e Inserção de Compósitos com Fibra de Carbono e Barras de Aço no Concreto de Cobrimento. 2005. Dissertação (Mestrado), Departamento de Engenharia Civil e Ambiental, Universidade de Brasília, Brasília, DF, 2005.

PANTELIDES, C. P. et al. Seismic retrofit of precast concrete panel connections with carbon fiber reinforced polymer composites. PCI Journal, v. 48, n. 1, p. 92-104, Jan./Feb., 2003.

PROTA, A. et al. Selective upgrade of beam-column joints with composites. Proceedings of the international conference of FRP composites in civil engineering. Hong Kong, Dec., 2001.

PROTA, A. et al. Selective Upgrade of Underdesigned Reinforced Concrete Beam-Column Joints Using Carbon Fiber- Reinforced Polymers. ACI Structural Journal, v. 101, n. 5, Sept/Oct., 2004.

QUATTLEBAUM, J. B.; HARRIES'K.A.; PETRON M. F. Comparison of three flexural retrofit system under monotonic and fatigue loads. Journal of bridge engineering, $v .10, \mathrm{n}$. 6, p. 731-704, Nov., 2005.

RILEM-FIP-CEB. Bond test for reinforcing steel: 1-Beam test (7-II-28 D). RILEM Journal Materials and Structures, v. 6, n. 32, Mar./Apr., p. 96-105, 1973.

SENA-CRUZ, J. M.; BARROS, J. A. Caracterização experimental da ligação de laminados de CFRP inseridos no betão de recobrimento. Relatório técnico n. 02-EEC/E15, Departamento de Engenharia Civil, Universidade do Minho, Portugal, set., 2002.

SHIELD, C.; FRENCH, C.; MILDE, E. The effect of adhesive type on the bond of NSM tape to concrete. . In: $7^{\text {th }}$ international symposium - Fiber-reinforced polymer reinforcement for concrete structures (FRPRCS - 7), p.355-372, Kansas City, 2005. Proceedings. CD ROM.

SOARES, A.M.M. Análise estrutural de pórticos planos de elementos pré-fabricados de concreto considerando a deformabilidade das ligações. 1998. Dissertação (Mestrado), Escola de Engenharia de São Carlos, Universidade de São Paulo, São Carlos. 1998.

SOUZA, R. et al. Análise experimental e analítica de consolos curtos de concreto armado reforçados com fibras de carbono. In: Congresso Brasileiro do Concreto, 48, 2006, Rio de Janeiro. Anais. CD ROM. 
TENG et al. Debonding failures of RC beams strengthened with near surface mounted CFRP strips. Journal of composites for construction, v.10, n. 2, p. 92-105, April, 2006. 


\section{APÊNDICE A - Equipamentos e instrumentação}
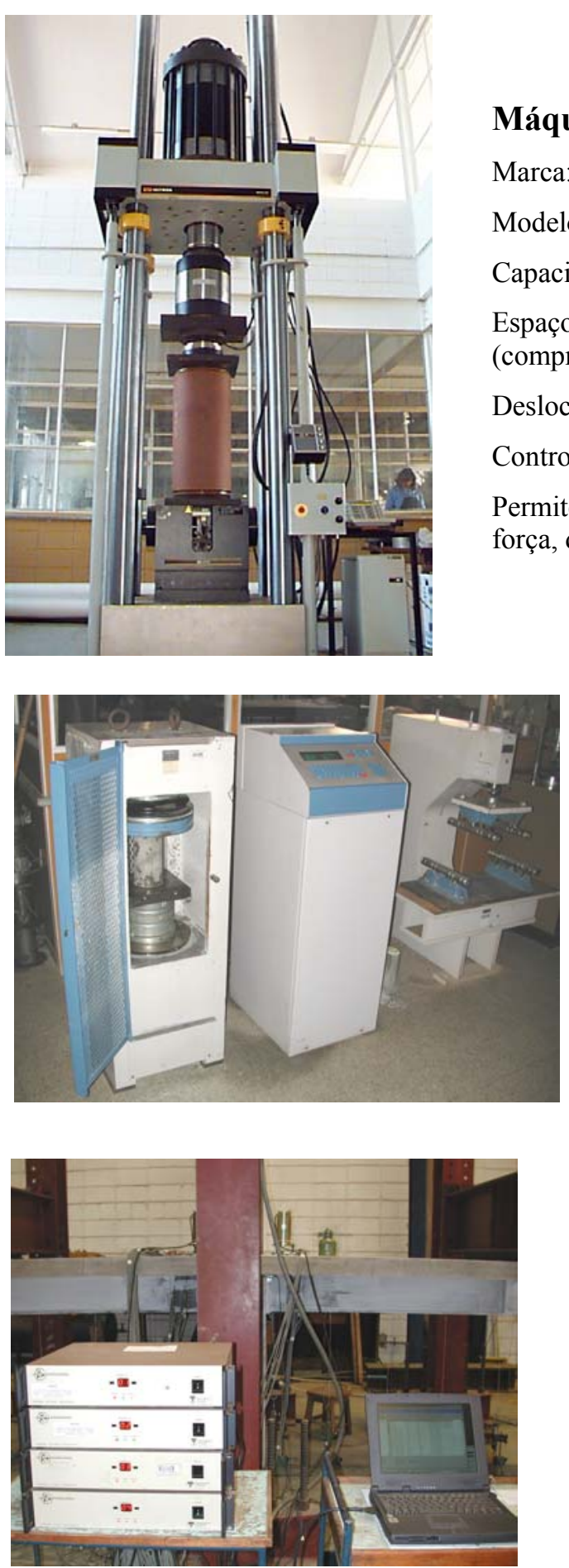

\section{Máquina universal de ensaios servo-hidráulica}

Marca: INSTRON

Modelo: 8506

Capacidade nominal de aplicação de força: $2.500 \mathrm{kN}$

Espaço para ensaio: $4000 \mathrm{~mm}$ (altura) x $822 \mathrm{~mm}$

(comprimento) x $514 \mathrm{~mm}$ (largura)

Deslocamento do pistão: $250 \mathrm{~mm}$

Controle digital por computador e acessórios

Permite realizar ensaios estáticos e dinâmicos com controles de força, deslocamento e deformação

Máquina hidráulica elétrica para ensaios de compressão e de flexão em corpos-deprova de concreto

Marca: ELE International

Modelo: Autotest 2000

Permite realizar ensaios de compressão (capacidade $2000 \mathrm{kN}$ ) e de flexão (capacidade $100 \mathrm{kN}$ ) com controle de força.

Espaço para ensaio de compressão: $360 \mathrm{~mm}$

Sistema de aquisição de dados para extensometria

Marca: Vishay Measurements Groups

Modelo: System 5000

Quantidade de canais: 80 


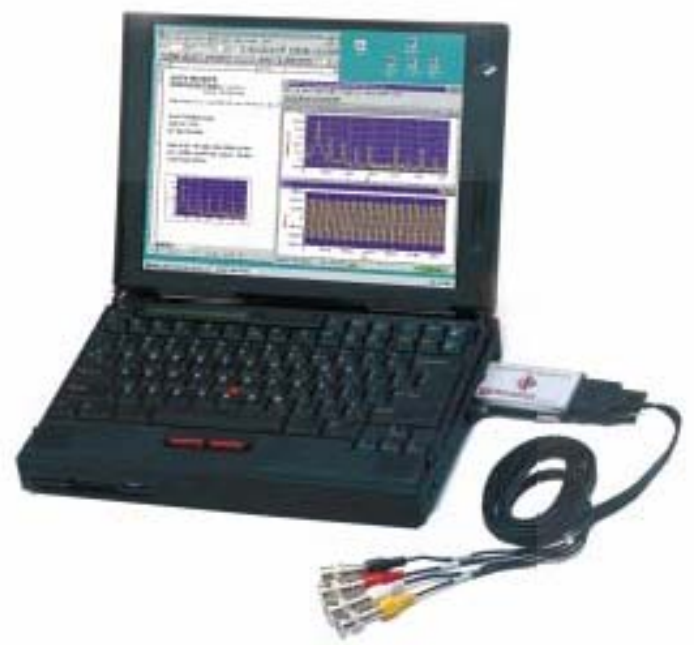

Sistema de aquisição de dados para acelerometria

Tipo: Analisador espectral de quatro canais

Marca: Data Physics

Modelo: SignalCalc ACE
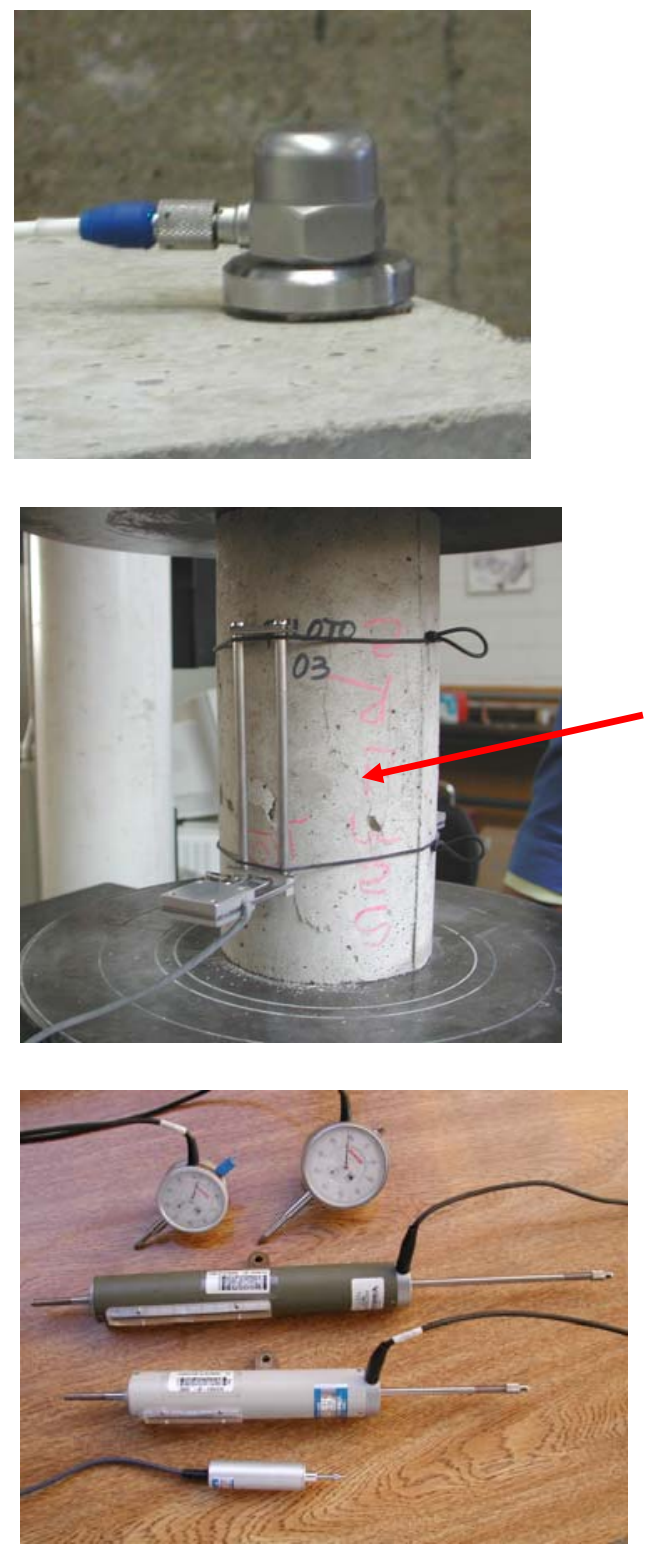

\section{Acelerômetro piezoelétrico}

Marca: Endevco

Modelo: 1254A-100

Sensibilidade: $104 \mathrm{mV} / \mathrm{g}$ e $105,5 \mathrm{mV} / \mathrm{g}$

Massa: $20 \mathrm{~g}$

\section{Extensômetros removíveis}

Modelo MSI (Micro Sensores Industrial)

Sensibilidade: $0,001 \mathrm{~mm}$

Curso: 2,5 mm (resposta linear até $1,5 \mathrm{~mm}$ )

Base de leitura: $5 \mathrm{~cm}$ e $10 \mathrm{~cm}$

Transdutor de deslocamento (à base de extensômetro elétrico de resistência)

Marca: Kyowa

Modelos: DTH-A-10 e DTH-A-20

Sensibilidade: $0,001 \mathrm{~mm}$ e $0,002 \mathrm{~mm}$

Curso: $10 \mathrm{~mm}$ e $20 \mathrm{~mm}$ 


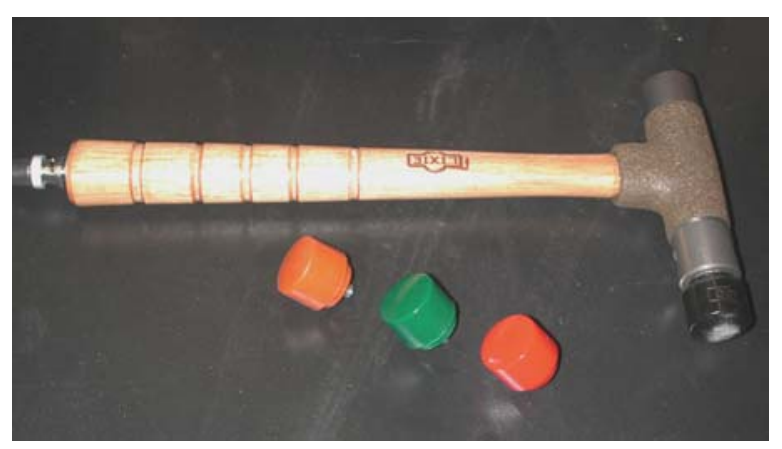

Martelo de impacto

Marca: Endevco

Modelo: 2303

Sensibilidade: 0,95 mV/lbf

Massa: $454 \mathrm{~g}$

Força máxima: $35.584 \mathrm{~N}$

Freqüência máxima: $10 \mathrm{kHz}$ 


\section{APÊNDICE B - Curvas "força x tempo"}

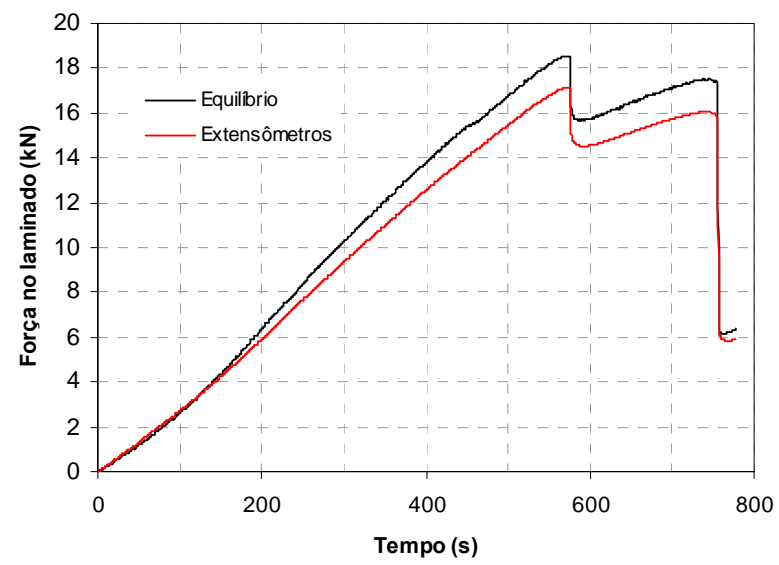

(a)

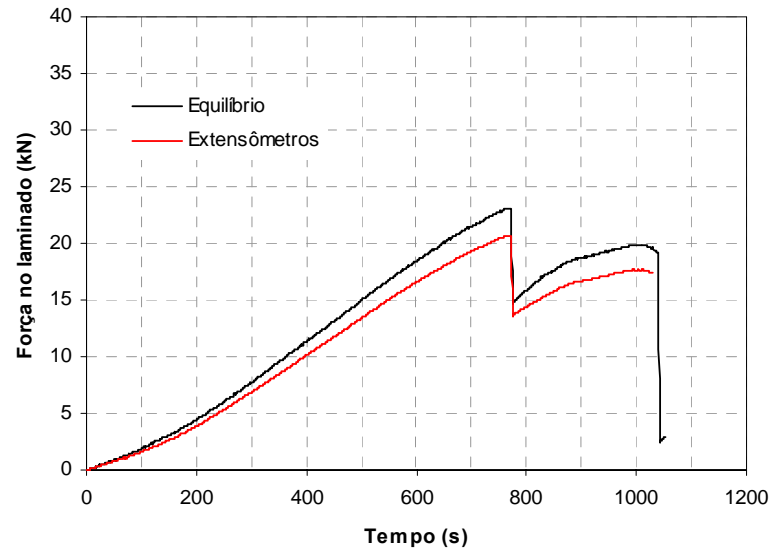

(c)

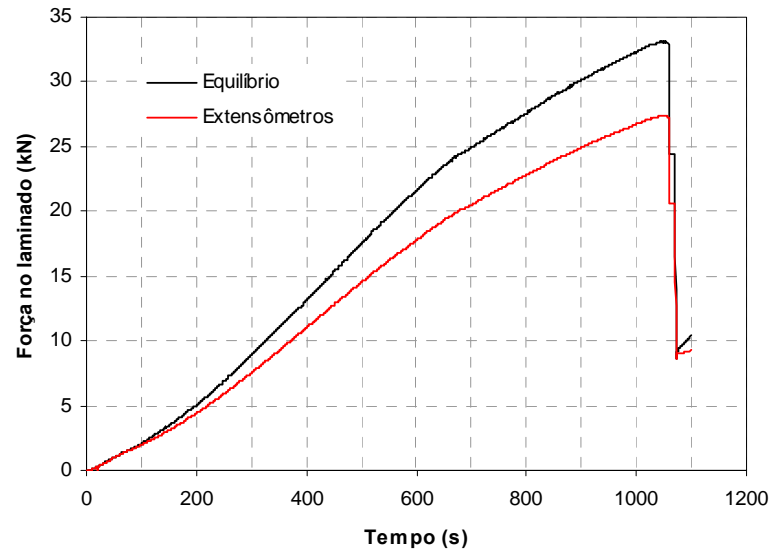

(e)

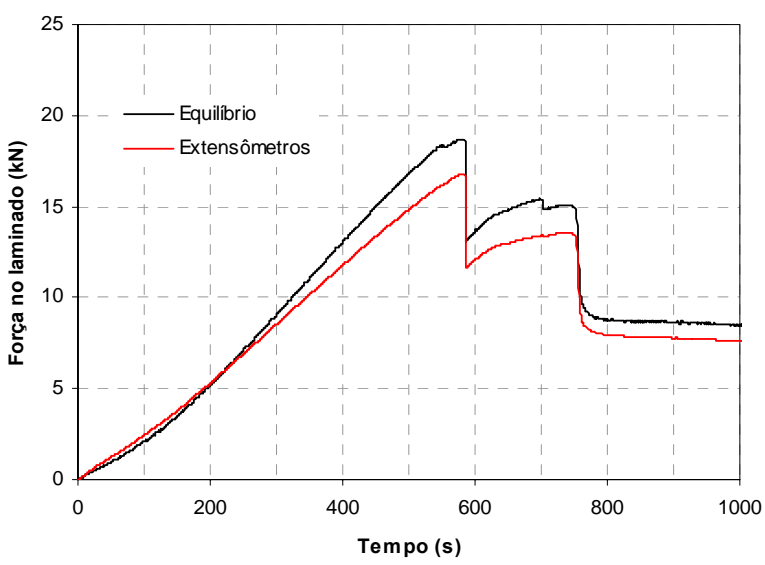

(b)

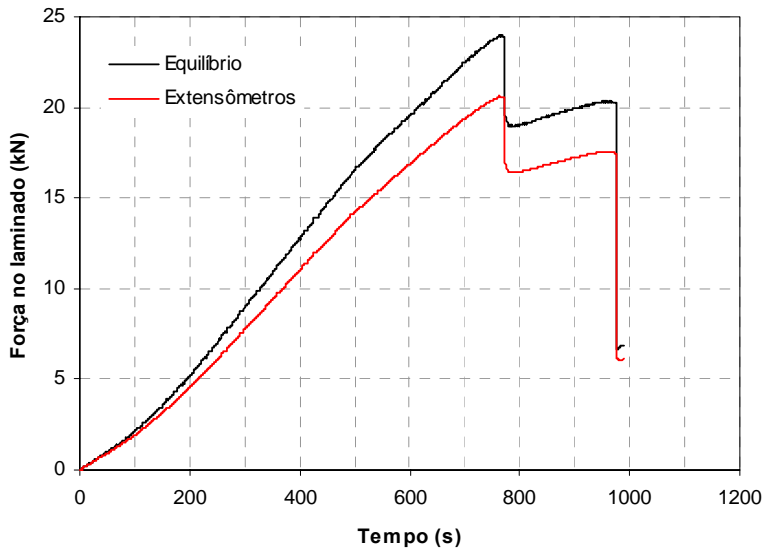

(d)

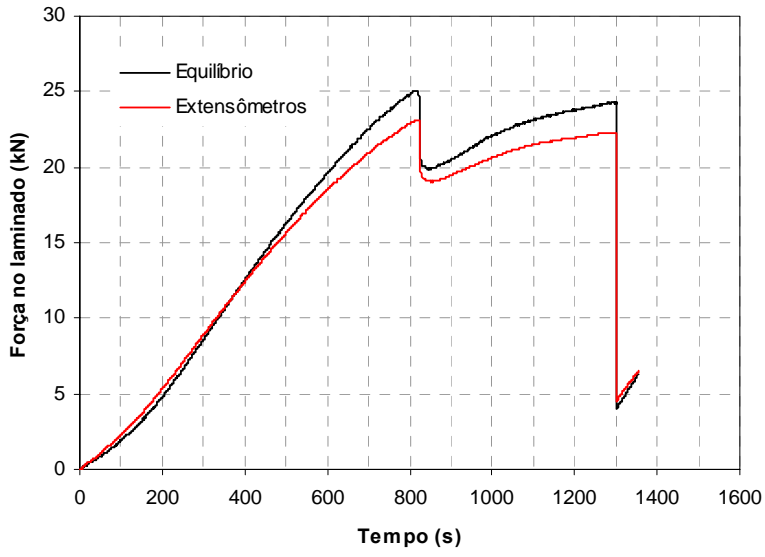

(f)

Figura 1-B - Variação da força média nos laminados com o tempo, nos ensaios de aderência da série R1: (a) M1L70R1; (b) M1L90R1; (c) M2L90R1; (d) M1L120R1; (e) M2L120R1; (f) M1L150R1; (g) M2L150R1. 


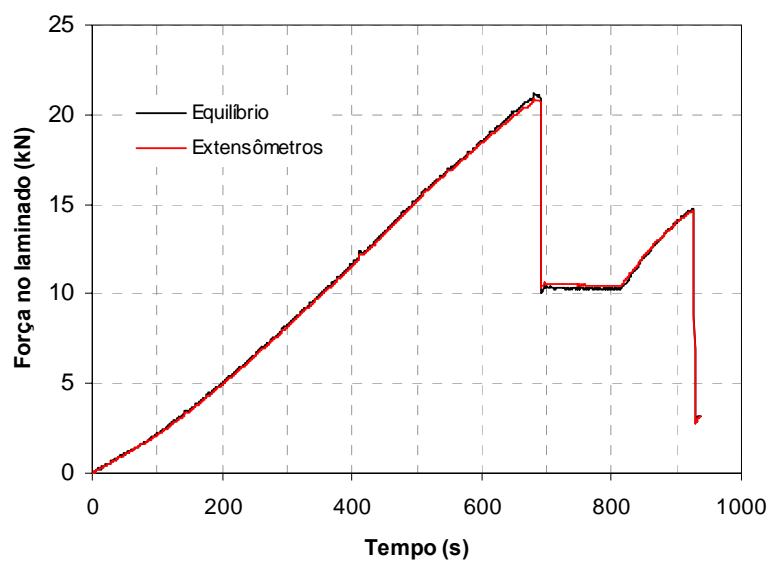

(a)

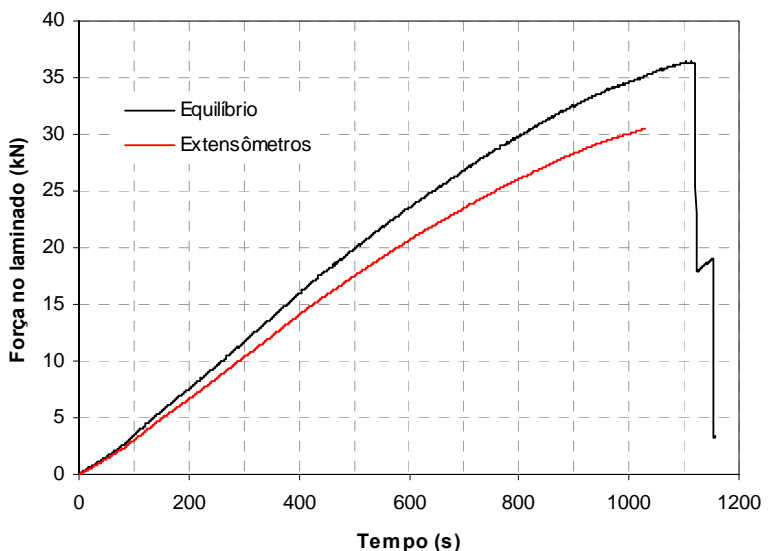

(c)

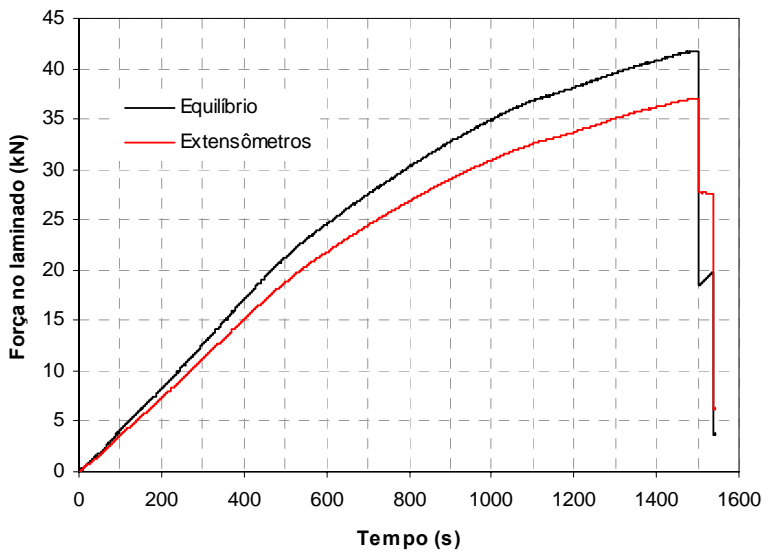

(e)

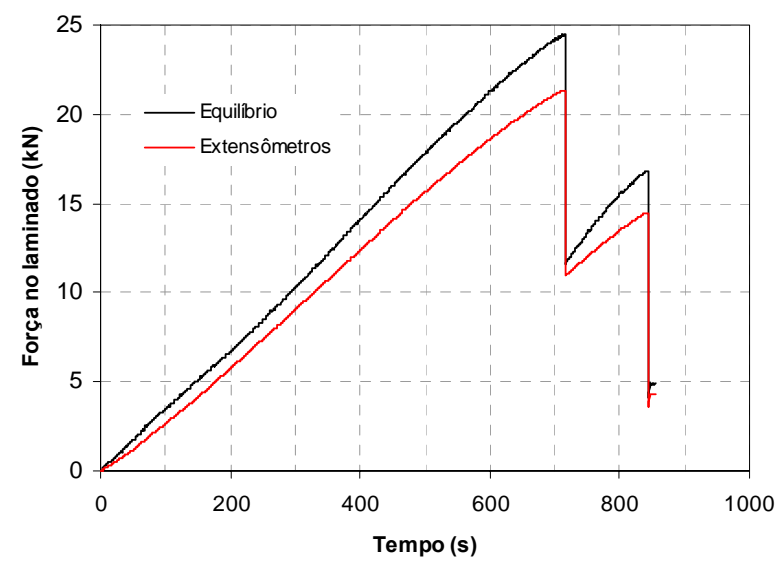

(b)

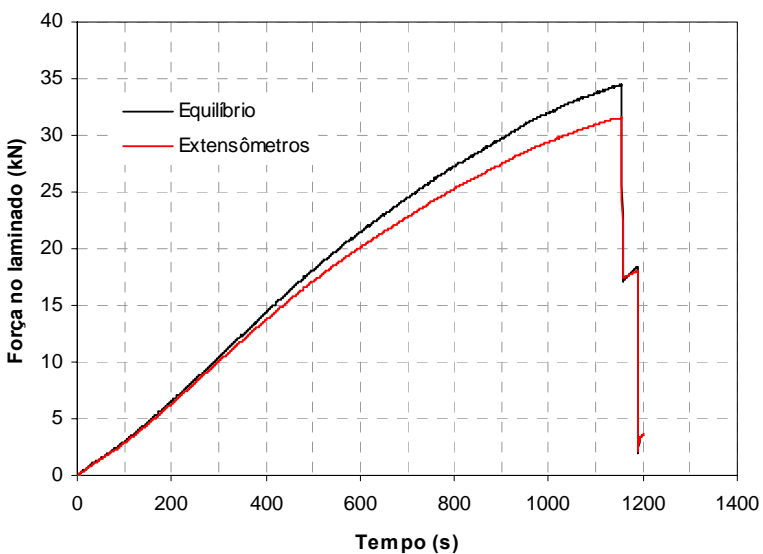

(d)

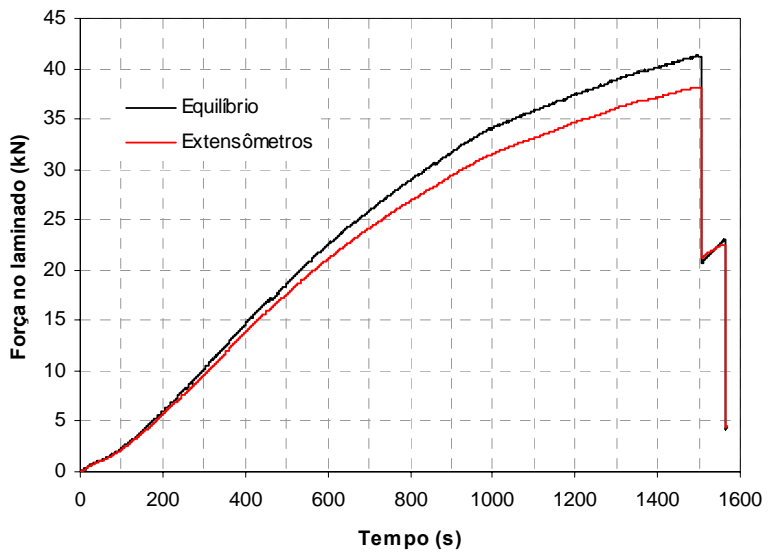

(f)

Figura 2-B - Variação da força média nos laminados com o tempo, nos ensaios de aderência da série R2: (a) M1L70R2; (b) M2L70R2; (c) M1L140R2; (d) M2L140R2; (e) M1L210R2; (f) M2L210R2. 


\section{APÊNDICE C - Curvas "tensão x deslizamento"}

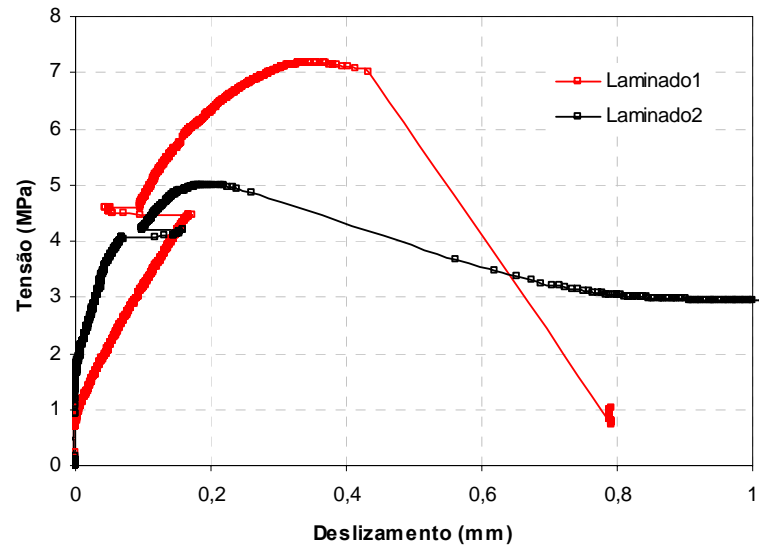

(a)

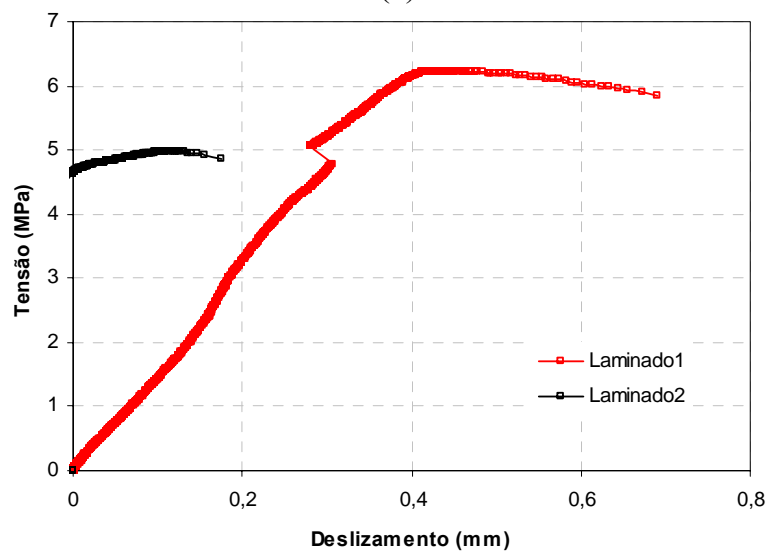

(c)

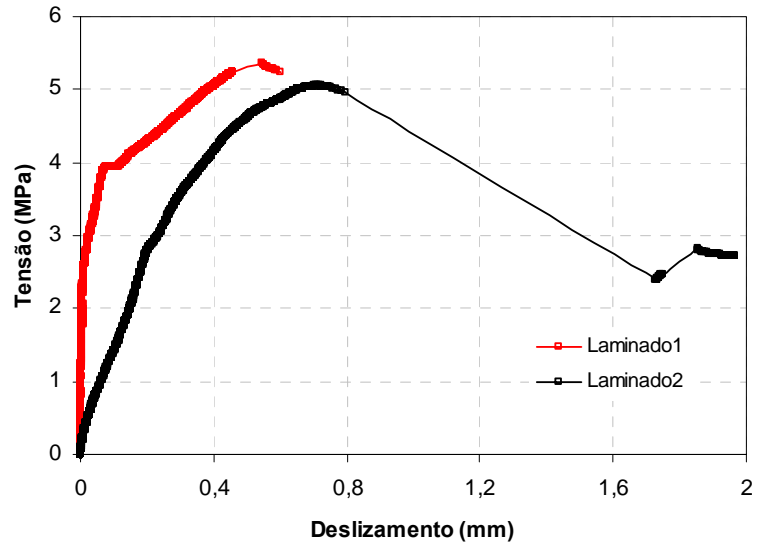

(e)

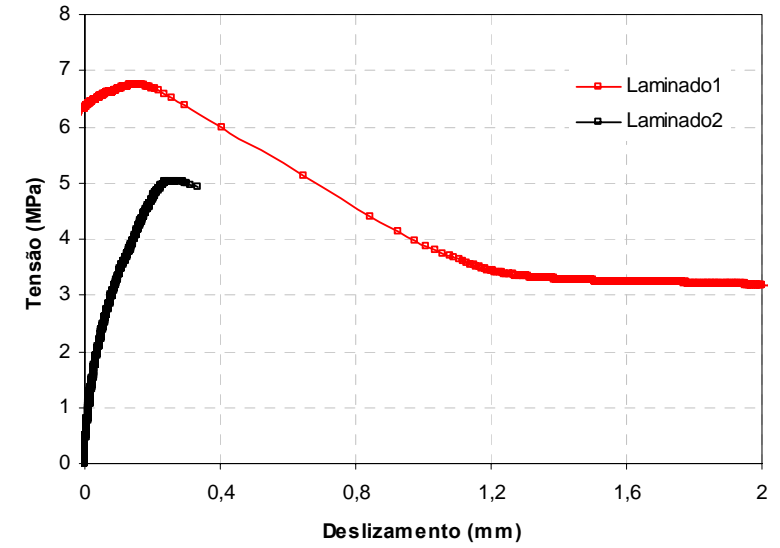

(b)

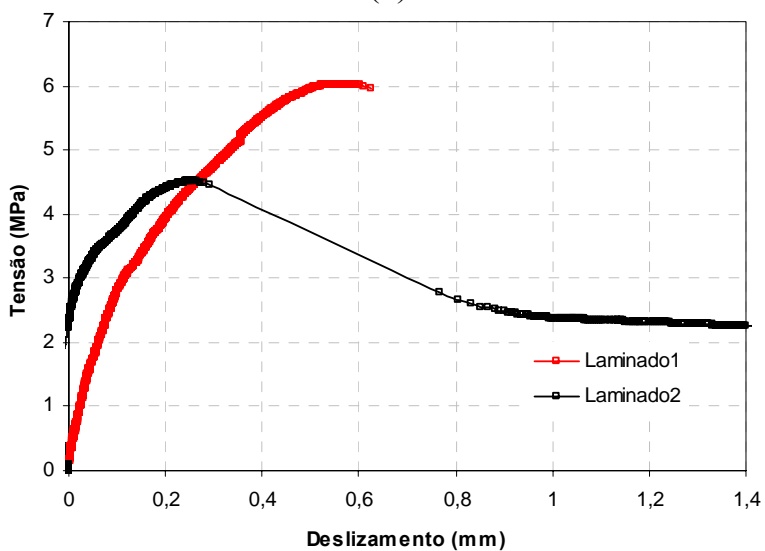

(d)

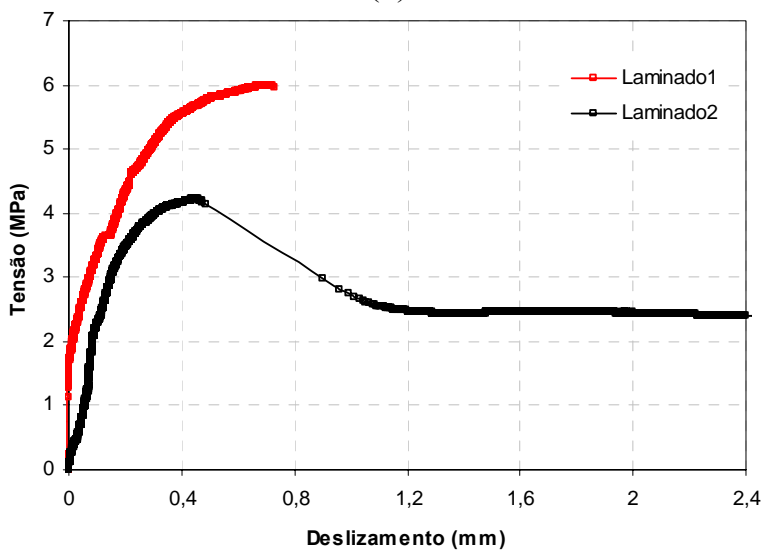

(f)

Figura 1-C - Curvas "tensão x deslizamento", no início da zona de ancoragem, obtidas nos ensaios de aderência da série R1: (a) M1L90R1; (b) M2L90R1; (c) M1L120R1; (d) M2L120R1; (e) M1L150R1; (f) M2L150R1. 


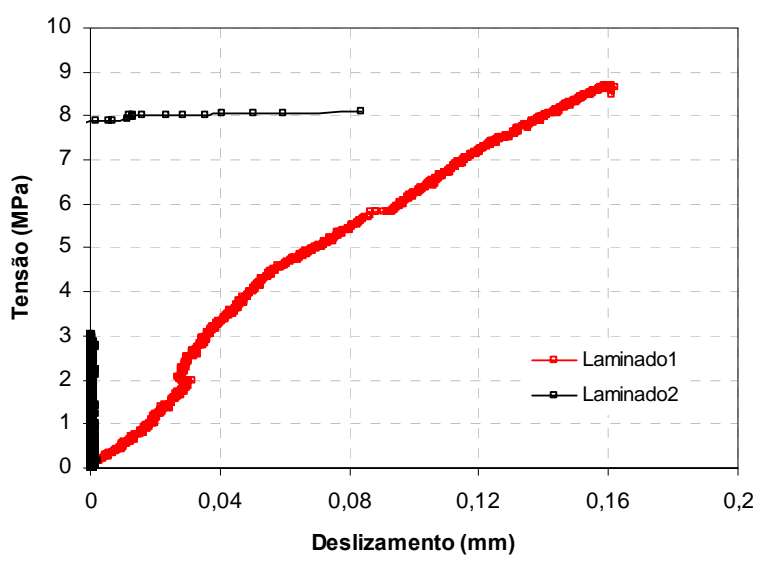

(a)

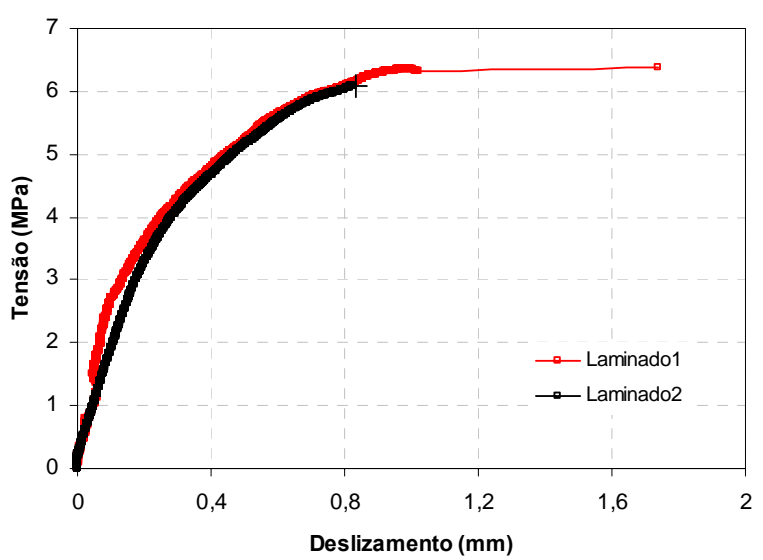

(c)

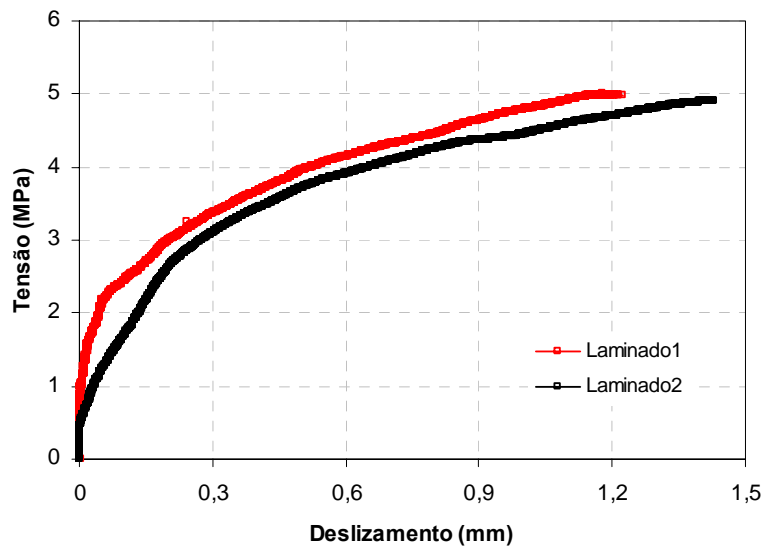

(e)

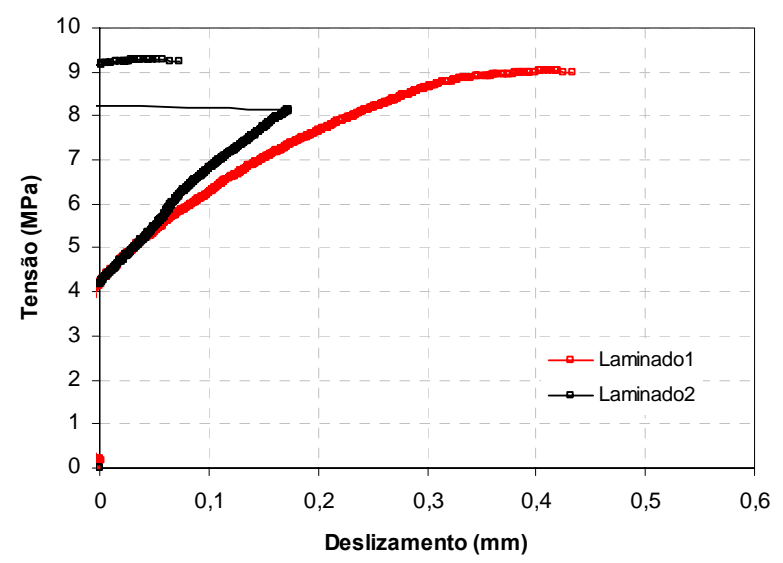

(b)

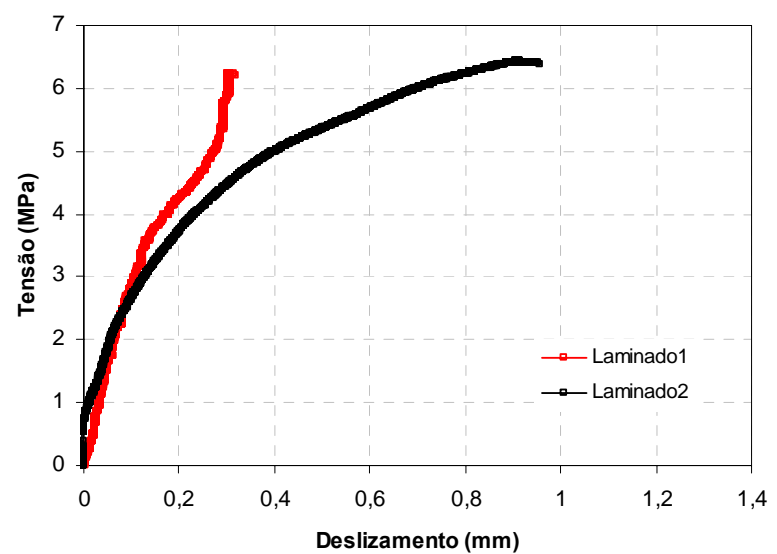

(d)

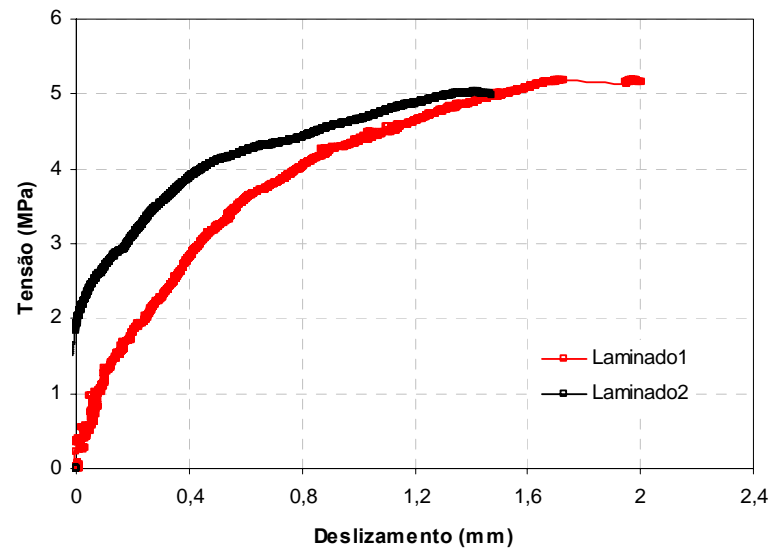

(f)

Figura 2-C - Curvas "tensão x deslizamento", no início da zona de ancoragem, obtidas nos ensaios de aderência da série R2: (a) M1L70R2; (b) M2L70R2; (c) M1L140R2; (d) M2L140R2; (e) M1L210R2; (f) M2L210R2. 


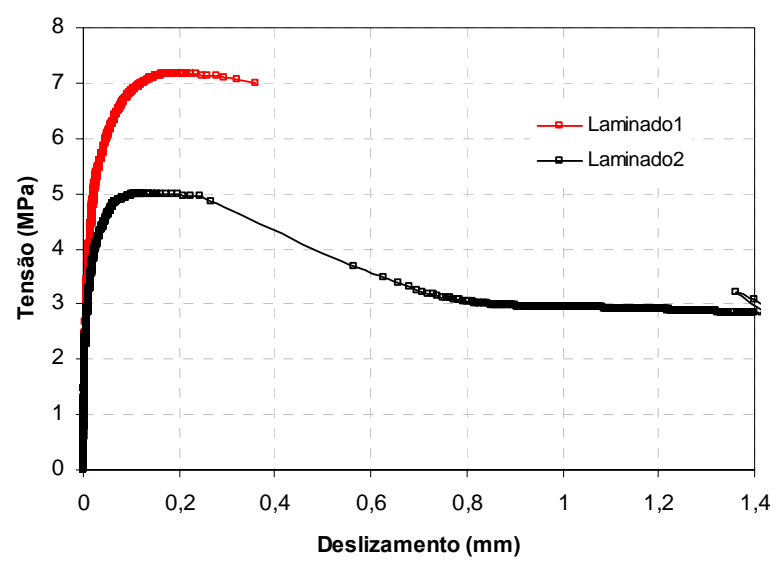

(a)

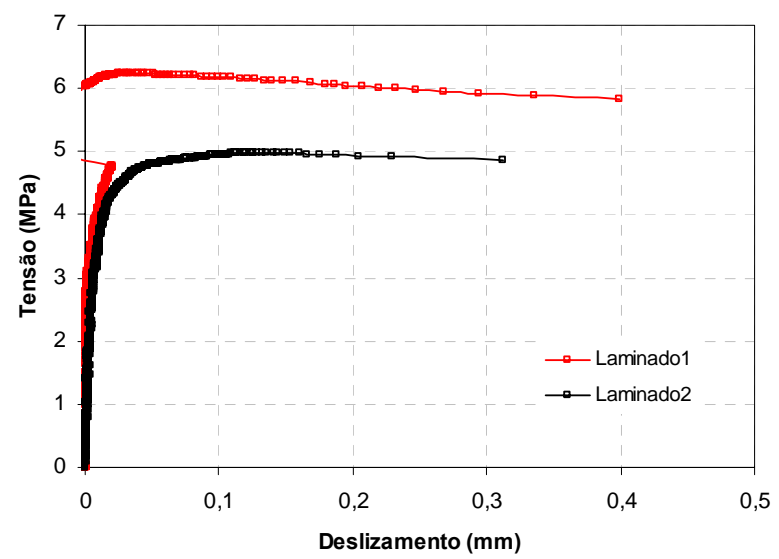

(c)

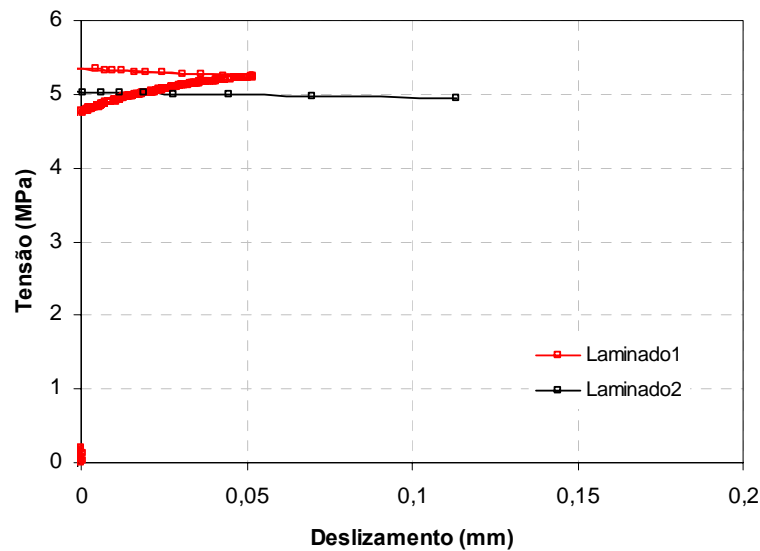

(e)

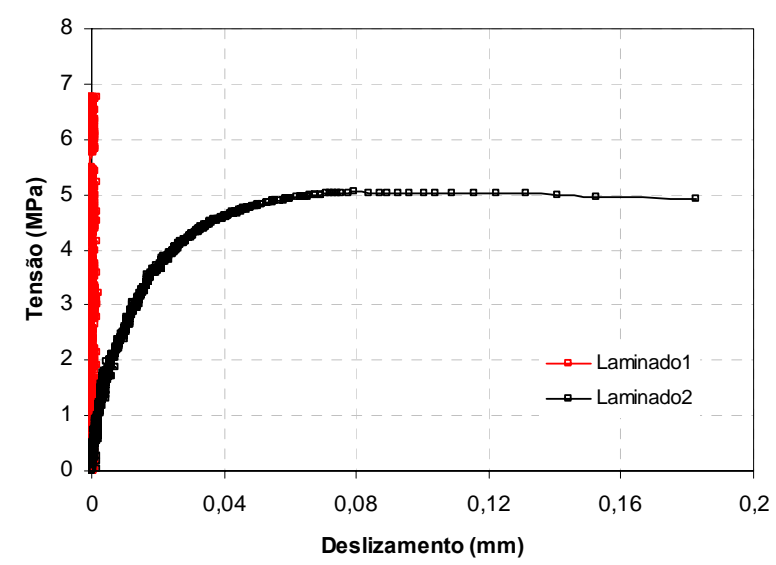

(b)

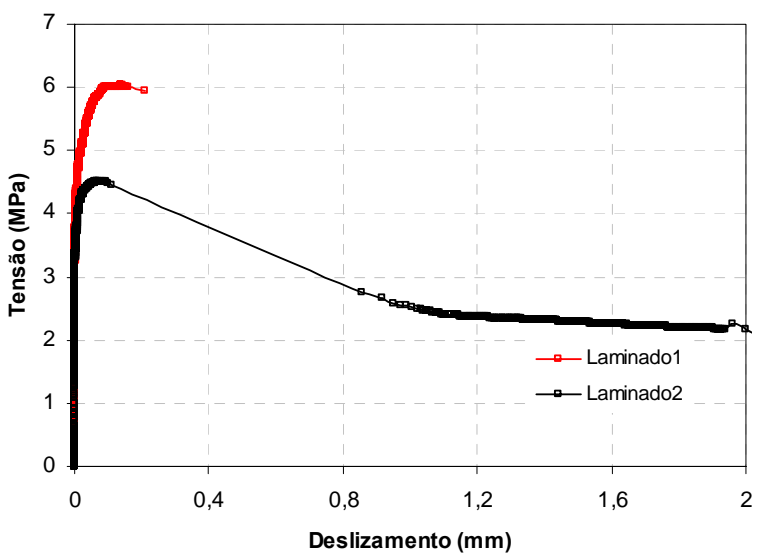

(d)

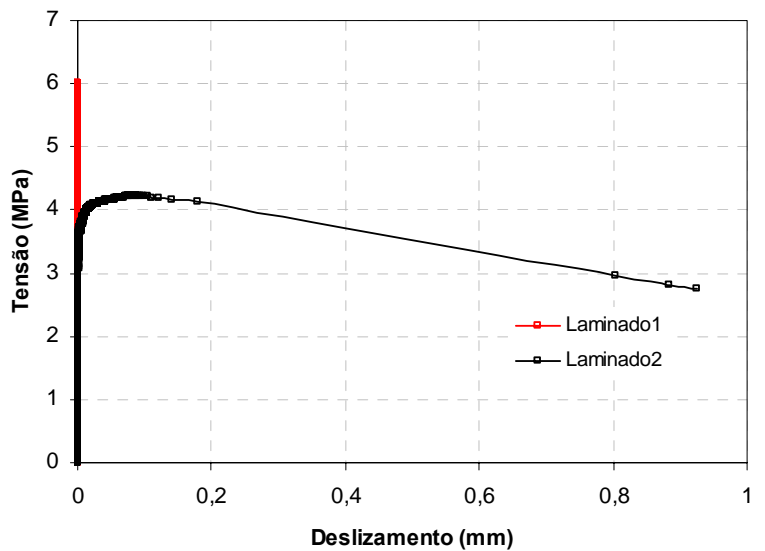

(f)

Figura 3-C - Curvas "tensão x deslizamento", no final da zona de ancoragem, obtidas nos ensaios de aderência da série R1: (a) M1L90R1; (b) M2L90R1; (c) M1L120R1; (d) M2L120R1; (e) M1L150R1; (f) M2L150R1. 


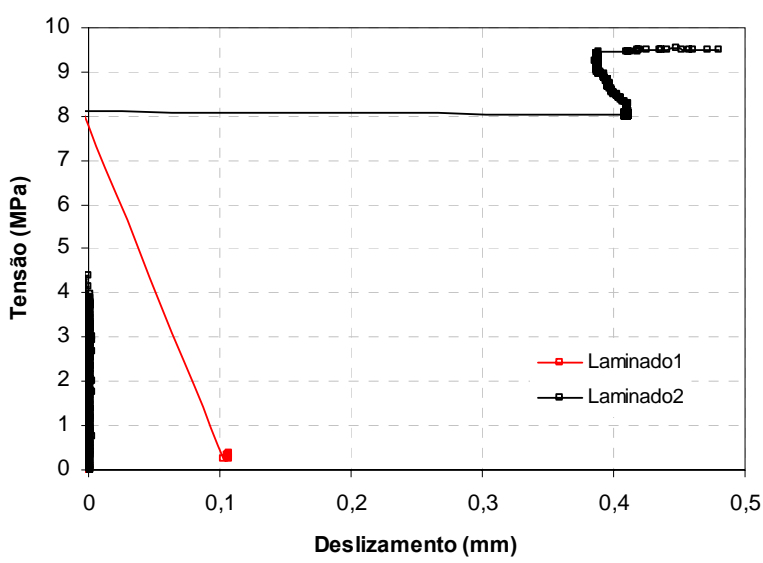

(a)

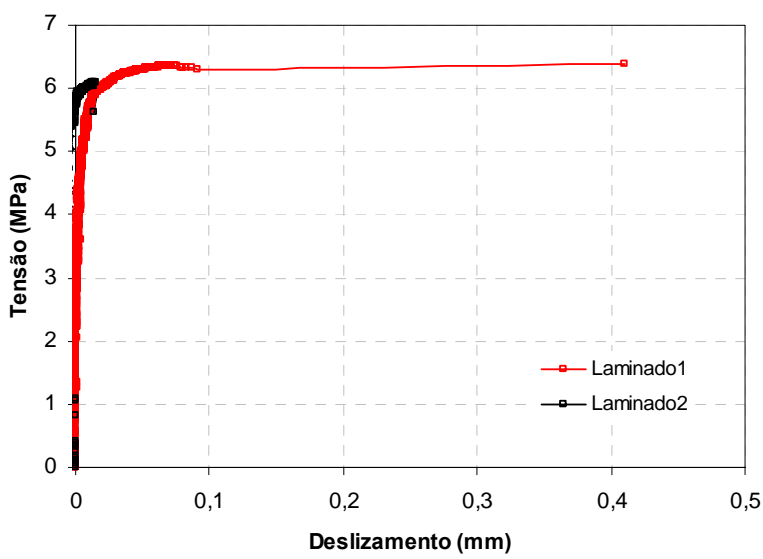

(c)

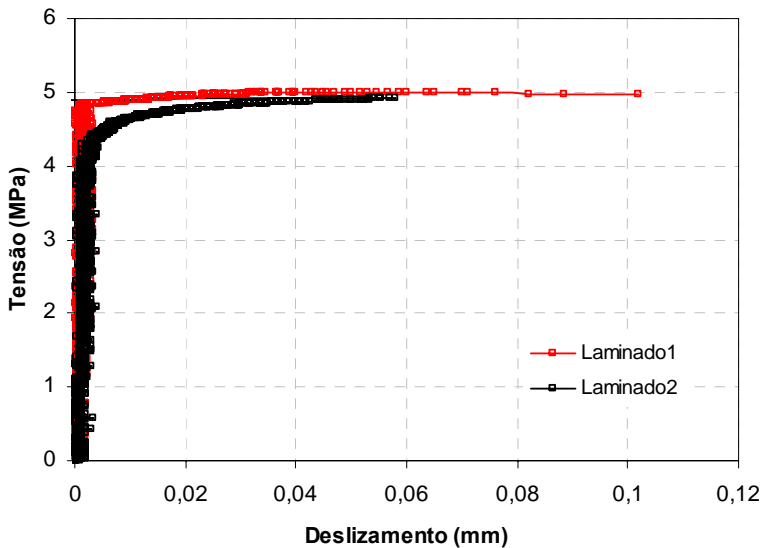

(e)

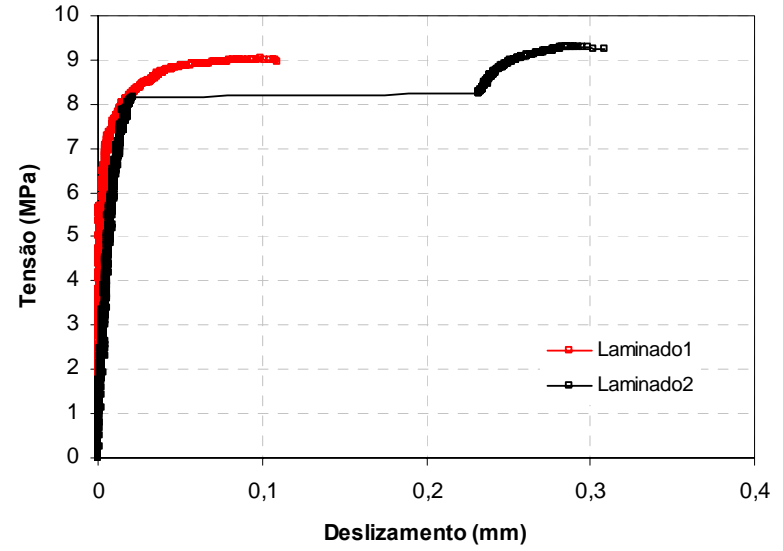

(b)

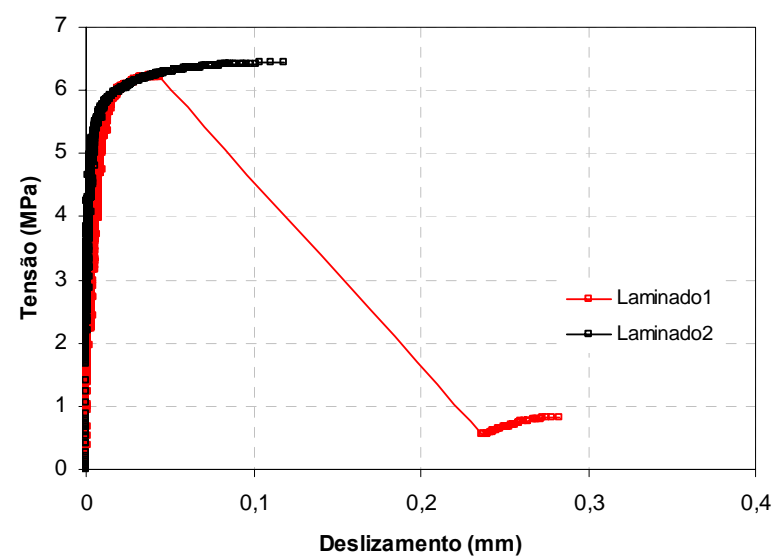

(d)

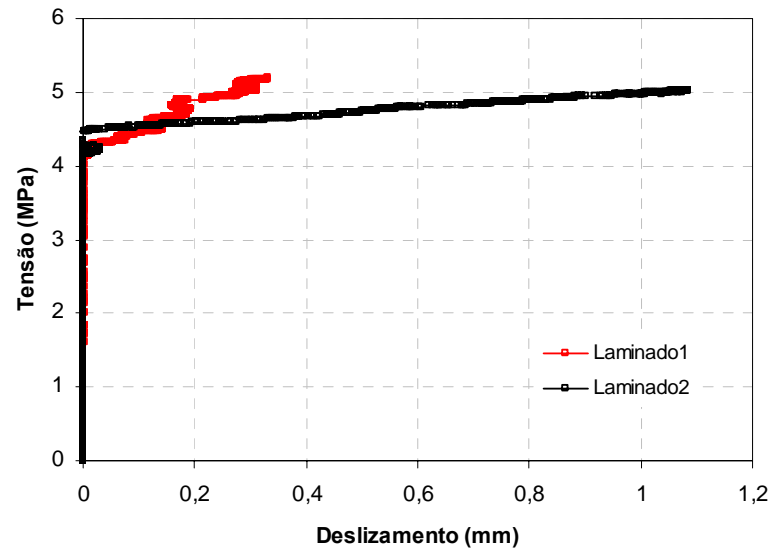

(f)

Figura 4-C - Curvas "tensão x deslizamento", no final da zona de ancoragem, obtidas nos ensaios de aderência da série R2: (a) M1L70R2; (b) M2L70R2; (c) M1L140R2; (d) M2L140R2; (e) M1L210R2; (f) M2L210R2. 


\section{APÊNDICE D - Estimativa da resistência da ligação}

$>$ Formulações utilizadas para o cálculo da resistência à flexão e deformação máxima no laminado

- ACI 440.1R-03 (2003)

A filosofia de projeto estabelece que a capacidade resistente à flexão da seção deve ser superior à solicitação gerada pelas ações multiplicadas por fatores probabilísticos. Isso se verifica por meio da Equação 1-D.

$$
\phi M_{n} \geq M_{u}
$$

Onde

$\phi$ - fator de redução

$M_{n}$ - momento resistente nominal, determinado por meio da compatibilidade de deformações, equilíbrio de forças internas e controle do modo de ruptura.

$M_{u}$ - Momento solicitante

O modo de ruptura pode ser determinado pela comparação entre a taxa de armadura de PRF, $\rho_{f}$ (Equação 2-D), e a taxa de armadura balanceada, $\rho_{f b}$ (Equação 3-D).

$$
\begin{aligned}
& \rho_{f}=\frac{A_{f}}{b d_{f}} \\
& \rho_{f b}=0,85 \beta_{1} \frac{f_{c}}{f_{f u}} \frac{E_{f} \varepsilon_{c u}}{E_{f} \varepsilon_{c u}+f_{f u}}
\end{aligned}
$$

Em que:

$$
\beta_{1}=\left\{\begin{array}{l}
0,85 \rightarrow \text { para } \rightarrow 0<f_{C}<27,6 \mathrm{MPa} \\
0,85-0,05 \cdot\left(\frac{f_{C}-27,6}{6,9}\right) \rightarrow \text { para } \rightarrow 27,6<f_{C}<55,2 \mathrm{MPa} \\
0,65 \rightarrow \text { para } \rightarrow f_{C}>55,2 \mathrm{MPa}
\end{array}\right.
$$


$A_{f}$ - área total de PRF na seção

$b$ - largura da seção

$d_{f}$ - distância da fibra mais comprimida de concreto ao centro de gravidade do PRF

$f_{c}$ - resistência do concreto à compressão

$E_{f}$ - módulo de elasticidade do PRF

$\varepsilon_{c u}$ - deformação do concreto na ruptura

$f_{f u}$ - resistência do PRF à tração

Para $\rho_{f}>1,4 \rho_{f b}$ (situação a qual se ajustaram todos os modelos), a ruptura é iniciada pelo esmagamento do concreto e a distribuição de tensões no concreto pode ser aproximada a um retângulo, conforme Figura 1-D. As Equações 4-D, 5-D e 6-D são deduzidas com base no equilíbrio de forças e compatibilidade de deformações.
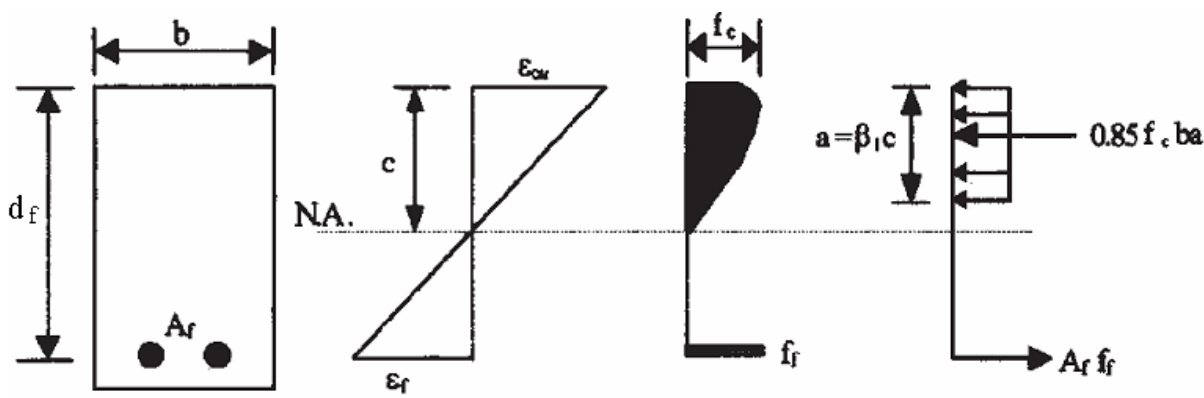

Figura 1-D - Distribuições de tensão e deformação no estado limite último para ruptura governada por esmagamento do concreto (Fonte: adaptado do ACI 440.1R-03 (2003)).

$$
\begin{aligned}
& M_{n}=A_{f} f_{f}\left(d_{f}-\frac{a}{2}\right) \\
& a=\frac{A_{f} f_{f}}{0,85 f_{c} b} \\
& f_{f}=E_{f} \varepsilon_{c u} \frac{\beta_{1} d_{f}-a}{a}
\end{aligned}
$$

Onde:

$f_{f}$ - tensão no PRF

Substituindo $a$ da Equação 5-D na Equação 6-D e isolando $f_{f}$.

$$
f_{f}=\left(\sqrt{\frac{\left(E_{f} \varepsilon_{c u}\right)^{2}}{4}+\frac{0,85 \beta_{1} f_{c}}{\rho_{f}} E_{f} \varepsilon_{c u}}-0,5 E_{f} \varepsilon_{c u}\right) \leq f_{f u}
$$


O momento resistente nominal pode ser expresso em termos da taxa de armadura de PRF, por meio da Equação 8-D.

$$
M_{n}=\rho_{f} f_{f}\left(1-0,59 \frac{\rho_{f} f_{f}}{f_{c}}\right) b d_{f}^{2}
$$

O fator de redução de resistência é determinado por meio da Equação 9-D. Para a seção dos modelos de viga estudados, $\phi=0,70$.

$$
\phi=\left\{\begin{array}{l}
0,50 \text { para } \rho_{f} \leq \rho_{f b} \\
\frac{\rho_{f}}{2 \rho_{f b}} \text { para } \rho_{f b}<\rho_{f}<1,4 \rho_{f b} \\
0,70 \text { para } \rho_{f} \geq \rho_{f b}
\end{array}\right.
$$

O ACI 440.1R-03 (2003) propõe a verificação de uma área mínima de PRF necessária apenas para elementos projetados com $\rho_{f}<\rho_{f b}$.

A Tabela 1-D resume os dados de entrada e resultados dos cálculos para determinação da resistência dos modelos e para estimativa de resistência de acordo com o ACI 440.1R-03 (2003).

Tabela 1-D - Dados de entrada e resultados dos cálculos dos momentos resistentes pelo ACI 440.1R-03 (2003).

\begin{tabular}{ccccccccccc}
\hline Modelo & $\begin{array}{c}\mathbf{d} \\
(\mathbf{m m})\end{array}$ & $\begin{array}{c}\mathbf{b} \\
(\mathbf{m m})\end{array}$ & $\begin{array}{c}\mathbf{f}_{\mathbf{c}} \\
(\mathbf{M P a})\end{array}$ & $\mathbf{\Phi}$ & $\begin{array}{c}\boldsymbol{\varepsilon}_{\mathrm{c}} \\
\mathbf{( \% )}\end{array}$ & $\begin{array}{c}\mathbf{A}_{\mathbf{f}} \\
\left(\mathbf{c m}^{2}\right)\end{array}$ & $\begin{array}{c}\mathbf{E}_{\mathbf{f}} \\
(\mathbf{M P a})\end{array}$ & $\begin{array}{c}\mathbf{f}_{\mathbf{f}} \\
(\mathbf{M P a})\end{array}$ & $\begin{array}{c}\mathbf{\varepsilon}_{\mathrm{f}} \\
(\mathbf{\% o})\end{array}$ & $\begin{array}{c}\mathbf{\Phi} \mathbf{M}_{\mathbf{n}} \\
(\mathbf{k N . m})\end{array}$ \\
\hline Piloto & 15 & 10 & 30,5 & 0,7 & 3,0 & 0,66 & 126000 & 2142 & 10,87 & 8,41 \\
CJ & 15 & 10 & 47,3 & 0,7 & 3,0 & 0,66 & 126000 & 2142 & 12,47 & 9,98 \\
SJ & 15 & 10 & 47,7 & 0,7 & 3,0 & 0,66 & 126000 & 2142 & 12,50 & 10,01 \\
Estimativa & 15 & 10 & 50,0 & 0,7 & 3,0 & 0,66 & 126000 & 2142 & 12,64 & 10,16 \\
\hline
\end{tabular}

\section{- FIB 9.3 TG (2003)}

Inicialmente se determina a altura efetiva $d$ (Figura 2-D), com base em um diâmetro de barra presumido. Assume-se que a ruptura será regida pelo esmagamento do concreto. Com $\varepsilon_{c}=0,35 \%$, a força de compressão no concreto é calculada por meio da Equação 10-D.

$$
F_{C d}=\frac{\alpha f_{c k} x b}{\gamma_{c}}
$$

Onde:

$\alpha=-68711 \varepsilon_{c}^{2}+464,79 \varepsilon_{c}+0,01$

$b$ - largura da seção 
$f_{c k}$ - resistência característica à compressão do concreto

$x$ - altura da linha neutra

$\gamma_{c}$ - fator de segurança do concreto

$\varepsilon_{c}$ - deformação do concreto

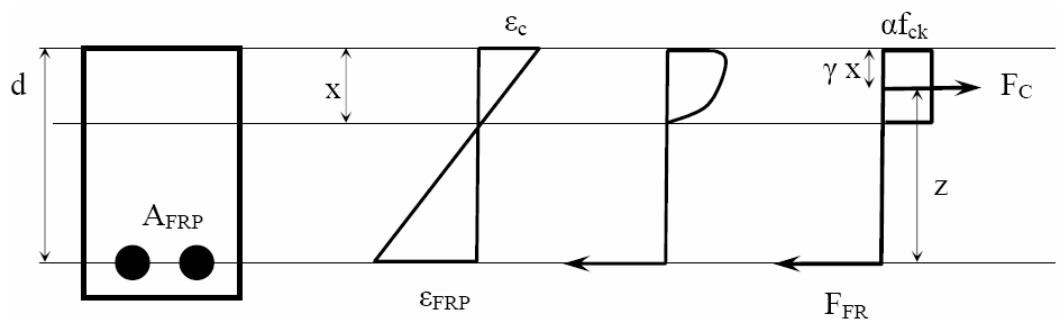

Figura 2-D - Modelo simplificado de distribuição de tensões proposto para estruturas de concreto armadas com PRF (Fonte: FIB 9.3 TG (2003)).

Assumindo-se a ruptura por esmagamento do concreto (hipótese para qual se ajustaram todos os modelos) a tensão no PRF, $f_{F R P}$ (Equação 12-D) deve ser menor que a tensão de projeto, $f_{F R P d}$ (Equação 13-D). A força de projeto no PRF é calculada por meio da Equação 14-D.

$$
\begin{aligned}
& f_{F R P}=\varepsilon_{F R P} E_{F R P} \\
& f_{F R P d}=\frac{f_{F R P k}}{\gamma_{F R P}} \\
& F_{F R P d}=A_{F R P} f_{F R P}=A_{F R P} \varepsilon_{F R P} E_{F R P}
\end{aligned}
$$

Onde:

$f_{F R P}$ - tensão no PRF

$\varepsilon_{F R P}$ - deformação do PRF

$E_{F R P}$ - módulo de elasticidade do PRF

$f_{F R P d}$ - resistência do PRF à tração de projeto

$f_{F R P k}$ - resistência do PRF à tração característica

$\gamma_{F R P}$ - fator de segurança do PRF

$F_{F R P d}$ - força no PRF de projeto

$A_{f}$ - área total de PRF na seção

Pelo diagrama de deformação na Figura 2-D deduz-se a Equação 15-D, para o cálculo do $x$.

$$
x=\frac{\varepsilon_{c} d}{\varepsilon_{F R P}+\varepsilon_{c}}
$$


Considerando o equilíbrio de forças, as Equações 10-D, 11-D e 14-D são resolvidas simultaneamente para determinar a deformação no PRF que é a solução da Equação do segundo grau 16-D.

$$
\varepsilon_{F R P}^{2}+\varepsilon_{c} \varepsilon_{F R P}-\frac{\alpha f_{c k} b d \varepsilon_{c}}{\gamma_{c} A_{F R P} E_{F R P}}=0
$$

Deve-se verificar se a deformação no PRF, $\varepsilon_{F R P}$, não ultrapassou a deformação de projeto, $\varepsilon_{F R P d}$, calculada por meio da Equação 17-D.

$$
\varepsilon_{F R P d}=\frac{f_{F R P d}}{E_{F R P}}
$$

O coeficiente, $\gamma$, que define o posicionamento da resultante da força de compressão e o braço de alavanca, z, são determinados pelas Equações 18-D e 19-D.

$$
\begin{aligned}
& \gamma=1962,6 \varepsilon_{c}^{2}+17,89 \varepsilon_{c}+0,33 \\
& z=d-\gamma x
\end{aligned}
$$

O momento resistente de projeto $M_{u}$ é calculado pela Equação 20-D

$$
M_{u}=F_{C d} Z
$$

A Tabela 2-D resume os dados de entrada e resultados dos cálculos para determinação da resistência dos modelos e para estimativa de resistência de acordo com o ACI 440.1R-03 (2003).

Tabela 2-D - Dados de entrada e resultados dos cálculos dos momentos resistentes pelo FIB 9.3 TG (2003).

\begin{tabular}{ccccccccccc}
\hline Modelo & $\begin{array}{c}\mathbf{d} \\
(\mathbf{m m})\end{array}$ & $\begin{array}{c}\mathbf{b} \\
(\mathbf{m m})\end{array}$ & $\begin{array}{c}\mathbf{f}_{\mathbf{c}} \\
(\mathbf{M P a})\end{array}$ & $\gamma_{\mathbf{c}}$ & $\begin{array}{c}\boldsymbol{\varepsilon}_{\mathbf{c}} \\
(\mathbf{\% o})\end{array}$ & $\begin{array}{c}\mathbf{A}_{\mathbf{f}} \\
\left(\mathbf{c m}^{2}\right)\end{array}$ & $\begin{array}{c}\mathbf{E}_{\mathbf{f}} \\
(\mathbf{M P a})\end{array}$ & $\begin{array}{c}\mathbf{f}_{\mathbf{f}} \\
(\mathbf{M P a})\end{array}$ & $\begin{array}{c}\boldsymbol{\varepsilon}_{\mathrm{f}} \\
(\mathbf{\% o})\end{array}$ & $\begin{array}{c}\mathbf{\Phi M}_{\mathbf{n}} \\
(\mathbf{k N . m})\end{array}$ \\
\hline Piloto & 15 & 10 & 30,5 & 1,4 & 3,5 & 0,66 & 126000 & 2142 & 8,84 & 9,75 \\
CJ & 15 & 10 & 47,3 & 1,4 & 3,5 & 0,66 & 126000 & 2142 & 11,37 & 12,83 \\
SJ & 15 & 10 & 47,7 & 1,4 & 3,5 & 0,66 & 126000 & 2142 & 11,42 & 12,90 \\
Estimativa & 15 & 10 & 50,0 & 1,4 & 3,5 & 0,66 & 126000 & 2142 & 11,73 & 13,28 \\
\hline
\end{tabular}

Estimou-se a força dividindo o momento estimado de $13 \mathrm{kN}$.m pela distância do apoio à face do pilar $(31 \mathrm{~cm})$, multiplicando por dois. 


\section{APÊNDICE E - Correção da rotação}

$>$ Cálculo dos descontos para correção da rotação

Os descontos efetuados nas leituras dos transdutores superiores e inferiores foram calculados por meio das Equações 1-E e 2-E

$$
\begin{aligned}
& \Delta s=\ell_{q, c} \cdot \varepsilon_{s} \\
& \Delta i=\ell_{q, c} \cdot \varepsilon_{i}
\end{aligned}
$$

Onde:

$\ell_{q, c}$ - distância entre a seção de fixação do quadro e a seção referencial em que se fixaram as cantoneiras (Figura 1-E)

$\Delta s$ - desconto da leitura do transdutor superior

$\Delta i$ - desconto da leitura do transdutor inferior
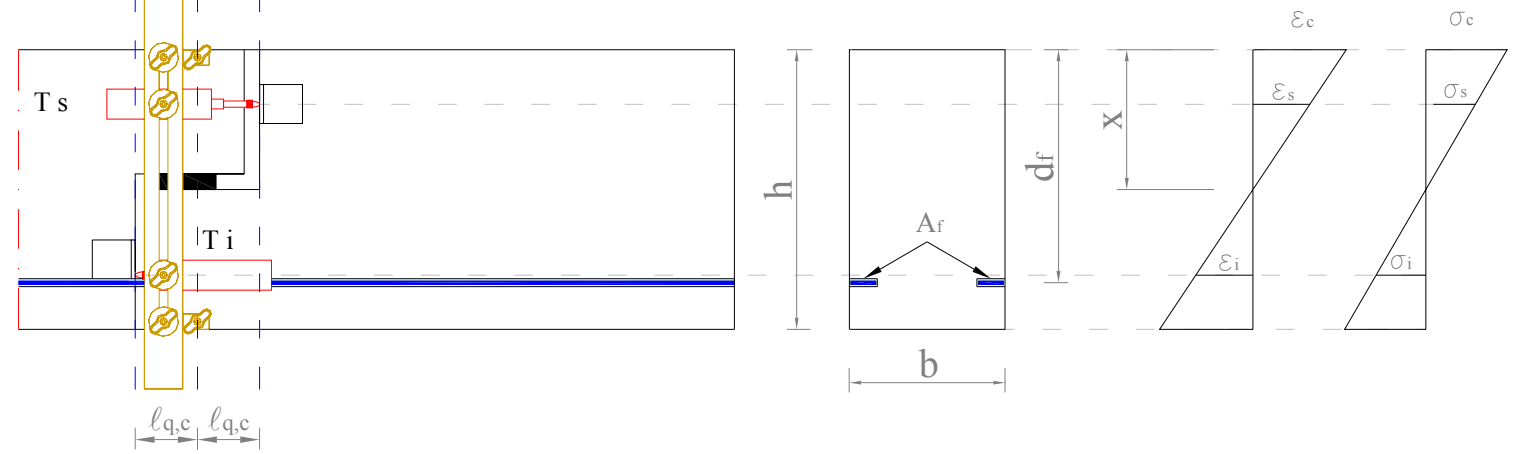

Figura 1-E - Distribuição de deformações e tensões na seção.

As deformações foram determinadas por meio das Equações 3-E e 4-E

$$
\begin{aligned}
& \varepsilon_{s}=\frac{\varepsilon_{c}(x-3,5)}{x} \\
& \varepsilon_{i}=\frac{\varepsilon_{c}(x-3,5)}{(h-x-3,5)}
\end{aligned}
$$

Onde: 
$\varepsilon_{s}$ - deformação na fibra de concreto de altura correspondente ao transdutor superior

$\varepsilon_{i}$ - deformação na fibra de concreto de altura correspondente ao transdutor inferior

$\varepsilon_{c}$ - deformação na fibra de concreto mais comprimida

$h$ - altura da seção transversal

$x$ - altura da linha neutra

A deformação na fibra mais comprimida e a tensão foram obtidas por meio das Equações 5-E e 6-E, respectivamente.

$$
\begin{gathered}
\varepsilon_{c}=\sigma_{c} \cdot E_{c} \\
\sigma_{c}=\frac{M_{a t} x}{I}
\end{gathered}
$$

Onde:

$\sigma_{c}$ - tensão atuando na fibra mais comprimida

$E_{c}$ - módulo de elasticidade do concreto

I - momento de inércia da seção

O momento de inércia da seção varia conforme o estádio de deformação em que a peça se encontra. As Equações 7-E e 8-E definem a altura da linha neutra e o momento de inércia da seção homogeneizada no estádio I.

$$
\begin{aligned}
& x_{I}=\frac{A_{f}\left(\alpha_{f}-1\right) d_{f}+b h^{2} / 2}{A_{f}\left(\alpha_{f}-1\right) d_{f}+b h} \\
& I_{I}=\frac{b h^{3}}{12}+b h\left(\frac{h}{2}-x_{I}\right)^{2}+A_{f}\left(\alpha_{f}-1\right)\left(d_{f}-x_{I}\right)^{2}
\end{aligned}
$$

Onde:

$x_{I}$ - altura da linha neutra no estádio I

$A_{f}$ - área total de PRF na seção

$\alpha_{f}$ - razão entre os módulos de elasticidade do PRF e do concreto $\left(\alpha_{f}=E_{f} / E_{c}\right)$

$d_{f}$ - distância da fibra mais comprimida de concreto ao centro de gravidade do PRF

$b$ - largura da seção

$I_{I}$ - momento de inércia da seção no estádio I

Para o limite do estádio II (estádio II puro) valem as Equações 9-E e 10-E para o cálculo da altura da linha neutra e do momento de inércia da seção homogeneizada. 
$x_{I I}=\frac{-a_{2} \pm \sqrt{a_{2}^{2}-4 a_{1} a_{3}}}{2 a_{1}}$

Em que:

$$
\begin{aligned}
& a_{1}=\frac{b}{2} ; a_{2}=A_{f} \alpha_{f} ; a_{3}=-A_{f} \alpha_{f} d_{f} \\
& I_{I I}=\frac{b x_{I I}^{3}}{12}+A_{f} \alpha_{f}\left(d_{f}-x_{I I}\right)^{2}
\end{aligned}
$$

Onde:

$x_{I I}$ - altura da linha neutra no estádio II

$I_{I I}$ - momento de inércia da seção no estádio II

Entre o final do estádio I e o estádio II puro, utilizou-se a formulação de Branson para determinação da altura da linha neutra (Equação 11-E extraída de Nóbrega (2004)) e do momento de inércia da seção (Equação 12-E extraída de Carvalho et al. (2004)).

$$
\begin{aligned}
& x_{m}=\left(\frac{M_{c r}}{M_{a t}}\right)^{2,5} \cdot x_{I}+\left[1-\left(\frac{M_{c r}}{M_{a t}}\right)^{2,5}\right] \cdot x_{I I} \leq x_{I} \\
& I_{m}=\left(\frac{M_{c r}}{M_{a t}}\right)^{n} \cdot I_{I}+\left[1-\left(\frac{M_{c r}}{M_{a t}}\right)^{n}\right] \cdot I_{I I}
\end{aligned}
$$

Onde:

$x_{m}$ - altura da linha neutra entre o final do estádio I e o estádio II puro

$M_{c r}$ - momento de fissuração

$M_{a t}$ - momento atuante

$I_{m}$ - momento de inércia da seção entre o final do estádio I e o estádio II puro

$n$ - índice de valor igual a 4 para situações em que a análise é feita para apenas uma seção da peça. 